
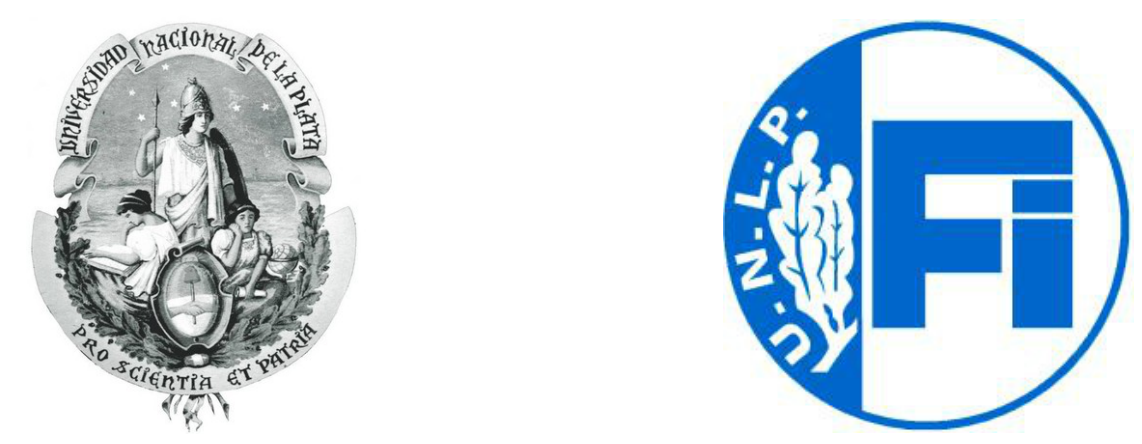

\title{
CARACTERIZACIÓN SUPERFICIAL DE ALEACIONES PARA IMPLANTES MEDIANTE TÉCNICAS ESPECTROSCÓPICAS Y MICROSCOPÍA ELECTRÓNICA DE BARRIDO
}

\author{
Tesis de Doctorado \\ KYUNG WON KANG \\ Presentada ante la Facultad de Ingeniería de la \\ Universidad Nacional de La Plata \\ como requisito para la obtención del grado académico de \\ DOCTOR EN INGENIERÍA \\ Director: Dr. Jorge Trincavelli \\ Codirector: Dr. Ing. Pablo Bilmes \\ Subdirector: Ing. Carlos Llorente
}

Jurados de Tesis: Dr. Ricardo Gregorutti

Dra. Lucía B. Avalle

Dra. Patricia E. Álvarez

La Plata, 10 de noviembre de 2017 
Esta tesis está dedicada a Marcos, compañero y amor de mi vida. Gracias por recorrer este camino conmigo. 


\section{AGRADECIMIENTOS}

En este espacio quisiera expresar mi agradecimiento a quienes me han acompañado y participado, en forma directa o indirecta, en el desarrollo de mi tesis.

A mi director, Dr. Jorge Trincavelli, por sus enseñanzas y por brindarme su tiempo y paciencia en el desarrollo de la tesis. Gracias Jorge, aprendí muchísimo de vos y espero que podamos seguir trabajando juntos.

A mi codirector, Dr. Ing. Pablo Bilmes, y mi subdirector, Ing. Carlos Llorente, por invitarme a trabajar en el LIMF y confiar en mí para formar parte del laboratorio. Gracias por su apoyo y seguimiento en el desarrollo de la tesis.

A la Dra. Rita Bonetto, por su gran aporte a esta tesis y, principalmente, por preocuparse siempre por mí, por sus consejos y sus charlas. Gracias Rita por animarme, siempre me decías que iba a terminar la tesis y hoy es una realidad.

A la Dra. María Elena Canafoglia y a la Lic. Mariela Theiller por su contribución en la adquisición de las imágenes en el microscopio. Gracias por las tardes de charlas y por su compañía mientras obteníamos las imágenes.

A los integrantes del FaMAF, en especial a Silvina, Víctor, Gustavo, Beto y Alejo, por abrirme sus puertas y hacerme sentir parte de su grupo cada vez que iba a Córdoba.

A los integrantes del LIMF, Clau, Tati, Adri, Juan, Daniel y Joaquín, por su apoyo y aliento durante el desarrollo de mi tesis, pero sobre todo por su amistad, por las horas compartidas, las charlas, las risas y los mates.

Al Dr. Claudio Gervasi, por su contribución en la parte electroquímica. Gracias Claudio por tu ayuda.

A Kinetical SRL y a Nicolás Scarano, por su buena predisposición y por ayudarme con el aporte de materiales utilizados en la tesis.

Al SiT y sus integrantes, Stella, Silvina, Augusto y sus tutores, por las charlas, los mates y bizcochitos compartidos en las distintas actividades y reuniones. Gracias por dejarme ser parte de ustedes.

A la Facultad de Ingeniería por abrirme sus puertas y hacerme parte de esta hermosa institución, en la cual espero seguir contribuyendo y trabajando con el mismo entusiasmo de siempre.

A mi familia, mi mamá, mis hermanas y hermano porque siempre están conmigo y me acompañan en todos los aspectos de mi vida. Los amo con todo mi corazón.

A Marcos, a quien le dedico esta tesis, gracias por estar a mi lado siempre, en las buenas y en las malas, por cuidarme en todo momento, por alentarme cuando estaba por darme por vencida. 


\section{ÍNDICE}

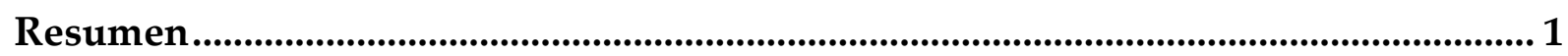

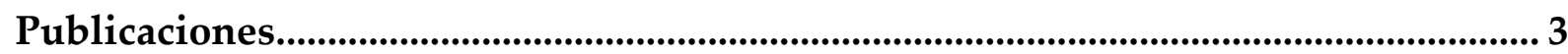

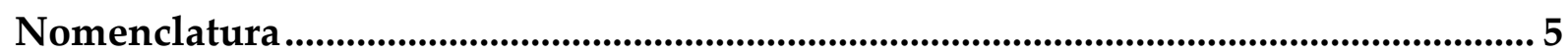

Capítulo 1: Biomateriales............................................................................................ 7

De dónde vienen y hacia dónde van ..............................................................................

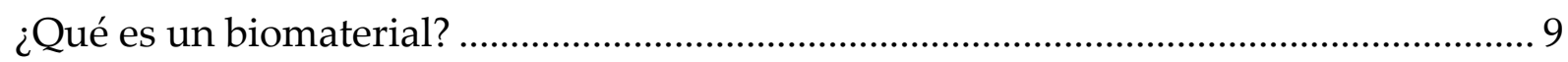

Definición de biocompatibilidad.................................................................................... 11

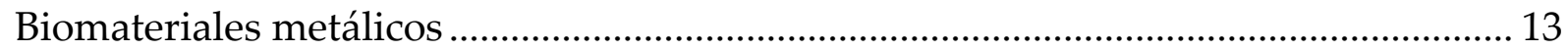

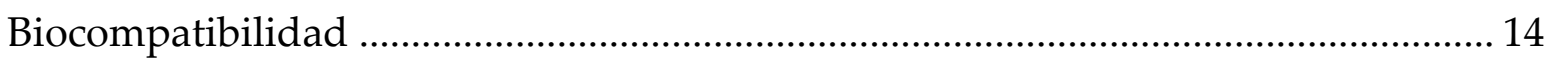

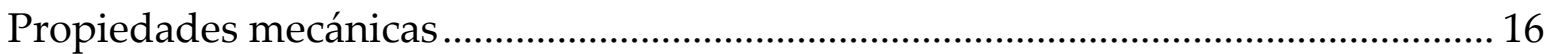

Resistencia a la corrosión y al desgaste …………………………………………..... 20

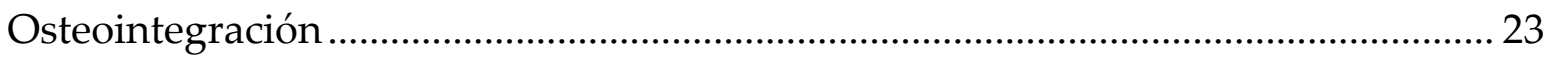

Propiedades superficiales de los biomateriales metálicos para implantes dentales y

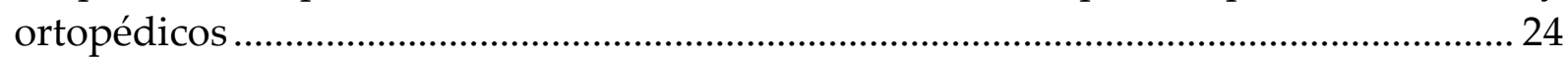

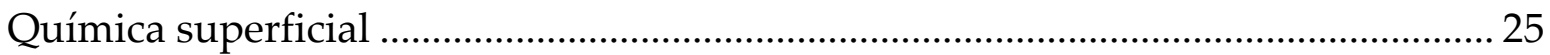

Topografía y rugosidad superficial......................................................................... 27

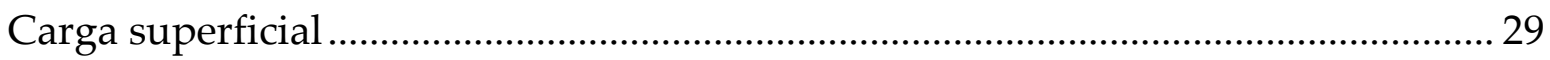

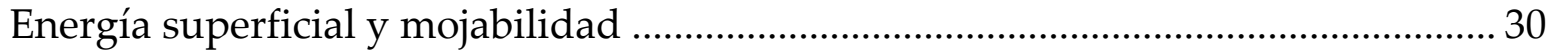

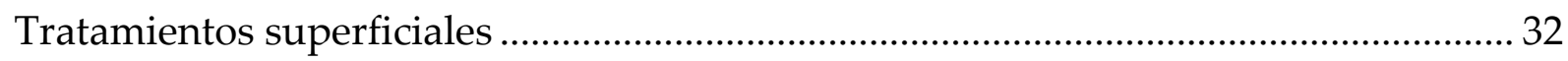

Capítulo 2: Técnicas de caracterización................................................................................. 35

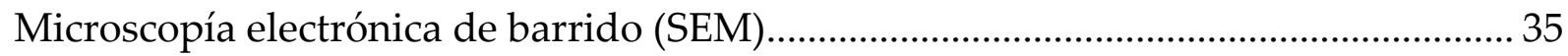

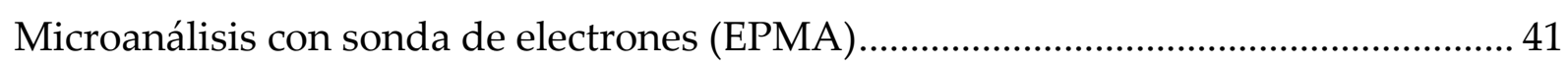

Sistemas de detección de rayos X................................................................................. 43

Espectrómetro dispersivo en longitudes de onda (WDS) ....................................... 44

Espectrómetro dispersivo en energías (EDS) ........................................................... 45

Espectroscopía de retrodispersión de Rutherford (RBS) ................................................ 47

Polarización potenciodinámica cíclica ........................................................................... 49

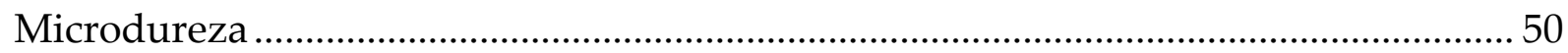

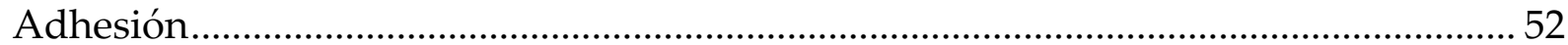

Capítulo 3: Estimación de incertezas de mediciones topográficas por microscopía electrónica de barrido 3D sobre la corrosión superficial de aceros ............................. 55 


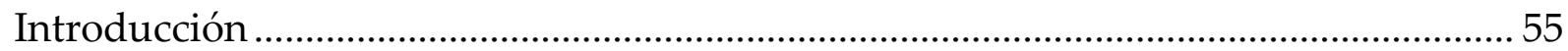

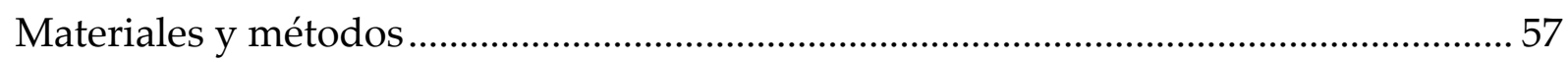

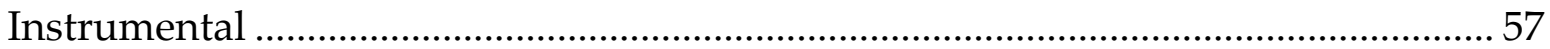

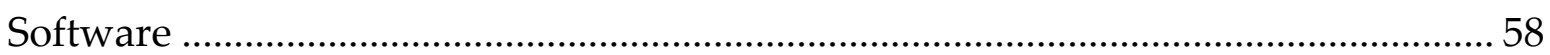

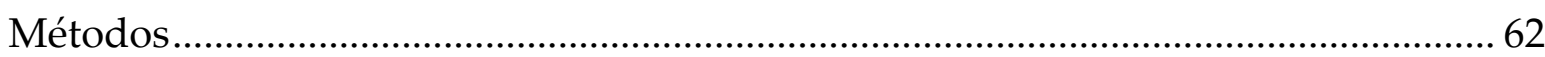

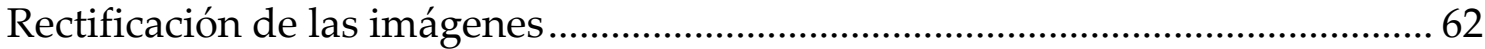

Análisis numérico de las incertezas para diferentes magnificaciones ................ 62

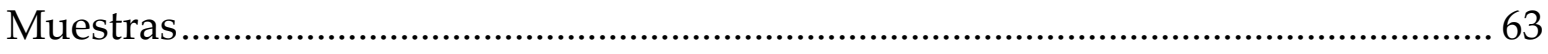

Muestras metálicas para el estudio de las incertezas de valores de altura ......... 63

Estudio de muestras de biomateriales metálicas................................................6 64

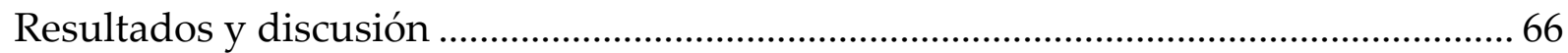

Análisis preliminar de la incerteza a diferentes magnificaciones ............................ 66

Estudio de las incertezas de los valores de altura en muestras de un tubo de caldera 68

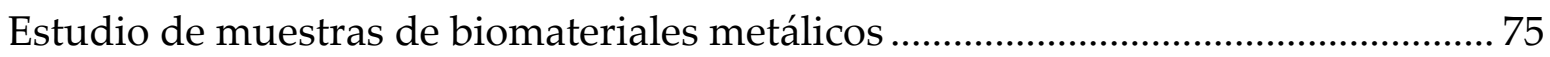

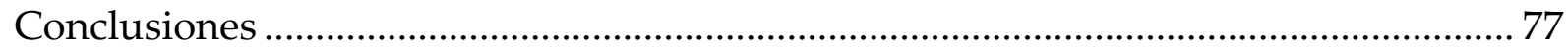

Capítulo 4: Tratamientos de blastinizado y pasivado químico en acero inoxidable ASTM F139 para implantes: efectos sobre la rugosidad superficial, dureza y

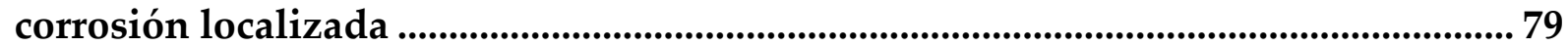

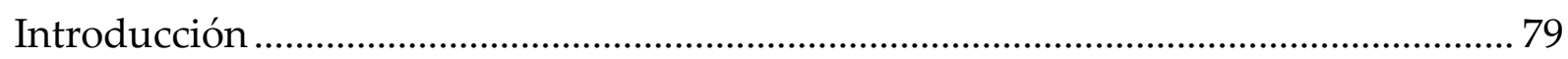

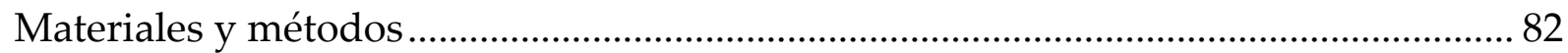

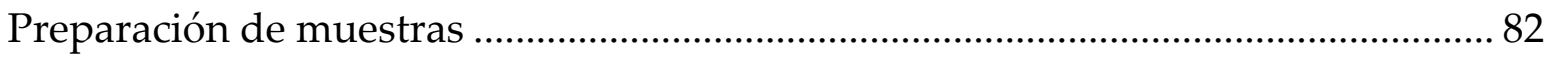

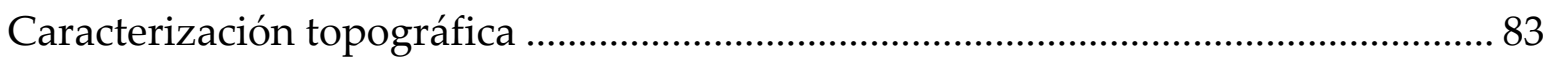

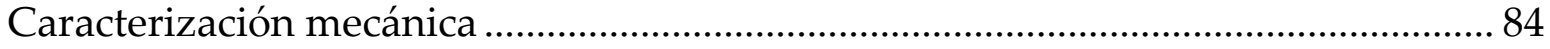

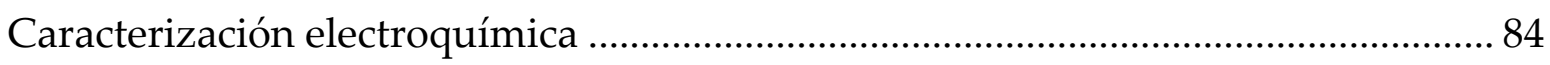

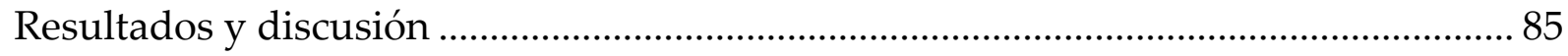

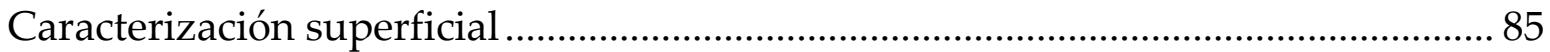

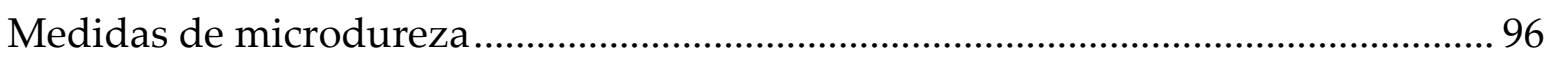

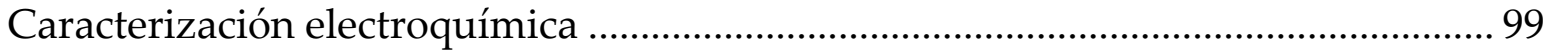

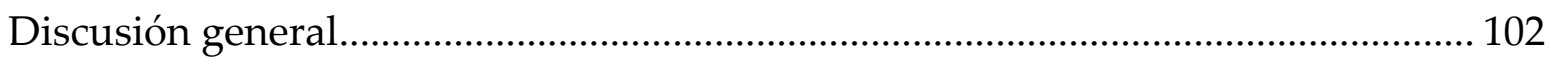

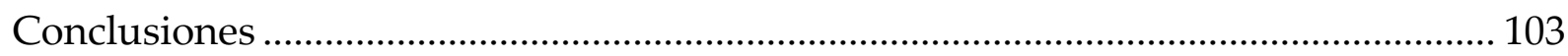


Capítulo 5: Blastinizado y anodizado por plasma químico en titanio c.p. para implantes: estudio de la rugosidad superficial, adherencia y dureza......................... 105

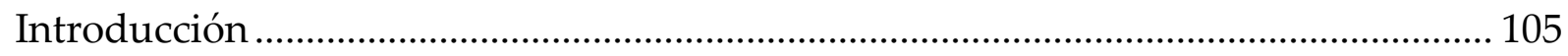

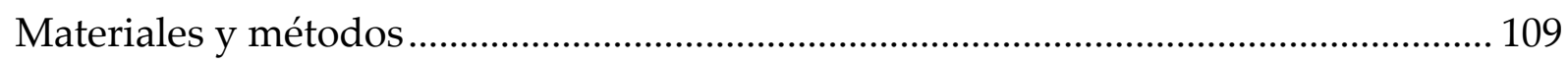

Preparación de muestras ............................................................................................... 109

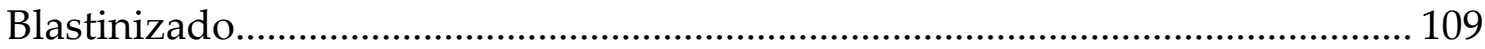

Blastinizado y anodizado por plasma químico …………………………………... 109

Caracterización topográfica ....................................................................................... 110

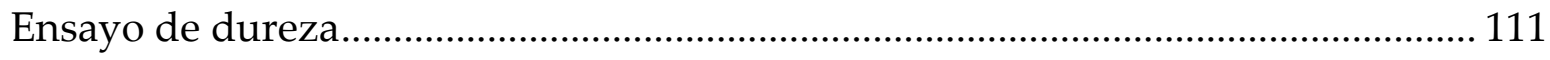

Ensayo de adhesión ................................................................................................ 111

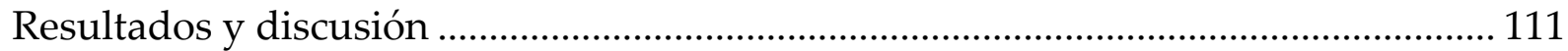

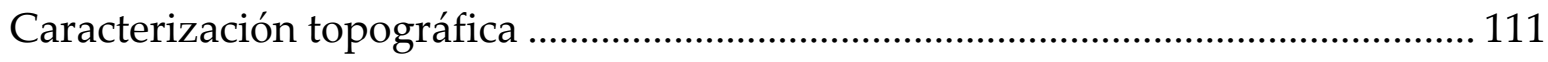

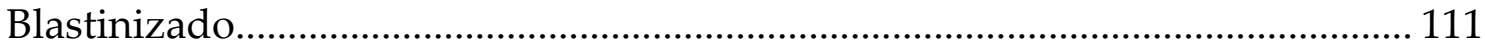

Blastinizado y anodizado por plasma químico …………………………………... 115

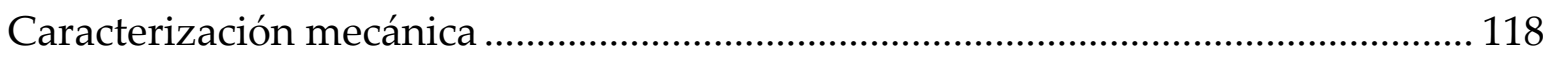

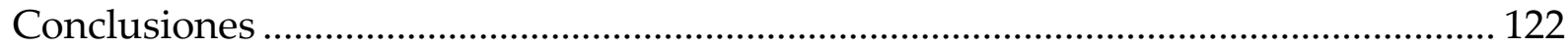

Caracterización topográfica ................................................................................... 122

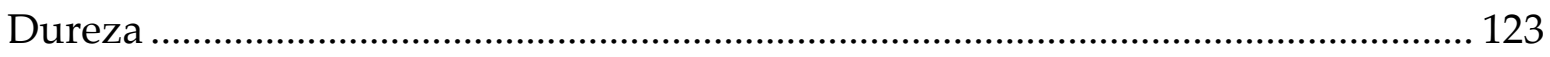

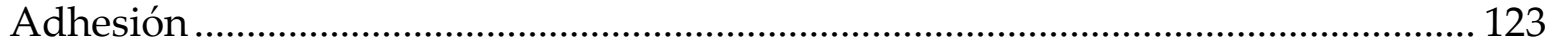

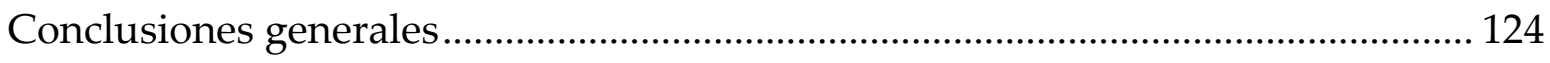

Capítulo 6: Determinación de espesores de óxido de titanio en implantes anodizados mediante microanálisis por sonda de electrones ...................................... 125

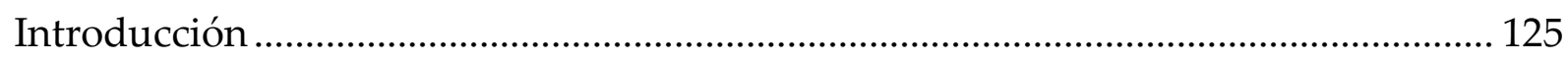

Materiales y métodos ................................................................................................ 127

Preparación de muestras ................................................................................... 127

Mediciones realizadas mediante RBS y EPMA ……….............................................. 128

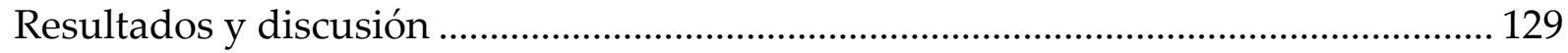

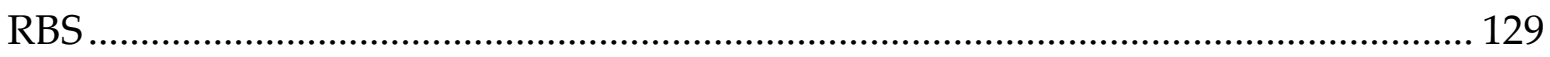

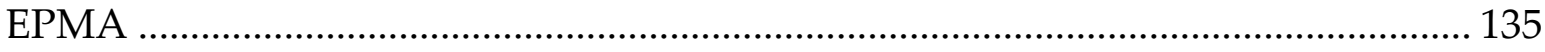

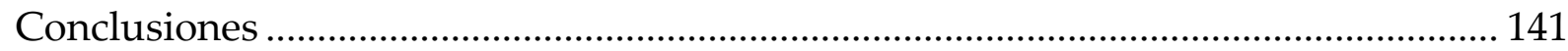

Conclusiones generales..................................................................................................... 143

Bibliografía ................................................................................................................... 146 


\section{RESUMEN}

El presente trabajo de tesis se enmarca en el estudio de biomateriales implantables de titanio y acero inoxidable con diferentes tratamientos superficiales con el propósito de desarrollar métodos y estrategias de caracterización superficial, analizando los parámetros que caracterizan cada tratamiento o conjunto de tratamientos a través de técnicas espectroscópicas y microscopía electrónica de barrido. Los resultados obtenidos fueron correlacionados con ensayos de microdureza, adhesión y/o polarización potenciodinámica cíclica. Vale destacar que la mejor combinación de técnicas para caracterizar un biomaterial implantable dependerá del tipo de material, del tratamiento superficial que tenga y de la función que cumplirá como implante.

Contar con métodos confiables para caracterizar daños por corrosión y/o tribocorrosión en diversos tipos de componentes y especialmente en implantes ortopédicos, resulta imprescindible para mejorar la calidad y asegurar la integridad de los mismos. Por ello, resulta de gran utilidad disponer de una herramienta de caracterización confiable de pits de corrosión mediante microscopía electrónica de barrido (SEM), ya que la corrosión por picado es un mecanismo de daño muy común y pernicioso en biomateriales y el SEM es una técnica hoy día muy versátil y accesible para el estudio de biomateriales. En este sentido, se evaluaron los errores en las mediciones topográficas en muestras de acero inoxidable 316LVM (Low Vacuum Melting) (ASTM F138 y F139/ISO 5832-1) con diferentes tratamientos superficiales, como el blastinizado (en inglés, blasting) y el pasivado químico, mediante el uso de pares estéreos de imágenes de microscopio electrónico; y los resultados fueron cotejados con mediciones electroquímicas.

La caracterización de la topografía superficial es fundamental en los biomateriales ya que determina el desempeño de los implantes, sobre todo de los dentales. Una de las maneras ampliamente utilizadas para caracterizar la topografía es a partir de la rugosidad. La rugosidad de una superficie se describe apelando a distintos conjuntos 
de parámetros, entre los cuales se encuentran los funcionales y los de amplitud. La utilidad de cada parámetro es motivo de estudio en el abordaje de una nueva aplicación y la correcta elección de los parámetros más significativos depende de las características del tratamiento superficial utilizado y del objetivo del estudio realizado. De acuerdo con lo expresado, se estudiaron superficies de aceros inoxidables 316LVM (Low Vacuum Melting) (ASTM F138 y F139/ISO 5832-1) y de titanio c.p. ASTM Grado 4 sometidas a diversos tipos de tratamientos -dentro de los cuales se encuentran el mecanizado, blastinizado, anodizado por plasma químico y pasivado químico. Estos estudios se realizaron a partir del análisis de los parámetros de rugosidad obtenidos mediante la técnica de pares estéreos de imágenes de microscopía electrónica de barrido, en combinación con ensayos de microdureza, adhesión y polarización potenciodinámica cíclica.

Finalmente, debido a que los implantes de titanio y sus aleaciones presentan diferentes capas superficiales de óxidos que pueden optimizar el desempeño de estos biomateriales, se desarrolló un método para determinar espesores de óxido de titanio en el intervalo de interés de los implantes dentales y ortopédicos a partir de espectros de rayos $\mathrm{X}$ obtenidos mediante la técnica de microanálisis con sonda de electrones. Para el estudio de las capas de óxido generadas mediante anodizado, la intensidad de la línea característica $\mathrm{K} \alpha$ del oxígeno fue relacionada con el espesor correspondiente. Debido a una alteración local del material causada por el haz de electrones, fue necesario efectuar una recalibración mediante la técnica de espectroscopía de retrodispersión de Rutherford. 


\section{PUBLICACIONES}

Los resultados obtenidos en la presente tesis fueron presentados en diferentes ámbitos académicos, dentro de los cuales se encuentran reuniones científicas, congresos nacionales e internacionales y revistas. A continuación se presenta una lista de todas las publicaciones producidas.

\section{Revistas:}

- "Thickness determination of anodic titanium oxide films by electron probe microanalysis". Kyung Won Kang, Silvina Limandri, Gustavo Castellano, Sergio Suárez, Jorge Trincavelli. Materials Characterization 130 (2017) 50-55.

- "Blasting and passivation treatments for ASTM F139 stainless steel for biomedical applications: Effects on surface roughness, hardening and localized corrosion". Adriana Lemos Barboza, Kyung Won Kang, Rita D. Bonetto, Carlos L. Llorente, Pablo D. Bilmes, Claudio A. Gervasi. Journal of Materials Engineering \& Performance 24 (2015) 175-184.

- “Uncertainty studies of topographical measurements on steel surface corrosion by 3D scanning electron microscopy". Kyung Won Kang, María Dolores Pereda, María Elena Canafoglia, Pablo Bilmes, Carlos Llorente, Rita Bonetto. Micron 43 (2012) 387-395.

\section{Congresos:}

- “Medición del espesor de óxido de titanio en implantes anodizados en solución de $\mathrm{H}_{3} \mathrm{BO}_{3} / \mathrm{H}_{3} \mathrm{PO}_{4}$ ". Kyung Won Kang, Silvina Limandri, Gustavo Castellano, Rita Bonetto, Jorge Trincavelli. XIV Seminario Latinoamericano de Análisis por Técnicas de Rayos X 2014. Página 95 del Libro de resúmenes.

- "Caracterización superficial y transversal de implantes dentales de titanio blastinizados y anodizados por plasma químico". Adriana Lemos, Agustín Cerliani, Kyung Won Kang, Juan Echarri, Carlos Llorente, Pablo Bilmes, 
Nicolás Scarano, Luciano Borasi. XI Congreso Iberoamericano de Ingeniería Mecánica CIBIM 2013. Páginas 1108-1117 de las Actas del XI Congreso Iberoamericano de Ingeniería Mecánica CIBIM 2013 - TRABAJOS COMPLETOS PARTE 1. E-Book, ISBN 978-950-34-1025-7.

- "Estudio de la rugosidad superficial de implantes dentales de titanio blastinizados mediante Microscopía Electrónica de Barrido en 3D". Kyung Won Kang, María Pereda, Adriana Lemos, Pablo Bilmes, Rita Bonetto, Mariano Scarano. Acta Microscopica, Vol. 21, Supp. A (2012) 65-66.

- "Impact of surface treatment on the corrosion resistance of ASTM F138-F139 stainless steel for biomedical applications". María Pereda, Kyung Won Kang, Rita Bonetto, Carlos Llorente, Pablo Bilmes, C. Gervasi. Procedia Materials Science 1 (2012) $446-453$.

- "Three-dimensional investigation of corroded and engineered surfaces by SEM images stereo pair technique". Kyung Won Kang, Pablo Bilmes, Carlos Llorente, María Elena Canafoglia, Rita Bonetto. Acta Microscopica, Vol. 18, Supp. C (2009) $265-266$. 


\section{NOMENCLATURA}

SEM Microscopía electrónica de barrido

ESEM Microscopía electrónica de barrido ambiental

$z(i, j) \quad$ Valores de altura correspondientes a cada píxel $(i, j)$

W Distancia de trabajo

M Magnificación

ф1 Ángulo de inclinación imagen izquierda del par estéreo

ф2 Ángulo de inclinación imagen derecha del par estéreo

$\mathrm{x}_{1} \quad$ Posición del pixel (i,j) en la imagen izquierda del par estéreo

$\Delta \mathrm{x} \quad$ Disparidad

$u_{z}^{2} \quad$ Varianza de la medida de elevación vertical

$\mathrm{u}_{2}(\Delta \phi) \quad$ Incerteza del ángulo de inclinación

$\mathrm{u}_{2}(\Delta \mathrm{x}) \quad$ Varianza en la paralaje

s Tamaño del píxel en micrones

$\mathrm{u}(\mathrm{s}) \quad$ Incerteza del tamaño del píxel en micrones

SCE Electrodo de calomel saturado

Hs Dato de altura relativa obtenido mediante estereometría

Hcs Dato de altura relativa obtenido en sección transversal

m Cantidad de material electroquímicamente consumido en gramos

P Peso molar $\left(\mathrm{g} \mathrm{mol}^{-1}\right)$

F Número de Faraday (96487 A s mol-1)

t Tiempo (s)

k Número de carga

Q Carga total (C) 
CP Curva de polarización

Ep Potencial de picado

Sigma Raíz cuadrada de la desviación cuadrática media de la topografía de la superficie (alturas relativas al plano que contiene el eje de inclinación de la muestra)

Sq Raíz cuadrada de la desviación cuadrática media de la topografía de la superficie

Sa Desviación media aritmética de la topografía de la superficie (alturas relativas al plano que contiene el eje de inclinación de la muestra)

Ssk Asimetría (Skewness) de la distribución de alturas de la topografía

Sku Curtosis (Kurtosis) de la distribución de alturas de la topografía

$\mathrm{Sz} \quad$ Diez-puntos (Ten-point) de la topografía de la superficie (diferencia de altura entre el promedio de los cinco puntos de mayor altura y los cinco puntos de menor altura)

Sbi Índice de contacto de la superficie

Sci Índice de retención de líquido en el centro o núcleo

Svi Índice de retención de líquido en el valle

D Estimador de la dimensión fractal

HV Microdureza Vickers

APQ Anodizado por plasma químico

EPMA Microanálisis con sonda de electrones

EDS Espectroscopía dispersiva en energías

WDS Espectroscopía dispersiva en longitudes de onda

RBS Espectroscopía de retrodispersión de Rutherford

AV Voltaje de anodizado 


\section{CAPÍTULO 1 \\ BIOMATERIALES}

\section{DE DÓNDE VIENEN Y HACIA DÓNDE VAN}

Desde la antigüedad, la humanidad ha utilizado dispositivos de diferentes materiales para reemplazar distintas partes del cuerpo, debido a su pérdida de forma natural o como consecuencia de accidentes o traumas. Tal es el caso del uso de implantes dentales en civilizaciones tempranas: los mayas utilizaban dientes de nácar de valvas marinas (600 d.C.) y en Francia se encontró un implante dental de hierro en un cadáver (200 d.C.), ambos con signos de lo que actualmente se conoce como osteointegración [1,2]. Por otra parte, los romanos, aztecas y fenicios utilizaban implantes dentales de madera unidos por alambres de oro [3]. También existen evidencias del uso de materiales en suturas como lino en el antiguo Egipto y metales como oro (130-200 d.C.), plomo (1816) y plata (1849). En 1860, Adolf Gaston Eugen Fick desarrolló la primera lente de contacto de vidrio exitosa y en el período de 1936 a 1948, se desarrollaron las primeras lentes de contacto plásticas, principalmente de polimetacrilato de metilo [4]. Sin embargo, antes de 1950, aun cuando ya se habían realizado diversos estudios sobre la bioreactividad de materiales de implantes, sobre todo de metales, la posibilidad de éxito de los mismos era muy baja por la pobre comprensión de los conceptos de biocompatibilidad y esterilización [4].

Las guerras mundiales impulsaron el desarrollo de nuevos materiales de alto desempeño. Estos desarrollos permitieron a los médicos cirujanos utilizar dichos materiales para reemplazar partes del cuerpo pero con un alto riesgo debido a que no existían regulaciones sobre el uso de esos materiales en humanos; a pesar de ello, dichos procedimientos se realizaban en un intento de mejorar la calidad de vida de los pacientes. Cuando alguno de los protocolos quirúrgicos realizados o algún evento relacionado no premeditado tenía éxito, dicha situación motivaba a los médicos cirujanos a colaborar con científicos e ingenieros en la investigación y desarrollo de 
biomateriales para su adecuada aplicación como implantes, como fue el caso de la lente intraocular. Después de la Segunda Guerra Mundial, el Dr. Harold Ridley tuvo la oportunidad de examinar aviadores que fueron involuntariamente implantados en sus ojos con fragmentos de polimetilmetacrilato de los aviones de combate y observó que las zonas donde habían impactado los fragmentos de plástico se habían curado sin reacción. Dicho suceso permitió el desarrollo de la lente intraocular y la cirugía de lente intraocular para pacientes con cataratas. Otro acontecimiento importante de mencionar es el desarrollo de la prótesis articular de cadera. Si bien desde 1891 se habían realizado cirugías de reemplazo de cadera, fue John Charnley, alrededor de 1961, quien desarrolló la primera prótesis articular de cadera exitosa. Dicha prótesis se constituía de un vástago de acero inoxidable, copa acetabular de polietileno de alta densidad y era cementada con polimetilmetacrilato. En el caso de los implantes dentales, como se mencionó al inicio, existen evidencias del uso del más variado tipo de materiales para reemplazar piezas dentales. En la historia más cercana, en el periodo que abarca desde el 1800 a 1950, se llevaron a cabo diversos desarrollos en cuanto al procedimiento quirúrgico y diseños de los implantes. Hasta que en 1952, Per-Ingvar Brånemark, cirujano ortopédico, desarrolló un experimento con el fin de estudiar el proceso de cicatrización y regeneración del hueso. Por ese motivo, implantó un sistema de microcámaras que eran sostenidas por un dispositivo de titanio que se enroscaba en el hueso de un conejo. Después de completar el experimento que duró varios meses, trató de retirar el dispositivo de titanio y lo encontró estrechamente integrado en el hueso [5,6]. El Dr. Brånemark denominó dicho fenómeno osteointegración (en inglés, osseointegration), y exploró con sumo éxito la aplicación de implantes de titanio a procedimientos quirúrgicos y dentales. También desarrolló protocolos quirúrgicos de bajo impacto para implantes dentales que redujeron la necrosis tisular y aumentaron la probabilidad de buenos resultados. En la actualidad, la gran mayoría de los implantes dentales y muchos de los ortopédicos se encuentran fabricados de titanio y sus aleaciones [7]. Como los casos mencionados anteriormente, existe una infinidad de acontecimientos que llevaron al 
desarrollo de los más variados tipos de materiales y dispositivos utilizados para reparar o sustituir un órgano o tejido del cuerpo humano; desde injertos vasculares, válvulas cardíacas y stents, hasta implantes mamarios, estos últimos utilizados con fines estéticos o de reconstrucción.

En los últimos años, con el objetivo de mejorar la calidad de vida y teniendo en cuenta que ha aumentado la longevidad de los seres humanos, combinado con el progreso en muchos campos diferentes, como la biología o la ciencia e ingeniería de los materiales, se ha allanado el camino a la creación de biomateriales innovadores para mejorar los tratamientos existentes y desarrollar otros nuevos. En la actualidad, las actividades en esta área se encuentran enfocadas, por mencionar algunos casos, al desarrollo de nuevos tratamientos superficiales para mejorar las propiedades de algunos biomateriales como el titanio y sus aleaciones; al desarrollo de hidrogeles, materiales atractivos debido a su alto contenido de agua y propiedades similares a los tejidos; a la síntesis de los denominados materiales inteligentes que se adaptan rápidamente al ambiente biológico en el que se encuentran implantados y permiten, entre otras cosas, la liberación de fármacos in situ [8].

Cabe mencionar que desde hace algunos años y mirando hacia el futuro, el próximo paso en el estudio de los biomateriales está ligado a dos nuevas tecnologías que impactarán fuertemente en el área: la ingeniería de tejidos y la medicina regenerativa. Se cree que la ingeniería de tejidos posibilitará sustituir tejidos y órganos dañados con reemplazos vivos y funcionales que surgirán de combinar materiales utilizados como andamios, células y moléculas biológicamente activas para crear tejidos. Por otro lado, la medicina regenerativa, que incluye la ingeniería de tejidos, permitirá la regeneración in vivo de órganos y tejidos enteros [8].

\section{¿QUÉ ES UN BIOMATERIAL?}

De acuerdo al American National Institute of Health (1984): "Biomaterial es cualquier material o combinación de materiales, de origen natural o sintético, que 
puede ser usado por algún período (estando continuamente o intermitentemente en contacto con fluidos humanos), como todo o como parte de un sistema que trata, aumenta o reemplaza algún tejido, órgano o función del cuerpo" [9]. En otras palabras, se podría decir que los biomateriales son los materiales (metálicos, poliméricos, cerámicos o combinaciones) utilizados en dispositivos médicos destinados a interactuar con sistemas biológicos [7]. Es importante destacar que no todos los materiales que componen los dispositivos médicos son considerados biomateriales, ya que estos dispositivos se definen como: "cualquier instrumento, aparato, implemento, máquina, implante, reactivo o calibrador in vitro, software, material u otros artículos similares o relacionados, destinados a ser utilizados, solos o en combinación, para seres humanos con los fines específicos del diagnóstico, la prevención, el seguimiento, el tratamiento, la investigación, el apoyo o el mantenimiento de la vida, el control de la concepción y la desinfección de los dispositivos médicos" [10]. Por lo general, al conjunto de materiales utilizados en dispositivos médicos se los conoce como materiales biomédicos $\mathrm{y}$, dentro de ellos, los biomateriales son aquellos materiales que son utilizados en contacto íntimo con los tejidos vivos, es decir, son implantados dentro del cuerpo humano.

Si se estudia la evolución de los biomateriales durante los últimos 70 años, se pueden diferenciar claramente cuatro generaciones [11]: materiales bioinertes (primera generación) cuyo propósito era no generar reacciones adversas en los fluidos y tejidos del cuerpo humano; materiales bioactivos (segunda generación) que tenían la finalidad de provocar una reacción controlada con los tejidos en los que fueron implantados con la intención de inducir un efecto terapéutico deseado; los materiales diseñados para estimular respuestas celulares específicas a nivel molecular (tercera generación) y, por último, los biomateriales inteligentes o biomiméticos (cuarta generación) que imitan la estructura y topografía de tejidos y órganos del cuerpo humano. Es muy importante mencionar que las cuatro generaciones mencionadas no deben ser interpretadas como cronológicas, sino conceptuales, ya que cada generación representa el progreso en las propiedades de los materiales involucrados. 
Esto significa que en la actualidad, se siguen estudiando biomateriales que, según sus propiedades, podrían considerarse de primera o segunda generación y los aportes que realizan los materiales de cada generación no necesariamente anulan el uso de los anteriores [12].

\section{DEFINICIÓN DE BIOCOMPATIBILIDAD}

Dado que un biomaterial está diseñado para ser utilizado en contacto íntimo con los tejidos vivos, es esencial que el material implantado no cause efectos nocivos en el organismo. El éxito de los biomateriales depende, entre otros factores, de la adecuada reacción del cuerpo humano con el implante; dicha propiedad de los biomateriales se la conoce como biocompatibilidad. La biocompatibilidad es la capacidad de un material de generar una respuesta apropiada del huésped en una situación específica [7,13,14]. La definición es amplia porque varía con las aplicaciones médicas específicas y los requerimientos que deben cumplir los biomateriales con relación a la biocompatibilidad son complejos y estrictos $[10,15]$.

El hecho más singular que distingue un biomaterial de cualquier otro material es la capacidad de existir en contacto con tejidos del cuerpo humano sin causar un grado de daño intolerable a este mismo. La biocompatibilidad ha sido tradicionalmente contemplada para productos implantables cuyo objetivo era permanecer en el cuerpo huésped durante un tiempo extenso. El paradigma de los biomateriales biocompatibles se definía en los orígenes de la ciencia de los biomateriales, como la capacidad de evitar una serie de eventos biológicos no deseados. Por lo tanto, durante las décadas del 1940 hasta 1980 se seleccionaban los biomateriales por su inercia química. Este paradigma ha evolucionado drásticamente en las últimas cuatro décadas redefiniendo el concepto de biocompatibilidad y la selección, desarrollo y evaluación de los biomateriales.

Tres conceptos principales llevaron a redefinir una primera vez el concepto de biocompatibilidad: 
1. Empezó a ponerse de manifiesto que un mismo biomaterial podía originar distintas respuestas según el sitio de implantación, por lo que se evidenció la necesidad de evaluar la biocompatibilidad de un biomaterial para una indicación dada.

2. Una serie de aplicaciones de los biomateriales requerían que el biomaterial tuviera una interacción clara con el tejido del huésped en vez de mantener un status quo. 3. Otras aplicaciones necesitaban que el material fuera degradable y absorbible, en otros términos reabsorbible, en vez de permanecer ad vitam æternam.

Lo que llevó a esta definición en 1987: “Biocompatibility refers to the ability of a material to perform with an appropriate host response in a specific situation".

Desde entonces la biocompatibilidad es un concepto que ha ido cambiando con las evoluciones de la ciencia de los biomateriales y de la ingeniería de tejidos hasta encontrar una definición que se adapta al contexto (biomateriales de larga implantación, biomateriales reabsorbibles, matrices y andamios para la ingeniería de tejidos). David Williams [16] ha establecido una definición más genérica en 2008: "Biocompatibility refers to the ability of a biomaterial to perform its desired function with respect to a medical therapy, without eliciting any undesirable local or systemic effects in the recipient or beneficiary of that therapy, but generating the most appropriate beneficial cellular or tissue response in that specific situation, and optimising the clinically relevant performance of that therapy."

Los parámetros que afectan la biocompatibilidad de un biomaterial son de naturaleza diversa y es la razón por la cual la ciencia de los biomateriales requiere de conocimientos procedentes de especialidades variadas. Una lista no exhaustiva comprende las siguientes propiedades:

- Química del biomaterial

- Propiedades físicas del biomaterial

- Propiedades mecánicas

- Propiedades interfaciales 
El control de estos parámetros permite el diseño de biomateriales para aplicaciones diversas cumpliendo con la función y aplicación deseada. La ciencia de los biomateriales ha conocido importantes progresos que han permitido controlar estas propiedades hasta el punto de poder imitar ciertos tejidos del cuerpo.

En resumen, de un implante se pretende que tenga constituyentes no tóxicos y que no genere inflamaciones ni reacciones alérgicas, citotóxicas, mutagénicas, etc. en el cuerpo humano. Un material utilizado satisfactoriamente como implante ortopédico puede no ser adecuado en aplicaciones cardiovasculares debido a sus propiedades trombogénicas. Por lo tanto, el biomaterial deberá cumplir con diferentes características, dependiendo de la aplicación, para ser considerado biocompatible. No obstante, el hecho de que un biomaterial sea compatible no asegura el éxito del implante ya que el mismo depende de otros factores como el diseño, la técnica utilizada para fabricar el dispositivo médico y su adecuada esterilización, el procedimiento quirúrgico que lleve a cabo el profesional médico, entre otros. De hecho, numerosos fracasos clínicos de reemplazos articulares, por ejemplo, se deben a imperfecciones del dispositivo o a deficientes técnicas quirúrgicas, en lugar de problemas relacionados a las propiedades de los materiales.

\section{BIOMATERIALES METÁLICOS}

La selección y diseño de un biomaterial depende de la aplicación médica específica [10,17]. En el caso de los biomateriales metálicos, son empleados en varias formas para sustituir componentes estructurales dañados y restaurar numerosas funciones dentro del cuerpo humano, debido a que combinan propiedades como resistencia a la corrosión, resistencia a la tracción, tenacidad a la fractura y resistencia a la fatiga $\mathrm{y}$, por ello, se justifica su aplicación en ortopedia para reemplazar articulaciones (cadera, rodilla, hombro, etc.), en osteosíntesis (placas y tornillos), en ortodoncia y odontología (aparatos e implantes dentales) y, además, como 
dispositivos cardiovasculares y neuroquirúrgicos: grampas, stents, entre otros. Además, los biomateriales metálicos no deben presentar propiedades magnéticas.

Como el propósito del biomaterial es poder cumplir el objetivo de funcionar, generalmente, durante un periodo largo sin rechazo por parte del cuerpo humano, un implante metálico debe poseer las siguientes características o propiedades [10,17]:

(a) Excelente biocompatibilidad

(b) Adecuadas propiedades mecánicas (biofuncionalidad)

(c) Elevada resistencia a la corrosión y al desgaste

(d) Osteointegración (en el caso de ciertas prótesis óseas)

\section{Biocompatilidad}

Como no existe un material que sea completamente inerte o no tóxico, la biocompatibilidad de un biomaterial metálico está directamente determinada por su resistencia a la corrosión y los efectos biológicos de los iones metálicos liberados. En el diseño de implantes metálicos se requiere, por lo tanto, el uso de aleaciones con elementos virtualmente inertes o aquéllos que existen como elementos traza en el cuerpo. Los biomateriales metálicos más ampliamente utilizados son titanio y sus aleaciones, aleaciones cobalto-cromo y aceros inoxidables, por lo que los implantes incluyen elementos como $\mathrm{Fe}, \mathrm{Cr}, \mathrm{Co}, \mathrm{Ni}, \mathrm{Ti}, \mathrm{Mo}, \mathrm{W}$, entre otros, y es sabido que dichos elementos son relativamente no citotóxicos en cantidades limitadas. Si bien algunos de estos elementos están presentes naturalmente en el cuerpo humano, y son vitales para muchas funciones celulares [10,18], en grandes cantidades pueden ser altamente tóxicos para el paciente. Por este motivo, el comportamiento de biodegradación in vivo de biomateriales metálicos es causa de gran preocupación, ya que un deterioro prematuro del biomaterial en un entorno fisiológico hostil puede no sólo socavar la integridad estructural del implante, sino también tener efectos nocivos en los tejidos peri-implantarios, produciendo una respuesta inflamatoria celular que puede conducir a una pérdida ósea contenida en la proximidad del 
implante, la osteólisis periprotésica, con el flujo de aflojamiento aséptico y el fracaso del biomaterial [18].

Otro asunto a considerar es que pese a que los avances en la ingeniería de materiales han permitido mejorar considerablemente las propiedades y el desempeño de los implantes metálicos, estos materiales presentan tendencias a fracasar después de un uso a largo plazo debido a diversos modos de falla: efecto escudo (en inglés, stress shielding), fatiga, desgaste, corrosión, etc. [19]. En relación a esto último, las diversas y nuevas técnicas de caracterización de materiales, a nivel superficial y volumétrico, resultan esenciales para efectuar los análisis de causa raíz de fallas de biomateriales implantables, que permiten determinar causas, mitigar y/o prevenir fallas y fracasos y acrecentar la integridad de los mismos.

La situación en relación a fallas lleva muchas veces a los profesionales médicos a realizar las denominadas cirugías de revisión, que no sólo causan traumas en el cuerpo del paciente sino que a su vez, no aseguran el éxito del implante posterior a dicha cirugía [17]. Además, por otro lado, es necesario considerar que el aumento de la tasa de la falla que ocurre en los implantes a largo plazo (teniendo en cuenta que tienen, en el mejor de los casos, una vida útil aproximada de 15 años, particularmente aquellos para traumatología y ortopedia) se debe a que, entre otras razones, se ha elevado la esperanza de vida de las personas y que a edades tempranas se requiere de implantes metálicos. Por dicha combinación es esencial aumentar la vida útil de los dispositivos implantables. En la figura 1.1, se pueden observar las principales causas de falla de los implantes que derivan en una cirugía de revisión [17]. 


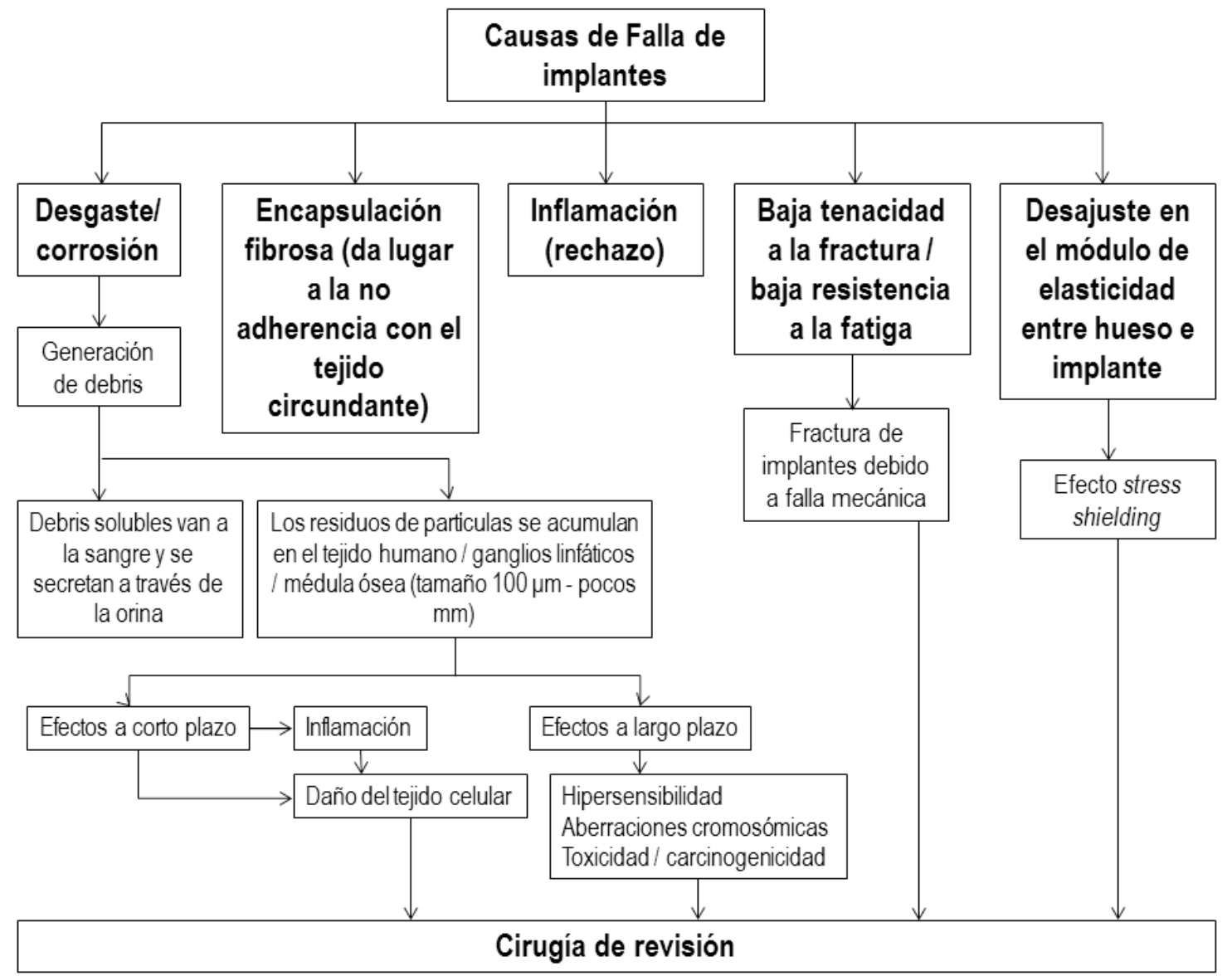

Figura 1.1: Varias causas de falla de los implantes que conducen a una cirugía de revisión [17].

\section{Propiedades mecánicas}

En el diseño y desarrollo de dispositivos implantables se deben tener presentes las propiedades mecánicas de los biomateriales que los conforman, como el módulo elástico, la resistencia a la tracción, a la fatiga, su tenacidad y dureza, entre otros. Aspectos como la resistencia inadecuada de un biomaterial o la falta de coincidencia entre las propiedades mecánicas del hueso y un implante se conocen como incompatibilidad biomecánica y pueden ser causa de fractura del implante [17]. Se espera que un biomaterial metálico tenga un módulo elástico parecido al del hueso que está sustituyendo (el módulo óseo varía en una magnitud de 10 a 30 GPa).

Los materiales utilizados actualmente tienen un módulo elástico mayor que el hueso pero siguen siendo populares principalmente debido a su capacidad para soportar cargas significativas y sufrir deformaciones plásticas antes de la rotura. En la tabla 
1.1 se presenta un resumen de las propiedades mecánicas para los tres biomateriales metálicos más utilizados: titanio y sus aleaciones, aceros inoxidables y aleaciones base cobalto $[10,14,17]$. Se puede observar que las aleaciones de titanio tienen un módulo elástico menor que los aceros inoxidables y aleaciones base cobalto (aunque con mayor resistencia a la fatiga en muchos casos; esto las hace más biofuncionales); sin embargo, la elección del material dependerá además, entre otras cuestiones, de la edad del paciente y del costo del implante.

Tabla 1.1: Propiedades mecánicas de varios biomateriales metálicos [14].

\begin{tabular}{|c|c|c|c|c|}
\hline Material & Condición & $\begin{array}{l}\text { Módulo } \\
\text { de Young } \\
\text { (GPa) }\end{array}$ & $\begin{array}{l}\text { Límite } \\
\text { elástico } \\
\text { (MPa) }\end{array}$ & $\begin{array}{c}\text { Resistencia } \\
\text { a la } \\
\text { tracción }\end{array}$ \\
\hline \multirow{3}{*}{$\begin{array}{l}\text { X2CrNiMo17122 } \\
\text { (AISI 316L) }\end{array}$} & Recocido & 190 & 331 & 586 \\
\hline & $\begin{array}{c}30 \% \text { deformado en } \\
\text { frío }\end{array}$ & 190 & 792 & 930 \\
\hline & Forjado en frío & 190 & 1213 & 1351 \\
\hline \multirow[t]{2}{*}{ Co28Cr6Mo } & Fundido & 210 & $448-517$ & $655-889$ \\
\hline & Forjado en caliente & 210 & 896-1200 & 1399-1586 \\
\hline \multirow[t]{2}{*}{ Co20Cr15W10Ni } & Forjado en caliente & 210 & $484-648$ & $951-1220$ \\
\hline & $44 \%$ forjado en frío & 210 & 1606 & 1896 \\
\hline Co35Ni35Cr20Mo10 & Trabajado & 232 & $965-1000$ & 1206 \\
\hline Ti c.p. & Grado 2 & $105-110$ & 250 & $390-540$ \\
\hline Ti6Al4V & Trabajado en frío & $100-110$ & $830-1070$ & $920-1140$ \\
\hline Ti6Al7Nb & - & 110 & $810-1010$ & $870-1010$ \\
\hline Ti5Al2.5Fe & - & $110-115$ & 780 & 860 \\
\hline Ti12Mo6Zr2Fe & - & $74-85$ & $1000-1060$ & $1060-1100$ \\
\hline Ti13Nb13Zr & - & $64-83$ & $435-905$ & $705-1035$ \\
\hline Ti29Nb13Ta4.6Zr & - & 65 & 400 & $1000-1050$ \\
\hline $\mathrm{Ti} 30 \mathrm{Nb}$ & - & $63-80$ & 500 & 700 \\
\hline Ti30Ta & - & $60-70$ & 590 & 740 \\
\hline
\end{tabular}


El elevado módulo elástico de los biomateriales metálicos impide que la tensión necesaria se transfiera al hueso adyacente, que soporta menos carga mecánica, dando como resultado la resorción ósea alrededor del implante, lo que conduce a su aflojamiento. Esta incompatibilidad biomecánica que conduce a la muerte de las células óseas se denomina efecto stress shielding (o de privación de tensiones o de efecto escudo).

Por otra parte, la respuesta del material a cargas dinámicas se determina por su límite o resistencia a la fatiga, lo cual determina el éxito a largo plazo de un implante sometido a carga cíclica. El límite o resistencia a la fatiga depende de la microestructura del biomaterial, de la calidad superficial del implante y de las condiciones de servicio (desgaste, ambiente corrosivo, etc.). Las fracturas por fatiga son muy peligrosas porque suceden sin advertencia previa a la rotura y normalmente se inician en sitios donde existe concentración de tensión, tales como: inhomogeneidades de la microestructura, defectos de fabricación del dispositivo metálico o imperfecciones superficiales que surgen de las operaciones de mecanizado. Las tensiones se concentran localmente en estos sitios y, finalmente, se desarrolla una fisura que crece progresivamente en condiciones normales de servicio hasta el fallo catastrófico. En la figura 1.2a se pueden observar los valores de resistencia a la fatiga de varios materiales metálicos [20] y en la figura 1.2b se muestran las curvas S-N (también denominadas curvas de Wöhler) de la aleación Ti29Nb-13Ta-4,6Zr y el límite de fatiga del Ti-64 recocido [21]. 
(a)

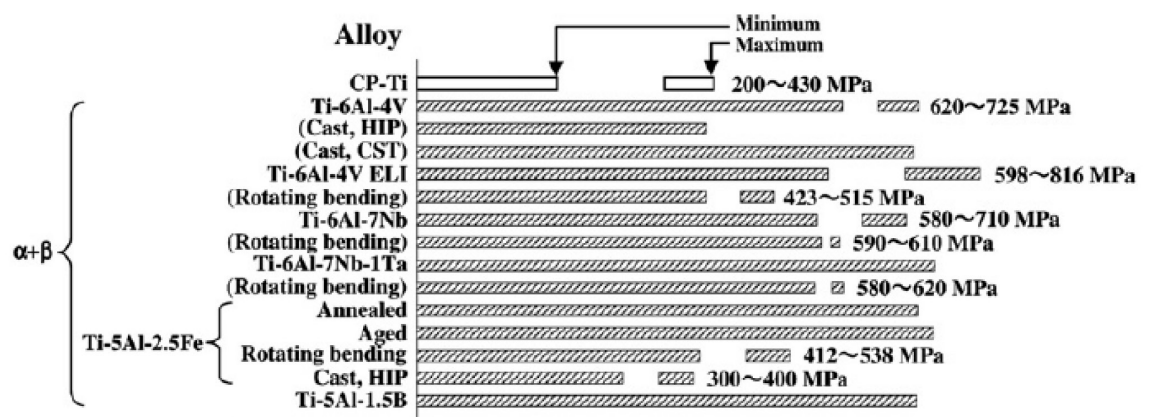

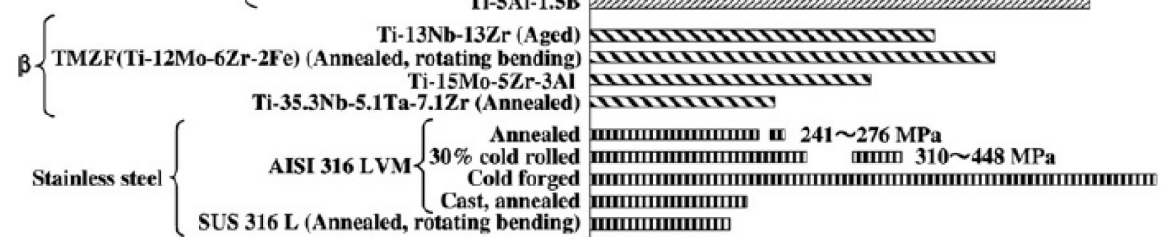
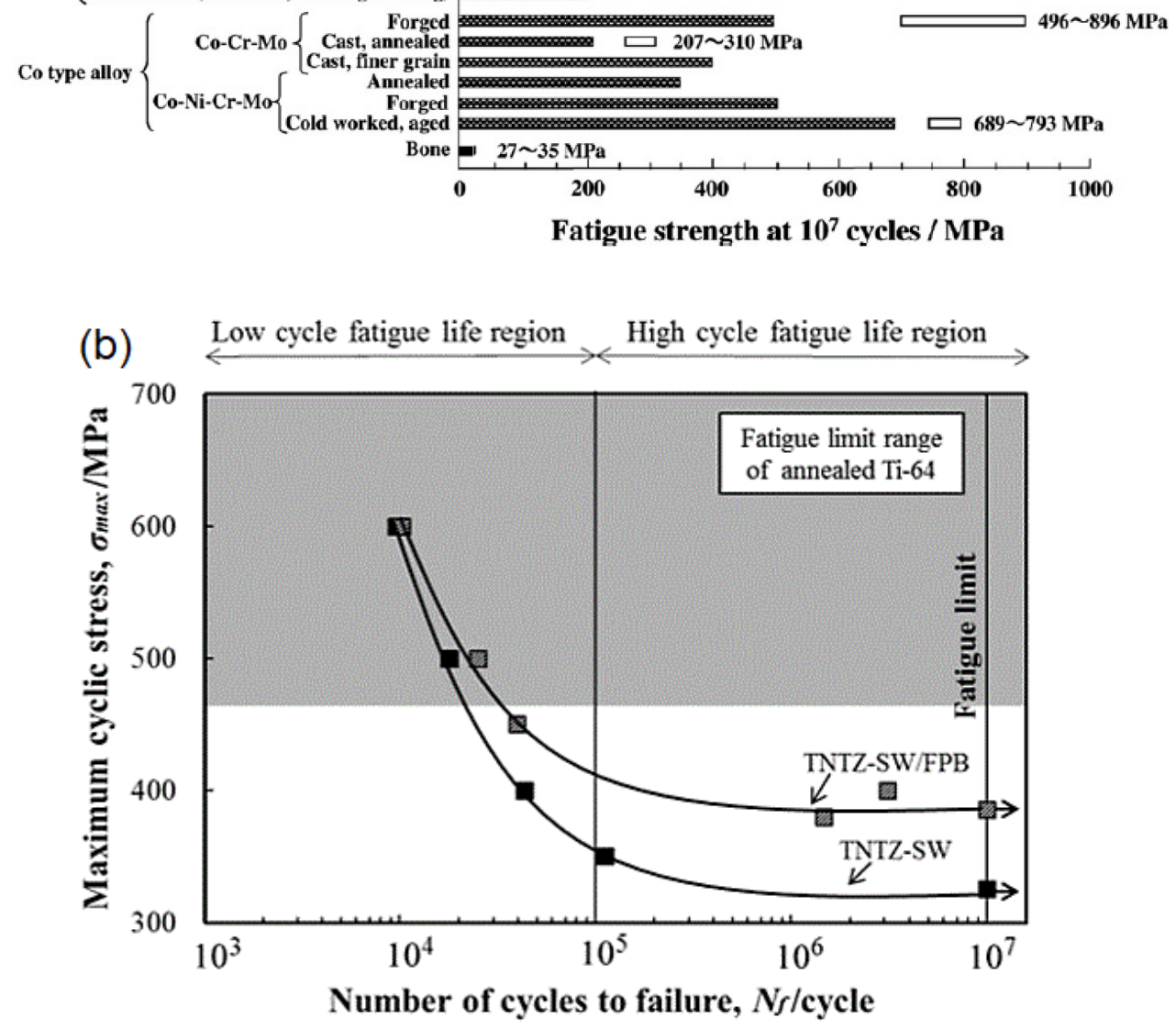

Figura 1.2: (a) Resistencia a la fatiga a $10^{7}$ ciclos de varios biomateriales metálicos [20]; (b) Curvas S-N de la aleación Ti-29Nb-13Ta-4,6Zr y límite de fatiga del Ti-64 recocido [21].

También se puede producir falla por fatiga debido a dos situaciones: por un lado, la fricción y, por el otro, el ambiente corrosivo en el que se encuentra el implante. En el primer caso, se produce como resultado de movimientos relativos de baja amplitud que pueden ocurrir entre las superficies de contacto de los componentes, lo que 
genera restos de óxido y superficies metálicas libres de óxido, y se puede iniciar una grieta en estos sitios de contacto que pronto se propagan hasta la rotura del implante. Las articulaciones artificiales de cadera y placas óseas son propensas a sufrir fatiga por fricción (en inglés, fretting fatigue). En el segundo caso, como se mencionó anteriormente, el desgaste superficial de los metales que conduce a la liberación de partículas, iones y compuestos metálicos, producto de la corrosión del material, pueden producir toxicidad y reacciones en el cuerpo humano; cuando la fatiga ocurre combinada con la corrosión producto de la fricción (o tribocorrosión), a este fenómeno se le conoce como fatiga por tribocorrosión (en inglés, fretting corrosion fatigue). En ambos casos el biomaterial pierde su límite de fatiga y al cabo de un dado número de ciclos fracturará por fatiga. En síntesis, se puede observar que el interior del cuerpo humano es un ambiente química y mecánicamente severo para los materiales metálicos.

\section{Resistencia a la corrosión y al desgaste}

Cualquier biomaterial, expuesto a fluidos biológicos corrosivos inevitablemente sufre corrosión en algún grado. En la tabla 1.2 se pueden observar las concentraciones iónicas del plasma sanguíneo y fluidos del tejido humano con los cuales se encuentran en contacto los implantes [22]. Se produce la descomposición de la capa de óxido superficial protectora que poseen los biomateriales metálicos y se genera una liberación incesante, y posterior acumulación, de partículas de desgaste y restos de degradación en el sitio de implantación, que se acelera por el inevitable y continuo desgaste del movimiento relativo en las superficies de apoyo y micromovimientos en las interfaces entre los componentes de un implante [18].

Ciertos metales de transición, entre ellos $\mathrm{V}, \mathrm{Cr}$, Co y Ni, son conocidos por causar efectos de neurotoxicidad, hepatotoxicidad y nefrotoxicidad. Además, la liberación de V puede conducir a hemólisis, anemia, disminución de la fertilidad, embriotoxicidad y teratogenicidad. Por otro lado, la dermatitis alérgica de contacto es comúnmente desencadenada por Ni, Co y Cr. Además, se ha demostrado que los 
iones metálicos que ejercen un efecto citotóxico directo en las células periimplantares, Ni, Al, Fe y, especialmente, Co y V, demostraron ser tóxicos, reduciendo la proliferación celular y la viabilidad, e induciendo alteraciones en la morfología celular de las células peri-implantares a concentraciones encontradas in vivo en pacientes con artroplastias articulares. Por último, la liberación de iones metálicos podría desencadenar la osteólisis, precipitando la pérdida ósea y el aflojamiento de la prótesis [13].

Tabla 1.2: Concentraciones iónicas (mM) del plasma sanguíneo humano [22].

\begin{tabular}{|c|c|c|}
\hline Ion & Fluido del tejido humano & Plasma sanguíneo humano \\
\hline $\mathbf{N a}^{+}$ & 142,0 & 142,0 \\
\hline $\mathbf{H C O}^{3-}$ & 4,2 & 27,0 \\
\hline $\mathbf{K}^{+}$ & 5,0 & 5,0 \\
\hline $\mathbf{H P O}_{4}^{2-}$ & 1,0 & 1,0 \\
\hline $\mathbf{M g}^{2+}$ & 1,5 & 1,5 \\
\hline $\mathbf{C l}^{-}$ & 147,8 & 103,0 \\
\hline $\mathbf{C a}^{2+}$ & 2,5 & 2,5 \\
\hline $\mathbf{S O}_{4}^{2-}$ & 0,5 & 0,5 \\
\hline
\end{tabular}

Se han observado cuatro tipos de corrosión en implantes metálicos:

(i) la corrosión galvánica, que se produce cuando existe una diferencia de potencial electroquímico entre dos metales diferentes o entre diferentes áreas de la misma superficie metálica, cuando se sumerge en un fluido biológico;

(ii) la corrosión por picado, que es causada por la despasivación localizada de la superficie, o áreas localizadas de diferente potencial debido a la microestructura del material, con disolución de metal dentro de los pits formados; 
(iii) la corrosión por rendija, que es similar a la corrosión por picado y ocurre en espacios confinados, donde existe una baja presión de oxígeno, $\mathrm{pH}$ bajo y alta concentración de cloruros que conducen a la destrucción de la capa pasiva de los metales;

(iv) la corrosión por fricción, cuando la capa pasiva se descompone mecánicamente debido a los micro-movimientos entre partes de un implante, dejando la superficie expuesta a un ataque corrosivo. Si bien la corrosión por rendija es más probable que ocurra en el sitio de fijación de las piezas metálicas, la corrosión por picado y la corrosión por fricción, así como el desgaste, afectan las superficies de apoyo [13]. Aunque los procesos de corrosión y desgaste se encuentran estrechamente relacionados, este último fenómeno necesariamente produce partículas.

El desgaste es un problema inevitable en cualquier reemplazo de articulaciones sin importar los materiales utilizados y la elección del material se determina, principalmente, por el tipo de articulación. El esqueleto humano tiene varios tipos de articulaciones móviles que involucran huesos largos como la cadera, rodilla, tobillo, hombro y codo; y articulaciones más estáticas como en el cráneo, la muñeca y el diente [10]. El desgaste acelera la velocidad de corrosión, incluyendo la liberación de los iones metálicos no sólo como consecuencia de la despasivación de las superficies de contacto, sino también por la corrosión de las partículas generadas por el desgaste, dando como resultado un aumento de la superficie metálica en contacto con los fluidos corrosivos del cuerpo. Por lo tanto, el desarrollo de implantes con alta resistencia a la corrosión y al desgaste es de primordial importancia para la longevidad del material en el cuerpo humano. Idealmente, la resistencia a la corrosión debe ser tal que la liberación de iones metálicos de un implante metálico se minimice en las condiciones más adversas del cuerpo y se mantenga en un nivel relativamente bajo durante un período de servicio largo (más de 30 años) en condiciones fisiológicas normales. 


\section{Osteointegración}

La osteointegración es un requisito fundamental en implantes dentales. En el caso de los implantes ortopédicos, la osteointegración es importante por ejemplo en copas acetabulares y vástagos femorales para articulaciones de cadera, pero no en las superficies de apoyo y en las zonas del implante donde deben existir movimientos entre las superficies de los componentes, como es el caso de las articulaciones.

El término osteointegración fue inicialmente definido por el profesor Per-Ingvar Brånemark a finales de los años cincuenta, como consecuencia de la observación de la integración entre el hueso y un implante de titanio, en el cual se generó la formación de una interfaz directa, libre de cualquier evidencia de la respuesta inflamatoria y la formación de tejido fibroso o conectivo, entre el hueso y el implante [13]. Es decir que, la osteointegración es el anclaje directo entre la superficie de un implante y el hueso a nivel microscópico, mediante la formación de tejido óseo alrededor del implante sin el crecimiento de tejido fibroso en la interfaz hueso-implante (fibrointegración). Por el contrario, la incapacidad de la superficie de un implante para unirse al hueso adyacente y otros tejidos debido a micro-movimientos, causará la formación de tejido fibroso alrededor del implante, lo que promueve el aflojamiento de la prótesis.

Asimismo, la osteointegración no es un fenómeno aislado, sino que depende de otros dos fenómenos: la osteoconducción y la osteoinducción [23]. El término osteoconducción hace referencia a que el hueso crece sobre una superficie. En otras palabras, una superficie osteoconductora es aquella que permite la formación de tejido óseo. En este caso, se produce la migración de células osteogénicas a la superficie del implante, a través de un andamiaje temporal de tejido conectivo, y se forma hueso que se osteoaposiciona sobre la superficie. El anclaje de este andamio a la superficie del implante depende del diseño de la superficie [24]. Es el caso de los materiales bioinertes como el titanio. Por otro lado, el fenómeno de osteoinducción se refiere al proceso por el cual se induce la osteogénesis. En este fenómeno las células primitivas, indiferenciadas y pluripotentes son de alguna manera estimuladas para 
desarrollarse en el linaje celular que forma hueso [23]. Los denominados biomateriales bioactivos son considerados osteoinductores. Como los biomateriales osteoinductores contienen calcio y fósforo, se piensa que los factores importantes para la osteoinducción son (i) la composición química del biomaterial, (ii) las propiedades específicas de disolución del biomaterial y (iii) la morfología superficial del biomaterial. Desde un punto de vista clínico, el biomaterial ideal que actúa como sustituto óseo debe poseer capacidad osteoconductora y osteoinductora, y debe tener propiedades mecánicas superiores [25]. Es necesario aclarar que, si bien la osteointegración inicial depende de la inducción y conducción ósea, este término implica que el anclaje óseo se mantiene con el tiempo [23].

En síntesis, la osteointegración es un proceso complejo que implica una serie de diferentes mecanismos afectados por las propiedades de los implantes y las características superficiales. Se ha demostrado que la química, la rugosidad y la topografía de la superficie desempeñan un papel importante en el desarrollo de una buena osteointegración [10,17].

\section{PROPIEDADES SUPERFICIALES DE LOS BIOMATERIALES METÁLICOS PARA IMPLANTES DENTALES Y ORTOPÉDICOS}

Si bien es cierto que las propiedades de volumen tienen una importante influencia en el rendimiento biológico de los biomateriales, los factores principales que determinan, en última instancia, el rechazo o aceptación de un biomaterial son sus características superficiales. Esto es debido a que la superficie es la interfaz a través de la cual los biomateriales interactúan con el entorno biológico. La superficie de un biomaterial se encuentra definida típicamente como la capa más externa de 100 nm de espesor de un implante. Por otro lado, es inusual que un biomaterial con propiedades de volumen adecuadas posea, a su vez, características superficiales apropiadas y, además, son escasas las superficies realmente biocompatibles $[7,13,14,26,27]$. 
Cuando se implanta un biomaterial dentro del cuerpo humano, las primeras biomoléculas que alcanzan la superficie son las moléculas de agua, que forman una mono o una bi-capa. El agua interacciona de manera diferente con las superficies, de acuerdo a las propiedades de mojabilidad de las mismas: en una superficie hidrofílica, las moléculas de agua se adhieren fuertemente a la superficie, mientras que en una superficie hidrofóbica, se adhieren débilmente. Luego, se incorporan los iones presentes en el medio biológico, como $\mathrm{Na}^{+} \mathrm{o} \mathrm{Cl}^{-}$, formando una doble capa y su amplitud depende de las propiedades electrostáticas entre la solución y la superficie. Poco tiempo después, se adsorbe una monocapa de proteínas y, posteriormente, llegan las células e interaccionan con las proteínas adsorbidas en la superficie del biomaterial. El tipo, la cantidad y la orientación de las proteínas adsorbidas están determinados por las propiedades superficiales de los biomateriales y por las propiedades de las proteínas. Las proteínas adsorbidas sobre una superficie influirán fuertemente en la adhesión, proliferación y diferenciación de las células. Por lo tanto, la naturaleza de la adsorción de las proteínas en la superficie de un biomaterial juega un papel importante en la determinación de la interfaz implante-célula. Además, las proteínas adsorbidas pueden alterar las propiedades superficiales y las propiedades de degradación del biomaterial [7,26,28].

Se pueden producir dos tipos de resultados de la interacción biomaterial-célula: osteointegración del implante o bien el encapsulamiento del mismo en una capa fibrosa. Cualquiera de los dos posibles resultados dependerá de las características superficiales del biomaterial, tales como la topografía y rugosidad, mojabilidad, composición química superficial, carga y energía superficial.

Las principales características superficiales de los biomateriales metálicos son discutidas a continuación.

\section{Química superficial}

La composición química de la superficie determina los grupos funcionales que se encuentran en interacción con las biomoléculas. Dependiendo del tipo de especie 
disponible y su exposición, las biomoléculas pueden tener diferentes afinidades en distintas superficies. La composición química de la superficie es representativa de la del volumen del material aunque la superficie incluirá enlaces insaturados altamente reactivos [13].

La mayoría de los biomateriales metálicos que se utilizan actualmente son aquéllos que forman una capa de óxido espontánea y estable en la superficie. Por lo tanto, la química superficial depende de la composición química de la capa de óxido. Dicha capa de óxido se compone principalmente de óxidos metálicos correspondientes a ese metal. Específicamente, el titanio tiene una capa de óxido de titanio en su superficie y el acero inoxidable 316L contiene principalmente óxido de cromo y algo de óxido de hierro. Además, la capa de óxido espontánea de la mayoría de los biomateriales metálicos contiene algunos grupos funcionales hidroxilos (-OH) [29] y también son muy comunes las contaminaciones de hidrocarburos $\left(-\mathrm{CH}_{3},-\mathrm{CH}_{2}\right.$ y $\left.-\mathrm{CH}\right)$ en la capa superficial de óxido. La concentración de estos grupos funcionales -OH y de los contaminantes en los óxidos metálicos, varía enormemente porque depende de las condiciones de limpieza y manufactura del metal [29,30]. En consecuencia, los biomateriales metálicos se limpian típicamente con una variedad de compuestos ácidos y solventes orgánicos para eliminar hidrocarburos y otras contaminaciones de la capa de óxido superficial.

Los biomateriales metálicos son comúnmente modificados superficialmente ya que es la forma más directa de influir en la adsorción de proteínas y el comportamiento celular, además de mejorar algunas propiedades como la resistencia a la corrosión y al desgaste. Esto implica alterar la superficie original o depositar un recubrimiento sobre la superficie existente [7]. Por lo tanto, las propiedades superficiales, entre ellas la química superficial, dependen entonces de la naturaleza de las superficies modificadas y no de las superficies originales. En el caso de los implantes de titanio, debido a que la osteointegración está directamente relacionada con el espesor de la capa de óxido, uno de los métodos de modificación más utilizados es el anodizado. Este tratamiento incrementa el espesor de la capa de óxido de titanio, modifica la 
química de la superficie y, además, mejora la resistencia a la corrosión y desgaste del implante. Los implantes con capas de óxido de titanio más gruesas, tales como implantes anodizados, muestran una fuerte respuesta ósea ya que aumentan la precipitación de la matriz mineral ósea en la superficie [27,31].

\section{Topografía y rugosidad superficial}

La topografía superficial es un factor clave que afecta la osteointegración de los implantes y se define por la orientación superficial y la rugosidad [32]. En el nivel micrométrico, como una superficie rugosa presenta un área de contacto mayor que una superficie lisa, dicha condición aumenta el anclaje óseo y refuerza el enclavamiento biomecánico del hueso con el implante, al menos hasta cierto nivel de rugosidad. A nivel nanométrico, la rugosidad aumenta la energía superficial y, por lo tanto, mejora la adsorción de proteínas, la migración y proliferación de las células óseas y finalmente la osteointegración [31]. Por estas razones, la interfaz de los implantes es mejorada físicamente por medio de distintos tratamientos superficiales. La modificación topográfica de las superficies de los biomateriales está dirigida a crear características tridimensionales en forma de microporos y nanoporos, rejillas, columnas, microranuras, puntos, pozos y rugosidad superficial aleatoria [27]. En la figura 1.3 se pueden observar superficies de titanio modificadas mediante distintos tratamientos.

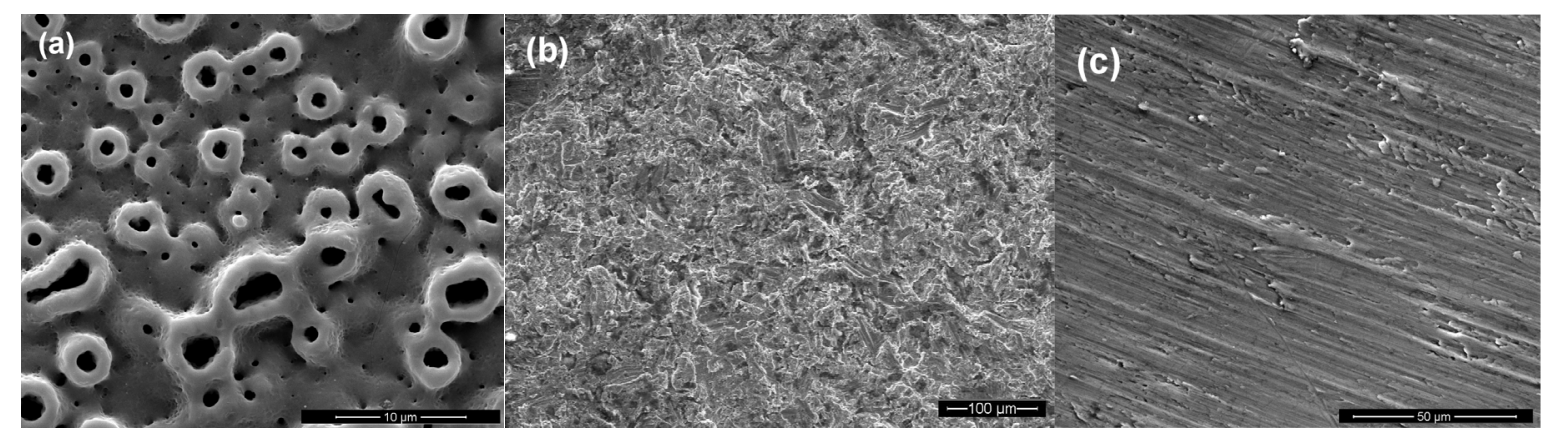

Figura 1.3: Superficies de titanio modificadas mediante: (a) Anodizado por plasma químico en una solución de ácido fosfórico-sulfúrico, (b) Blastinizado con partículas de sílice y (c) Mecanizado. 
La topografía superficial se caracteriza típicamente por una sucesión de picos y valles, que puede cuantificarse utilizando perfiles bidimensionales o parámetros tridimensionales. Actualmente, no existe evidencia sustancial de que la orientación superficial afecte la osteointegración del implante, una vez que se controla el efecto de la rugosidad [32]. En contraste, la rugosidad de la superficie es crucial para los biomateriales y puede clasificarse en tres grupos principales: macrorugosidad (100 micrones-milímetros), microrugosidad (100 nm-100 micrones) y nanorugosidad (<100 $\mathrm{nm})$. Los distintos niveles de rugosidad tienen una influencia específica en la respuesta celular [33]. La macrorugosidad está directamente relacionada con la geometría del implante y su efecto es mayormente mecánico, con conformaciones que refuerzan mecánicamente el anclaje del implante, pero que son demasiado grandes para ser reconocidas por las células. La microrugosidad maximiza el anclaje entre el hueso mineralizado y la superficie del implante [34] y la escala nanométrica juega un papel importante en la adsorción de proteínas y adhesión celular, entre otros factores [35].

En una escala tridimensional (3D), en el rango de la microrugosidad, las superficies rugosas se definen cuando la desviación media aritmética de la topografía de la superficie (Sa) es mayor que $2 \mu \mathrm{m}$, las superficies moderadamente rugosas tienen valores de Sa de 1-2 $\mu \mathrm{m}$, superficies mínimamente rugosas con Sa de 0,5-1 $\mu$ m y las superficies lisas tienen un Sa menor a 0,5 $\mu \mathrm{m}$ [36]. Diversos estudios han demostrado que rugosidades moderadas de la superficie se han asociado con respuestas óseas in vitro e in vivo más fuertes [31,32,37], constituyendo un potencial rango óptimo de rugosidad para la osteointegración de los implantes [38]. En particular, a nivel celular, la rugosidad moderada parece ser óptima para la fijación celular, mientras que superficies excesivamente rugosas dejan distancias extremadamente grandes entre sus picos. Estos grandes "valles" son percibidos por las células como superficies planas, que causan el aplanamiento excesivo de las células y comprometen su nutrición [32]. 
Los procesos de fabricación de superficies existentes actualmente, dan lugar a un amplio rango de características de rugosidad superficial. Generalmente, en la mayoría de los trabajos los datos se presentan sólo por medio del parámetro Sa (Ra en el caso unidimensional), lo que dificulta las comparaciones entre topografías analizadas por distintos autores. Por este motivo es necesario combinar dichos resultados con otros parámetros de amplitud, funcionales o híbridos para una adecuada comprensión de la topografía superficial [32,36]. A partir de la insuficiente caracterización de la rugosidad, se informan resultados contradictorios en superficies microrugosas, es decir, las características topográficas óptimas para mejorar la adhesión, proliferación y diferenciación celular varía según el estudio. Sin embargo, Wennerberg y Albrektsson [32] concluyeron que, sobre la base de evidencias en estudios in vivo y clínicos, hay una indicación de que la respuesta ósea depende de la microtopografía, y con ella, la calidad de la osteointegración. En consecuencia, es sumamente importante contar con técnicas que permitan una buena caracterización topográfica de los biomateriales.

\section{Carga superficial}

Las interacciones electrostáticas, al igual que la química y la mojabilidad de las superficies, tienen un papel muy importante en las interacciones de índole biológica ya que la presencia de carga superficial en la interfaz sólido-solución es una de las características que promueven la adsorción de proteínas y la adhesión celular [27,28]. Si bien, en términos generales, el crecimiento celular es mejor en superficies cargadas en comparación con las superficies neutras, las superficies cargadas positivamente promueven la adhesión celular, mientras que las superficies cargadas negativamente la reducen $[27,28]$. Es interesante mencionar que la adhesión celular en superficies cargadas negativamente se reduce por la disminución de las interacciones iónicas cuando el alcance de la fuerza electrostática es grande. Por el contrario, la adhesión celular es mayor cuando las interacciones iónicas son fuertes, la fuerzas de repulsión se vuelven insignificantes y dominan las fuerzas de Van der Waals [39-41]. 


\section{Energía superficial y mojabilidad}

La energía superficial es un exceso de energía libre por unidad de área que se genera cuando se establece una superficie. En la escala atómica, esta energía está presente como enlaces químicos no terminados. En consecuencia, los átomos superficiales tratarán de reducir su energía libre reordenando y/o uniéndose a cualquier molécula o átomo reactivo disponible para alcanzar un estado energético más favorable [27]. Dicha propiedad se encuentra estrechamente relacionada con otra propiedad denominada mojabilidad o humectabilidad, cuando la superficie del material interacciona con líquidos, como sucede en el caso de los biomateriales. La mojabilidad se puede calcular a partir de un ensayo en el cual se realizan mediciones de ángulo de contacto con gotas de algún líquido como el agua. Ángulos de contacto altos (mayores que $90^{\circ}$ ) indican que la superficie es hidrofóbica y ángulos de contacto bajos (menores que $90^{\circ}$ ) señalan que la superficie es hidrofílica (figura 1.4).

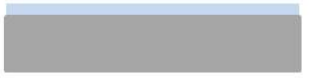

Súper hidrofílica

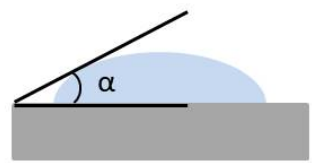

Hidrofílica

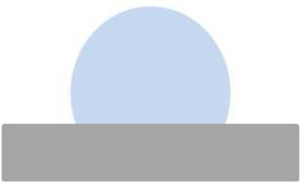

Hidrofóbica

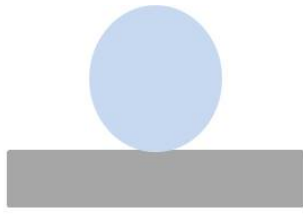

Súper hidrofóbica

Figura 1.4: Ángulo de contacto medido en ensayos de mojabilidad sobre diferentes sustratos.

En efecto, la hidrofilia o hidrofobicidad de una superficie es el resultado de su energía superficial: una superficie hidrofóbica presenta bajas energías superficiales y, al contrario, una superficie hidrofílica tiene altas energías superficiales. Además, la energía superficial está asociada con la distribución de cargas eléctricas, que a su vez, es una consecuencia de la química superficial y la cristalinidad, y todas estas propiedades se ven afectadas por la topografía superficial [42]. En definitiva, los tres factores que afectan la mojabilidad de una superficie son su composición química, su topografía microestructural y su carga superficial [43]. 
La mojabilidad de la superficie de un biomaterial es de vital importancia para la adsorción de proteínas y la adhesión celular. La humectación de la superficie es la primera de una cadena de eventos que ocurren cuando se implanta un biomaterial dentro del cuerpo humano, ya que las primeras biomoléculas que alcanzan la superficie son las moléculas de agua. Esto controla además la adsorción de las proteínas, seguido de la unión de las células a la superficie del implante. Por lo tanto, la humectabilidad superficial se considera un criterio importante a tener en cuenta en el diseño de los implantes.

Varios estudios indican que las superficies de baja energía superficial (hidrófobicas) tienden a adsorber más proteínas, mientras que las superficies de alta energía superficial (hidrofílicas) tienden a resistir la adsorción de proteínas [13,27]. Una posible explicación a este comportamiento en superficies hidrofóbicas se encuentra relacionada con un menor calor de adsorción sobre este tipo de superficies y un mayor despliegue de las proteínas adsorbidas debido a las interacciones entre los dominios hidrófobos internos de las proteínas y la superficie hidrofóbica [44]. En general, las moléculas de proteínas cambian sus conformaciones en mayor medida en superficies hidrófobas que en superficies hidrofílicas. Por el otro lado, las superficies hidrofílicas tienden a interactuar con los grupos funcionales cargados y polares de la superficie de la proteína, influyendo en la orientación de la proteína, pero con una menor tendencia a hacer que la proteína se despliegue y se disemine por la superficie [27].

Por el contrario, numerosos estudios han demostrado que una superficie hidrofílica experimenta un aumento significativo en la fijación, extensión, proliferación y diferenciación celular [13,27]. Algunos estudios indican que las superficies hidrofílicas ayudan a la adhesión celular a través de la adsorción de proteínas tales como fibronectina y colágeno $[13,31,45]$. Otros estudios indican que las células osteoblásticas generalmente se adhieren y proliferan mejor en sustratos moderados a altamente hidrofílicos, y esto probablemente se explica por la mayor adsorción de proteínas observadas, como la fibronectina [46]. 


\section{TRATAMIENTOS SUPERFICIALES}

Los tratamientos superficiales efectuados en implantes ofrecen la capacidad de mejorar las respuestas biológicas a través de cambios en la química, la topografía, la energía y la carga superficial de los materiales, y además, permiten incrementar la resistencia a la corrosión y al desgaste, manteniendo al mismo tiempo las propiedades de volumen del biomaterial. Nouri y otros [27] consideran que las modificaciones superficiales pueden clasificarse ampliamente en tres categorías: (1) adición de materiales con funciones específicas a la superficie, (2) modificación de la superficie existente en composiciones y/o topografías más convenientes, y (3) extracción del material de la superficie existente para crear topografías específicas. No existe un único tratamiento superficial aplicable a todos los biomateriales y las variaciones surgen dependiendo de la aplicación y del tipo de material. Por ejemplo, en materiales para implantes dentales se requiere de una rápida osteointegración, en cambio en materiales utilizados en stents cardíacos se debe evitar la proliferación celular. En el caso de los implantes dentales y ortopédicos, un problema asociado a los biomateriales metálicos de titanio es que son bioinertes, es decir, son materiales osteoconductores que permiten la formación de tejido óseo sobre la superficie aunque sólo existe adsorción física [47]. La manera de aumentar la velocidad inicial de desarrollo óseo, como así también el anclaje biológico de fijación del implante al hueso de un biomaterial metálico, es a partir de distintos tratamientos superficiales, por ejemplo para tornarlo bioactivo, lo cual conduce a una fijación más fuerte al hueso a través de una adsorción química. Además, estas mejoras reducen el tiempo y costo de hospitalización y mejoran la calidad de vida de los pacientes. La elección de un tratamiento $\mathrm{u}$ otro depende de varios factores: el material del sustrato, el diseño y la geometría de los dispositivos, el costo y las terminaciones finales. Hay que destacar dos aspectos del proceso de modificación superficial, el espesor del recubrimiento y la temperatura del proceso [27]. 
Según Dohan Ehrenfest y otros [31] la investigación dirigida a mejorar la interfaz hueso-implante, con el objetivo de acelerar la cicatrización ósea y mejorar el anclaje óseo al implante, típicamente sigue dos enfoques diferentes. En el primer enfoque, la interfaz se mejora químicamente incorporando fases inorgánicas, por ejemplo, en titanio se agrega fosfato de calcio sobre o dentro de la capa de óxido de titanio. Esta modificación química inorgánica podría estimular la regeneración ósea y aumentar el entrelazamiento químico entre las proteínas de la matriz ósea y los materiales de superficie. Otra posibilidad, es la modificación de la superficie de manera bioquímica y se refiere específicamente a la incorporación de moléculas orgánicas, tales como proteínas, enzimas o péptidos, para inducir células específicas y respuestas tisulares. En el segundo enfoque, la interfaz es mejorada físicamente a partir de la modificación de la topografía superficial. Muchos tratamientos superficiales se han desarrollado durante los últimos años con el objetivo de mejorar la osteointegración desde un punto de vista físico y/o químico. Las primeras superficies osteointegradas fueron producidas a partir del mecanizado que producía superficies mínimamente rugosas con algunas microranuras periódicas residuales. A pesar del éxito clínico de dichas superficies, se han desarrollado otros tipos de procesos para mejorar la microtopografía de la superficie, por ejemplo el grabado ácido o el blastinizado. El ataque ácido se realiza frecuentemente utilizando ácido fluorhídrico, nítrico o sulfúrico y combinaciones de los mismos. El blastinizado se realiza mediante la proyección de partículas de sílice (blastinizado con arena), fosfatos de calcio, alúmina u óxido de titanio de distintos tamaños, y se termina comúnmente mediante un pasivado químico para homogeneizar la microtopografía del implante y eliminar la mayor cantidad posible de partículas residuales de blastinizado. Por otro lado, muchos tratamientos superficiales pueden combinar modificaciones químicas y físicas. Por ejemplo, el anodizado de la superficie de titanio puede promover un aumento del espesor y la incorporación de elementos del electrolito en la capa de óxido de titanio, mientras que la ruptura del material superficial da como resultado estructuras porosas y micro o nanotopografía. 
Los procedimientos de preparación de superficies son numerosos y los parámetros que definen cada proceso (por ejemplo, temperatura, presión, tiempo, tipo y tamaño de partículas, tipo y concentración de electrolitos de ataque y anodizado) pueden modificarse ampliamente. Por lo tanto, el número de diferentes superficies que se pueden obtener es casi ilimitado y son difíciles de agrupar en distintas categorías de acuerdo a su proceso de fabricación. Por lo tanto, se necesita el desarrollo de un sistema de clasificación exhaustivo y consensuado, basado en parámetros químicos y físicos estandarizados [31]. 


\section{CAPÍTULO 2 \\ TÉCNICAS DE CARACTERIZACIÓN}

Como se mencionó en el capítulo 1, existe una gran variedad de parámetros que describen las superficies: composición química, textura superficial, carga superficial, micro y nano estructuras, mojabilidad, cristalinidad, entre otros [7,28]. Mientras más parámetros sean medidos, mejor será la descripción de la superficie [7]. Desafortunadamente, no es posible todavía especificar cuáles parámetros son de mayor importancia para entender las respuestas biológicas de las superficies. Se han publicado numerosos trabajos en cada uno de los cuales se resalta la importancia de alguno de estos parámetros. Como no es posible estar seguro de cuáles son las magnitudes predominantes en cada situación o aplicación, éstas deben determinarse independientemente a partir del uso de diversas técnicas de caracterización tales como espectroscopías, microscopía electrónica, interferometría, entre otras [7,31]. Por otra parte, una caracterización completa requiere el uso de diferentes estrategias para combinar, comparar y evaluar los resultados que se han obtenido con las distintas técnicas, dependiendo de las propiedades que debe poseer un implante para una determinada aplicación: implante dental, prótesis de cadera, rodilla, varillas de fijación, etc. Además, cuál es la mejor combinación de técnicas para caracterizar el biomaterial depende del material, del tratamiento superficial y de la función que cumplirá el implante.

A continuación se describen brevemente las técnicas de caracterización utilizadas durante el desarrollo del presente trabajo de tesis.

\section{MICROSCOPÍA ELECTRÓNICA DE BARRIDO}

El microscopio electrónico de barrido (SEM, siglas en inglés de Scanning Electron Microscope) permite la observación y el análisis de características microestructurales de materiales orgánicos e inorgánicos heterogéneos en la escala 
del nanómetro $(\mathrm{nm})$ al micrómetro $(\mu \mathrm{m})$ [48]. La popularidad del SEM se debe a su alta resolución (de 10-50^) y a su capacidad de obtener imágenes de apariencia tridimensional a causa de su alta profundidad de foco (aproximadamente entre $100 \mathrm{y}$ 1000 veces mayor que la de un microscopio óptico a la misma magnificación) [48]. El SEM puede proveer inclusive información de la tercera dimensión, a partir de obtener dos imágenes de la muestra a dos ángulos de inclinación levemente diferentes (pares estéreo) que da lugar a la técnica conocida como estereoscopía que, además, permite la evaluación cuantitativa de la topografía superficial [49].

Un esquema de la columna de electrones y óptica del SEM puede observarse en la figura 2.1. La fuente de electrones funciona normalmente en un rango de voltaje de hasta $30 \mathrm{kV}$, aunque a veces se puede extender a $60 \mathrm{kV}$ dependiendo del tipo de instrumento y la aplicación. Los electrones se aceleran a este potencial mientras que un par de bobinas electromagnéticas denominadas lentes condensadoras, demagnifican el haz una cierta cantidad dada por la corriente aplicada a las mismas, mientras que un segundo par de bobinas, llamadas lentes objetivo concentran el haz hasta una sección mínima, que puede variar de 1 a 500 nm. Un par de bobinas de deflexión electromagnéticas permiten realizar el barrido del haz de electrones en la muestra en sincronismo con la impresión en la pantalla del monitor de visión de la imagen. 


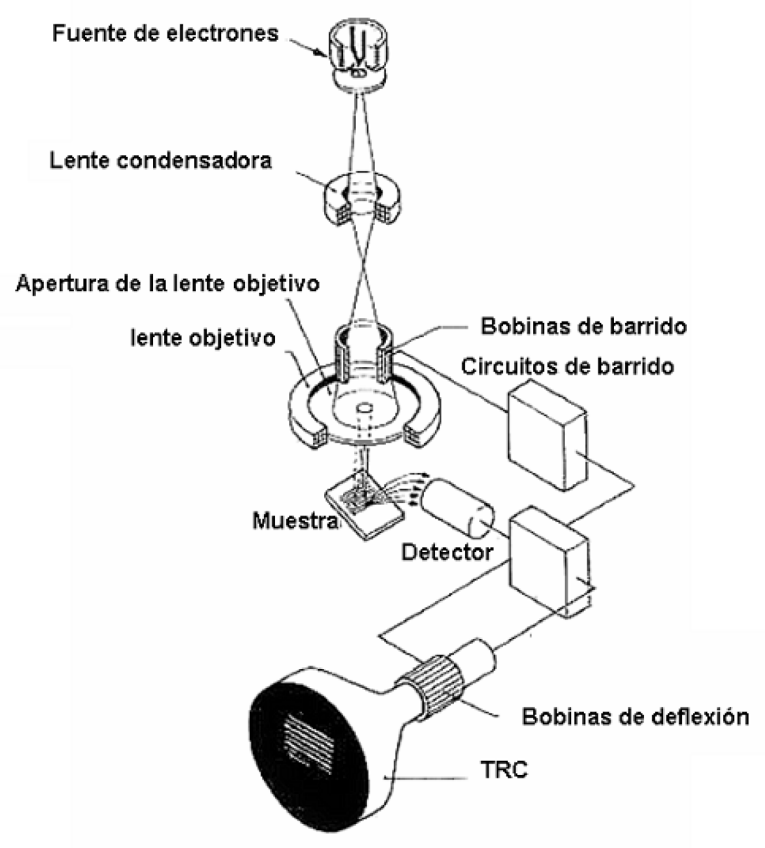

Figura 2.1: Diagrama esquemático de un microscopio electrónico de barrido.

En el SEM, la muestra es irradiada con un fino haz de electrones que puede barrer una trama rectangular de líneas paralelas a través de la superficie de la muestra para formar imágenes o puede permanecer en forma estática para realizar un análisis en una posición. La interacción del haz de electrones con la materia produce distintos y complejos fenómenos entre los cuales se incluyen la emisión de electrones secundarios, electrones retrodispersados, rayos $\mathrm{X}$ característicos, rayos $\mathrm{X}$ del continuo y electrones Auger. Las señales de mayor interés para obtener imágenes mediante SEM son los electrones secundarios y los electrones retrodispersados porque varían principalmente como resultado de diferencias en la topografía de las superficies [48]. Cuando la interacción del electrón incidente es con los electrones más periféricos de los átomos de la muestra, muchos de estos electrones de valencia son eyectados fuera de la muestra como electrones secundarios de baja energía (< $50 \mathrm{eV})$. Por otro lado, en la interacción del electrón con el intenso campo coulombiano cerca del núcleo de los átomos de la muestra, se produce una gran deflexión en la dirección del electrón. Si bien el ángulo de deflexión más probable es $\sim 5^{\circ}$ el rango del mismo está entre $0^{\circ}$ y $180^{\circ}$. De esta manera, uno o más de estos electrones pueden ser 
dispersados elásticamente hacia atrás y hasta salir de la superficie de la muestra (electrones retrodispersados).

Los electrones retrodispersados de alta energía son útiles porque la intensidad de la señal retrodispersada refleja la densidad de masa o el número atómico promedio de la muestra y no sólo la topografía de la superficie. Las regiones más brillantes son, por lo tanto, una indicación clara de una zona más densa o con un número atómico medio más alto. Sin embargo, la señal electrónica secundaria es la más útil para construir una imagen topográfica de alta resolución. Puesto que los electrones secundarios son generados con bajas energías (del orden de los eV), sólo alcanzan a abandonar la muestra los que fueron originados en una delgada capa, de unos pocos $\mathrm{nm}$, sobre la superficie de la muestra. De esta manera, la imagen construida a partir de la señal de electrones secundarios tiene una excelente resolución espacial. Por otro lado, estos electrones secundarios pueden ser recogidos con una eficiencia cercana al $100 \%$. Los electrones secundarios pueden ser generados, por un lado, por el haz incidente al entrar en la muestra y, además, por electrones retrodispersados de alta energía que están saliendo de la muestra. La resolución de los electrones secundarios no se degrada, en primera aproximación, por la dispersión inelástica del haz primario, sino que se determina principalmente por la capacidad de enfocar el haz y es típicamente del orden de los $2 \mathrm{~nm}$. Si además se consideran los electrones secundarios generados por el flujo de electrones retrodispersados, la resolución se degrada llegando a ser del orden de 20-50 nm [49].

La distancia promedio desde la superficie de la muestra hasta el punto que alcanzan los electrones primarios, conocida como el rango del electrón, depende de la energía del haz incidente y del número atómico de la muestra. El volumen desde el cual provienen las diferentes señales está relacionado con dicho rango. Si bien en la literatura existen numerosas descripciones del rango del electrón, se tomará como referencia la ecuación del rango de Kanaya y Okayama [50] cuya expresión es: 
$R_{K O}(\mu m)=\frac{0,0276 A E_{0}^{1,57}}{Z^{0,89} \rho}$

donde Eo: energía del electrón incidente $(\mathrm{keV})$, A: peso atómico $(\mathrm{g} / \mathrm{mol})$, Z: número atómico y @: densidad de la muestra $\left(\mathrm{g} / \mathrm{cm}^{3}\right)$.

En la figura 2.2 se puede observar una representación esquemática de las señales y sus volúmenes de interacción que se producen en la interacción de los electrones con la materia.

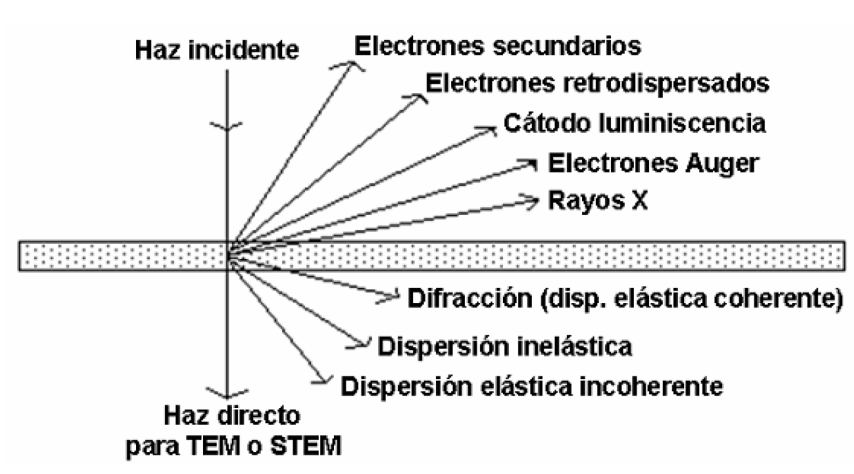

(a)

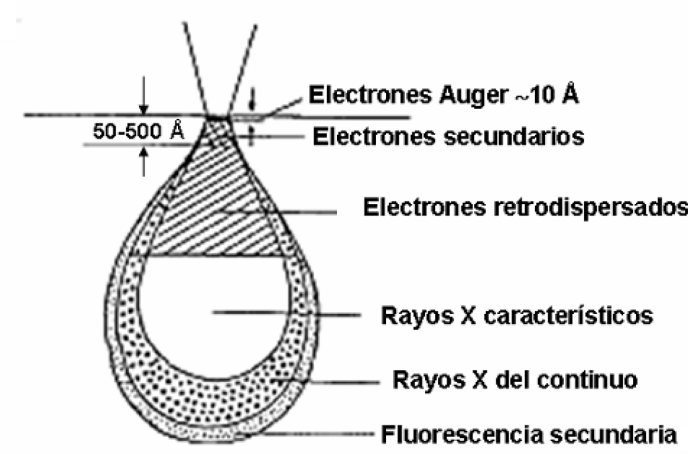

(b)

Figura 2.2: (a) Diagrama esquemático de las señales que se producen de la interacción de los electrones con la materia; (b) Volúmenes de interacción de los electrones secundarios, retrodispersados y Auger, y de rayos $\mathrm{X}$ característicos y del continuo.

Si un haz de electrones de corriente ів constante incide sobre una muestra que se encuentra conectada a tierra, dicha corriente se divide en tres contribuciones: la corriente de electrones retrodispersados $\left(\mathrm{i}_{\eta}\right)$, la de electrones secundarios (i⿱宀⿻三丨口 $)$ emitidos y la corriente de espécimen o corriente absorbida (iE). El balance de la corriente se puede expresar de la siguiente manera: $i_{B}=i_{\eta}+i_{\diamond}+i_{E}[51]$.

La falta de un flujo continuo de la corriente de espécimen a tierra se convierte en un problema crítico cuando se trata de muestras aislantes (orgánicas, biológicas, vidrios, cerámicos, polímeros, etc.) ya que pueden sufrir el fenómeno de acumulación de cargas, a menos que se introduzca un camino conductor artificial en o sobre la muestra. El fenómeno de acumulación de cargas ocurre por la alta resistividad de las 
muestras aislantes que impiden el flujo de los electrones del haz incidente a través de la muestra a tierra, de manera que los electrones se acumulan en la zona de impacto del haz y pueden degradar severamente las imágenes del SEM [48]. Existen varias maneras de reducir o eliminar la acumulación de cargas pero la más utilizada es depositar, mediante distintos métodos, una capa muy fina (del orden de los nanómetros) de un material conductor sobre la superficie de la muestra, entre los cuales se pueden mencionar $\mathrm{Au}, \mathrm{Au}-\mathrm{Pd}, \mathrm{Pt}, \mathrm{Cr}, \mathrm{Cu}, \mathrm{C}$, entre otros. La función de la capa depositada es aumentar la conductividad eléctrica y térmica de la superficie y, en algunos casos, incrementar la señal de electrones secundarios y retrodispersados [51].

En la década de 1980, se desarrollaron nuevos microscopios electrónicos de barrido que permitieron estudiar muestras aislantes sin preparación previa, conocidos como ESEM (siglas en inglés de Environmental Scanning Electron Microscope) [48,52]. La característica principal que distingue el ESEM es la presencia de un gas en la cámara de la muestra que provee un vacío parcial (hasta 20 torr) comparado con el alto vacío del SEM convencional $\left(10^{-6}-10^{-7}\right.$ torr). Los electrones secundarios emitidos por la muestra, acelerados en el campo eléctrico generado entre la muestra y el detector, colisionan con las moléculas de gas y generan electrones secundarios adicionales (causando una cascada de electrones) y, por lo tanto, amplificando la señal antes de llegar al detector. Los iones positivos resultantes de este proceso en cascada son una característica esencial en el ESEM, ya que estos iones se desplazan hacia la superficie de la muestra y, de este modo, ayudan a equilibrar la acumulación de carga negativa en la superficie, por lo que las muestras aislantes se pueden observar sin la necesidad de una capa conductora. Los gases utilizados en este microscopio incluyen el óxido nitroso, dióxido de carbono, helio, argón, nitrógeno y vapor de agua, siendo este último el más eficiente en la amplificación de la señal por lo que es el más utilizado [52]. Por último, en los ESEM se puede variar la temperatura, además de la presión, por lo que se pueden realizar estudios en muestras hasta con un 100\% de humedad relativa y hasta $1500^{\circ} \mathrm{C}$ de temperatura. 


\section{MICROANÁLISIS CON SONDA DE ELECTRONES}

La información sobre la composición química de las diferentes características microestructurales de los materiales es a menudo de primordial importancia y se ha dedicado un gran esfuerzo a la técnica de microanálisis con sonda de electrones (EPMA, siglas en inglés de Electron Probe Microanalysis) para complementar resultados obtenidos con otro tipo de técnicas. Así, el microanálisis con sonda de electrones es una técnica de caracterización no destructiva para determinar la composición química de distintos tipos de materiales orgánicos e inorgánicos con una resolución espacial entre 0,1 y $1 \mu \mathrm{m}$.

Como se mencionó anteriormente, en la interacción del haz de electrones con la materia se generan múltiples fenómenos, entre ellos la interacción inelástica con los núcleos, en la cual la partícula incidente experimenta un cambio en su dirección inicial, y en algunos casos se emite un cuanto de radiación y la partícula interactuante pierde una cantidad equivalente de energía incidente, dando lugar al espectro continuo o Bremsstrahlung $[48,49,53]$.

Por otro lado, la interacción inelástica del electrón incidente con los electrones de los niveles atómicos internos del átomo, da lugar al espectro de rayos $\mathrm{X}$ de líneas características de los elementos presentes en una muestra. De dicha interacción, se originan vacancias que se ocupan mediante el decaimiento de electrones procedentes de niveles más externos; cuando estas vacancias se llenan de manera radiativa, se emite un fotón característico. Debido a la conservación de la energía, la energía de este fotón es igual a la diferencia de energía del átomo entre el estado inicial y final, por lo que, es característica de dicho decaimiento y del elemento en el cual se produjo. Por otro lado, algunas veces ocurre que la vacancia producida en un nivel interno se llena con un electrón a través de una transición no radiativa, es decir, el átomo utiliza la energía disponible de tal transición para eyectar otro electrón. Este 
fenómeno, que compite con la emisión de rayos $\mathrm{X}$ característicos se denomina efecto Auger $[48,49,53]$.

Los electrones de un átomo ocupan niveles o capas alrededor del átomo que tienen energías de ligadura específicas y para poder arrancar un electrón de alguna capa electrónica es necesario que la energía del electrón incidente sea mayor que la energía de ligadura de dicha capa. En orden de energía creciente desde el núcleo atómico, las capas atómicas, según la notación de Barkla, se designan: $\mathrm{K}, \mathrm{L}, \mathrm{M}, \mathrm{N}, \mathrm{O}, \mathrm{P}$, etc. A su vez, estas capas se dividen en subcapas, a excepción de la capa K. Por ejemplo, la capa L está compuesta de tres subcapas y la capa M tiene cinco subcapas. Los electrones ocupan estas subcapas en un esquema definido como se muestra en la tabla $2.1[48]$.

Tabla 2.1: Capas y subcapas electrónicas de los átomos [48].

\begin{tabular}{|c|c|c|c|c|c|}
\hline $\begin{array}{c}\text { Notación } \\
\text { de } \\
\text { rayos X }\end{array}$ & $\begin{array}{c}\text { Notación } \\
\text { moderna }\end{array}$ & $\begin{array}{c}\text { Electrones } \\
\text { que pueden } \\
\text { llenar los } \\
\text { estados } \\
\text { vacantes } \mathrm{K}\end{array}$ & $\begin{array}{c}\text { Electrones } \\
\text { que pueden } \\
\text { 1lenar los } \\
\text { estados } \\
\text { vacantes L }\end{array}$ & $\begin{array}{c}\text { Electrones } \\
\text { que pueden } \\
\text { llenar los } \\
\text { estados } \\
\text { vacantes M }\end{array}$ & $\begin{array}{c}\text { Ocupación } \\
\text { máxima de } \\
\text { la subcapa } \\
\text { electrónica }\end{array}$ \\
\hline $\mathrm{K}$ & $1 \mathrm{~s}$ & & & & 2 \\
\hline $\mathrm{LI}_{\mathrm{I}}$ & $2 \mathrm{~s}$ & & & & 2 \\
\hline $\mathrm{LIII}$ & $2 \mathrm{p}^{1 / 2}$ & $\mathrm{x}$ & & & 2 \\
\hline $\mathrm{L}_{\mathrm{III}}$ & $2 \mathrm{p}^{3 / 2}$ & $\mathrm{x}$ & & & 4 \\
\hline $\mathrm{M}_{\mathrm{I}}$ & $3 \mathrm{~s}$ & $\mathrm{x}$ & & & 2 \\
\hline $\mathrm{M}_{\mathrm{II}}$ & $3 \mathrm{p}^{1 / 2}$ & $\mathrm{x}$ & & & 4 \\
\hline $\mathrm{M}_{\mathrm{III}}$ & $3 \mathrm{p}^{3 / 2}$ & $\mathrm{x}$ & $\mathrm{x}$ & & 4 \\
\hline $\mathrm{M}_{\mathrm{v}}$ & $3 \mathrm{~d}^{3 / 2}$ & $\mathrm{x}$ & $\mathrm{x}$ & & 6 \\
\hline $\mathrm{M}_{\mathrm{IV}}$ & $3 \mathrm{~d}^{5 / 2}$ & $\mathrm{x}$ & $\mathrm{x}$ & & 2 \\
\hline $\mathrm{N}_{\mathrm{I}}$ & $4 \mathrm{~s}$ & $\mathrm{x}$ & $\mathrm{x}$ & & 4 \\
\hline
\end{tabular}




\begin{tabular}{|c|c|c|c|c|c|}
\hline $\mathrm{N}_{\text {II }}$ & $4 \mathrm{p}^{1 / 2}$ & $\mathrm{x}$ & $\mathrm{x}$ & & 2 \\
\hline $\mathrm{N}_{\mathrm{III}}$ & $4 \mathrm{p}^{3 / 2}$ & $\mathrm{x}$ & $\mathrm{x}$ & $\mathrm{x}$ & 4 \\
\hline $\mathrm{N}_{\mathrm{IV}}$ & $4 \mathrm{~d}^{3 / 2}$ & $\mathrm{x}$ & $\mathrm{x}$ & $\mathrm{x}$ & 4 \\
\hline $\mathrm{N}_{\mathrm{V}}$ & $4 \mathrm{~d}^{5 / 2}$ & $\mathrm{x}$ & $\mathrm{x}$ & $\mathrm{x}$ & 6 \\
\hline $\mathrm{N}_{\mathrm{VI}}$ & $4 \mathrm{f}^{5 / 2}$ & $\mathrm{x}$ & $\mathrm{x}$ & $\mathrm{x}$ & 6 \\
\hline $\mathrm{N}_{\mathrm{VII}}$ & $4 \mathrm{f}^{7 / 2}$ & $\mathrm{x}$ & $\mathrm{x}$ & $\mathrm{x}$ & 8 \\
\hline
\end{tabular}

Las líneas de rayos $\mathrm{X}$ características resultan de las transiciones entre subcapas, sin embargo, la teoría atómica expresa que, en la llamada aproximación dipolar, sólo se permiten las transiciones entre ciertas subcapas. Esto significa que no todas las transiciones entre las capas atómicas dan como resultado rayos $\mathrm{X}$ característicos con una probabilidad relevante. Este fenómeno se plasma en las reglas de selección dipolar, según las cuales las transiciones permitidas son aquéllas que satisfacen las siguientes condiciones para los números cuánticos: $\Delta \mathrm{n} \geq 1, \Delta \mathrm{l}= \pm 1$ y $\Delta \mathrm{j}=0$ ó \pm 1 , siendo $\mathrm{n}$ el número cuántico principal que indica la capa atómica, 1 el momento angular del orbital correspondiente y j el vector resultante de la suma del momento angular y el momento de espín.

\section{Sistemas de detección de rayos $X$}

La detección de los rayos X característicos emitidos por la muestra puede llevarse a cabo mediante espectrómetros dispersivos en energías (EDS, siglas en inglés de Energy Dispersive Spectrometer) o espectrómetros dispersivos en longitudes de onda (WDS, siglas en inglés de Wavelength Dispersive Spectrometer). Dichos espectrómetros se complementan de acuerdo al requerimiento de cada aplicación. En ambos sistemas, la detección se basa en el efecto fotoeléctrico: el fotón de rayos $\mathrm{X}$ es absorbido por un átomo con la posterior expulsión de uno de los electrones unidos a ese átomo. Dicho fotoelectrón tiene una energía cinética igual a la energía del fotón menos la energía de enlace del electrón al átomo y el átomo queda en un estado 
excitado correspondiente a la energía de enlace del electrón emitido. El fotoelectrón se dispersa inelásticamente en el detector, depositando energía y creando como resultado portadores de carga. Estos portadores de carga se utilizan de diferentes maneras en los detectores EDS y WDS [54]. A continuación se describen brevemente ambos sistemas.

\section{Espectrómetro dispersivo en longitudes de onda}

En el espectrómetro dispersivo en longitudes de onda, la separación de los rayos $X$ de diferentes energías se consigue utilizando la naturaleza ondulatoria del fotón a través del fenómeno de difracción. Para un cristal de espaciamiento interplanar d, la ley de Bragg proporciona la relación entre la longitud de onda de los rayos $X(\lambda)$ y el ángulo crítico $(\theta)$ al cual se produce interferencia constructiva:

$\mathrm{n} \lambda=2 d \operatorname{sen} \theta$

donde $\mathrm{n}$ es un entero. La resolución típica de un pico de WDS en términos de energía es 10 eV o menor para la línea $\mathrm{Mn} \mathrm{K} \alpha$.

Un espectrómetro WDS consiste en un sistema mecánico de alta precisión para establecer el ángulo de Bragg crítico entre la muestra y el cristal de difracción y entre el cristal de difracción y el detector de rayos X. Un esquema simple del sistema se muestra en la figura 2.3.

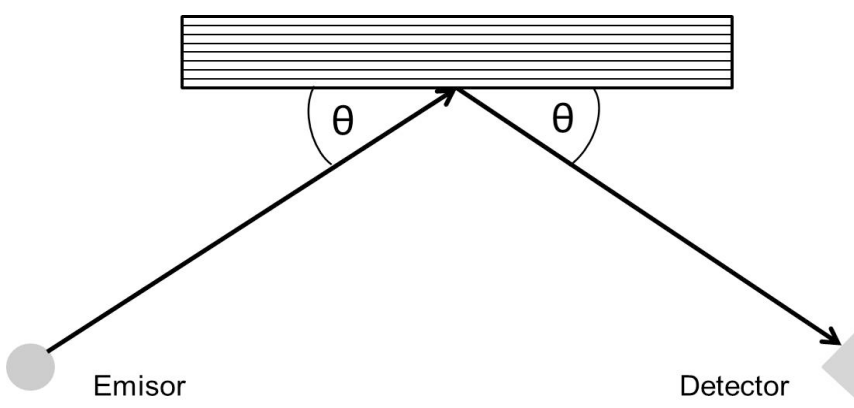

Figura 2.3: Esquema de la configuración más sencilla del sistema WDS formado por el emisor, el cristal analizador y el detector. 
Con el fin de medir rayos $\mathrm{X}$ de diferentes energías (longitudes de onda), las posiciones del cristal analizador y el detector deben ser cambiados con respecto a la muestra para alterar los ángulos. Para cubrir el rango de longitudes de onda de rayos $\mathrm{X}$ a medir, por ejemplo, de 6,8 nm en B K $\alpha(183 \mathrm{eV})$ a 0,092 nm en U L $\alpha(13,4 \mathrm{keV})$, se deben utilizar varios cristales de difracción diferentes y los espectrómetros incluyen a menudo hasta cuatro cristales intercambiables montados en una torreta. Por otro lado, la detección de los rayos X en un espectrómetro WDS se lleva a cabo en un contador proporcional. El fotón es absorbido fotoeléctricamente por un átomo del gas que llena el detector y el fotoelectrón eyectado ioniza otros átomos, produciendo una cascada de electrones expulsados que son acelerados por un voltaje aplicado a un alambre en el centro del detector [54].

\section{Espectrómetro dispersivo en energías (EDS)}

El detector EDS consiste en un cristal de silicio que está polarizado por medio de electrodos colocados en las superficies anterior y posterior. Los fotones incidentes generan fotoelectrones en el silicio, cuya dispersión crea pares de electrones-huecos libres en la estructura de bandas del semiconductor. Los electrones y los huecos son separados por el voltaje aplicado a través del detector y la carga se recoge en los electrodos superficiales. El detector se mantiene a temperaturas de nitrógeno líquido y está protegido del entorno por medio de una ventana. Esta ventana suele estar fabricada de berilio que permite mantener el vacío dentro del detector y debe soportar la presión atmosférica durante la ventilación del equipo. Desafortunadamente, esta ventana de berilio es suficientemente gruesa y absorbe en gran medida los rayos $\mathrm{X}$ característicos correspondientes a líneas $\mathrm{K}$ generadas por elementos de número atómico menor que 12. Como alternativa, se puede utilizar una ventana más delgada que la anterior, fabricada de un polímero que mantiene la integridad del vacío alrededor del detector mientras que la pueden atravesar rayos $X$ 
de energías tan bajas como la línea C-K $\alpha$. Un esquema del EDS se puede observar en la figura 2.4 .

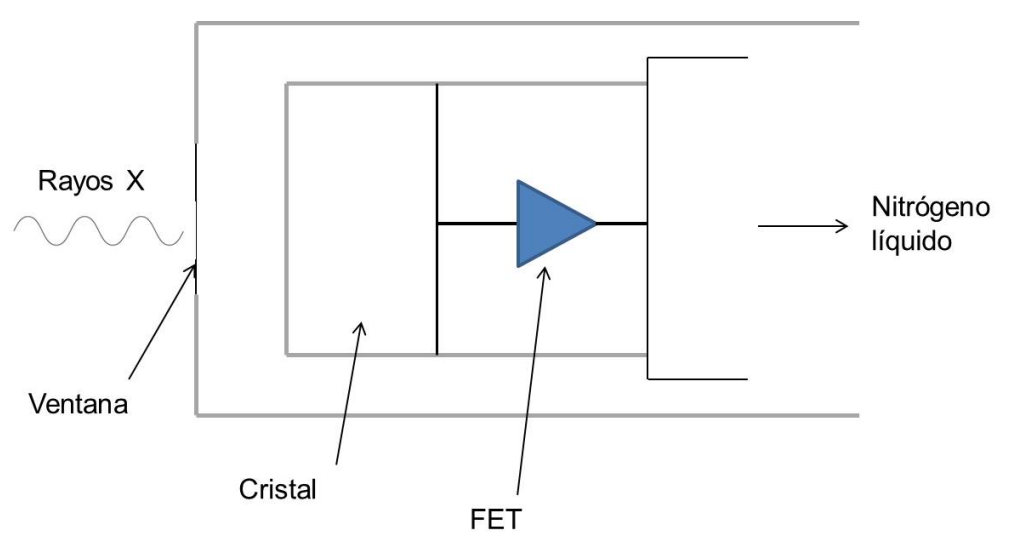

Figura 2.4: Esquema de la configuración del sistema EDS.

El espectrómetro EDS convierte un fotón de rayos $X$ en un pulso eléctrico con características específicas de amplitud y ancho. Este pulso eléctrico se convierte en una señal digital y se añade al canal de energía correspondiente. La detección de los fotones de rayos $\mathrm{X}$ de diferentes energías se realiza prácticamente en forma simultánea y los conteos acumulados producen un espectro de rayos $\mathrm{X}$ con los picos principales superpuestos sobre el fondo [55]. El detector de cristal de silicio dopado con litio es seguido por un preamplificador FET (siglas en inglés de Field Effect Transistor) que se mantiene a temperaturas criogénicas con nitrógeno líquido, un amplificador principal y varias otras funciones de procesamiento de señales [54].

El sistema que se describió anteriormente es el detector que se ha utilizado en la mayoría de los equipos. En la actualidad, se ha incorporado otra clase de detector EDS denominado detector SDD (siglas en inglés de Silicon Drift Detector), desarrollado por E. Gatti and P. Rehak en el año 1983, que se basa en el mismo principio mencionado anteriormente pero que posee cambios significativos en el diseño que mejoran su sensibilidad. Gatti y Rehak desarrollaron un sistema que puede operar mucho más cerca de la temperatura ambiente con sólo un enfriamiento moderado y se puede utilizar en aplicaciones que requieren altas tasas de conteo [55]. 
En síntesis, los espectrómetros EDS presentan la ventaja de ser rápidos, al detectar todos los fotones del espectro simultáneamente, mientras que los WDS, que lo hacen en forma secuencial, son mucho más lentos. Como contrapartida, la resolución de estos últimos es uno o dos órdenes de magnitud mejor.

\section{ESPECTROSCOPÍA DE RETRODISPERSIÓN DE RUTHERFORD}

La espectrometría de retrodispersión de Rutherford (RBS, siglas en inglés de Rutherford Backscattering Spectrometry) es una técnica en la cual se bombardea la superficie de un material con un haz de iones de alta energía (generalmente partículas alfa) que son retrodispersadas luego de su colisión con los átomos de la muestra y, a partir de determinar la energía y el número de partículas, se puede obtener información cuantitativa de la composición de películas delgadas, materiales estratificados, entre otros [53]. Además, debido a que la información cuantitativa puede obtenerse sin muestras estándar, los análisis de RBS a menudo sirven como estándares para otras técnicas que son mucho más sensibles pero requieren de calibración [54].

El primer concepto básico del RBS es que en una colisión elástica, tal como sucede en la retrodispersión, la transferencia de energía de una partícula a un objetivo (en este caso el átomo) se puede calcular a partir de la cinemática de las colisiones. La masa del átomo puede determinarse midiendo la transferencia de energía debida a colisión o midiendo la energía dispersada por la partícula retrodispersada. El segundo concepto básico es que la probabilidad de colisión elástica entre las partículas y los átomos es altamente predecible, de manera que la sección eficaz de dispersión permite un análisis cuantitativo de la composición atómica. Por último, cuando una partícula atraviesa un material pierde energía como resultado de su colisión con los átomos $\mathrm{y}$, por lo tanto, las partículas que provienen de un espesor mayor tienen una energía menor que las partículas retrodispersadas de la superficie [53,54]. La combinación e interacción de estos tres conceptos permite al análisis RBS obtener 
información del espesor y de la composición atómica de películas delgadas y materiales estratificados.

Los componentes del equipo de RBS consisten en una fuente de iones de alta energía (generalmente son partículas alfa de 1-3 MeV) y un acelerador tándem capaz de acelerar los iones a la energía deseada. Luego de pasar a través de un tubo, el haz de iones entra en un imán analizador que selecciona la especie y energía de los iones dependiendo del experimento. Después de pasar el imán, el haz de iones es colimado y dirigido hacia el objetivo o muestra. Además de un acelerador tándem para producir el haz necesario para el análisis, también se requieren detectores y componentes electrónicos para el manejo de la señal. La figura 2.5 muestra un esquema del sistema de RBS [54].

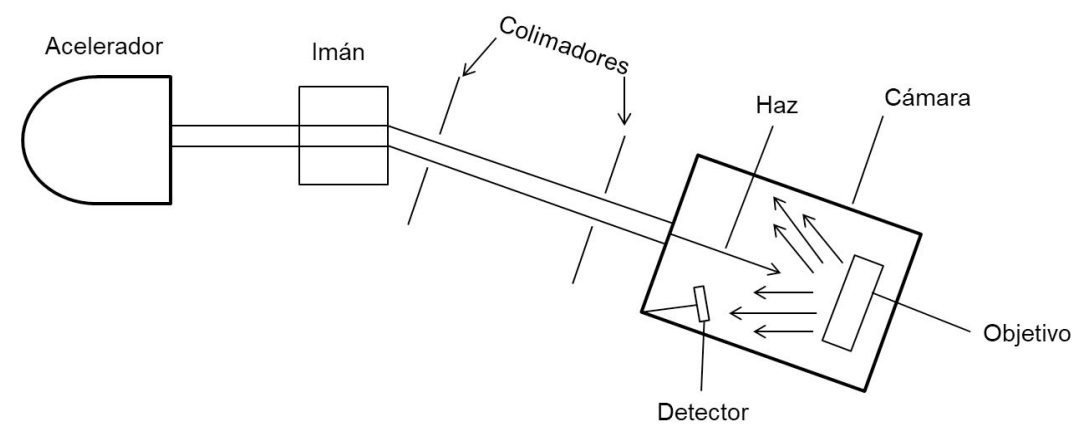

Figura 2.5: Esquema del sistema para análisis por RBS.

Los iones retrodispersados por los átomos de la muestra son detectados y analizados mediante un detector de estado sólido. Generalmente, se utiliza un detector de barrera de superficie de silicio de aproximadamente de $2 \mathrm{~cm}$ de diámetro para colectar las partículas retrodispersadas en un ángulo sólido pequeño a un ángulo de retrodispersión fijo. Este detector en combinación con un preamplificador y un amplificador lineal genera una señal de voltaje proporcional a la energía de la partícula que llega al detector. Un analizador multicanal digitaliza la señal del voltaje de entrada analógica y ordena todas las señales durante el experimento. Al finalizar 
la medición, el detector de barrera de superficie recibe aproximadamente $10^{6}$ partículas con diversas energías. Una medición suele tardar entre 10 y 30 minutos hasta una hora de análisis. El analizador multicanal proporciona el número de eventos de dispersión por unidad de intervalo de energía en función de la energía de las partículas retrodispersadas. A partir del espectro RBS se puede obtener información de la muestra analizando las energías de las partículas dispersadas [54].

\section{POLARIZACIÓN POTENCIODINÁMICA CÍCLICA}

La corrosión por picado es una forma de corrosión localizada que con frecuencia es una preocupación en aplicaciones que involucran la pasivación de metales y aleaciones en entornos agresivos. Es una forma muy dañina de corrosión que no se evalúa fácilmente por los métodos utilizados para la corrosión uniforme. Por lo tanto, se han diseñado ensayos especiales acelerados para evaluar la resistencia relativa a la corrosión localizada de aleaciones pasivas [56]. Existen varios métodos para evaluar la susceptibilidad de un material a la corrosión localizada, entre los cuales se encuentra el ensayo de polarización potenciodinámica cíclica [56]. La norma ASTM G61 presenta un método de ensayo estándar utilizando medidas de polarización potenciodinámica cíclica para determinar la susceptibilidad a la corrosión localizada de aleaciones a base de hierro, níquel o cobalto en entornos con cloruros. En este ensayo, una muestra se polariza usando un potenciostato y una celda convencional de tres electrodos (electrodo de trabajo, contraelectrodo y un electrodo de referencia (electrodo de calomel saturado)). Comenzando a un potencial de corrosión libre (o circuito abierto), se genera una curva de polarización barriendo el potencial a muy baja velocidad de la muestra de ensayo en la dirección anódica (el gráfico logarítmico de densidad de corriente vs. potencial se graba generalmente en forma automática). El barrido se invierte con algún criterio preestablecido (potencial o densidad de corriente). De la curva de polarización se obtiene el potencial de ruptura de la pasividad o potencial de picado, el potencial de repasivación 
(protección) y el comportamiento de histéresis (diferencia entre los barridos anódicos directo e inverso) y se utiliza para comparar la resistencia a la corrosión de los materiales de ensayo. Cabe señalar que el potencial de picado, el potencial de repasivación y el comportamiento de histéresis no son propiedades del material sino que son valores empíricos que están influenciados por la técnica experimental y el procedimiento. Sin embargo, son útiles para clasificar el desempeño de la aleación cuando nominalmente se sigue el mismo procedimiento de ensayo [56]. Por otro lado, una indicación de la susceptibilidad al inicio de la corrosión localizada en este método de ensayo está dada por el potencial al cual la corriente anódica aumenta rápidamente por arriba de la corriente pasiva y que corresponde al potencial de picado. Cuanto más noble sea este potencial, obtenido a una velocidad de barrido fija en este ensayo, menos susceptible es la aleación al inicio de la corrosión localizada. Por otra parte es mayor la susceptibilidad a esta forma de corrosión cuanto más apartados resulten entre sí, el potencial de picado y el de repasivación, o lo que es lo mismo el área bajo el ciclo de histéresis.

\section{MICRODUREZA}

El término dureza, tal como es utilizado en la industria, puede definirse como la capacidad de un material para resistir una indentación o deformación permanente cuando está en contacto con un indentador bajo carga. Generalmente, un ensayo de dureza consiste en presionar un indentador de geometría y propiedades mecánicas conocidas sobre el material de ensayo. La dureza del material se cuantifica utilizando una variedad de escalas que indican directa o indirectamente la deformación de la superficie de ensayo. Dado que el indentador se presiona en el material durante el ensayo, la dureza también se ve como la capacidad de un material para resistir cargas de compresión. El indentador puede ser esférico (ensayo de Brinell), piramidal (ensayos de Vickers y Knoop) o cónico (ensayo de Rockwell). En el caso de los ensayos de Brinell, Vickers y Knoop, el valor de dureza es la carga soportada por 
unidad de área de la indentación, expresada en kilogramos por milímetro cuadrado $\left(\mathrm{kgf} / \mathrm{mm}^{2}\right)$. Por otro lado, en el ensayo de Rockwell, se determina la profundidad de indentación a una carga determinada y se convierte en un número de dureza (sin unidades de medida), que está inversamente relacionado con la profundidad. El ensayo de dureza es, quizás, el método más simple y menos costoso de caracterizar mecánicamente un material, ya que no requiere de una elaborada preparación de muestras, implica equipos de ensayos de bajo costo y es relativamente rápido. Las investigaciones teóricas y empíricas han dado lugar a relaciones cuantitativas bastante exactas entre la dureza y otras propiedades mecánicas de materiales tales como la resistencia a la tracción, el límite elástico, el coeficiente de endurecimiento por deformación y la resistencia a la fatiga y fluencia. Estas relaciones ayudan a medir estas propiedades con una precisión suficiente para el control de calidad durante las etapas intermedia y final de la fabricación de piezas y componentes [57]. Los ensayos de dureza pueden clasificarse en función de la magnitud de la carga aplicada como macrodureza, microdureza y nanodureza. En el caso del ensayo de microdureza, un indentador de diamante de geometría específica se imprime en la superficie de la muestra usando una fuerza aplicada (comúnmente llamada carga) de 1 a 1000 gf. El número de dureza se basa en las mediciones realizadas de la indentación formada en la superficie de la muestra de ensayo. En el caso del ensayo de microdureza Vickers, la fuerza (que debe conocerse con precisión) se aplica suavemente, sin impacto y se mantiene en contacto durante 10 a 15 segundos. Luego de retirar la fuerza, se miden ambas diagonales y se utiliza el promedio para calcular el HV según:

$$
H V=\frac{2000 P \operatorname{sen}\left(\frac{\alpha}{2}\right)}{D^{2}}=\frac{1854,4 P}{D^{2}}
$$

Donde $D$ es la diagonal media en $\mu \mathrm{m}$, P es la carga aplicada en gf y $\alpha$ es el ángulo de la cara $\left(136^{\circ}\right.$, ver figura 2.6$)$. La mayoría de los modernos equipos de microdureza 
tienen la capacidad de cálculo incorporada y muestran el valor de dureza junto con las diagonales medidas. Un libro de tablas de $\mathrm{HV}$ en función de $D$ y $\mathrm{P}$ también acompaña a la mayoría de los equipos y la norma ASTM E 384 incluye tales tablas [57]. En la figura 2.6 se puede observar un esquema del indentador de microdureza Vickers y la indentación que produce en la superficie del material.

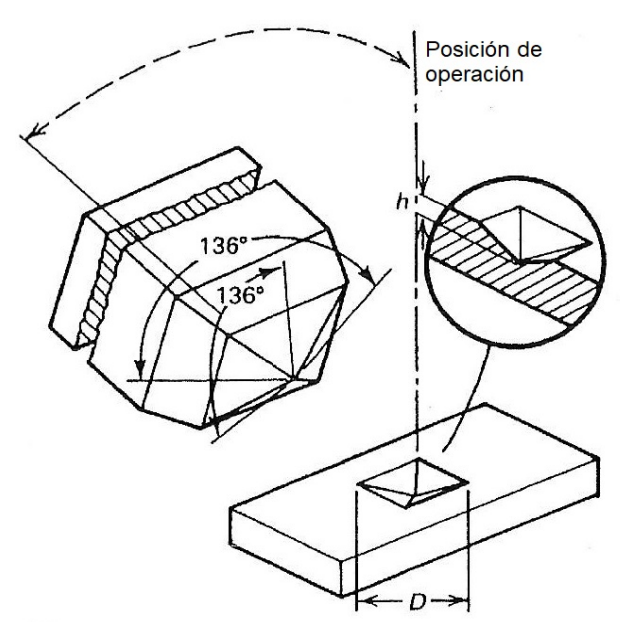

Figura 2.6: Esquema del indentador piramidal de diamante utilizado en el ensayo de microdureza Vickers y un ejemplo de la indentación que produce [57].

\section{ADHESIÓN}

La adhesión tiene un importante significado en la evaluación de películas y recubrimientos y puede ser evaluada de varias maneras dependiendo de la configuración de la muestra y de los requisitos de la aplicación. Por esta razón existen muchos métodos para medir la adhesión de películas y recubrimiento al material del sustrato. Uno de los ensayos utilizados en biomateriales para el análisis de la adhesión de películas y recubrimientos es el ensayo de indentación Rockwell C según la norma VDI 3198 [58-61].

El ensayo de indentación Rockwell C determinada por la norma VDI 3198, es un ensayo de calidad destructivo para evaluar en forma cualitativa compuestos recubiertos. Un indentador de diamante cónico penetra en la superficie del recubrimiento de un material induciendo así deformación plástica masiva al sustrato 
y fractura del recubrimiento. Como en todos los ensayos de dureza, el espesor total de la muestra debe ser al menos 10 veces mayor que la profundidad de la indentación. El tipo y el volumen de la zona de falla del recubrimiento muestran, en primer lugar, la adhesión de la película o recubrimiento y, en segundo lugar, su fragilidad. La muestra puede ser evaluada adecuadamente mediante microscopía óptica pero la evaluación es más efectiva al utilizar microscopía electrónica de barrido. La geometría de contacto, en combinación con la intensa transferencia de carga, induce tensiones de corte en la interfaz. La norma VDI 3198 define la calidad de adhesión en una escala que va desde HF1 a HF6 (figura 2.7). Los recubrimientos bien adherentes logran soportar estas tensiones de corte y previenen la delaminación extendida circunferencialmente a la indentación. La figura 2.7 (HF1-HF4) ilustra las formas de las indentaciones que garantizan fuertes enlaces interfaciales entre el recubrimiento y el sustrato. Por otra parte, la delaminación prolongada en la proximidad de la indentación indica una pobre adhesión interfacial (HF5-HF6). Por otro lado, las grietas radiales y la pobre delaminación indican un recubrimiento fuertemente adherido pero también frágil [58]. Es necesario destacar que, a diferencia de otros ensayos de adhesión, este método puede aplicarse fácilmente utilizando equipos muy accesibles, lo que permite ahorrar costo y tiempo de ensayo. 
HF 1

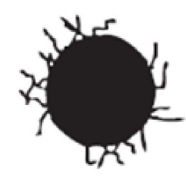

HF 3

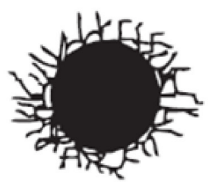

HF 5

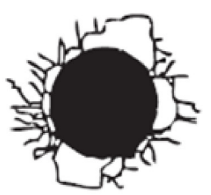

HF 2

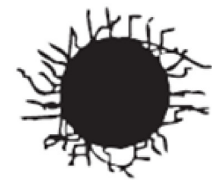

HF 4

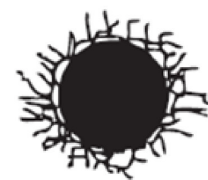

HF 6

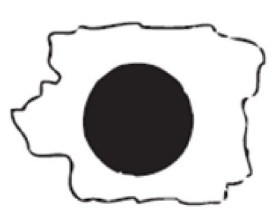

敢 Fisuras

$\checkmark$ Delaminación

Figura 2.7: Clasificación de la calidad de adhesión según la norma VDI 3198 [59]. 


\title{
CAPÍTULO 3
}

\section{ESTIMACIÓN DE INCERTEZAS DE MEDICIONES TOPOGRÁFICAS POR MICROSCOPÍA ELECTRÓNICA DE BARRIDO 3D SOBRE LA CORROSIÓN SUPERFICIAL DE ACEROS}

\begin{abstract}
La corrosión por picado es uno de los mecanismos de daño más graves y peligrosos en diversos componentes de acero para muy diversas aplicaciones estructurales, como ser en tubos de calderas de aceros al carbono y aleados para plantas de energía (vitales para la mayoría de las industrias), y en aceros inoxidables para implantes ortopédicos (cuya demanda mundial se incrementa continuamente debido al aumento de la expectativa de vida y la alta tasa de accidentes de tránsito). Por ello, son cada vez más necesarios métodos fiables para caracterizar este tipo de daño cuando se trata de evaluar el avance del mismo y establecer los mejores procedimientos para la inspección de los componentes con el fin de determinar la vida útil y la mitigación de fallas. En el presente capítulo, se presenta un estudio sobre las incertezas de mediciones topográficas en pits de corrosión a partir de imágenes de microscopía electrónica de barrido 3D, obtenidas a bajas magnificaciones (donde los errores son mayores) y diferentes ángulos de inclinación mediante un software previamente desarrollado. Adicionalmente, se realizaron mediciones de profundidades de pits en superficies de implantes ortopédicos de acero inoxidable, sometidas a dos tratamientos de superficie diferentes. Además, las diferentes distribuciones de profundidad obtenidas fueron contrastadas con mediciones electroquímicas.
\end{abstract}

\subsection{Introducción}

Como se mencionó en el capítulo 2, el microscopio electrónico de barrido (SEM) es ampliamente utilizado para la caracterización de materiales debido a su gran versatilidad, gran profundidad de campo y alta resolución lateral, que permite obtener imágenes de "apariencia" tridimensional. No obstante, los cambios en los niveles de gris en las imágenes de SEM están relacionados con cambios en la pendiente y no con cambios en la altura. Además, el brillo de la imagen también puede verse afectado por un aumento de la emisión de los bordes y puntas, efectos de contaminación superficial como la oxidación local, variaciones locales de la composición, posición del detector, propiedades eléctricas y magnéticas, entre otras. Por lo tanto, los parámetros para caracterizar una superficie, utilizando una única 
imagen de SEM, se encuentran más relacionados con la textura de la imagen que con la rugosidad de la superficie. Sin embargo, en muchos casos estos parámetros pueden ser utilizados para "cuantificar" diferencias superficiales de muestras sometidas a diferentes procesos.

En las aplicaciones actuales, se requiere la posición exacta de los objetos estudiados en el espacio o información topográfica del espécimen; por lo tanto, son necesarias las coordenadas en las tres dimensiones.

Los métodos de reconstrucción de topografía de superficies en 3D, necesarios para obtener parámetros de rugosidad, se pueden dividir en dos categorías principales:

1) Estereoscopía, en la que se utiliza un par estéreo de imágenes de SEM. El par estéreo se puede obtener desviando el haz de electrones, pero generalmente se implementa inclinando el portamuestras de donde se obtienen dos imágenes con diferentes ángulos de inclinación [62-76]. En este caso, es posible la observación de imágenes en 3D y la medición de datos de altura en 3D. En particular, superponiendo las imágenes de pares estéreo, por ejemplo, una de ellas en rojo y la otra en azul o cian, es posible construir una imagen anaglifa (en inglés, anaglyph) que es una imagen que produce un efecto de profundidad cuando son utilizados lentes de colores rojo-azul o rojo-cian. En diferentes áreas científicas, las imágenes anaglifas fueron utilizadas usualmente como una técnica de investigación complementaria, que permitió un estudio más completo sobre la morfología de las muestras analizadas mediante SEM [77]. La limitación principal que posee el método estereoscópico es que no puede aplicarse a superficies muy lisas ya que carecen de detalles distinguibles.

En las últimas dos décadas, este método ha sido ampliamente utilizado por la disponibilidad de procesadores informáticos más rápidos, que ha permitido el desarrollo de paquetes de software comerciales como el $\mathrm{MeX}^{\mathrm{TM}}$, Scandium Solution Height o 3D_TOPx y de software libre como el EZEImage (utilizado en la presente tesis) [68]. 
2) El método shape from shading, que en primer lugar fue utilizado para obtener una imagen de alturas de superficie a partir de una única imagen bidimensional de un objeto iluminado con luz [78] y luego, implementado para imágenes de SEM, en diferentes versiones en las cuales se incluían uno o varios detectores [79-86].

La principal desventaja del método shape from shading (basada en el modelo de Lambert para las distribuciones angulares de electrones secundarios y retrodispersados), es que la distribución angular se aparta de la ley de Lambert en los casos reales, donde las muestras tienen diferentes orientaciones locales respecto al haz de electrones incidente $y$, en muchos casos, se requieren varios detectores para obtener imágenes desde diferentes orientaciones.

En este capítulo, a partir de la utilización del primer método de reconstrucción de topografía de superficies en 3D presentado, se realizó un estudio sobre las incertezas en la topografía de pits de corrosión en muestras metálicas, mediante el programa EZEImage y un microscopio SEM 505 de Philips. Se utilizaron muestras de acero al carbono de un tubo de caldera de un generador termoeléctrico de potencia para hallar dichas incertezas bajo diferentes condiciones experimentales. Son cada vez más necesarios métodos fiables para caracterizar los pits de corrosión en cualquier tipo de muestras corroídas [87-89], y particularmente, en muestras de acero inoxidable para implantes ortopédicos, ya que este mecanismo de daño es muy común y peligroso en estos dispositivos médicos [90-92]. Por lo tanto, se analizaron las distribuciones de profundidad de pits de corrosión en muestras bajo diferentes tratamientos de superficie para ser utilizadas como implantes. Por último, los resultados obtenidos fueron contrastados con ensayos electroquímicos.

\subsection{Materiales y métodos}

\subsubsection{Instrumental}

Se utilizó un microscopio electrónico de barrido Philips SEM 505, equipado con una interfaz de barrido digital ADA II y el software de análisis de imágenes 
Scandium SIS del Laboratorio de Microscopía del "Centro de Investigación y Desarrollo en Ciencias Aplicadas. Jorge J. Ronco" (CINDECA).

En dicho microscopio la posición del eje de inclinación no es normal al eje óptico y en la calibración se obtuvo una rotación de $12^{\circ}$ en sentido horario. El software EZEImage [68] se utilizó para obtener mapas densos de altura. En este software, el eje de inclinación de las imágenes debe estar en la misma dirección que el eje óptico (eje y), por lo tanto, las imágenes fueron giradas $102^{\circ}$ en sentido contrario a las agujas del reloj.

\subsubsection{Software}

Cuando se obtienen dos imágenes con diferentes ángulos de inclinación, como en el par estéreo, las características superficiales de diferentes alturas difieren en su desplazamiento lateral (paralaje o disparidad) y se pueden calcular las alturas relativas (coordenada z) para cada píxel de la imagen utilizando el correspondiente valor de disparidad.

Ponz y otros [68] desarrollaron el programa EZEImage para obtener mapas de altura a partir de pares estéreos de imágenes de SEM. En este software, se implementó el método de Sun [93] para encontrar el mapa denso de disparidades, que utiliza la correlación cruzada rápida y dos etapas de programación dinámica. Dicho software funciona en imágenes estéreo epipolares rectificadas de modo que los puntos coincidentes se encuentran en las mismas líneas de barrido de las imágenes del par estéreo. Esto significa que el eje de inclinación de la imagen debe ser el eje y y el centro de la imagen debe ser el punto eucéntrico que es el punto donde el eje de inclinación y el eje óptico se intersectan y, además, se toma como punto de referencia (valor de la disparidad igual a cero). Considerar el eucéntrico como centro de la imagen tiene la ventaja de que, para todos los puntos en cada línea perpendicular al eje de inclinación (epipolar) en la imagen izquierda, la paralaje sucede solamente en la misma línea en la imagen derecha. 
La ecuación para encontrar los valores de altura $z(i, j)$ correspondientes a cada píxel $(i, j)$, medidas con respecto a un plano que contiene el eje de inclinación y forma un ángulo de (90- $\left.\phi_{1}\right)$ con respecto al eje óptico es la siguiente [68]:

$Z(i, j)=\frac{\left(x_{1} / M\right)\left(\left(x_{i}-\Delta x\right) \operatorname{sen} \varphi_{2} / W M+\cos \varphi_{2}\right)-\left(\left(x_{1}-\Delta x\right) / M\right)\left(x_{1} \operatorname{sen} \varphi_{1} / W M+\cos \varphi_{1}\right)}{\left(1+x_{1}\left(x_{1}-\Delta x\right) /(W M)^{2}\right) \operatorname{sen}\left(\varphi_{2}-\varphi_{1}\right)+\Delta x \cos \left(\varphi_{2}-\varphi_{1}\right) / W M}$

Donde $W$ y $M$ son la distancia de trabajo y la magnificación, respectivamente, y son iguales para ambas imágenes durante la inclinación en el eucéntrico, $\phi_{1}$ y $\phi_{2}$ son los ángulos de inclinación correspondientes a las imágenes izquierda y derecha, respectivamente, $x_{1}$ es la posición del pixel $(i, j)$ cuyo valor de altura se debe conocer en la imagen izquierda, $\Delta x$ es la disparidad y $x_{1}-\Delta x$ es la posición del píxel del mismo punto en la imagen derecha (medida en el epipolar y tomando el centro de la imagen como origen de coordenadas). Los parámetros $x_{1}$ y $\Delta x$ son medidos en las mismas unidades que $W$. La expresión $z(i, j)$ en el trabajo de Ponz y otros [68] es incorrecta porque el denominador no debe estar elevado al cuadrado.

La ecuación (3.1) es la ecuación general de Lane [62,63] adaptada para pares estéreo inclinados eucéntricamente. Cuando la muestra es inclinada $\pm \Delta \phi$ alrededor de un eje normal al haz, puede escribirse de la siguiente manera:

$z(i, j)=\frac{2\left(x_{1} / M\right)\left(x_{1}-\Delta x\right) \operatorname{sen} \Delta \varphi / W M+\Delta x \cos \Delta \varphi / M}{\left(1+\left(x_{1} / M\right)\left(x_{1}-\Delta x\right) / W M^{2}\right) \operatorname{sen} 2 \Delta \varphi+\Delta x \cos 2 \Delta \varphi / W M}$

En la figura 3.1 se puede observar un diagrama geométrico con la indicación de las variables involucradas en la ecuación (3.2). 

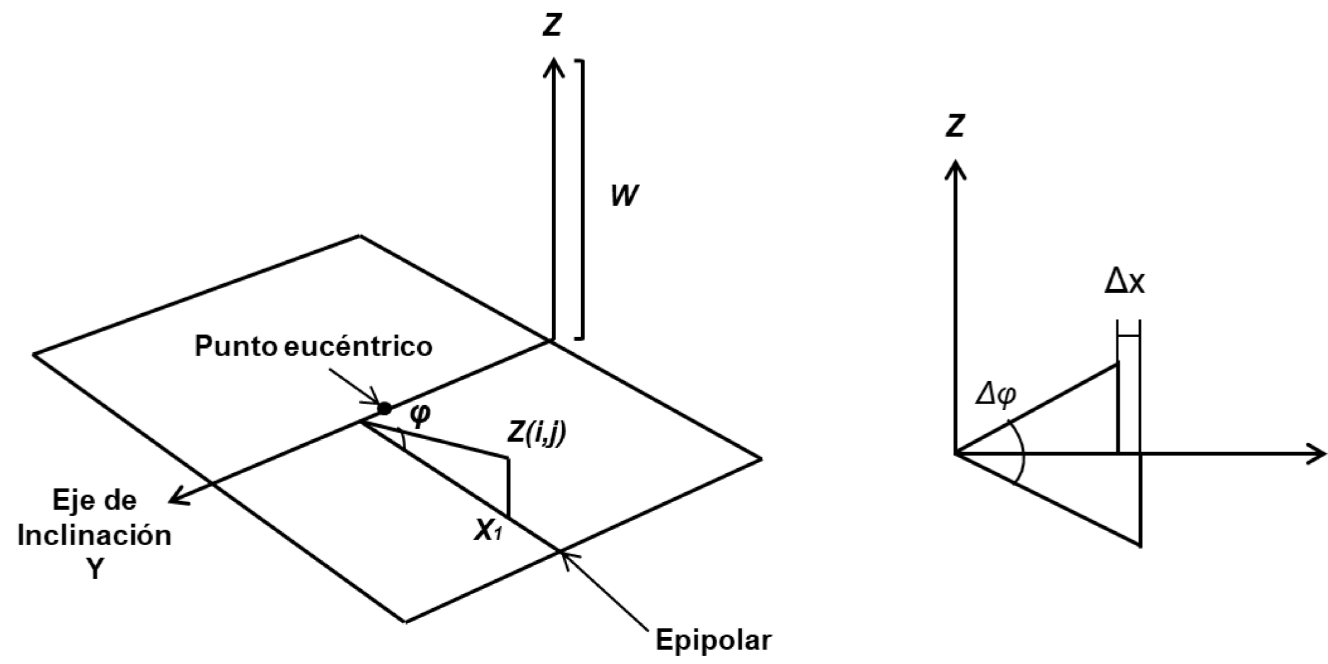

Figura 3.1: Diagrama geométrico de la ecuación (3.2), con la indicación de las variables involucradas.

Además de las variables independientes $W, \Delta \phi, x_{1}$ y $\Delta x$, hay un número de variables adicionales que influyen en la calidad de la reconstrucción, tales como: la robustez del algoritmo del software, nitidez de las imágenes del par estéreo, entre otras [70,94]. Bariani y otros [94] presentaron un modelo teórico del cálculo de la incerteza en la elevación vertical de un solo punto, que depende principalmente de la exactitud del ángulo de inclinación y la calibración de la magnificación. Los autores encontraron que las desviaciones experimentales de los valores de altura nominal confirmaron la tendencia predicha por su modelo, donde se utilizó la siguiente expresión para la varianza de la medida de elevación vertical:

$u_{z}^{2}=\left(\frac{\partial z}{\partial \Delta x}\right)^{2} u^{2}(\Delta x)+\left(\frac{\partial z}{\partial \Delta \varphi}\right)^{2} u^{2}(\Delta \varphi)$

Donde $u^{2}(\Delta \phi)$ es la incerteza del ángulo de inclinación y la expresión de la varianza en la paralaje, $u^{2}(\Delta x)$, está dada por:

$u^{2}(\Delta x)=\frac{s^{4}}{12}+\Delta x^{2} \frac{u^{2}(s)}{s^{2}}+\Delta x \frac{s^{2}}{\sqrt{3}} \frac{u(s)}{s}$ 
Donde $s$ es el tamaño del píxel en micrones y $u(s)$ es su incerteza. Bariani y otros [94] calibraron el ángulo de inclinación en su microscopio por medio de un sistema de interferometría láser y obtuvieron 10 segundos de arco como error residual del ángulo de inclinación en las medidas de sus muestras. Ellos efectuaron la calibración del ángulo de inclinación abriendo la puerta de la cámara del microscopio, colocando la fuente láser justo afuera de la misma y el reflector angular cerca del portamuestras. Las mediciones las llevaron a cabo a diferentes ángulos de inclinación. Por otro lado, calibraron la magnificación y encontraron en el tamaño de píxel un error relativo de $1,9 \%$ y $0,81 \%$ en los casos de magnificaciones de 100X y 400X, respectivamente. En este caso, la calibración del tamaño del píxel la efectuaron con una regla unidimensional calibrada de $50 \mu \mathrm{m}$ de paso a magnificaciones menores a $1000 \mathrm{X}$ y para magnificaciones mayores a 1000X utilizaron un patrón de calibración 2D utilizado en las microscopías de barrido por sondas con una dimensión de celda de 2,12 $\mu \mathrm{m}$. Para magnificaciones de 100X y 200X obtienen como resultado $u(s) / s \approx 0,02$ y para la magnificación de $400 \mathrm{X}, u(s) / s \approx 0,01$.

Marinello y otros [70] buscaron los factores críticos en el método estereoscópico utilizando un cristal de galena y un software comercial. Dichos autores encontraron que es posible obtener desviaciones en los valores de altura de referencia (con un paso del cristal de 22,95 $\mu \mathrm{m}$ ) dentro del $5 \%$ de la altura total del paso, en condiciones ideales, es decir, tamaño de píxel y portamuestras calibrados, magnificaciones en un intervalo de 1000X-3000X y sin desviaciones de la condición de eucéntrico, mientras que un error del $30 \%$ podría esperarse fuera de estas condiciones óptimas.

Ponz y otros [68] especificaron que debido al hecho de que la disparidad es un número entero en una imagen digital, la resolución del orden del subpíxel alcanzada por el programa EZEImage (que permite aumentar la precisión en la diferencia de valores de altura, alcanzando un valor igual o menor que la resolución lateral dependiendo del ángulo $\Delta \phi)$, sólo es válida en el eje epipolar y en las "mesetas" con valores de disparidad cuasi constantes. Por lo tanto, y teniendo en cuenta que en dicho software no fue implementado un método de suavizado sobre los valores de 
disparidad entre dos mesetas, el error máximo estimado de la disparidad $\Delta x$ será 1 píxel en micrones, es decir, $u_{\max }(\Delta x)=122 / M[\mu \mathrm{m}]$ para el microscopio utilizado en este capítulo.

\subsubsection{Métodos}

\subsubsection{Rectificación de las imágenes}

Una condición importante a tener en cuenta en la adquisición de los pares estéreo es mantener el punto eucéntrico en el centro de la imagen cuando se utiliza el software EZEImage. Por lo tanto, algunas imágenes que no satisfacían esta condición fueron rectificadas, para que la posición de la textura correspondiente al centro de la imagen izquierda fuera la misma que la del centro de la imagen derecha. Finalmente, se obtuvieron áreas centradas de 600x700 píxeles de los dos pares de imágenes y se utilizaron en el cálculo de valores de altura.

\subsubsection{Análisis numérico de las incertezas para diferentes magnificaciones}

Para efectuar la calibración del ángulo de inclinación se implementó un método simple para estimar una cota máxima de $u(\Delta \phi)$ que no requiere del uso de un interferómetro láser, como en el caso del procedimiento de la calibración de Bariani y otros [94]. Esto se llevó a cabo mediante el estudio de la variación del ángulo $\alpha$ entre la normal al plano medio de cuadrados mínimos (que mejor ajusta a todos los valores de altura de la superficie) y la normal al plano $x y$. Este valor del ángulo se obtuvo del archivo de texto "height" generado por el programa EZEImage. Para analizar dicha variación angular, se obtuvieron quince pares estéreos de imágenes de SEM a distintos ángulos de inclinación, verificando en todos los casos la posición eucéntrica, es decir, que el detalle en el centro de las imágenes de los dos pares fuera la misma. La variación del ángulo puede ser debido tanto a una variación de la inclinación del portamuestras como a la variación del subpíxel de la posición eucéntrica. En este estudio, asociamos el cambio del ángulo sólo a la variación de la inclinación del 
portamuestras. Esta aproximación produciría un valor máximo del error de inclinación $u(\Delta \phi)$ que, obviamente, fue mayor que el obtenido por Bariani y otros [94], que fue de 10 segundos de arco. Además, como se mencionó anteriormente, en este trabajo se consideró un error máximo de $u(\Delta x)= \pm 1$ píxel $[\mu \mathrm{m}]$ debido al hecho de que la disparidad es un número entero en una imagen digital.

De esta manera, las incertezas relativas $u z / z$ con estos posibles errores máximos de $\Delta \phi$ y $s$ se calcularon utilizando las ecuaciones (3.3) y (3.4), con $\Delta \phi= \pm 8^{\circ}$ alrededor de un eje normal al haz y distancia de trabajo de $W=44 \mathrm{~mm}$. Por otra parte, las incertezas relativas $u z / z$ se calcularon con $\Delta \phi= \pm 8^{\circ}$ y $W=44 m m$ en las condiciones estudiadas por Bariani y otros [94], es decir, $u(s) / s \approx 0,02$ para magnificaciones de 100X y 200X; y $u(s) / s \approx 0,01$ para la magnificación de $400 \mathrm{X}$ y $u(\Delta \phi)=10$ segundos de arco para las tres magnificaciones. Los resultados se muestran en la sección 3.3.1.

\subsubsection{Muestras}

\subsubsection{Muestras metálicas para el estudio de las incertezas de valores de altura}

Tres muestras de $400 \mathrm{~mm}^{2}$ de área, denominadas en adelante muestras I, II y III, se obtuvieron a partir de una pieza extraída de un tubo de caldera corroída de un generador termoeléctrico de potencia. Se utilizó una solución de ácido clorhídrico a $30^{\circ} \mathrm{C}$ como único tratamiento de limpieza superficial para remover las capas de óxido en su superficie interna.

Un análisis preliminar de la muestra I reveló varios pits de corrosión en su superficie y, particularmente, uno de ellos en el borde de la muestra. Se obtuvo un par estéreo en la región del borde (ver figura 3.4a en la sección 3.3.2.1) para poder comparar las profundidades de los pits en diferentes lugares obtenidos a partir de valores 3D proporcionados por el programa EZEImage, con los mismos valores medidos directamente en la sección transversal (figura 3.4b en la sección 3.3.2.1) utilizando el software del microscopio. 
Teniendo en cuenta que el método implementado en el software EZEImage para encontrar puntos coincidentes (en inglés, matching point), requiere una región local relativamente suave del mapa de disparidades [68], los píxeles de los bordes no tendrán valores de altura válidos. Debido a este hecho, en una primera etapa se obtuvo un par estéreo y en una segunda etapa se eliminaron 10 micrones de la superficie de la sección transversal con papel de lija de SiC \#1000 (esta magnitud se estimó mediante imágenes de SEM antes y después de la eliminación del material). Posteriormente, se volvió a colocar la muestra en el SEM con la superficie perpendicular al eje óptico, con el fin de obtener valores de altura para diferentes coordenadas $(\mathrm{x}, \mathrm{y})$ del pit. Por lo tanto, con las imágenes estéreo obtenidas previamente, los valores de altura estéreo correspondientes a cualquier punto del pit de la muestra (representado por el píxel de la imagen) podrán compararse con los valores correspondientes medidos en la sección transversal de la muestra pulida.

Para buscar posibles variaciones en los valores de altura cuando se utilizan mayores magnificaciones, se obtuvieron pares estéreo con $\Delta \phi= \pm 8^{\underline{o}}$, de un mismo pit con magnificaciones de 100X y 400X de la muestra II.

Finalmente, con el fin de estudiar la certeza de los valores de altura en cualquier inclinación de la muestra, se obtuvieron pares estéreo en diferentes condiciones de ángulo de inclinación en la muestra III.

\subsubsection{Estudio de muestras de biomateriales metálicas}

Se utilizaron muestras con un área de $100 \mathrm{~mm}^{2}$ y $3 \mathrm{~mm}$ de espesor de una placa de acero inoxidable 316LVM (Low Vacuum Melting) (ASTM F138 y F139/ISO 5832-1). Estos aceros inoxidables fueron elegidos porque tienen una extensa aplicación como biomateriales, particularmente como implantes ortopédicos, ya que combinan una buena biofuncionalidad con biocompatibilidad aceptable a bajo costo. Seis de estas muestras (muestras IV a IX) se sometieron a procesos de blastinizado (vulgarmente 
denominado granallado) y pasivado químico en diferentes condiciones de tratamiento y posteriormente fueron expuestos bajo un mismo proceso de corrosión.

\subsubsection{Tratamientos de superficie y ensayos electroquímicos}

El proceso de blastinizado se llevó a cabo a una presión de $3 \mathrm{~kg} / \mathrm{cm}^{2}$ con partículas de silicato de aluminio de tamaños comprendidos entre 10-150 $\mu \mathrm{m}$ para las muestras IV a VI y a una presión de $5 \mathrm{~kg} / \mathrm{cm}^{2}$ con partículas de sílice de tamaño promedio de $100 \mu \mathrm{m}$ en el caso de las muestras VII a IX.

En primer lugar, las muestras se sumergieron en acetona durante 30 minutos, se lavaron con agua y se secaron en una estufa. Posteriormente en una segunda etapa, se limpiaron por ultrasonido durante 20 minutos en acetona y luego durante 10 minutos en alcohol etílico al 96\% v/v. Finalmente, las muestras se lavaron con alcohol al $96 \% \mathrm{v} / \mathrm{v}$ y se secaron.

Posteriormente, los tratamientos de pasivado químico se llevaron a cabo a temperatura ambiente en soluciones de ácido nítrico al 40\% v/v durante 30 minutos para las muestras IV a VI y ácido nítrico al $20 \% \mathrm{v} / \mathrm{v}$ durante $1 \mathrm{~h}$ para las muestras VII a IX.

Finalmente, con el fin de estudiar la profundidad de los pits de corrosión formados en las muestras IV a IX, se efectuaron ensayos electroquímicos en una celda convencional de tres electrodos en una solución Ringer $(8,6 \mathrm{~g} / \mathrm{L}$ de NaCl, 0,3 g/L de $\mathrm{KCl}, 0,33 \mathrm{~g} / \mathrm{L}$ de $\mathrm{CaCl}_{2}$ ) con nitrógeno purificado durante $1 \mathrm{~h}$ a $37^{\circ} \mathrm{C}$. Se utilizó un alambre de platino como contraelectrodo y un electrodo de calomel saturado (SCE) como electrodo de referencia. Se registraron curvas de polarización potenciodinámica cíclica a $50 \mathrm{~V} / \mathrm{h}(13,8 \mathrm{mV} / \mathrm{s})$ de $-1,2 \mathrm{~V}$ hasta 1,2 V.

\subsubsection{Obtención y procesamiento de la imagen SEM}

Se obtuvieron pares estéreo de diferentes regiones en ambos conjuntos de muestras (IV-VI y VII-IX). Los pares estéreo para las muestras IV a VI se obtuvieron 
con un ángulo de inclinación de $\Delta \phi= \pm 5^{\circ}$ alrededor de un eje normal al haz y con una magnificación de $M=100 X$ mientras que los correspondientes a las muestras VII a IX se obtuvieron a $\Delta \phi= \pm 8^{\underline{o}}$ y $M=200 X$. Aunque se recomienda utilizar los mayores ángulos de inclinación y magnificaciones posibles para minimizar los errores, los valores menores permiten estudiar un mayor número de pits en un solo par de imágenes de SEM. Se obtuvo un par estéreo adicional con dos de los pits de la muestra IX a $\Delta \phi= \pm 5^{\underline{o}}$ y $M=100 X$ para comparar las profundidades de los pits para las dos condiciones superficiales utilizadas.

\subsection{Resultados y discusión}

\subsubsection{Análisis preliminar de la incerteza a diferentes magnificaciones}

El error de inclinación obtenido, como se mencionó en la sección 3.2.3.2, proporcionó un valor de $u(\Delta \phi)= \pm 97$ arcosegundos, que se utilizó para obtener los valores de las incertezas relativas $u z / z$ que se considerarán máximas mostradas en la figura 3.2a para magnificaciones de 100X, 200X y 400X y $\Delta \phi= \pm 8^{\circ}$. En la figura 3.2b se pueden observar los resultados obtenidos utilizando las condiciones estudiadas por Bariani y otros [94], que serán considerados como incertezas relativas mínimas.
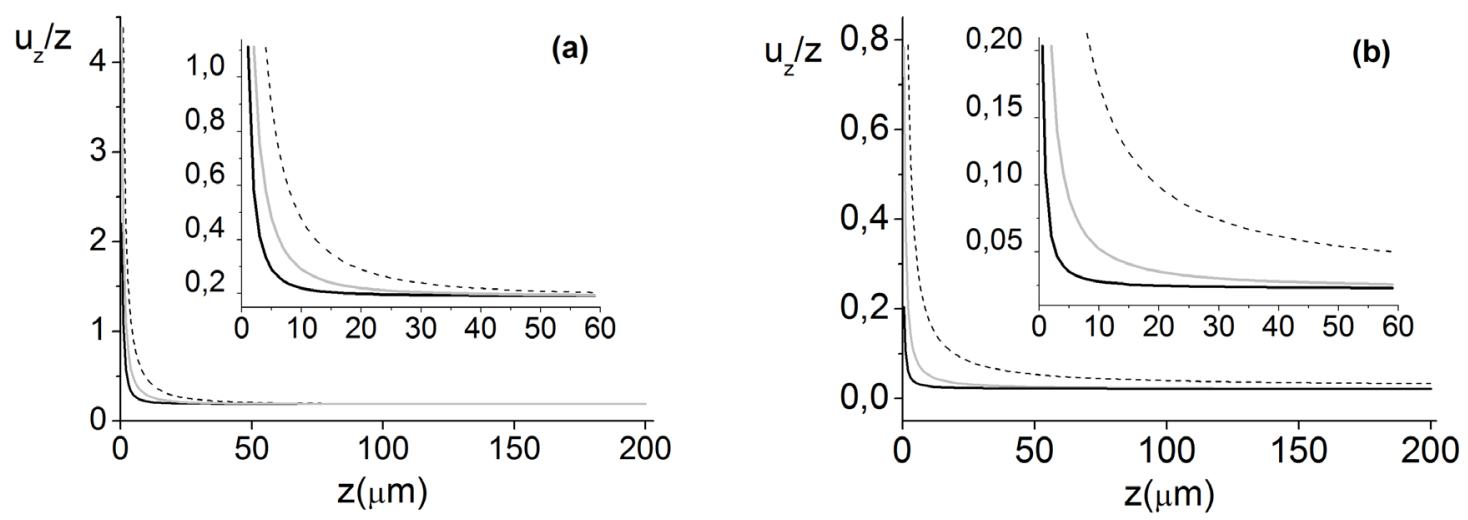

Figura 3.2: Incertezas relativas para $\Delta \phi= \pm 8^{\circ}$ y $W=44 \mathrm{~mm}$. Línea punteada: 100X, línea gris: 200X y línea negra sólida: 400X. En las figuras insertadas, se muestra el detalle de las curvas para valores de $z$ bajos; (a) Máximas $(u(\Delta x)= \pm 1$ píxel $[\mu \mathrm{m}]$ y $u(\Delta \phi)= \pm 97$ arcosegundos); (b) Mínimas $(u(s) / s=0,02$ para magnificaciones de 100X y 200X, $u(s) / s=0,01$ en el caso de $400 \mathrm{X}$ y $u(\Delta \phi)=10$ segundos de arco). 
En la figura 3.3, se muestran cálculos similares para $\Delta \phi= \pm 5^{\circ}$ y magnificación de 100X.
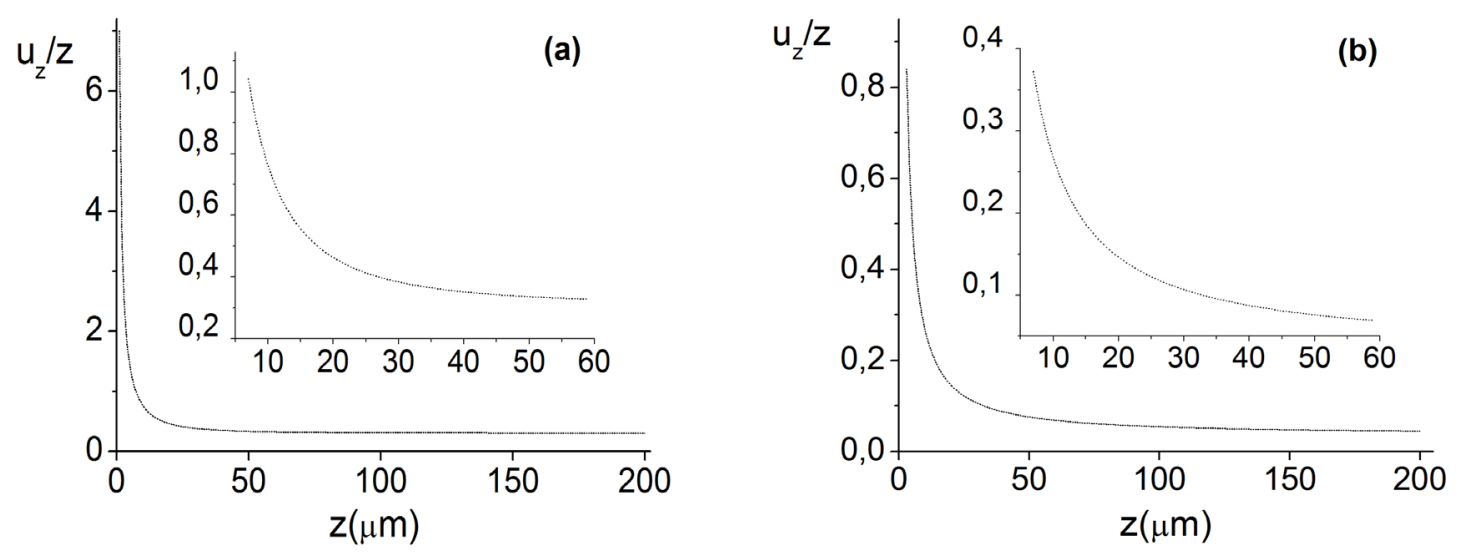

Figura 3.3: Incertezas relativas para $\Delta \phi= \pm 5^{\circ}, W=44 \mathrm{~mm}$ y magnificación de 100X. (a) Máximas $(u(\Delta x)= \pm 1$ píxel $[\mu \mathrm{m}]$ y $u(\Delta \phi)= \pm 97$ arcosegundos); (b) Mínimas $(u(s) / s=0,02$ y $u(\Delta \phi)=10$ segundos de arco). Las figuras insertadas muestran vistas ampliadas de las incertezas relativas para valores de $z$ bajos.

Como se desarrolló en la sección 3.2.3.2 y se observa en la figura 3.2b, las incertezas relativas rondan el $8 \%$ para valores de altura de $30 \mu \mathrm{m}$ y el $5 \%$ a partir de $60 \mu \mathrm{m}$ considerando un ángulo de inclinación $\Delta \phi= \pm 8^{\underline{o}}$, una magnificación de $M=100 \mathrm{X}$ y teniendo en cuenta condiciones mínimas en los $\Delta \phi$ y en los errores de tamaño de píxeles. En el caso de magnificaciones de 200X y 400X, se obtuvieron valores de $u z / z$ inferiores al 5\% a partir de valores de altura de $10 \mu \mathrm{m}$ y $3 \mu \mathrm{m}$, respectivamente. Por otro lado, en las condiciones de $\Delta \phi$ y $\Delta s$ máximas, las incertezas relativas para valores de altura cercanos a $30 \mu \mathrm{m}$ aumentaron al 24\%, 21\% y 20\% a magnificaciones de 100X, 200X y 400X, respectivamente.

En el caso de $\Delta \phi= \pm 5^{\circ}$ y $M=100 X$, se obtuvieron valores de $u z / z$ inferiores al $10 \%$ a partir de valores de altura de $30 \mu \mathrm{m}$ en condiciones ideales, mientras que para valores $z$ cercanos a $30 \mu \mathrm{m}$ las incertezas relativas aumentaron hasta $38 \%$ en el caso de los errores de $\Delta \phi$ y $\Delta x$ máximos. 


\subsubsection{Estudio de las incertezas de los valores de altura en muestras de un tubo de}

caldera

\subsubsection{Verificación de la fiabilidad de los valores de altura mediante la sección transversal de un pit de corrosión}

Debido a la ausencia de normas de estándares de calibración adecuadas, la precisión de los cálculos de los valores de altura en un pit de corrosión (figura 3.4a) con el programa EZEImage y el microscopio SEM 505 de Philips, se puso a prueba mediante varias mediciones en la sección transversal del mismo pit (figura 3.4b). En la tabla 3.1 se resumen los valores de altura obtenidos mediante los pares estéreo (a una distancia de trabajo $W=44 \mathrm{~mm}$, ángulo de inclinación $\Delta \phi= \pm 8^{\circ}$ y magnificación de $M=100 X)$ y a partir de la observación directa de la sección transversal (a M=220X).

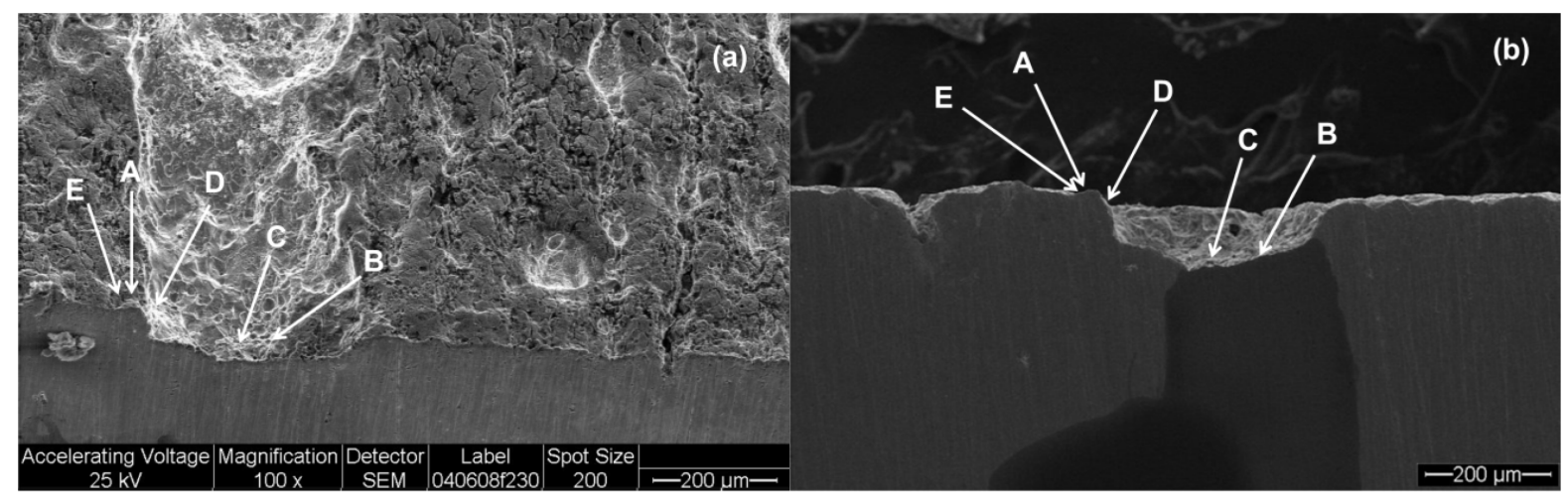

Figura 3.4: (a) Imagen SEM de un pit de corrosión de la muestra I obtenida con un ángulo de inclinación de $+8^{0}$ y una magnificación de 100X; (b) Corte transversal del pit de corrosión de la imagen (a). Los puntos A, B, C, D y E de ambas imágenes son los mismos que los de la tabla 3.1, y representan las coordenadas de mediciones equivalentes obtenidas por ambos métodos.

Los datos de profundidad obtenidos con una magnificación de 100X son muy robustos considerando el mínimo error estimado. Como puede observarse en la quinta columna de la tabla 3.1, excepto en el punto E, las diferencias entre los datos de altura obtenidos mediante estereometría $(\Delta \mathrm{Hs})$ y los obtenidos a partir de la sección transversal $\left(\Delta \mathrm{H}_{\mathrm{cs}}\right)$ se encuentran dentro de la incerteza mínima estimada (figura 3.2b). Para valores de profundidad pequeños (como en el caso del punto E) es 
conveniente utilizar magnificaciones mayores a 100X, donde la incerteza mínima estimada es alrededor de 11\% para 200X y $4 \%$ para 400X (figura $3.2 b$ ).

Tabla 3.1: Valores de altura del pit de corrosión de la muestra I medidos por EZEImage con respecto al centro de la imagen (Hs). La tercera y cuarta columnas muestran los correspondientes valores de altura (con respecto al punto A) por medio de pares estéreo y la sección transversal del pit, respectivamente. En la tercera columna $(\Delta \mathrm{Hs})$ se indican entre paréntesis las incertezas mínimas estimadas. En el cálculo de los errores en la cuarta columna $(\Delta \mathrm{Hcs})$, se utilizó la ecuación (3.4) asumiendo $u(s) / s=0,02$.

\begin{tabular}{|c|c|c|c|c|}
\hline $\begin{array}{c}\text { Coordenadas } \\
(\mathrm{X}, \mathrm{Y})[\mathrm{pixel}]\end{array}$ & $\mathrm{Hs}[\mu \mathrm{m}]$ & $\Delta \mathrm{Hs}[\mu \mathrm{m}]$ & $\Delta \mathrm{H}_{\mathrm{cs}}[\mu \mathrm{m}]$ & $\mathrm{I}(\Delta \mathrm{Hcs}-\Delta \mathrm{Hs}) / \Delta \mathrm{H} c s \%$ \\
\hline$(605 ; 742)(\mathrm{A})$ & 52,6 & & & \\
\hline$(556 ; 533)(\mathrm{B})$ & $-61,4$ & $114,0(4,5)$ & $112,0(2,7)$ & 1,8 \\
\hline$(569 ; 614)$ & $-78,9$ & $131,5(4,9)$ & $130,1(3,0)$ & 1,1 \\
\hline$(570 ; 592)(\mathrm{C})$ & $-74,5$ & $127,1(4,8)$ & $124,1(2,9)$ & 2,4 \\
\hline$(583 ; 673)$ & $-52,6$ & $105,2(4,2)$ & $108,4(2,5)$ & 2,9 \\
\hline$(584 ; 662)$ & $-56,97$ & $109,57(4,3)$ & $108,4(2,5)$ & 1,1 \\
\hline$(592 ; 692)$ & $-35,1$ & $87,7(3,5)$ & $85,5(2,1)$ & 2,6 \\
\hline$(596 ; 713)$ & $-30,7$ & $83,3(3,3)$ & $85,5(2,1)$ & 2,6 \\
\hline$(604 ; 734)(\mathrm{D})$ & 30,69 & $21,91(2,0)$ & $22,89(0,90)$ & 1,0 \\
\hline$(613 ; 771)(\mathrm{E})$ & 48,23 & $4,37(1,8)$ & $7,23(0,59)$ & 40 \\
\hline$(623 ; 836)$ & 74,52 & $-21,92(1,95)$ & $20,48(0,85)$ & 7,0 \\
\hline
\end{tabular}




\subsubsection{Estudio de confiabilidad de datos para dos magnificaciones diferentes}

En la figura 3.5, se puede observar un pit a una magnificación de 100X y 400X de la muestra II. La tabla 3.2 muestra varios datos de altura relativos a un punto arbitrario (punto 1 de la tabla), obtenido a partir de los correspondientes pares estéreo para cada magnificación.
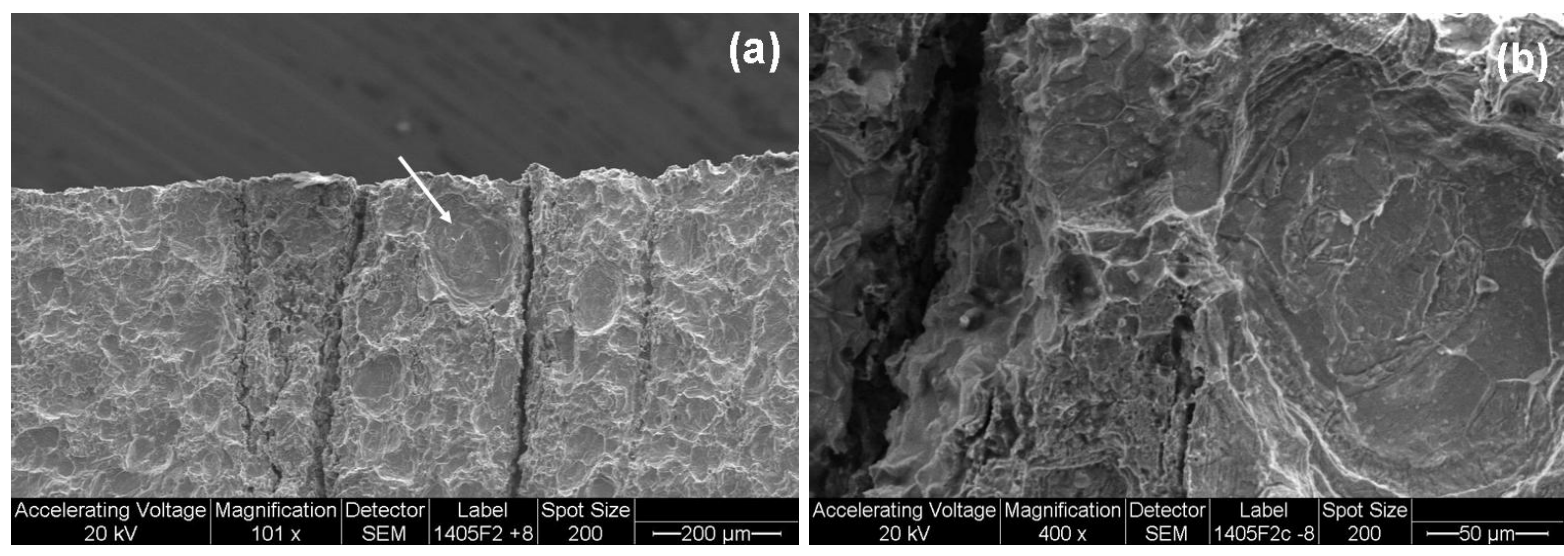

Figura 3.5: Micrografías que muestran el pit en la muestra II. (a) A una magnificación de 100X; (b) Pit marcado con una flecha blanca en (a) a 400X.

Considerando las incertezas máximas estimadas (figura 3.2a), los valores de profundidad obtenidos a las magnificaciones de 100X y 400X (cuarta y séptima columna de la tabla 3.2, respectivamente) se pueden considerar equivalentes. Como se puede observar en todos los casos, la diferencia entre ambos valores de altura $(\varepsilon \%)$ es menor que el mínimo entre ambas incertezas máximas estimadas, es decir, aquéllas que corresponden a un aumento de 400X. 
Tabla 3.2: Valores de altura $(\Delta \mathrm{H})$ correspondientes al pit de corrosión mostrado en la figura 3.4, con respecto al punto 1 , con dos aumentos diferentes. En la cuarta $\left(\Delta \mathrm{H}_{100 x}\right)$ y séptima $\left(\Delta \mathrm{H}_{400 x}\right)$ columna se indican entre paréntesis las incertezas máximas estimadas; en la última columna $\varepsilon \%=100 \times \mid\left(\Delta \mathrm{H}_{100 x}-\Delta \mathrm{H}_{400 x}\right) / \Delta \mathrm{H}_{100 x} \mathrm{l}$.

\begin{tabular}{|c|c|c|c|c|c|c|c|}
\hline Punto & $\begin{array}{c}\text { Coordenadas } \\
100 \mathrm{X}\end{array}$ & $\begin{array}{c}\mathrm{H}_{100 \mathrm{x}} \\
{[\mu \mathrm{m}]}\end{array}$ & $\begin{array}{c}\Delta \mathrm{H}_{100 x} \\
{[\mu \mathrm{m}]}\end{array}$ & $\begin{array}{c}\text { Coordenadas } \\
400 \mathrm{X}\end{array}$ & $\begin{array}{c}\mathrm{H}_{400 x} \\
{[\mu \mathrm{m}]}\end{array}$ & $\begin{array}{c}\Delta \mathrm{H}_{400 x} \\
{[\mu \mathrm{m}]}\end{array}$ & $\varepsilon \%$ \\
\hline 1 & $(418 ; 430)$ & $-17,53$ & & $(346 ; 448)$ & $-15,34$ & & \\
\hline 2 & $(404 ; 398)$ & $-35,1$ & $-17,5(5,4)$ & $(278 ; 308)$ & $-32,9$ & $-17,5(4,0)$ & 0,0 \\
\hline 3 & $(364 ; 406)$ & $3,73 \times 10^{-4}$ & $17,53(5,4)$ & $(108 ; 354)$ & 3,29 & $18,63(4,1)$ & 6,3 \\
\hline 4 & $(468 ; 382)$ & $-35,1$ & $-17,5(5,4)$ & $(558 ; 236)$ & $-34,0$ & $-18,6(4,1)$ & 6,3 \\
\hline 5 & $(432 ; 424)$ & $-4,38$ & $13,15(5,1)$ & $(402 ; 420)$ & $-3,29$ & $12,05(2,5)$ & 8,4 \\
\hline 6 & $(416 ; 382)$ & $-39,5$ & $-21,9(5,9)$ & $(336 ; 238)$ & $-38,4$ & $-23,0(4,8)$ & 5,0 \\
\hline 7 & $(410 ; 430)$ & $-21,9$ & $-4,4(4,9)$ & $(306 ; 448)$ & $-18,63$ & $-3,3(1,4)$ & 25 \\
\hline
\end{tabular}

3.3.2.3. Dependencia de los datos de altura con diferentes condiciones de inclinación de la muestra

Una de las posibles formas de obtener una imagen SEM es con la muestra inclinada lejos de la incidencia normal (es decir, $\phi \neq 0$ ), ya que más electrones secundarios escapan de la muestra con mayores ángulos de inclinación. Por lo tanto, es necesario verificar que los valores de altura obtenidos con EZEImage son equivalentes a cualquier ángulo de inclinación de la muestra.

Para la muestra III se obtuvieron mapas densos de altura a partir de diferentes condiciones de inclinación de la muestra para las imágenes izquierda y derecha (pares estéreo) con una magnificación de $M=100 X$. Los valores de altura se calculan respecto del centro de la imagen (punto eucéntrico) y en el mapa denso de altura cada valor de gris equivale a una altura relativa, siendo los valores más oscuros los más profundos. 

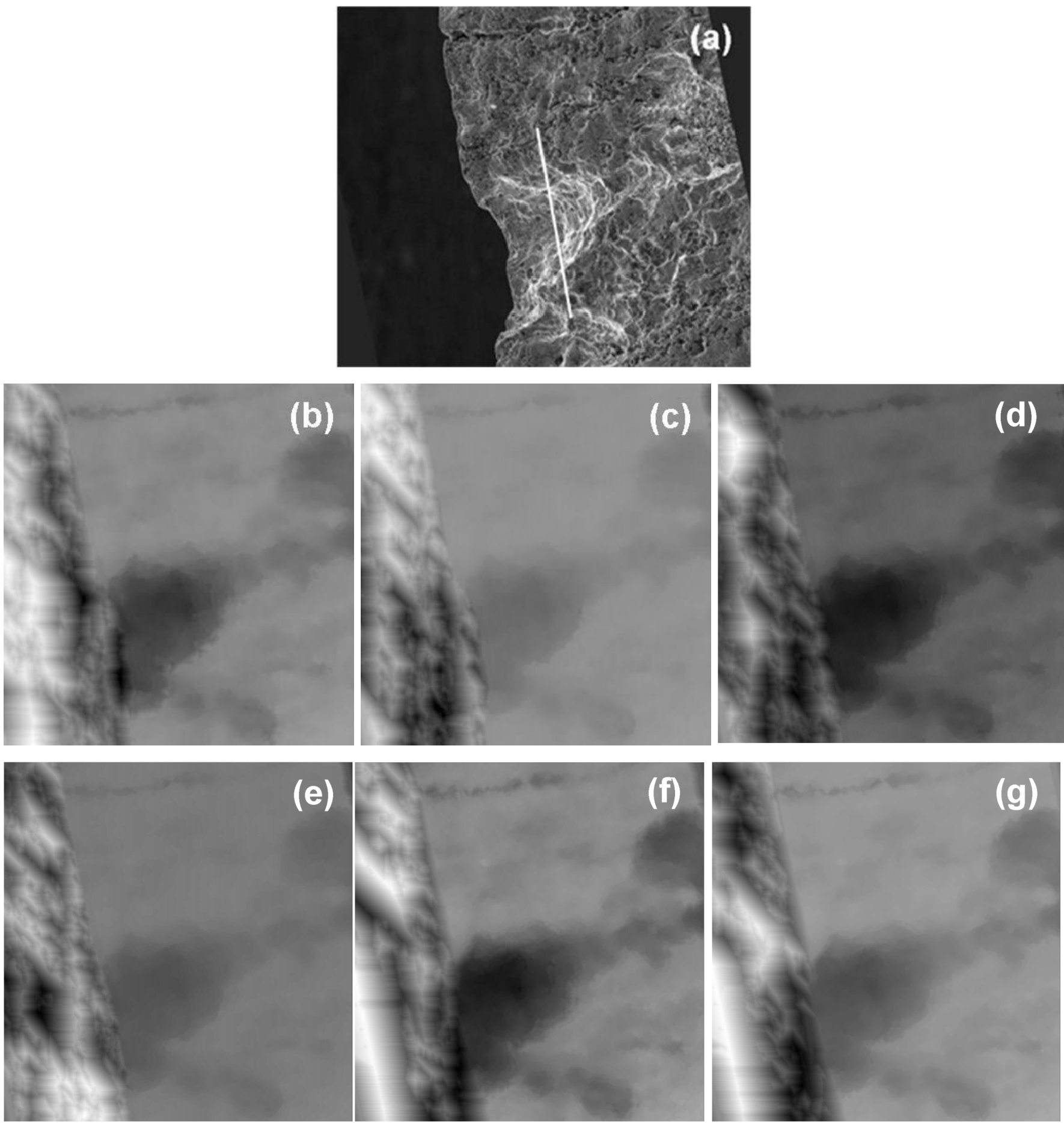

Figura 3.6: Pit de corrosión de la muestra III: (a) Imagen SEM obtenida a $M=100 X$ y a un ángulo de inclinación de $\phi_{2}=32^{\circ}$ (imagen derecha del par estéreo). La línea blanca corresponde a la región más profunda del pit donde se calcularon los perfiles de altura; (b) - (g) Mapas densos de altura de los pares estéreo en los siguientes ángulos de inclinación $\left(\phi_{1}, \phi_{2}\right):\left(16^{\circ}, 32^{\circ}\right) ;\left(16^{\circ}, 2^{\circ}\right) ;\left(8^{\circ}, 24^{\circ}\right) ;\left(8^{\circ}, 16^{\circ}\right) ;\left(-8^{\circ}, 16^{\circ}\right)$ y $\left(-8^{\circ}, 8^{\circ}\right)$, respectivamente. 
La figura 3.6a muestra un pit de corrosión correspondiente a la tercera muestra corroída, a un ángulo de inclinación de $\phi_{2}=32^{\circ}$ (imagen derecha del par estéreo, ver sección 3.2.2) y M=100X. En las figuras 3.6b-g se pueden observar los mapas densos de altura para diferentes condiciones de inclinación. La pérdida de nitidez que se produce en las regiones de discontinuidad de la profundidad, como se mencionó en la sección 3.2.4.1, se puede observar en las regiones que se encuentran a la izquierda de cada imagen.

En la figura 3.7, se muestra el perfil de alturas transversales del pit de corrosión para las diferentes condiciones de inclinación. En la tabla 3.3, se muestran los valores de la profundidad del pit correspondientes a la diferencia entre el promedio de los valores de altura en la meseta y el promedio de los valores en el valle.

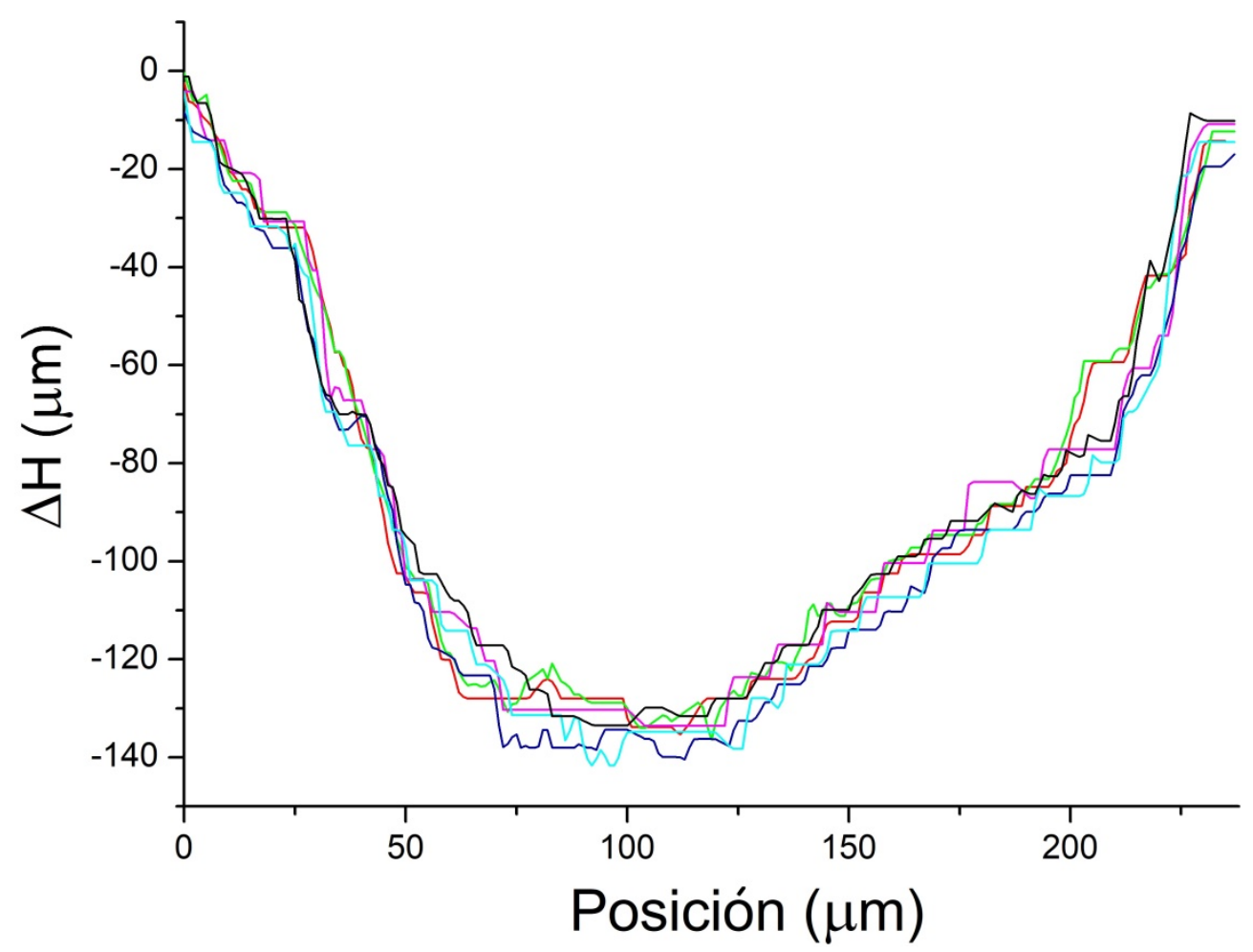

Figura 3.7: Perfiles de altura transversales del pit de corrosión para las diferentes condiciones de inclinación: $\left(16^{\circ}, 32^{\circ}\right)$ línea negra; $\left(16^{\circ}, 24^{\circ}\right)$ línea turquesa; $\left(8^{\circ}, 24^{\circ}\right)$ línea azul; $\left(8^{\circ}, 16^{\circ}\right)$ línea fucsia; $\left(-8^{\circ}, 16^{\circ}\right)$ línea verde y $\left(-8^{\circ}, 8^{\circ}\right)$ línea roja, respectivamente. 
Como se puede observar tanto en la figura 3.7 como en la tabla 3.3, el método de adquisición de datos en 3D y su procesamiento correspondiente, implementado en el programa EZEImage es bastante robusto para reproducir los datos de profundidad de pits obtenidos en diferentes inclinaciones de la muestra, dentro del error mínimo estimado (Figura 3.2b). Aunque la incerteza de reproducir la verdadera forma del pit a partir de los pares estéreo puede ser grande debido a que poseen variadas morfologías y relaciones de aspecto (ancho/profundidad), los cálculos de sus profundidades pueden obtenerse con un error menor, incluso trabajando a ángulos de inclinación inferiores a $\pm 8^{\circ}$. Obviamente, en el caso de mediciones de profundidad muy pequeñas, siempre se debe tener en cuenta que se producirán errores menores cuando se use un ángulo de inclinación $\Delta \phi$ mayor. En el caso contrario, cuando las medidas de profundidad son grandes, se pueden utilizar ángulos de inclinación tanto menores como mayores a $\pm 8^{\circ}$. Si se requiere toda la reconstrucción del perfil, se aconseja utilizar altas magnificaciones y $\Delta \phi$ mayor que $8^{\circ}$, con el fin de minimizar los errores.

Tabla 3.3: Profundidad del pit de la muestra III calculada como la diferencia entre el promedio de los valores de altura en la meseta y el promedio de los valores en el valle y su error estándar, del perfil de altura correspondiente a las diferentes condiciones de inclinación de la muestra.

\begin{tabular}{|c|c|}
\hline$\left(\phi_{1}, \phi_{2}\right)$ & Profundidad del pit $(\mu \mathrm{m})$ \\
\hline$\left(-8^{o}, 8^{o}\right)$ & $123,2(1,6)$ \\
\hline$\left(-8^{\mathrm{o}}, 16^{\mathrm{o}}\right)$ & $123,7(1,6)$ \\
\hline$\left(8^{\mathrm{o}}, 16^{\mathrm{o}}\right)$ & $126,6(0,9)$ \\
\hline$\left(8^{\underline{o}}, 24^{\underline{o}}\right)$ & $125,1(1,1)$ \\
\hline$\left(16^{\circ}, 24^{\circ}\right)$ & $122,6(1,9)$ \\
\hline$\left(16^{\mathrm{o}}, 32^{\mathrm{o}}\right)$ & $125,7(1,5)$ \\
\hline
\end{tabular}




\subsubsection{Estudio de muestras de biomateriales metálicos}

La distribución de la profundidad de los pits de corrosión de las muestras IV a IX puede verse en la figura 3.8. En esta figura, la profundidad de los pits se calculó como la diferencia entre el promedio de los valores de altura en las mesetas y el promedio de los valores en el valle del perfil de altura correspondiente.
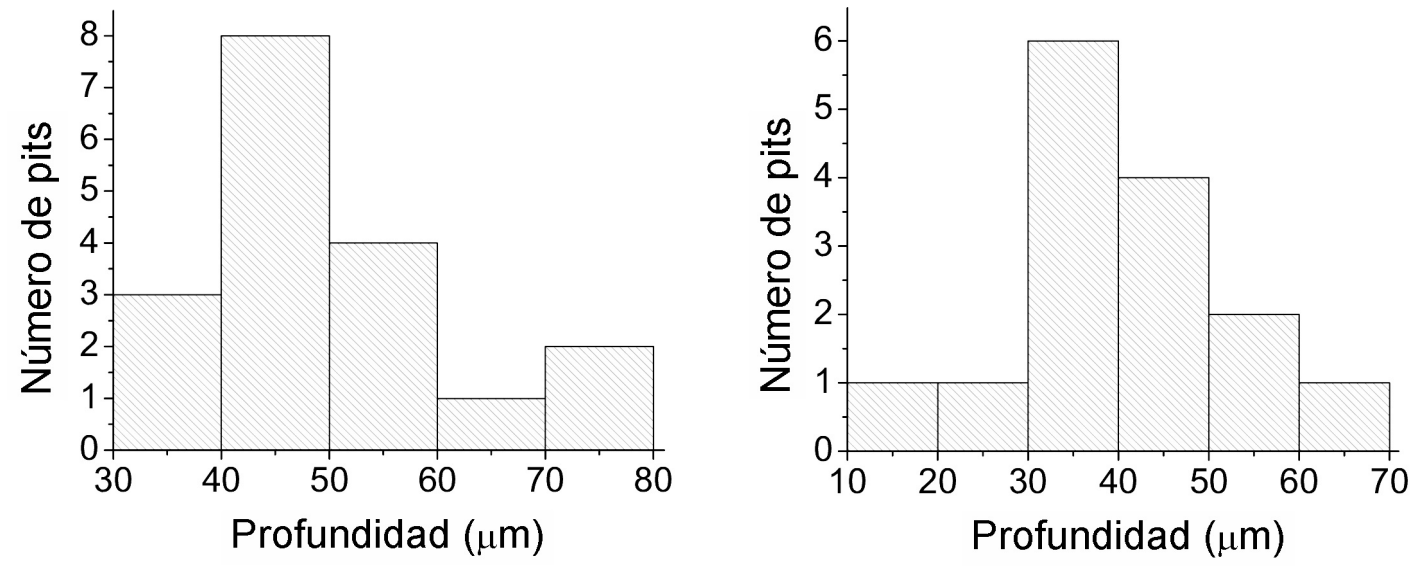

Figura 3.8: Las distribuciones de profundidad de los pits para las muestras IV a VI, con profundidad promedio de pits $=50( \pm 12) \mu \mathrm{m}$ (izquierda) y muestras VII a IX, con profundidad media de pits $=40( \pm 13) \mu \mathrm{m}$ (derecha).

Los valores promedio de los diámetros de los pits analizados mostraron una dispersión mayor que los correspondientes a sus profundidades, siendo $83( \pm 32) \mu \mathrm{m}$ para las muestras IV-VI y $96( \pm 31) \mu \mathrm{m}$ para las muestras VII a IX. En las figuras 3.9a y $3.9 \mathrm{~b}$ se pueden observar los pits generados mediante el ensayo electroquímico de las muestras IV y VII, respectivamente. 

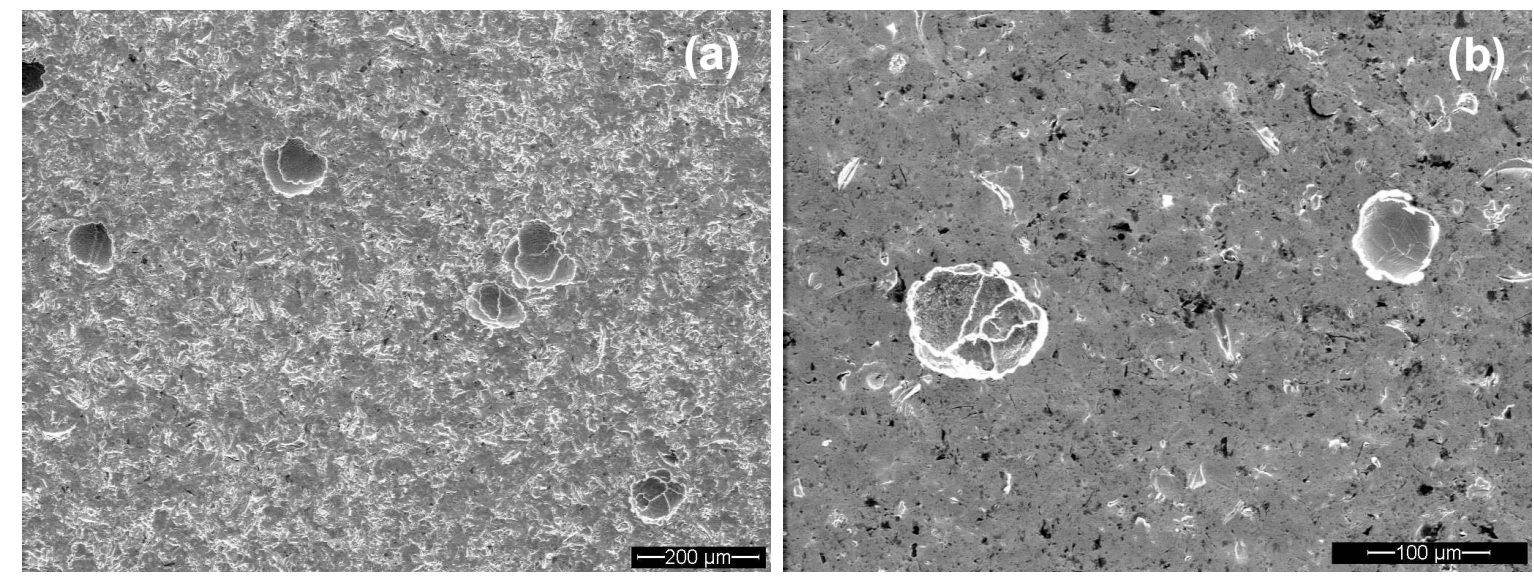

Figura 3.9: Imágenes SEM de los pits de corrosión de (a) muestra IV a una magnificación de 100X y (b) muestra VII a una magnificación de 200X.

Por otro lado, los resultados presentados en la figura 3.8 se correlacionaron con ensayos electroquímicos a partir de la ley de Faraday [95]. En todos los procesos de corrosión llevados a cabo por un mecanismo electroquímico, el consumo de material en la reacción parcial particular está relacionado con la corriente eléctrica I (A) por la ley de Faraday [95]:

$m=P I t /(k F)=P Q /(k F)$

Donde $\mathrm{m}$ es la cantidad de material electroquímicamente consumido (g), P es el peso molar (g mol-1), F es el número de Faraday (96487 A s mol-1), t es el tiempo (s), k es el Número de carga (número de moles de electrones), y $\mathrm{Q}$ es la carga total (C). El valor de $\mathrm{Q}$ es proporcional al área contenida en el bucle de histéresis entre el potencial de repasivación y el límite anódico del ensayo electroquímico (1.2 V) [96]. El ensayo de polarización mostró la iniciación y propagación de la corrosión por picado durante el barrido anódico y la repasivación en el barrido inverso. El potencial de formación de pits fue de 0,563 V para las muestras IV a VI y 0,672 V en el caso de las muestras VII a IX. Los valores de Q obtenidos fueron: 192,5 C para las muestras IV-VI y 129,03 C para las muestras VII-IX. Por lo tanto, la cantidad de material consumido en el 
primer conjunto de muestras fue mayor que en el segundo, que se correlaciona bien con las profundidades de los pits, ya que eran mayores para las muestras IV a VI.

Es necesario destacar que esta correlación fue posible porque se asumió que las diferencias observadas en los dos histogramas de la figura 3.8 se debieron a los diferentes métodos aplicados al tratamiento de superficie [97-99] y no debido al uso de diferentes magnificaciones y ángulos de inclinación en cada conjunto de muestras. Esta afirmación también se confirmó estudiando las profundidades de dos pits en la muestra IX en las mismas condiciones que las muestras IV-VI, es decir, magnificaciones de 100X y $\Delta \phi= \pm 5^{\circ}$, obteniendo $48,51 \mu \mathrm{m}$ a $M=200 X, \Delta \phi= \pm 8^{\circ}$ y 48,43 $\mu \mathrm{m}$ a $\mathrm{M}=100 \mathrm{X}, \Delta \phi= \pm 5^{\circ}$ para el primer pit, y $47,34 \mu \mathrm{m}$ a $\mathrm{M}=200 \mathrm{X}, \Delta \phi= \pm 8^{\circ}$ y $48,41 \mu \mathrm{m}$ a $M=100 X, \Delta \phi= \pm 5^{\circ}$ para el segundo pit. Los resultados mostraron que la diferencia relativa entre ambas profundidades para un pit dado era menor que el error mínimo estimado (5\% para $100 \mathrm{X}$ y $2 \%$ para $200 \mathrm{X})$.

\subsection{Conclusiones}

En este capítulo se llevó a cabo un estudio sobre las incertidumbres de las profundidades de pits de corrosión a bajas magnificaciones y diferentes ángulos de inclinación, utilizando pares estéreos de imágenes de SEM con un SEM 505 de Philips y el software EZEImage. Este método se aplicó a una pieza de tubo de caldera corroída de un generador termoeléctrico de potencia. Los resultados obtenidos en el caso de las profundidades de los pits en el intervalo de $30-150 \mu m$ indican que se obtendrían valores confiables trabajando incluso con una magnificación tan baja

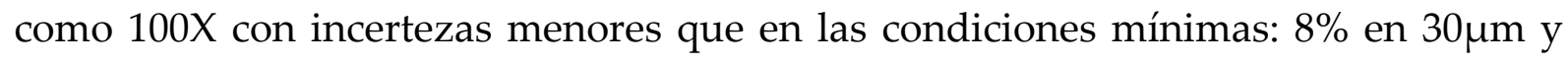
$3 \%$ en $150 \mu \mathrm{m}$ para ángulos de inclinación $\Delta \phi= \pm 8^{\circ} ; 10 \%$ para $30 \mu \mathrm{m}$ y $5 \%$ para $150 \mu \mathrm{m}$ para ángulos de inclinación $\Delta \phi= \pm 5^{\circ}$. Aunque sus errores disminuyen notablemente cuando se aumentan las magnificaciones a 200X y 400X y un ángulo de inclinación $\Delta \phi= \pm 8^{\circ}$. 
Los resultados de las diferencias entre los datos de altura obtenidos mediante estereometría $\left(100 \mathrm{X}\right.$ y $\left.\Delta \phi= \pm 8^{\circ}\right)$ y los obtenidos a partir de mediciones en la sección transversal se encuentran dentro de la incerteza mínima estimada. Lo mismo ocurre en el caso de los valores de profundidad obtenidos a las magnificaciones de 100X y 400X a $\Delta \phi= \pm 8^{\circ}$, donde la diferencia es menor que el mínimo entre ambas incertezas máximas estimadas (las que corresponden a una magnificación de 400X). Sin embargo, en el caso de valores de profundidad pequeños (menores a $15 \mu \mathrm{m}$ ) es conveniente utilizar magnificaciones mayores a 100X, donde para una profundidad aproximada de $4 \mu \mathrm{m}$ (tablas 3.1 y 3.2) la incerteza mínima estimada es de 40,5\% a 100X pero disminuye a $11 \%$ para $200 \mathrm{X}$ y $4 \%$ para $400 \mathrm{X}$.

Los resultados obtenidos para muestras de implantes ortopédicos bajo dos tratamientos de superficie diferentes coinciden con los resultados electroquímicos aunque las condiciones en ambos métodos son muy diferentes, es decir, no generan pits con distribuciones de igual profundidad. Estos primeros resultados alientan a desarrollar un estudio más profundo con mayor estadística y condiciones experimentales más acordes a una óptima correlación entre los resultados de distintos tratamientos superficiales. 


\title{
CAPÍTULO 4
}

\section{TRATAMIENTOS DE BLASTINIZADO Y PASIVADO QUÍMICO EN ACERO \\ INOXIDABLE ASTM F139 PARA IMPLANTES: EFECTOS SOBRE LA RUGOSIDAD SUPERFICIAL, DUREZA Y CORROSIÓN LOCALIZADA}

\begin{abstract}
Debido a la combinación de una buena biofuncionalidad y biocompatibilidad a bajo costo, el acero inoxidable AISI 316 LVM (Low Vacuum Melting), de acuerdo a la norma ASTM F139, es considerada a menudo la primera opción para biomateriales implantables, particularmente para uso como implantes estructurales en cirugía traumatológica y ortopédica. Para asegurar las interacciones adecuadas de la aleación con los tejidos del cuerpo humano se debe realizar un acabado superficial apropiado que, a su vez, permita que el material proporcione el rendimiento deseado. El objetivo del presente capítulo es caracterizar las superficies obtenidas por blastinizado con partículas de sílice, seguido de diferentes condiciones de pasivado con ácido nítrico en acero inoxidable AISI 316LVM. La evaluación de la rugosidad se realizó mediante parámetros funcionales, de amplitud y un estimador de la dimensión fractal que caracterizan la topografía de las superficies. Los resultados obtenidos indican que el tratamiento de blastinizado debe llevarse a cabo bajo condiciones controladas para obtener propiedades superficiales y subsuperficiales similares; de lo contrario, una variación en uno de los parámetros podría modificar las propiedades superficiales, ejerciendo un profundo impacto en su aplicación como biomaterial.
\end{abstract}

\subsection{Introducción}

El esfuerzo dedicado al diseño, la síntesis y la fabricación de biomateriales utilizados en cirugía ortopédica se centra en obtener las mejores propiedades que se encuentran gobernadas por las estructuras de volumen de los materiales [100]. Sin embargo, el comportamiento biofuncional apropiado, depende críticamente de las interacciones adecuadas entre el medio biológico y las películas superficiales de estos materiales para implantes. En consecuencia, como se mencionó en un capítulo anterior, se requiere la aplicación de diferentes tratamientos que modifiquen la superficie original, por ejemplo, para mejorar las resistencias al desgaste y a la corrosión. Por lo tanto, es evidente que obtener los mejores resultados de estos biomateriales supone una caracterización sistemática previa de los efectos de los 
tratamientos superficiales sobre la composición química, la micro o nanoestructura, la rugosidad, el espesor de la película superficial y una correlación de esta información con propiedades fisicoquímicas, biocompatibilidad, resistencia a la corrosión, entre otros.

Aún cuando el blastinizado (vulgarmente mencionado como granallado), como parte de un tratamiento superficial, ha sido ampliamente estudiado y aplicado en relación al Ti c.p. y a los implantes de Ti6Al4V [97,98,101,102], sólo se dispone de pocos estudios que consideren la aplicación del blastinizado sobre aceros inoxidables para biomateriales [103-106], como es el caso de los aceros inoxidables 316LVM (Low Vaccuum Melting). Estos aceros tienen una masiva aplicación como implantes para traumatología y ortopedia porque su biocompatibilidad es aceptable (en algunos países desarrollados su uso es temporario y una vez resuelta su aplicación el componente debe retirarse del cuerpo humano), son relativamente baratos y sus propiedades mecánicas se pueden controlar en un amplio rango de acuerdo a los requerimientos del caso. Este tipo de material no tiene una óptima resistencia a la corrosión para un uso prolongado como implante en el cuerpo humano y en algunos pacientes en contacto con los tejidos causa reacciones adversas. Sin embargo, es al presente una de las opciones más comunes en países no desarrollados frente a otras bioaleaciones de considerable mayor precio.

En el proceso de blastinizado, partículas abrasivas de diferentes tamaños, formas y composición química, son arrastradas por una corriente de aire hasta impactar con el material, a una presión y tiempos determinados. En general, este proceso genera varias modificaciones en la superficie y subsuperficie del material [107]. Aunque algunas de estas modificaciones pueden ser de naturaleza química [102], otras están relacionadas con la microestructura, como el refinamiento del grano $[103,104,108]$ o asociadas a propiedades mecánicas, como la dureza o tensiones residuales de compresión [103,104,108,109,110,111]. En particular en [106], se puede encontrar una discusión sobre cómo el tratamiento de blastinizado mejora la dureza superficial y subsuperficial. Sin embargo, se ha establecido en la literatura [109] que el aumento de 
la rugosidad superficial es el factor clave que regula el efecto perjudicial del blastinizado sobre ciertas formas de corrosión en lugar de la formación de la fase martensita y la generación de tensiones residuales. En cuanto al aumento de la rugosidad de la superficie, los siguientes parámetros de blastinizado permiten controlar el alcance de este efecto: tamaño de las partículas, forma de las partículas y composición química, presión y tiempo de blastinizado [107]. El blastinizado, el primer paso de todo el tratamiento superficial, es seguido por un pasivado químico o un electropulido como paso final, aplicado sobre la superficie blastinizada. Este último paso tiene como objetivo lograr una limpieza eficaz y una mayor resistencia a la corrosión [56].

La topografía final obtenida sobre el biomaterial tratado superficialmente afecta la interacción con los tejidos [32] y el grado de degradación corrosiva generada por los fluidos biológicos [100]. La liberación de productos de corrosión o iones metálicos de naturaleza no biocompatible puede causar la aparición de reacciones adversas en el organismo huésped, como hipersensibilidad, inflamación o citotoxicidad [100,112]. Además, la corrosión podría causar la pérdida de integridad del implante disminuyendo su vida útil.

Para el análisis del acabado superficial se requiere de un conjunto de parámetros que determinen con precisión las características topográficas de la superficie. Estos parámetros dan información tanto de propiedades de amplitud (rugosidad promedio Ra o Sq, por ejemplo - ver tabla 4.2) como funcionales (área de contacto, retención de fluido, entre otras) y la utilidad de cada uno de ellos es motivo de estudio en cada nueva situación o interacción abordada. En general, resultan difíciles de comparar los datos obtenidos con los publicados anteriormente por otros investigadores, debido a caracterizaciones superficiales inadecuadas [32]. En cuanto al comportamiento electroquímico, pocos trabajos se llevaron a cabo sobre el estudio de la relación entre los distintos parámetros de blastinizado y la resistencia a la corrosión para aplicaciones médicas como en Ti c.p. [97] y Ti6Al4V [98] u otras aplicaciones como en AISI 304 [113] y AISI 316L [110]. Los estudios electroquímicos in vitro pueden 
realizarse en ambientes controlados y proveer de métodos para predecir el comportamiento de la corrosión y para proyectar y caracterizar los materiales que se pretenden utilizar en aplicaciones quirúrgicas [56].

El objetivo de este capítulo es evaluar el efecto del proceso de blastinizado sobre los parámetros de rugosidad, resistencia a la corrosión por picado y endurecimiento superficial en muestras de acero inoxidable AISI 316LVM con diferentes tratamientos superficiales que se basaron en el blastinizado con partículas de sílice.

\subsection{Materiales y métodos}

\subsubsection{Preparación de muestras}

Se utilizó como material de estudio placas de acero inoxidable AISI 316 LVM laminadas en frío $(0,019 \% \mathrm{C}, 1,86 \% \mathrm{Mn}, 17,29 \% \mathrm{Cr}, 2,77 \% \mathrm{Mo}, 14,34 \% \mathrm{Ni}, 0,36 \% \mathrm{Si}$, 0,017\% P, 0,001\% S, 0,14\% Cu, 0,086\%). Las muestras fueron blastinizadas por un proveedor industrial durante 30 segundos, $2 \mathrm{~min}, 5 \mathrm{~min}$ y $15 \mathrm{~min}$ con partículas de sílice de tamaños comprendidos entre 30-160 $\mu \mathrm{m}$ de diámetro a una presión de 5 $\mathrm{kg} / \mathrm{cm}^{2}$ sin efectuar ningún tratamiento de recocido luego del blastinizado. Posteriormente, dichas muestras fueron pasivadas químicamente en $\mathrm{HNO}_{3}$ al 20\% (v/v) durante 30 min y 60 min y en $\mathrm{HNO}_{3}$ al 40\% (v/v) durante $30 \mathrm{~min}$ a temperatura ambiente. Los resultados se compararon con muestras preparadas mediante pulido mecánico con pasta de diamante de $6 \mu \mathrm{m}$, con y sin pasivado químico posterior en $\mathrm{HNO}_{3}$ al 20\% (v/v) durante 60 minutos y con muestras blastinizadas durante 2 minutos sin pasivado químico. La tabla 4.1 muestra la nomenclatura de las muestras utilizadas para los diferentes tratamientos. El símbolo (I) indica que el material fue blastinizado, por el proveedor industrial, durante los tiempos de tratamiento mostrados en la tabla 4.1. El símbolo (II) indica que otras muestras del mismo material fueron blastinizadas, en un tiempo posterior por el mismo proveedor, durante los tiempos de tratamiento indicados en la tabla 4.1. 
Tabla 4.1: Nomenclatura de las muestras utilizadas para los diferentes tratamientos superficiales. Los símbolos (I) y (II) se refieren a diferentes tandas de muestras, preparadas en distintos momentos.

\begin{tabular}{|c|c|}
\hline $\begin{array}{l}\text { Nomenclatura } \\
\text { de la muestra }\end{array}$ & Tratamiento superficial \\
\hline MP & Pulido mecánico con pasta de diamante de $6 \mu \mathrm{m}$ \\
\hline MPP2060 & $\begin{array}{c}\text { Pulido mecánico con pasta de diamante de } 6 \mu \mathrm{m} \text { y pasivado } \\
\text { químico en } 20 \% \text { de } \mathrm{HNO} 3(\mathrm{v} / \mathrm{v}) \text { durante } 60 \mathrm{~min}\end{array}$ \\
\hline B30s(I) & Blastinizado por 30 segundos \\
\hline B2m (I) y (II) & Blastinizado por $2 \mathrm{~min}$ \\
\hline $\mathrm{B} 5 \mathrm{~m}(\mathrm{I})$ & Blastinizado por $5 \mathrm{~min}$ \\
\hline B15m(II) & Blastinizado por $15 \mathrm{~min}$ \\
\hline BP30s2060(I) & $\begin{array}{l}\text { Blastinizado por } 30 \text { segundos y pasivado químico en } 20 \% \text { de } \\
\qquad \mathrm{HNO}_{3}(\mathrm{v} / \mathrm{v}) \text { durante } 60 \text { minutos }\end{array}$ \\
\hline $\begin{array}{l}\mathrm{BP} 2 \mathrm{~m} 2060(\mathrm{I}) \mathrm{y} \\
(\mathrm{II})\end{array}$ & $\begin{array}{l}\text { Blastinizado por } 2 \text { min y pasivado químico en } 20 \% \text { de } \mathrm{HNO}_{3} \\
(\mathrm{v} / \mathrm{v}) \text { durante } 60 \text { minutos }\end{array}$ \\
\hline BP5m2060(I) & $\begin{array}{l}\text { Blastinizado por } 5 \text { min y pasivado químico en } 20 \% \text { de } \mathrm{HNO}_{3} \\
(\mathrm{v} / \mathrm{v}) \text { durante } 60 \text { minutos }\end{array}$ \\
\hline BP15m2060(II) & $\begin{array}{l}\text { Blastinizado por } 15 \text { min y pasivado químico en } 20 \% \text { de } \\
\qquad \mathrm{HNO}_{3}(\mathrm{v} / \mathrm{v}) \text { durante } 60 \text { minutos }\end{array}$ \\
\hline BP2m2030(II) & $\begin{array}{l}\text { Blastinizado por } 2 \text { min y pasivado químico en } 20 \% \text { de } \mathrm{HNO}_{3} \\
(\mathrm{v} / \mathrm{v}) \text { durante } 30 \text { minutos }\end{array}$ \\
\hline BP2m4030(II) & $\begin{array}{l}\text { Blastinizado por } 2 \text { min y pasivado químico en } 40 \% \text { de } \mathrm{HNO}_{3} \\
(\mathrm{v} / \mathrm{v}) \text { durante } 30 \text { minutos }\end{array}$ \\
\hline
\end{tabular}

\subsubsection{Caracterización topográfica}

La medición de la rugosidad superficial se llevó a cabo mediante el uso de la microscopía electrónica de barrido 3D (3D SEM) en observaciones basadas en la técnica de los pares estéreo. En el capítulo 3, se presenta una discusión en profundidad sobre la incertezas en las mediciones topográficas utilizando 3D SEM. Por otro lado, Ostadi y otros [76] realizaron una comparación de diferentes métodos de análisis de rugosidad superficial mostrando que el método de 3D SEM mediante la técnica de los pares estéreo proporciona la mejor resolución de datos. En este capítulo, el análisis de la rugosidad se realizó utilizando un SEM Philips 505 equipado con una interfaz de barrido digital ADA II y el software de análisis de 
imágenes Scandium SIS. Las condiciones en las cuales se obtuvieron los pares estéreo fueron $25 \mathrm{kV}$ de voltaje de haz de electrones y $200 \mathrm{~nm}$ de tamaño de spot. Se obtuvieron quince pares estéreo de imágenes SEM con ángulos de inclinación ($8^{\circ},+8^{\circ}$ ), a una distancia de trabajo de $12 \mathrm{~mm}$ y a una magnificación de $203 \mathrm{X}$ en cada muestra blastinizada y pasivada y se procesaron para obtener los parámetros de rugosidad con el software EZEImage [68].

\subsubsection{Caracterización mecánica}

Se evaluó el comportamiento mecánico de las superficies de diferentes muestras (muestras blastinizadas y muestras sometidas a pulido mecánico con pasta de diamante de $6 \mu \mathrm{m}$ ) con un equipo de microdureza Future Tech FM-700. Se realizaron ensayos de microdureza Vickers en las superficies y secciones transversales de las muestras con una carga de 10 gf durante 10 segundos (tiempo de carga) según ASTM E 384-89 [114].

\subsubsection{Caracterización electroquímica}

Los ensayos electroquímicos se realizaron en solución Ringer $(8,6 \mathrm{~g} / \mathrm{L} \mathrm{NaCl}, 0,3$ $\mathrm{g} / \mathrm{L} \mathrm{KCl}, 0,33 \mathrm{~g} / \mathrm{L} \mathrm{CaCl}_{2}$ ) desaireada a $37 \pm 1^{\circ} \mathrm{C}$. Todos los potenciales fueron referidos al electrodo de calomel saturado (SCE). Las curvas de polarización potenciodinámica cíclica $(\mathrm{CP})$ se registraron a una velocidad de barrido de $13,8 \mathrm{mV} / \mathrm{s}$ entre $-1,2 \mathrm{~V}$ y 1,6 V para evaluar los valores de potencial de picado (Ep). Los potenciales de picado se consideraron como el potencial en el que la densidad de corriente subió desde el nivel de densidad de corriente pasiva hasta alcanzar los $200 \mu \mathrm{A} / \mathrm{cm}^{2}[115,116]$. Se replicaron los experimentos 4 veces dando resultados altamente reproducibles. 


\subsection{Resultados y discusión}

\subsubsection{Caracterización superficial}

La caracterización de la topografía superficial realizada a través de parámetros de rugosidad es fundamental en muchas industrias de ingeniería debido a su significativa influencia en las propiedades funcionales de la superficie. Existe una gran variedad y diferentes tipos de parámetros que pueden ser utilizados para describir superficies, entre los cuales se encuentran los funcionales, espaciales, híbridos y de amplitud. Decidir qué parámetro es el más relevante para describir la topografía superficial con respecto a una aplicación específica sigue siendo una tarea difícil [117-119]. La correcta elección de los parámetros más significativos dependerá de las características del tratamiento superficial utilizado y del objetivo del estudio realizado. Sin embargo, dado que es difícil utilizar e interpretar muchos de ellos, es preferible recurrir a unos pocos pero con una mayor relevancia [101,120-123]. La tabla 4.2 muestra los parámetros incluidos en el programa EZEImage y su significado. Todos los parámetros, excepto Sigma y Sa, se calcularon a partir de las alturas relativas al plano medio de cuadrados mínimos.

En el presente estudio se analizó el comportamiento de los parámetros de amplitud Sq, Sa, Sz, Sku y Ssk, que proporcionan información de la geometría superficial, de los parámetros funcionales Sbi, Sci y Svi y de la dimensión fractal D. Sa y Sq proveen características estadísticas de alturas de la superficie y son útiles para detectar variaciones en la altura de la superficie general. Se incluyó Sa (Ra en el caso unidimensional) porque se usa ampliamente para describir la rugosidad de la superficie con tratamientos de blastinizado [97,101,102-104,109,110,113,124,125]. Sin embargo, es importante destacar que el uso de este único parámetro no siempre permite una cuantificación exhaustiva de la rugosidad. Sq representa la desviación estándar de la topografía y se utiliza en cálculos de Skewness y Kurtosis. 
Tabla 4.2: Parámetros comúnmente utilizados en las medidas de rugosidad, provistos por el programa EZEImage.

\begin{tabular}{|c|l|}
\hline Parámetro & \multicolumn{1}{|c|}{ Descripción } \\
\hline Sigma & $\begin{array}{l}\text { Raíz cuadrada de la desviación cuadrática media de la topografía } \\
\text { de la superficie (alturas relativas al plano que contiene el eje de } \\
\text { inclinación de la muestra) }\end{array}$ \\
\hline Sq & $\begin{array}{l}\text { Raíz cuadrada de la desviación cuadrática media de la topografía } \\
\text { de la superficie }\end{array}$ \\
\hline Sa & $\begin{array}{l}\text { Desviación media aritmética de la topografía de la superficie } \\
\text { (alturas relativas al plano que contiene el eje de inclinación de la } \\
\text { muestra) }\end{array}$ \\
\hline Ssk & Asimetría (Skewness) de la distribución de alturas de la topografía \\
\hline Sku & Curtosis (Kurtosis) de la distribución de alturas de la topografía \\
\hline Sz & $\begin{array}{l}\text { Diez-puntos (Ten-point) de la topografía de la superficie } \\
\text { (diferencia de altura entre el promedio de los cinco puntos de } \\
\text { mayor altura y los cinco puntos de menor altura) }\end{array}$ \\
\hline Sbi & Índice de contacto de la superficie \\
\hline Sci & Índice de retención de líquido en el centro o núcleo \\
\hline Svi & Índice de retención de líquido en el valle \\
\hline D & Estimador de la dimensión fractal \\
\hline
\end{tabular}

Según Dong y otros [118], el parámetro Sa no proporciona más información que Sq para muchos tipos de superficies, sin embargo Sq tiene un significado estadístico más significativo y por lo tanto estos autores sugieren usar Sq en lugar de Sa. Sin embargo, se compararon ambos parámetros para conocer si su tendencia es similar para el tratamiento de superficie analizado en este estudio. Por otra parte, Sz describe características de altura máxima de la superficie y se calcula mediante el promedio de los cinco puntos de mayor altura y los cinco puntos de menor altura. Ssk y Sku establecen la forma de la distribución de alturas de la superficie. Para una superficie con topografía de distribución simétrica, de tipo gaussiano, el valor de Ssk es cero. En el caso de una superficie con preponderancia de picos o crestas, el valor de Ssk tiende a ser positivo y en el caso de un predominio de valles o huecos, el valor tiende a ser negativo. Un gran nivel de asimetría se refleja en un mayor valor absoluto de este último parámetro. Sku caracteriza el ancho de la distribución de las alturas, en el caso de una superficie con distribución topográfica gaussiana el valor es cercano a 3. 
Un valor mayor que 3 indica una distribución más angosta y un valor menor que 3 indica una distribución más dispersa de las alturas. Generalmente presentan errores grandes y debería tenerse en cuenta en el estudio de superficies que presentan inhomogeneidades.

Los parámetros de amplitud proveen una descripción general de la topografía y es importante combinarlos con el conjunto de parámetros funcionales, ya que éstos describen características relevantes para una determinada aplicación. Los parámetros Sbi, Sci y Svi son índices que se emplean para establecer características cualitativas de las formas y discriminar diferentes tipos de topografías porque son más fáciles de interpretar y comparar entre distintos tipos de superficies y procesos de manufactura. Estos parámetros se originan de dividir las alturas de la superficie en tres zonas (zona de pico, zona del núcleo y zona del valle) y posteriormente se realiza un cálculo de volúmenes basados en las zonas. La distribución de altura es representada gráficamente en una curva, denominada curva de bearing (también conocida como curva de Abbot-Firestone), de alturas normalizadas (con Sq) en función de la proporción de área de bearing (0-100\%) (figura 4.1a). El área de bearing es la proporción de área de superficie de contacto plana, que se obtiene truncando los picos por un plano paralelo al plano medio de cuadrados mínimos, a un determinado nivel de seccionado (figura 4.1b). Las tres zonas (pico, núcleo y valle) son obtenidas trazando dos líneas horizontales en el gráfico de la curva de bearing, cuya intersección con la curva sea a 5 y 80\% de la proporción del área de bearing, como se muestra en la figura 4.1a [118]. 

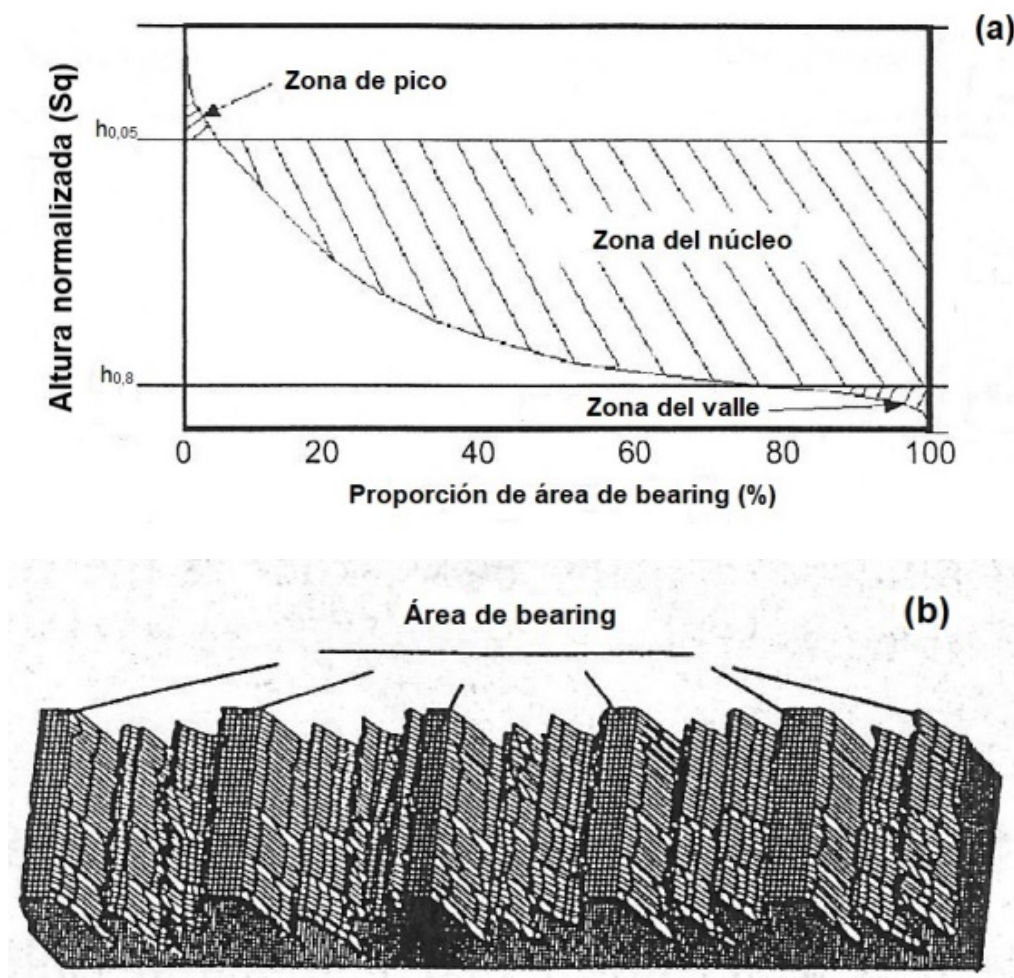

Figura 4.1: (a) Curva de bearing (b) Diagrama esquemático del área de bearing [118].

Por otra parte, varios trabajos recomiendan el uso de la dimensión fractal dentro de los parámetros de rugosidad establecidos [119,126-129]. Consideremos una línea poligonal. Si corresponde a un segmento recto su dimensión es 1; si por el contrario es muy irregular, tenderá a llenar una porción del plano, cuya dimensión es 2 . Partiendo de esta base, se define la dimensión fractal D como un número entre 1 y 2, que será mayor para perfiles más irregulares y menor para perfiles más uniformes. En la figura 4.2 se puede observar, a modo de ejemplo, un gráfico donde se muestran algunos perfiles topográficos y su dimensión fractal [126]. Extendiendo este concepto, la dimensión fractal de una superficie es un número entre 2 y 3, que será mayor para superficies más rugosas y menor para superficies más homogéneas. Según Risović y otros [128], superficies con diferentes topografías que tienen el mismo valor de Ra (Sa en el presente estudio) pueden tener diferentes valores de dimensión fractal. La dimensión fractal describe la irregularidad superficial o la complejidad que no puede describirse por los parámetros de rugosidad utilizados para la caracterización cuantitativa de la superficie. 


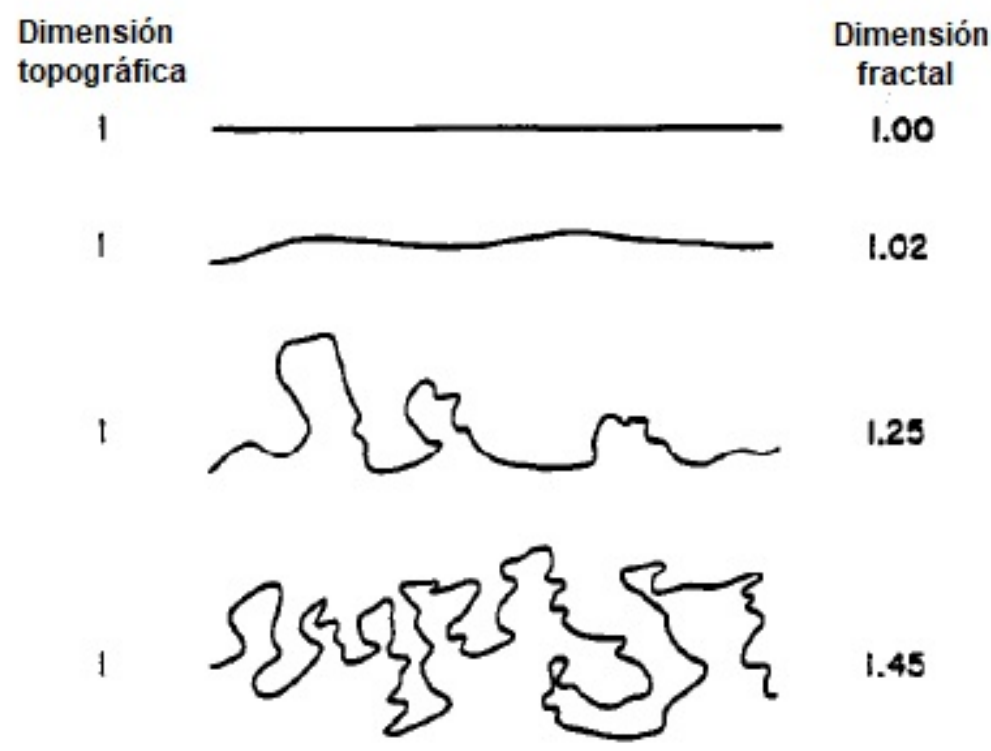

Figura 4.2: Perfiles topográficos y su la dimensión fractal [126].

El programa EZEImage proporciona los datos necesarios para obtener un estimador de dimensión fractal D mediante dos métodos diferentes. En este estudio se utiliza el método del variograma que consiste en un gráfico logarítmico de la varianza de la variación de alturas en una superficie en función del paso es decir, de la longitud entre dos posiciones diferentes en el mapa denso de alturas [67]. Con la pendiente del gráfico se obtiene el estimador de la dimensión fractal $\mathrm{D}$, donde $\mathrm{D}=3-$ pendiente/2. Los valores de D que varían entre 2 y 2,5 indican superficies suaves persistentes mientras que valores entre 2,5 y 3 corresponden a superficies antipersistentes siendo una superficie completamente rugosa cuando D es cercano a 3. En el caso particular donde $\mathrm{D}=2,5$ dicho valor corresponde a superficies brownianas [130].

Las diferentes topografías obtenidas en las tandas (I) y (II) para el mismo tiempo de blastinizado y tratamiento de pasivado químico se muestran en las imágenes SEM (figuras 4.3a y 4.3c) y en la representación del mapa denso de alturas (que provee el EZEImage) obtenida con el software Image [131] (figuras 4.3b y 4.3d). 

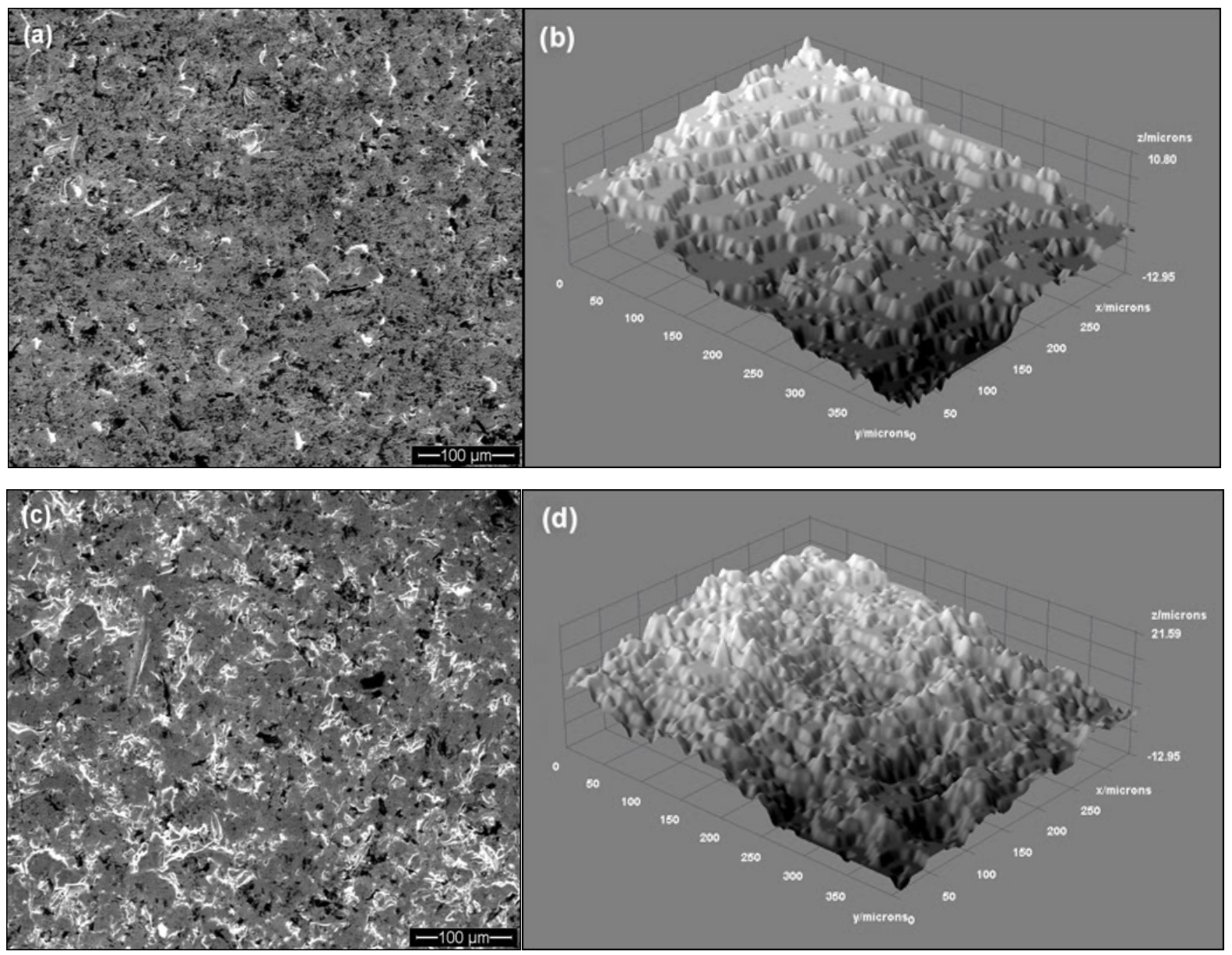

Figura 4.3: Imágenes SEM y topografías superficiales: (a, b) BP2m2060 (I) y (c, d) BP2m2060 (II), respectivamente.

También, en la figura 4.4 se puede observar que el tratamiento realizado en las tandas (I) y (II) no genera las mismas características superficiales. La figura 4.4a muestra que la rugosidad es mayor en las muestras de la tanda (II) que en las de la tanda (I), para el mismo tiempo de blastinizado y pasivado químico, pero no indica la distribución topográfica de las superficies. Con el estimador de dimensión fractal D (figura $4.4 \mathrm{~b}$ ) se pudo corroborar que las superficies no tienen el mismo tipo de irregularidades. 

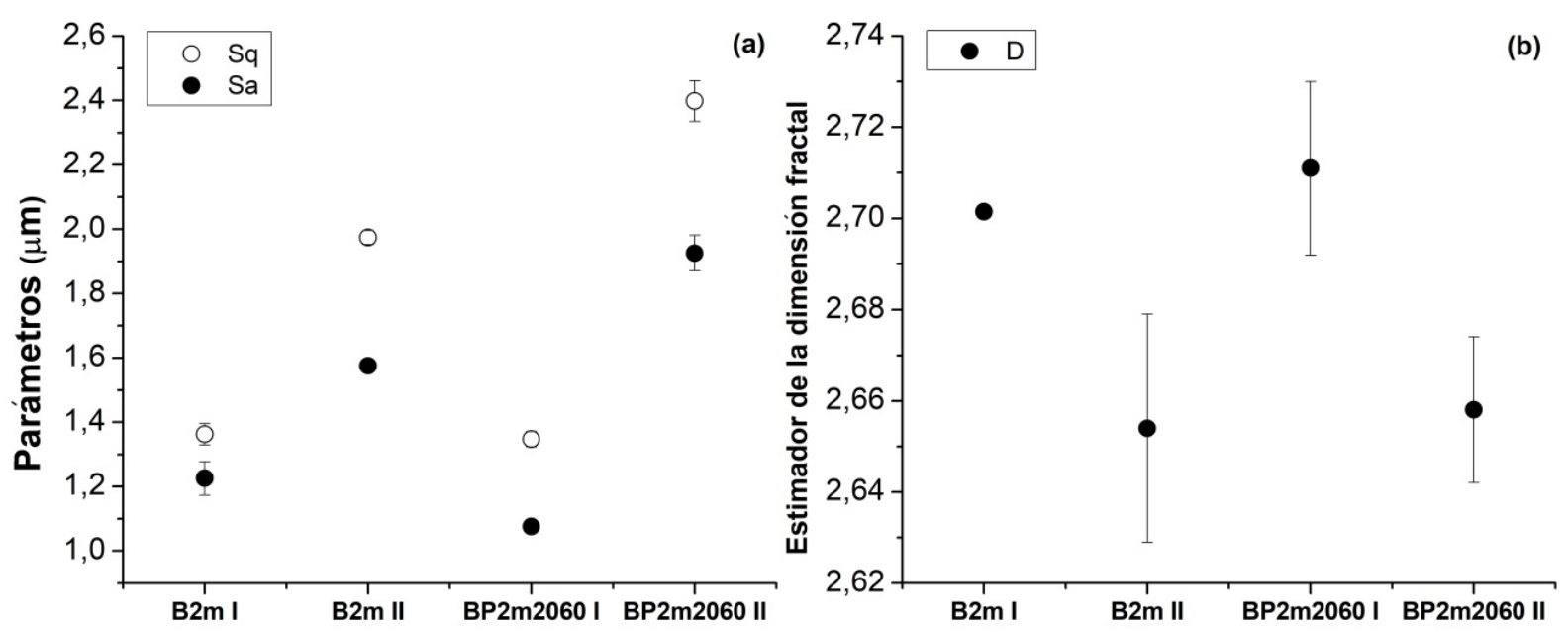

Figura 4.4: (a) Parámetros Sq y Sa y (b) Estimador D de dimensión fractal para B2min (I) y (II) y, BP2m2060 (I) y (II).

Aunque la rugosidad de las muestras obtenidas en la tanda (II) fue mayor en comparación con las muestras de la tanda (I), el parámetro D mostró que aquéllas presentan una superficie con deformaciones más suaves que éstas. Estos resultados indican que, si bien los tratamientos (I) y (II) fueron realizados a 2 minutos y $5 \mathrm{~kg} / \mathrm{cm}^{2}$ por el mismo proveedor industrial, hubo variación en otros parámetros en el proceso de blastinizado en ambas tandas, como el ángulo de incidencia, la distancia de aplicación, la forma y/o el tamaño de las partículas, etc. [105,108,110,127].

En la figura 4.5 se analizó el efecto de diferentes tratamientos de pasivado químico sobre la topografía en la condición de blastinizado B2m (II). Sólo los tratamientos de pasivado químico 2030 y 2060 generaron un aumento de la rugosidad superficial en comparación con la muestra sin pasivado (figura 4.4a). La figura 4.5b muestra la relación entre Ssk y Svi para estas condiciones superficiales. Se analizó la relación de estos dos parámetros ya que según el estudio realizado por Méndez-Vilas y otros [132] en muestras pulidas y blastinizadas, los autores encontraron una fuerte correlación entre estos dos parámetros donde obtienen como resultado que cuanto menor es Ssk, mayor es el valor de Svi, en concordancia con los resultados que se muestran en la figura 4.5b. Además, sugieren el uso de estos parámetros en combinación con ensayos de ángulo de contacto para estudiar la mojabilidad de superficies con distintas topografías. 

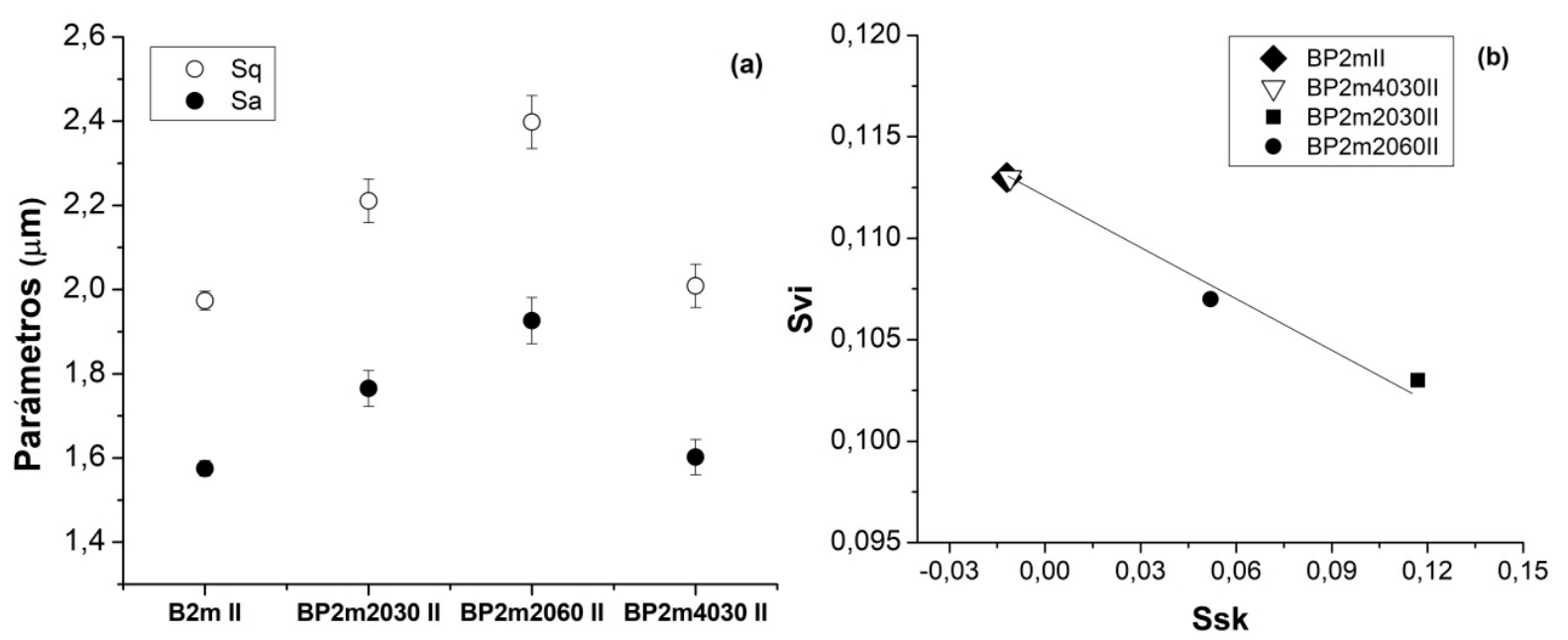

Figura 4.5: Pasivación del ácido nítrico en muestras de 2 min de blastinizado (tanda (II)). (a) Efecto sobre los parámetros Sq y Sa; (b) relación entre Svi y Ssk.

Se observó que las superficies obtenidas en las muestras pasivadas BP2m2030 (II) o BP2m2060 (II) mostraron menor proporción de valles (Ssk) y un menor valor del índice de retención de líquido en el valle (Svi) que las muestras B2m (II) y BP2m4030 (II). Estos resultados se pueden interpretar considerando que el tratamiento de pasivado con $\mathrm{HNO}_{3}$ al $20 \%$ atacaría los valles. Este ataque eliminaría las irregularidades como crestas dentro de los valles y los haría más profundos. El resultado final es un aumento de Sa y Sq (figura 4.5a). Además, la curva de bearing se reajustó cuando se modificó la superficie, y por lo tanto se cambió la relación de volumen considerada como valle. Este cambio provoca una disminución en Svi y un aumento en Sci (tabla 4.4). 
Tabla 4.3: Valores de parámetros de amplitud y parámetros funcionales obtenidos con SEM-EZEImage en muestras de la tanda (I). Los números entre paréntesis indican el error en la última cifra significativa.

\begin{tabular}{|c|c|c|c|c|c|c|}
\hline Parámetro & B30s(I) & B2m(I) & B5m(I) & $\begin{array}{c}\text { BP30s } \\
2060(\mathrm{I})\end{array}$ & $\begin{array}{c}\text { BP2m } \\
2060(\mathrm{I})\end{array}$ & $\begin{array}{c}\text { BP5m } \\
2060(\mathrm{I})\end{array}$ \\
\hline Sq $(\mu \mathrm{m})$ & $1,10(1)$ & $1,36(3)$ & $1,27(2)$ & $1,09(1)$ & $1,35(2)$ & $1,29(3)$ \\
\hline Sa $(\mu \mathrm{m})$ & $0,868(8)$ & $1,23(5)$ & $1,02(2)$ & $0,860(7)$ & $1,08(2)$ & $1,03(3)$ \\
\hline $\mathrm{Ssk}$ & $0,05(4)$ & $0,07(5)$ & $0,02(3)$ & $0,01(9)$ & $0,04(3)$ & $0,02(4)$ \\
\hline $\mathrm{Sku}$ & $3,7(2)$ & $3,4(3)$ & $2,95(5)$ & $4,1(4)$ & $3,04(8)$ & $3,15(8)$ \\
\hline $\mathrm{Sz}(\mu \mathrm{m})$ & $17,1(6)$ & $15(1)$ & $12,8(5)$ & $17(1)$ & $14,3(9)$ & $14,0(6)$ \\
\hline $\mathrm{Sbi}$ & $0,618(6)$ & $0,601(7)$ & $0,608(5)$ & $0,619(5)$ & $0,603(5)$ & $0,611(5)$ \\
\hline Sci & $1,54(2)$ & $1,58(2)$ & $1,56(2)$ & $1,54(2)$ & $1,58(2)$ & $1,55(2)$ \\
\hline Svi & $0,112(2)$ & $0,108(3)$ & $0,110(2)$ & $0,112(3)$ & $0,111(3)$ & $0,112(3)$ \\
\hline $\mathrm{D}$ & $2,695(9)$ & $2,702(1)$ & $2,70(1)$ & $2,696(7)$ & $2,71(2)$ & $2,70(1)$ \\
\hline
\end{tabular}

Tabla 4.4: Valores de parámetros de amplitud y parámetros funcionales obtenidos con SEM-EZEImage en muestras de la tanda (II). Los números entre paréntesis indican el error en la última cifra significativa.

\begin{tabular}{|c|c|c|c|c|c|c|}
\hline Parámetro & B2m(II) & $\begin{array}{c}\text { BP2m } \\
\text { 2030(II) }\end{array}$ & $\begin{array}{c}\text { BP2m } \\
\text { 2060(II) }\end{array}$ & $\begin{array}{c}\text { BP2m } \\
4030(\mathrm{II})\end{array}$ & B15m(II) & $\begin{array}{c}\text { BP15m } \\
2060(\mathrm{II})\end{array}$ \\
\hline Sq $(\mu \mathrm{m})$ & $1,97(2)$ & $2,21(5)$ & $2,40(6)$ & $2,01(5)$ & $2,35(9)$ & $2,27(5)$ \\
\hline Sa $(\mu \mathrm{m})$ & $1,58(2)$ & $1,77(4)$ & $1,93(6)$ & $1,60(4)$ & $1,86(7)$ & $1,80(4)$ \\
\hline Ssk & $-0,01(4)$ & $0,12(4)$ & $0,05(5)$ & $-0,01(5)$ & $-0,05(7)$ & $-0,12(6)$ \\
\hline Sku & $3,2(1)$ & $3,09(9)$ & $3,03(7)$ & $3,03(4)$ & $3,3(1)$ & $3,3(1)$ \\
\hline Sz $(\mu \mathrm{m})$ & $17,3(8)$ & $20,0(9)$ & $22,5(8)$ & $17,3(7)$ & $23(2)$ & $14(1)$ \\
\hline Sbi & $0,607(5)$ & $0,593(5)$ & $0,601(5)$ & $0,601(7)$ & $0,607(8)$ & $0,627(8)$ \\
\hline Sci & $1,56(2)$ & $1,61(2)$ & $1,59(2)$ & $1,58(1)$ & $1,56(3)$ & $1,50(2)$ \\
\hline Svi & $0,113(2)$ & $0,103(3)$ & $0,107(3)$ & $0,113(2)$ & $0,114(5)$ & $0,121(4)$ \\
\hline D & $2,65(3)$ & $2,64(3)$ & $2,66(2)$ & $2,66(2)$ & $2,67(2)$ & $2,67(2)$ \\
\hline
\end{tabular}

A partir de la figura 4.4a se observó que en la tanda (I), la aplicación del tratamiento de pasivado químico 2060 no generó la misma intensidad de cambios en la superficie que en la tanda (II). Esto se verificó mediante la comparación de los parámetros Sa y Sq, entre las condiciones B2m(I) y BP2m2060(I) y entre las condiciones B2m(II) y B2m2060(II). Esto lleva a pensar que las superficies resultantes del blastinizado podrían variar en su reactividad frente al ataque con ácido nítrico. Los resultados del 
pasivado químico indican que no se podrían generar superficies finales similares a partir de superficies iniciales que sean marcadamente diferentes.

Las figuras 4.6a y 4.6b muestran los parámetros de rugosidad en función del tiempo de blastinizado. Los valores se normalizaron al valor de 30 seg para la tanda (I) y al valor de 2 min para la tanda (II) (tablas 4.3 y 4.4). En la tanda (I), se observaron valores de parámetros de rugosidad máximos y mínimos a los $2 \mathrm{~min}$. En lo que sigue se denotan todos los parámetros normalizados con su nomenclatura previa más una letra " $\mathrm{n}$ " al final. El aumento en San y Sqn después de 30 segundos de blastinizado indica que las diferencias en la altura superficial aumentan mientras que la disminución en Skun $(S k u=4,1(4)$ para la muestra BP30s2060) muestra que la distribución de picos es más gaussiana. No se observaron cambios significativos después de 5 minutos de blastinizado teniendo en cuenta las incertezas en los parámetros. Este comportamiento, también observado para la tanda (II) en el periodo de tiempo de blastinizado de $2 \mathrm{~min}$ a $15 \mathrm{~min}$, se debe a un fenómeno conocido como overblasting [108,111]. Después de algún tiempo de blastinizado, la capa superficial fue endurecida y no fue posible un aumento significativo en la rugosidad por deformación plástica. Además, los picos en la superficie se comenzaron a achatar. Este efecto se puede observar a través de las variaciones en el parámetro Sz en ambas tandas (I y II), donde los valores disminuyeron con el aumento del tiempo de blastinizado (tablas 4.3 y 4.4 ). 

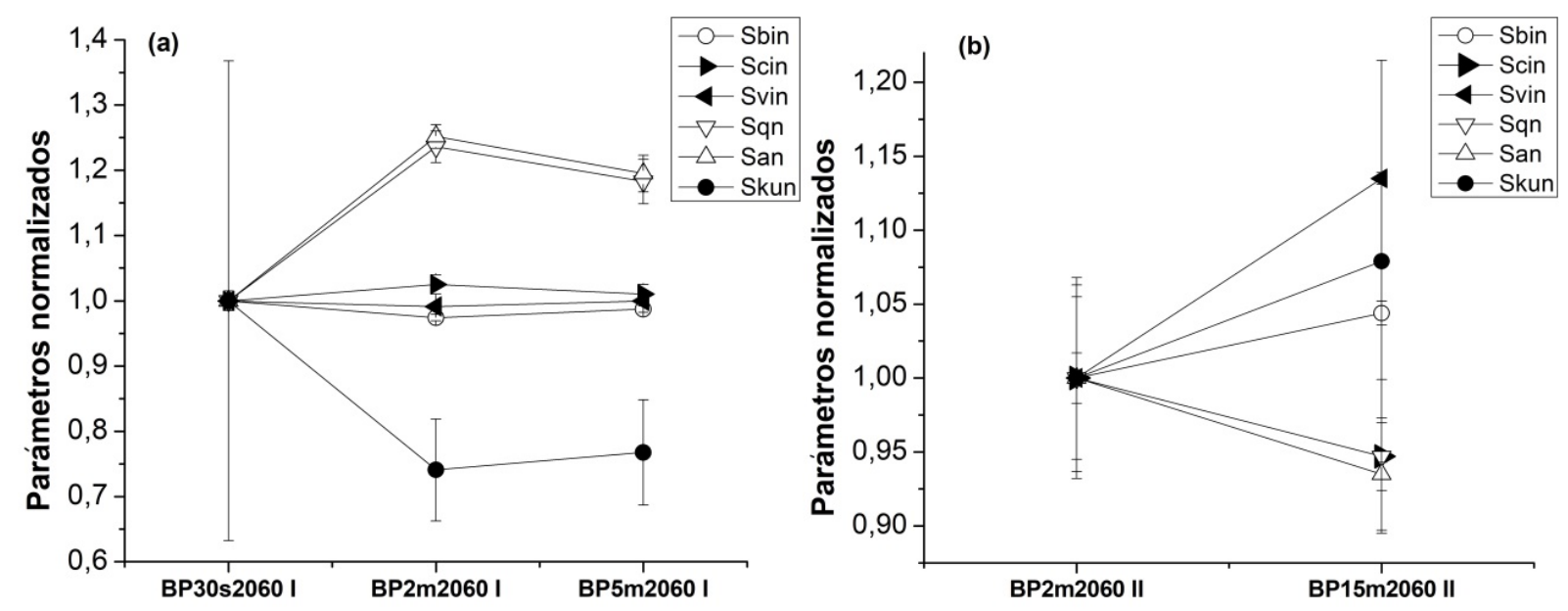

Figura 4.6: (a) Parámetros de rugosidad normalizados a $30 \mathrm{seg}$. Valor en función del tiempo de blastinizado con el mismo tratamiento de pasivado para muestras realizadas en la tanda (I); (b) idem (a) pero realizado en la tanda (II) y normalizado a un valor de $2 \mathrm{~min}$.

Con respecto a los parámetros funcionales, se observa que en la tanda (I) los parámetros Sbin y Scin son muy sensibles a las diferentes características superficiales de las muestras, mientras que en la tanda (II) los parámetros más sensibles son Svin y Scin. Arvidsson y otros [101] encontraron que los parámetros más sensibles para las superficies con blastinizado fueron Sbi y Sci, aunque propusieron que sólo Sci se debería tener en cuenta para la caracterización de la superficie. En este trabajo Sci varía simultáneamente con Sbi o Svi y, en consecuencia, el análisis de dos parámetros combinados, es decir, Sci-Sbi o Sci-Svi, proporciona más información. En definitiva, es significativo estudiar todos los parámetros que se modifican, ya sea de amplitud o funcional, ya que esto permite una mejor descripción cualitativa de los cambios que experimentan los picos, valles y núcleos según las diferentes topografías. Por ejemplo, con respecto al análisis del efecto del pasivado químico en la tanda (II), la variación de los parámetros Svi y Sci sucedió con una variación de los parámetros Ssk y Sa o Ssk y Sq (tabla 4.4).

De acuerdo con los resultados presentados, las variaciones de Sa y Sq fueron tan similares que sería suficiente utilizar sólo uno de ellos en relación con cambios en la rugosidad resultante de un tratamiento de blastinizado. Sin embargo, en algunos 
casos es necesario combinar Sa o Sq con otros parámetros como el estimador de dimensión fractal D y parámetros funcionales, como se mostró en el caso de las muestras B2m(I)-(II) y BP2m2060(I)-(II) (figura 4.4) y en el caso de las muestras B2m(II) y BP2m(II) con distintas condiciones de pasivado químico (figura 4.5).

\subsubsection{Medidas de microdureza}

El examen de las secciones transversales de las muestras B30s (I) y B2m (I) mediante SEM (figura 4.7) reveló la presencia de una morfología irregular deformada en la subsuperficie. Esta zona deformada aumentó en espesor durante tiempos de blastinizado superiores a 30 segundos. Micrografías de SEM del resto de las muestras a diferentes tiempos de blastinizado mostraron la misma morfología que B2m (I). El proceso de blastinizado genera una fuerte deformación plástica en la superficie, que afecta a la microestructura y a las propiedades mecánicas de la superficie y subsuperficie del material. A medida que aumenta la deformación superficial, se incrementan los defectos cristalinos (dislocaciones, maclas, etc.). La existencia de una alta densidad de dislocaciones dificulta sus movimientos y produce un aumento de la dureza del material $[99,104,133]$.

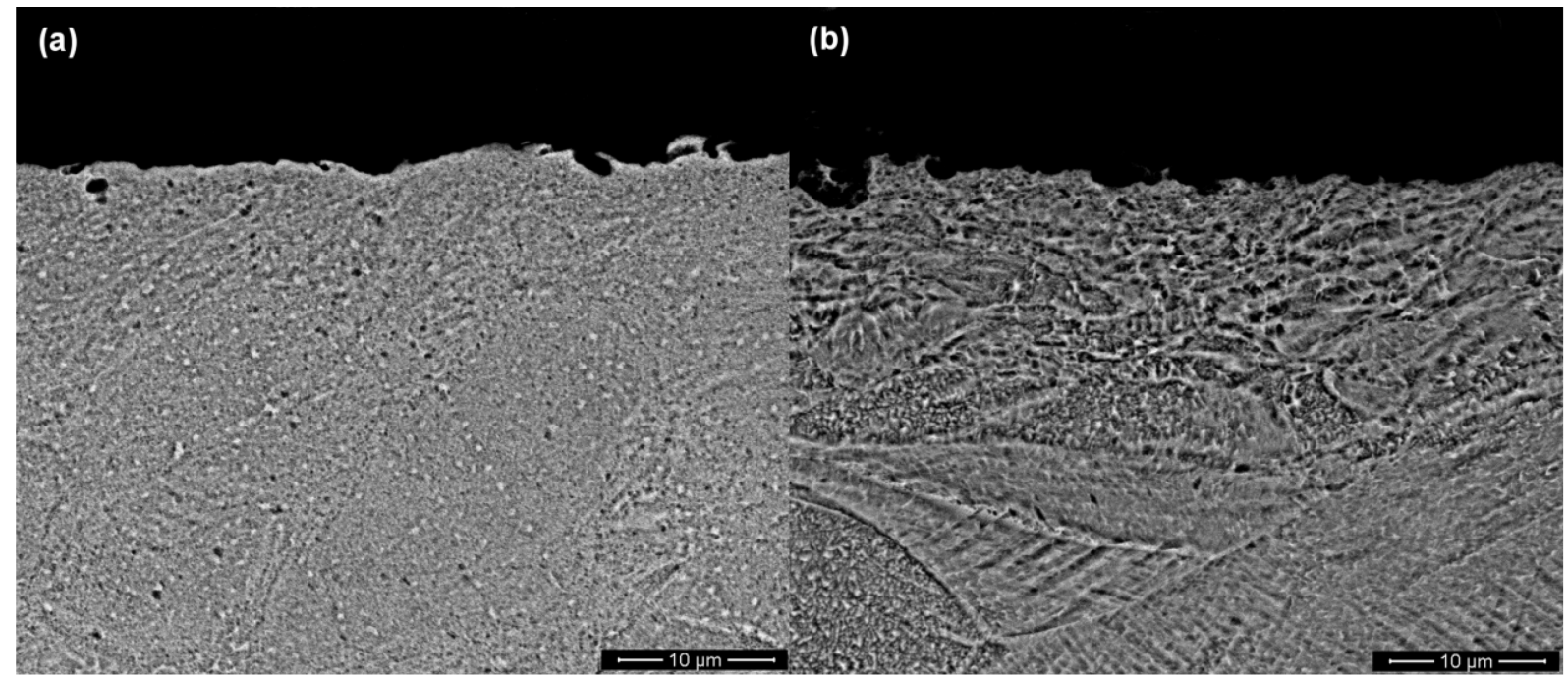

Figura 4.7: Imágenes SEM de la sección transversal de las muestras (a) B30s (I) y (b) B2m (I). 
En la tabla 4.5 se muestran los valores de microdureza superficial para diferentes tiempos de blastinizado y tandas de preparación junto con el valor para la condición MP. La dureza de la superficie se incrementó con el tiempo de blastinizado en cada tanda y fue siempre mayor que la medida para MP. La dureza superficial disminuyó de B2m (I) a B2m (II), lo que puede ser el resultado de haber utilizado diferentes parámetros de tratamiento, como por ejemplo el ángulo de blastinizado [108,110]. Además, si los parámetros del tratamiento hubieran sido los mismos en las dos tandas, la dureza superficial de B15m (II) debería haber sido mayor que B5m (I) [111].

Tabla 4.5: Valores de microdureza superficial y desviaciones estándar para diferentes tiempos de blastinizado y tandas de preparación y para condiciones de MP.

\begin{tabular}{|c|c|c|c|c|c|c|}
\hline & MP & B30s(I) & B2m(I) & B5m(I) & B2m(II) & B15m(II) \\
\hline $\begin{array}{c}\text { Dureza } \\
\text { (HV) } \\
\text { Carga 10 gf }\end{array}$ & $301 \pm 12$ & $461 \pm 10$ & $500 \pm 11$ & $539 \pm 12$ & $447 \pm 11$ & $530 \pm 11$ \\
\hline
\end{tabular}

En la figura 4.8 se puede observar la distribución de la dureza de la sección transversal de las muestras blastinizadas medidas a lo largo de una línea perpendicular a la superficie. En todos los casos se consideró el valor de dureza de la muestra MP como el límite de la zona afectada por el tratamiento (tabla 4.5). Las medidas de dureza disminuyen gradualmente con el aumento de la distancia desde la superficie para todos los diferentes tiempos y tandas de blastinizado. La penetración en profundidad de la capa endurecida osciló entre 40 y $60 \mu \mathrm{m}$ dependiendo de la condición de blastinizado. 

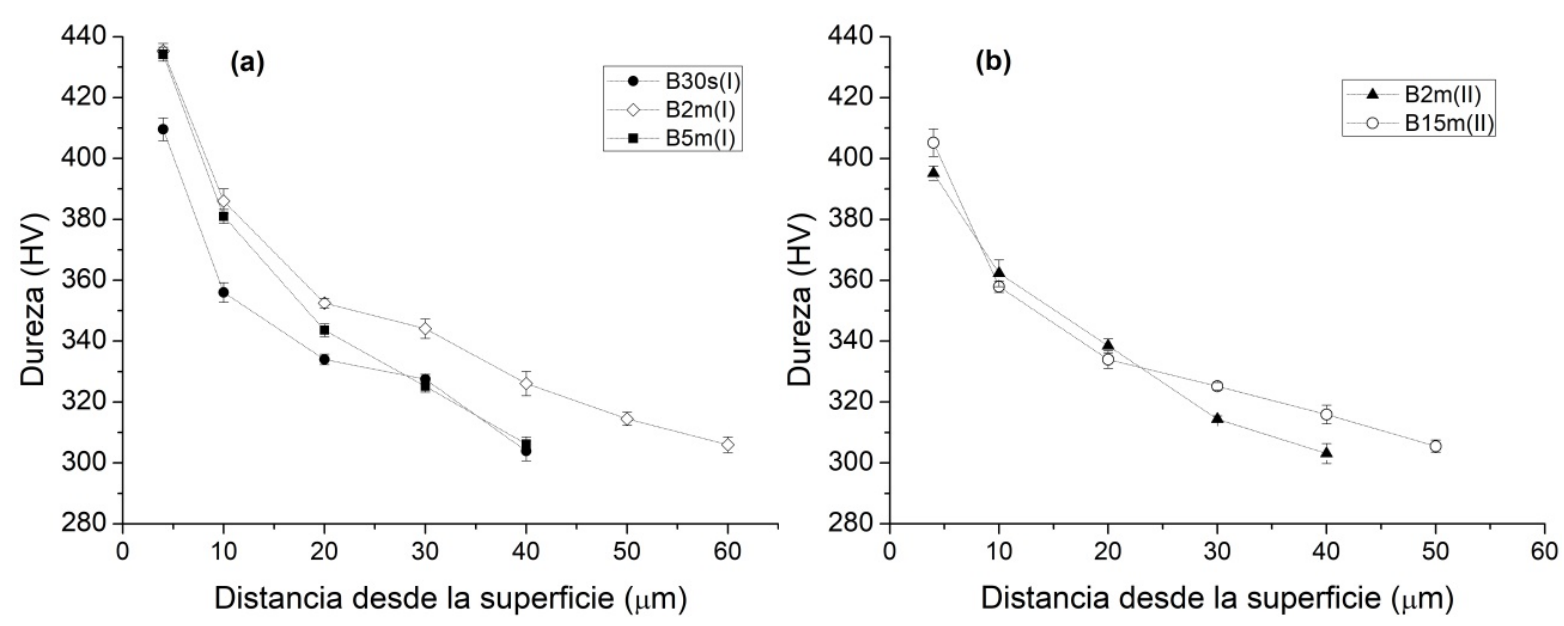

Figura 4.8: Perfil de microdureza HV (con carga de 10gf) de: (a) tiempos de blastinizado de $30 \mathrm{seg}, 2 \mathrm{~min}$ y 5 min para las muestras de la tanda (I) y (b) tiempos de blastinizado de 2 min y 15 min para las muestras de la tanda (II).

En la figura 4.8a se puede observar que en la muestra B2m (I) la capa endurecida se extiende hasta una profundidad mayor que en las muestras B30s (I) y B5m (I). Sin embargo, B5m (I) debería haber exhibido la mayor profundidad de penetración o al menos igual a B2m (I) si los parámetros del tratamiento de blastinizado hubieran sido los mismos en ambas muestras. Cabe destacar que, si se varía el ángulo de incidencia sin cambiar los otros parámetros de blastinizado, la profundidad de penetración de la dureza también sufriría una variación [108]. Además, las muestras B2m (I) y B5m (I) presentan valores de dureza similares cerca de la superficie. Por otro lado, para las muestras tratadas en la tanda (II) la dureza disminuyó gradualmente con la distancia desde la superficie, como se muestra en la figura 4.8b. La figura 4.9 compara la distribución de la dureza de la sección transversal de muestras blastinizadas durante 2 min en las dos tandas, es decir, B2m (I) y B2m (II). La primera presenta una mayor dureza cerca de la superficie y mayor profundidad de penetración que B2m (II). La dureza y la profundidad de penetración deberían ser iguales de una tanda a otra si se hubiese realizado el tratamiento bajo los mismos los parámetros de blastinizado. Este resultado, sumado al hecho de que B5m (I) no mostró la tendencia esperada, es decir, igual o mayor profundidad de penetración de dureza que B2m (I), sugiere que los parámetros de blastinizado no sólo cambiaron de una tanda a otra sino también de una condición a otra dentro de la misma tanda. 


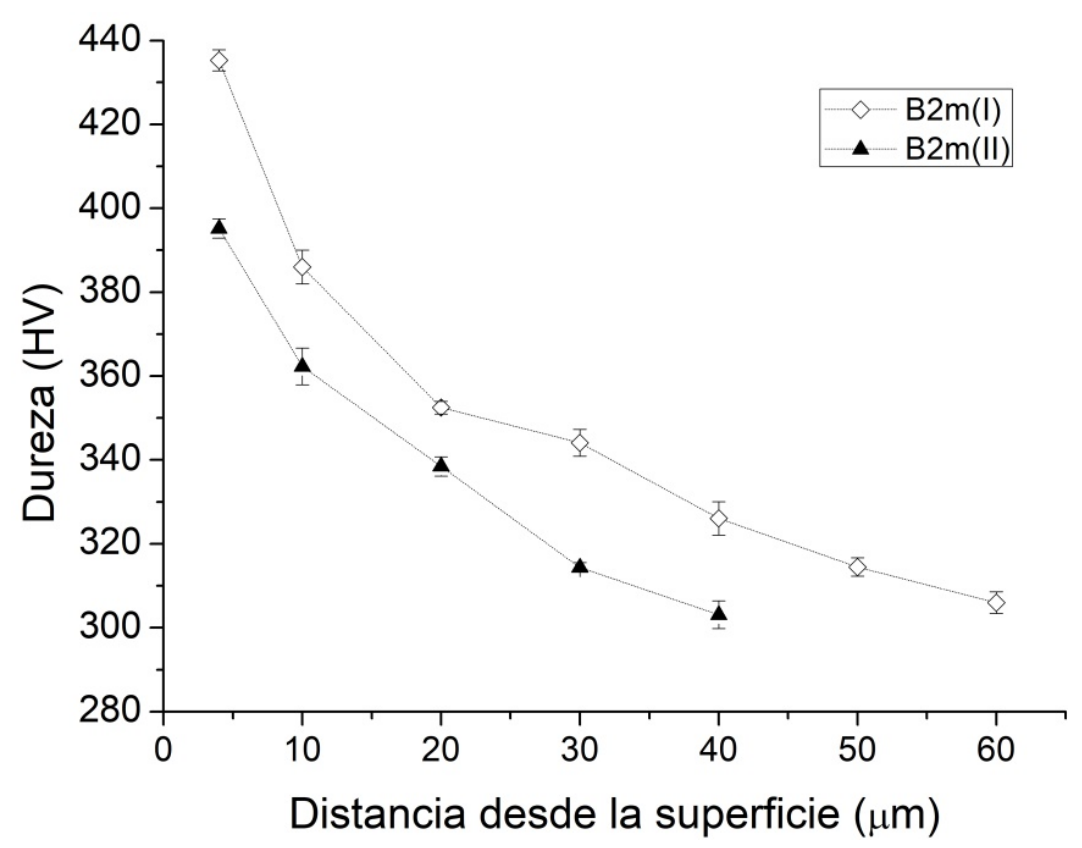

Figura 4.9: Perfil de microdureza HV (con carga de 10 gf) de 2 min de tiempo de blastinizado para las muestras preparadas en las tandas (I) y (II).

\subsubsection{Caracterización electroquímica}

Las curvas de polarización CP que se pueden observar en la figura 4.10 muestran, durante el barrido anódico, los potenciales de corrosión de aproximadamente $-1,0 \mathrm{~V}$ seguidos por una región de pasividad y finalmente, la iniciación y propagación de la corrosión por picado en potenciales más anódicos que Ep. Por razones de claridad, los bucles de histéresis obtenidos durante los barridos catódicos no se muestran en la figura 4.10. Las curvas de polarización para las condiciones MP y MPP2060 se pueden ver en el gráfico insertado en la figura 4.10 y confirman el efecto beneficioso de la etapa de pasivado químico. En particular, para la condición superficial MPP2060 se puede observar un pico de corriente en la curva de polarización CP que se inicia a aproximadamente 0,6 V. Este pico de corriente está relacionado con la oxidación transpasiva de especies $\mathrm{Cr}$ (III) en el óxido a especies $\mathrm{Cr}$ (IV). Ep no puede ser detectado, lo que indica que bajo las variables experimentales seleccionadas (composición de electrolitos y temperatura), esta condición superficial tiene una excelente resistencia a la corrosión por picado. En este estudio el análisis de 
corrosión se centró (como es típico para todos los aceros inoxidables) a la corrosión localizada que podría tener lugar en el caso de un aumento en el poder oxidante del medio. Claramente, los procesos de corrosión que se producen con un potencial de corrosión que se encuentra dentro de la región pasiva (figura 4.10), no se espera que sean de principal preocupación. El comportamiento transpasivo sólo puede detectarse en conexión con la muestra MPP2060 porque para el resto de las condiciones estudiadas la corrosión por picado comienza en los potenciales más activos durante el barrido anódico. En otras palabras, la descomposición local de la capa pasiva tiene lugar en sitios de iniciación de pits a potenciales anódicos menores que el rango de potencial para la oxidación transpasiva, y la corriente aumenta rápidamente debido a la disolución anódica de la aleación dentro de los pits.

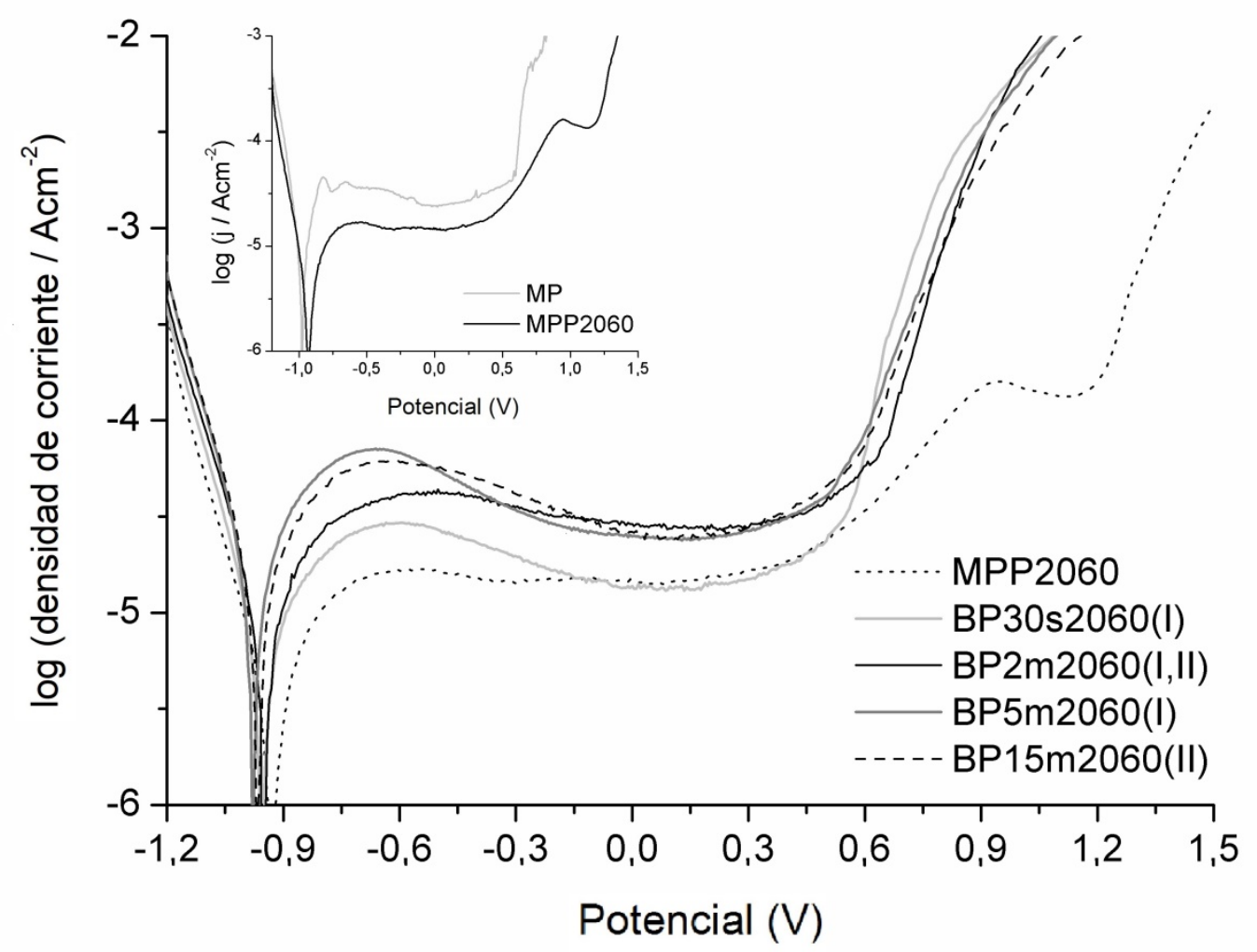

Figura 4.10: Curvas de polarización de las muestras blastinizadas y pasivadas para diferentes tiempos y de muestras pulidas mecánicamente y pasivadas. El gráfico insertado muestra las curvas de polarización de las muestras MPP2060 y MP (ver la tabla 4.1 para la nomenclatura de la muestra). 
La figura 4.11 muestra los valores de potencial de picado medidos para los diferentes tratamientos de superficie como se indica en el eje de las abscisas del gráfico. Los valores de Ep para las muestras blastinizadas y pasivadas en la tanda (I) que se observan en la figura 4.11 disminuyen de acuerdo con la siguiente secuencia BP2m2060 (I)> BP5m2060 (I)> BP30s2060 (I). La condición de BP2m2060 (I) se comparó con la condición de BP2m2060 (II) puesto que el tratamiento de blastinizado se realizó en dos momentos diferentes. No hay diferencia significativa entre los potenciales de picado medidos para cada una de las dos condiciones y, en consecuencia, ambos serán renombrados BP2m2060 (I, II) en el texto a continuación.

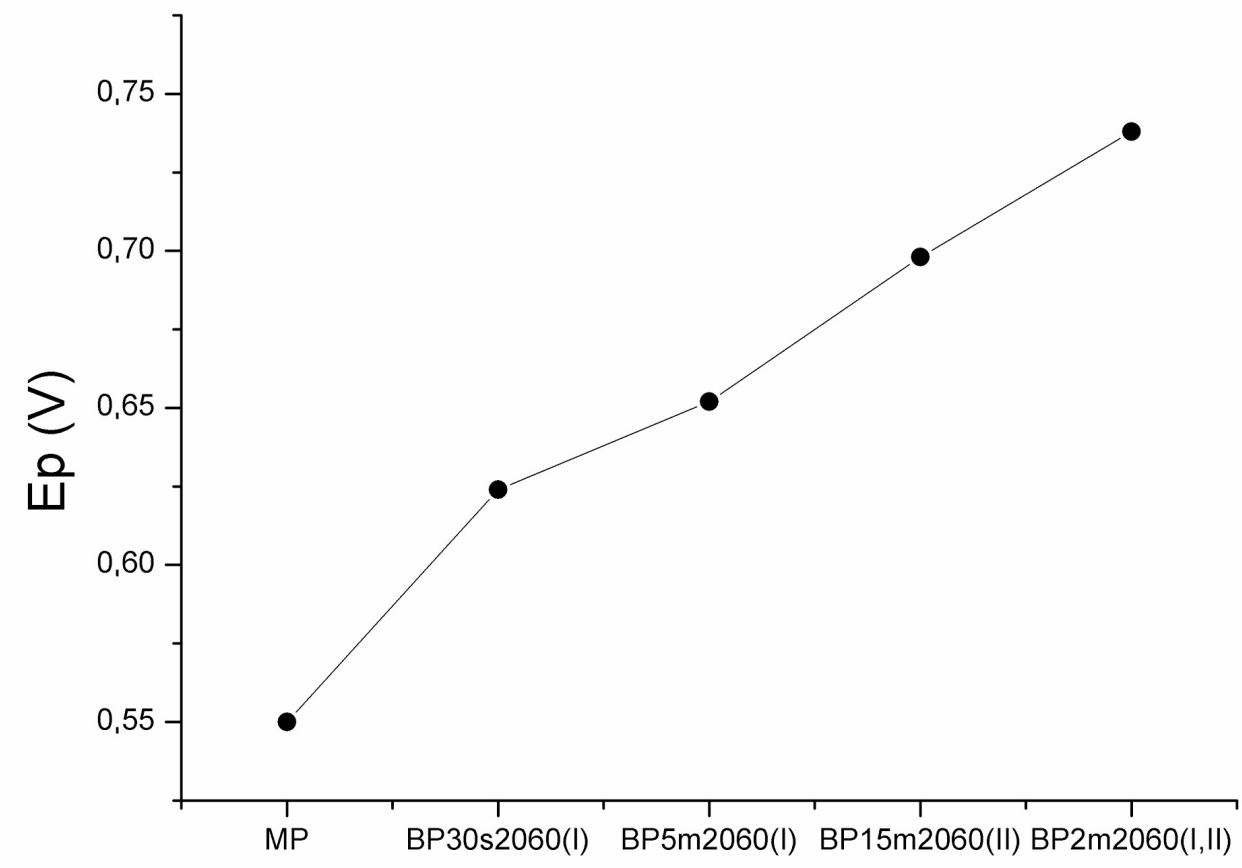

Figura 4.11: Potencial de picado Ep para muestras químicamente pasivadas y blastinizadas para diferentes tiempos así como muestras de pulido mecánico (ver tabla 4.1 para las definiciones de las abreviaturas en el eje de abscisas).

La condición BP15m2060 (II) muestra un potencial de picado menor que BP2m2060 (I, II) pero mayor que B5m2060 (I) (figura 4.11). Esto significa que 2 min es el tiempo de blastinizado óptimo para aumentar la resistencia a la corrosión por picado en el sistema estudiado. 
El blastinizado con tratamiento de pasivado químico disminuyó su resistencia a la corrosión localizada del AISI 316 LVM en comparación con la condición MPP2060. Cabe destacar que los estudios sobre la corrosión por picado en muestras con blastinizado [102,110,113] mostraron que el efecto del blastinizado sin posterior pasivación genera un desplazamiento de los valores de Ep en una dirección menos noble.

\subsubsection{Discusión general}

Como se señaló a lo largo de este capítulo, el blastinizado aumenta la rugosidad del implante y también aumenta la dureza superficial. Dado que este proceso de modificación de superficie no puede producir una superficie completamente pasivada y libre de impurezas, de acuerdo con la norma ASTM 86-12, es esencial que el tratamiento de superficie incluya una etapa de pasivado químico posterior para aumentar la resistencia a la corrosión del implante. Dicho tratamiento da como resultado las propiedades superficiales requeridas en los implantes, es decir, alta resistencia a la corrosión y al desgaste y biocompatibilidad mejorada. Esto, a su vez, preservaría las propiedades de volumen del biomaterial y reduciría significativamente los costos.

A partir de los resultados presentados en este capítulo, se puede observar que los parámetros del proceso de blastinizado no sólo cambian de una tanda a otra, sino también de una condición a otra dentro de la misma tanda. Esto puede conducir a diferentes topografías y propiedades mecánicas para diferentes lotes de fabricación $\mathrm{y}$, en consecuencia, a modificaciones en el comportamiento del implante y sus interacciones con el tejido vivo. Debido a eso, es importante llevar a cabo un control de calidad de los implantes fabricados, a través de técnicas tales como medición de rugosidad, dureza y ensayos de resistencia a la corrosión localizada.

Existen varias características de superficie, descritas con los diferentes parámetros de rugosidad, que pueden provocar un incremento en el potencial de picado y se 
encontró que estas características están relacionadas entre sí. Además, se observó que cuanto más gaussiana es la superficie (disminución de Sku hacia valores cercanos a 3) más alto es el valor de Ep (tablas 4.3, 4.4 y figura 4.11). A su vez, la simetría de la rugosidad de la superficie causó un aumento en la distancia entre los picos y valles (aumento en San y Sqn), y este efecto fue acompañado por una disminución de la capacidad de retención de líquidos en el valle, pero un aumento en el núcleo. De manera similar, como se explica en la sección 4.3.1, con respecto al efecto del pasivado químico en las superficies resultantes (figura 4.5), los cambios en la topografía que pueden disminuir la susceptibilidad a la corrosión por picado están relacionados con ciertas características superficiales del valle y núcleo. Las características superficiales que inducen valores más pequeños de Ep implican un mayor número de imperfecciones con un núcleo más estrecho (valores más pequeños de Scin y valores más altos de Svin). En este caso, el intercambio de electrolitos dentro del valle será inhibido y favorecería condiciones de bloqueo. La reducción de estas imperfecciones y el aumento de Scin, contribuye al intercambio de electrolitos $\mathrm{y}$, en consecuencia, a una mayor resistencia a la corrosión por picado. Estas conclusiones son similares a las de Faller y otros [113], aunque estos autores utilizaron perfiles de rugosidad y sólo valores de Ra.

\subsection{Conclusiones}

A lo largo de este capítulo se destacó la importancia de seleccionar un conjunto adecuado de parámetros de rugosidad para caracterizar los tratamientos superficiales efectuados en biomateriales. Esta selección permite correlacionar los parámetros de diseño de los tratamientos con las superficies finales y verificar la reproducibilidad de las superficies. Parámetros de rugosidad como Sa o Sq (fácilmente medibles con un perfilómetro) y la dureza proporcionarían métodos cuantitativos satisfactorios de monitoreo en línea del proceso de blastinizado en lugar de los métodos cualitativos actualmente utilizados basados en operadores. Sin 
embargo, para analizar cambios en la topografía, puede ser necesario combinar Sa o Sq con otros parámetros como la dimensión fractal D y parámetros funcionales.

Desde el punto de vista de la corrosión por picado, las condiciones óptimas de tratamiento superficial para el acero inoxidable ASTM F139 para implantes en solución de Ringer desaireada a $37 \pm 1^{\circ} \mathrm{C}$ corresponden a un tiempo de blastinizado de $2 \mathrm{~min}$. La realización de un paso de pasivado posterior al blastinizado es particularmente importante para evitar perjudicar la resistencia al picado de las muestras blastinizadas. En este estudio, los mejores resultados se obtuvieron mediante pasivado químico en $20 \%$ de $\mathrm{HNO}_{3}$ (v/v) durante $60 \mathrm{~min}$. 


\title{
CAPÍTULO 5
}

\section{BLASTINIZADO Y ANODIZADO POR PLASMA QUÍMICO EN TITANIO C.P. PARA IMPLANTES: ESTUDIO DE LA RUGOSIDAD SUPERFICIAL, ADHERENCIA Y DUREZA}

\begin{abstract}
Los implantes de titanio c.p. comprendidos en la norma ASTM F67-06 tienen una extensa aplicación como biomateriales debido a que combinan biocompatibilidad y resistencia a la corrosión superiores a los aceros inoxidables. Teniendo en cuenta que la respuesta biológica se encuentra estrechamente relacionada con las propiedades superficiales, una de las áreas más importantes en el estudio de los implantes es la caracterización de modificaciones superficiales. En el presente capítulo se realizaron estudios de rugosidad, adherencia y microdureza Vickers de implantes dentales de titanio c.p. sometidos a tratamientos de blastinizado y anodizado por plasma químico. Las superficies resultantes se compararon con superficies con el mismo tratamiento de anodizado pero sin la aplicación de un blastinizado anterior. Los resultados obtenidos indican que el parámetro del proceso de blastinizado que genera variación en la rugosidad es el tamaño de granalla y que en el anodizado por plasma químico, la aplicación previa del blastinizado mejora la adherencia del recubrimiento generado. También se encontró que se generan variaciones en la adherencia del recubrimiento por la degradación de los insumos utilizados para la realización de los tratamientos superficiales.
\end{abstract}

\subsection{Introducción}

En la actualidad, el titanio es el biomaterial de mayor uso como implante dental y ortopédico. La amplia aplicación de este biomaterial como implante dental se debe a que es uno de los metales más biocompatibles con una excelente combinación de resistencia a la corrosión, alto desempeño mecánico [16]; y su característica más especial: su capacidad de fusionarse con el hueso, un proceso que se conoce como osteointegración [23]. Su relativo bajo módulo elástico, su alta relación resistencia mecánica/densidad, su alto desempeño frente a solicitaciones de fatiga, y todo esto junto a gran resistencia a la corrosión y biocompatibilidad; vuelven a este biomaterial como una referencia superior en aplicaciones estructurales ortopédicas y de traumatología, comparado con otros metales como las aleaciones base cobalto y los aceros inoxidables. La resistencia del titanio a la corrosión se debe a su capacidad 
para formar una capa de óxido protectora, bioinerte, químicamente estable, continua y altamente adherente sobre su superficie [14].

Dentro de las designaciones de titanio más utilizadas como biomateriales se encuentran el titanio c.p. (comercialmente puro) y las aleaciones de titanio con aluminio y vanadio como elementos de aleación. El titanio cp. (ASTM F67-13) es categorizado en 4 grados, donde el porcentaje en peso (\%wt) de inclusiones se ve incrementado desde el Grado I al IV alcanzando un máximo de 0,7\%wt. Los niveles de $\mathrm{O}(0,18-1,4 \% w t), \quad \mathrm{N}(0,03-0,05 \% w t)$ y $\mathrm{Fe}(0,2-0,5 \% w t)$ son monitoreados estrictamente debido a que afectan notablemente la tenacidad y ductilidad del titanio. En el caso de las aleaciones de titanio que poseen mejores propiedades mecánicas que las variantes de titanio puro, las más utilizadas como biomateriales son el Ti6Al4V y Ti6Al4V ELI según norma ASTM F1472-14 y ASTM F136-13, respectivamente.

Se encuentra ampliamente documentado en la bibliografía que el titanio es un material osteoconductor, ya que permite la osteointegración por aposición de tejido óseo sobre su superficie (con mínima y/o nula formación de tejido conectivo o fibroso) [23]. No obstante, su capacidad de inducir formación de hueso es bastante pobre o nula, a diferencia de los materiales bioactivos, como las apatitas, que en determinadas condiciones presentan características osteoinductoras, es decir, inducen o estimulan una diferenciación de células madre a células osteogénicas $[23,25]$. La bioactividad se define como la propiedad que provoca una respuesta biológica específica en la interfaz de un material, que resulta en la formación de un enlace químico entre el tejido y el material [134]. Sin embargo, mediante diferentes tratamientos superficiales realizados sobre el titanio y sus aleaciones se pueden producir superficies bioactivas [12], como es el caso del proceso de anodizado por plasma químico (APQ), también conocido como MAO (siglas en inglés de micro-arc oxidation), en soluciones electrolíticas con calcio y fósforo. Este tratamiento genera un recubrimiento cerámico bioactivo de óxido de titanio enriquecido en calcio y fósforo 
que posee una elevada microdureza, adhesión al metal base y mayor resistencia al desgaste [135].

La oxidación anódica (o anodizado) es un método ampliamente utilizado que permite producir diferentes tipos de películas de óxidos protectores sobre metales. Las características topográficas y composicionales de dichas películas dependen de los parámetros del tratamiento de anodizado como la composición del electrolito (ácidos, básicos y con sales disueltas), densidad de corriente o voltaje aplicado y tiempo [135].

Si el tratamiento de anodizado se lleva a cabo a voltajes superiores a $100 \mathrm{~V}$ aproximadamente, el proceso conducirá a un aumento en la evolución de gases y, frecuentemente, de chispas. Este tipo de anodizado es conocido como anodizado por plasma químico (APQ) y se basa en la ruptura dieléctrica de una capa de óxido aislante en la superficie de un ánodo metálico en contacto con un electrolito adecuado. En este tratamiento, el componente se sumerge en un baño con un electrolito acuoso que contiene sales disueltas (silicatos, fosfatos y sales de calcio, entre otros). En el baño electrolítico, el sustrato metálico actúa como ánodo y una lámina de acero inoxidable, plomo o aluminio como cátodo. El tratamiento es llevado a cabo en un rango de 1-180 minutos, con una densidad de corriente que varía de 500 a $2000 \mathrm{~A} / \mathrm{m}^{2}$ y voltajes que pueden llegar a 1000V. Durante el proceso se producen chispas en la superficie del ánodo y desprendimiento de gas en forma de burbujas [136].

Por otro lado, varios autores han puesto de manifiesto que la rugosidad superficial afecta la velocidad de osteointegración y produce una mejor fijación biomecánica que la correspondiente a superficies lisas [32,101,137]. Entre los tratamientos superficiales que incrementan la rugosidad de los implantes de titanio se encuentran el anodizado por plasma químico, mencionado anteriormente, y el blastinizado. Como se mencionó en el capítulo 4, en el tratamiento de blastinizado se utilizan pequeñas partículas abrasivas propulsadas por una corriente de aire que impactan en la superficie. La magnitud de la modificación superficial depende de los parámetros del 
proceso: tamaño, composición y forma de la partícula, presión, tiempo de blastinizado, entre otros [107]. En general, en el blastinizado de los implantes de titanio, se utilizan partículas de óxido de titanio $\left(\mathrm{TiO}_{2}\right)$, sílice $\left(\mathrm{SiO}_{2}\right)$ y alúmina $\left(\mathrm{Al}_{2} \mathrm{O}_{3}\right)$ de distintos tamaños y formas [32,101,137]. El mayor inconveniente que genera el uso de estas partículas es que una gran cantidad de las mismas permanece adherida a la superficie luego del tratamiento y limpieza del implante. Algunos estudios han demostrado que la liberación de estas partículas no biocompatibles provocan una reacción adversa en el huésped [138]. Por esta razón, se han empezado a utilizar partículas biocompatibles, que contienen calcio y fósforo, que no comprometen la interacción del implante con el tejido. Al mismo tiempo, como en el caso de los aceros inoxidables, el blastinizado generaría severas modificaciones en la superficie y en la subsuperficie del titanio [107]. Las modificaciones podrían ser de naturaleza química [102], relacionadas con la microestructura (como el refinamiento de grano $[103,104])$ o asociadas con las propiedades mecánicas como dureza o tensiones residuales de compresión [103,104,109,110,139]. Debe destacarse que no se han encontrado, en la búsqueda bibliográfica, estudios donde se caractericen las superficies resultantes de la aplicación combinada de un tratamiento de blastinizado con partículas biocompatibles con un posterior anodizado por plasma químico.

De acuerdo a lo anterior, resulta de interés evaluar y comparar las variaciones en los parámetros de rugosidad mediante la técnica del par estéreo, el endurecimiento superficial y la adherencia del recubrimiento bioactivo en titanio c.p. para implantes donde, por un lado se aplicó un blastinizado previo al tratamiento APQ y por el otro, se efectuó el anodizado partiendo de superficies mecanizadas. Además, en este capítulo se estudiaron los cambios que se generan en la topografía por la variación de algunos parámetros del proceso de blastinizado (tamaño de granalla, presión y tiempo). Por último, se estudió la incidencia de la degradación o agotamiento de los insumos (soluciones electrolíticas, tamaño de granallas, etc.) en las características superficiales de los tratamientos. 


\subsection{Materiales y métodos}

\subsubsection{Preparación de muestras}

Se utilizó como material de estudio titanio c.p. ASTM Grado 4 (0.0039\% N, 0.0112\% C, 0.11\% Fe, 0.24\% O, 0.00\% H, Ti BAL). Se emplearon muestras cilíndricas de $8 \mathrm{~mm}$ de diámetro y $3 \mathrm{~mm}$ de espesor. Los tratamientos de blastinizado y anodizado por plasma químico, que se describen a continuación, fueron realizados por una empresa fabricante de implantes.

\subsubsection{Blastinizado}

El tratamiento de blastinizado fue realizado en cinco muestras a $5 \mathrm{~cm}$ de distancia de la superficie con partículas angulares de fosfato de calcio de dos tamaños y a tres presiones diferentes. El tiempo de blastinizado fue tal que la cantidad de material removido fue el mismo en cada muestra. En la tabla 5.1 se muestra la nomenclatura y las condiciones de proceso.

Tabla 5.1: Nomenclatura y condiciones del proceso de blastinizado.

\begin{tabular}{|c|c|c|c|}
\hline Muestra & $\begin{array}{c}\text { Tamaño de } \\
\text { granalla }(\mu \mathrm{m})\end{array}$ & $\begin{array}{c}\text { Presión } \\
(\mathrm{bar})\end{array}$ & $\begin{array}{c}\text { Tiempo } \\
(\text { segundos })\end{array}$ \\
\hline B1 & 180 & 3,5 & 50 \\
\hline B2 & 180 & 4,5 & 40 \\
\hline B3 & 300 & 3,5 & 50 \\
\hline B4 & 300 & 4,5 & 25 \\
\hline B5 & 300 & 5 & 25 \\
\hline
\end{tabular}

\subsubsection{Blastinizado y anodizado por plasma químico}

Partiendo de superficies mecanizadas, las muestras se sometieron a un tratamiento de blastinizado a $5 \mathrm{~cm}$ de distancia a la superficie durante 2 minutos y 6 bar de presión con partículas angulares de fosfato de calcio con un tamaño de 300

$\mu \mathrm{m}$. El tamaño de la granalla luego de 10 hs de uso disminuyó a $160 \pm 30 \mu \mathrm{m}$. A continuación, dichas muestras fueron anodizadas por medio de un plasma químico en una solución electrolítica a base de fosfato de calcio anhidro $\left(\mathrm{CaHPO}_{4}\right)$ y acetato 
de calcio $\left(\mathrm{Ca}\left(\mathrm{CH}_{3} \mathrm{COO}\right)_{2}\right)$. En la tabla 5.2 se indica la nomenclatura utilizada para los diferentes tratamientos.

Tabla 5.2: Nomenclatura de los diferentes tratamientos superficiales utilizados.

\begin{tabular}{|c|l|}
\hline Muestra & \multicolumn{1}{|c|}{ Tratamiento Superficial } \\
\hline $\mathrm{Ba}$ & Blastinizado con partículas de fosfato de calcio nuevas. \\
\hline $\mathrm{Bb}$ & $\begin{array}{l}\text { Blastinizado con partículas de fosfato de calcio luego de 10 horas } \\
\text { de uso }\end{array}$ \\
\hline MAPQa & $\begin{array}{l}\text { Mecanizado y anodizado por plasma químico con electrolito sin } \\
\text { uso. }\end{array}$ \\
\hline MAPQb & $\begin{array}{l}\text { Mecanizado y anodizado por plasma químico con electrolito } \\
\text { previamente utilizado para preparar } 324.000 \mathrm{~mm}^{2} \text { de superficies } \\
\text { de Ti. }\end{array}$ \\
\hline BAPQa & $\begin{array}{l}\text { Blastinizado y anodizado por plasma químico con granalla nueva } \\
\text { y con electrolito sin uso. }\end{array}$ \\
\hline BAPQb & $\begin{array}{l}\text { Blastinizado y anodizado por plasma químico con granalla usada } \\
\text { por } 10 \text { hs. y con electrolito previamente utilizado para preparar } \\
324.000 \mathrm{~mm}^{2} \text { de superficies de titanio. }\end{array}$ \\
\hline
\end{tabular}

\subsubsection{Caracterización topográfica}

El análisis de la rugosidad se realizó a través de la técnica de estereometría [67,68]. Se obtuvieron seis pares de imágenes estéreos en distintas regiones de las muestras con un ESEM FEI Quanta 200, con ángulos de inclinación $\left(-5^{\circ},+5^{\circ}\right)$ a una distancia de trabajo de $10 \mathrm{~mm}$. Para el estudio de las muestras blastinizadas, se obtuvieron los parámetros de rugosidad de cada par estéreo considerando dos tamaños de áreas: $145 \times 153 \mu \mathrm{m}^{2}$ y $68 \times 73 \mu \mathrm{m}^{2}$. En el caso de las muestras con blastinizado y $\mathrm{APQ}$, se obtuvieron los parámetros de rugosidad de cada par estéreo con un área de $116 \times 116 \mu \mathrm{m}^{2}$. En ambos casos, las imágenes se procesaron para la obtención del conjunto de parámetros de rugosidad con el programa EZEImage [68] (ver capítulo 4 ). 


\subsubsection{Ensayo de microdureza}

Las medidas de microdureza Vickers se obtuvieron con un microdurómetro Future Tech FM-700, en secciones transversales con una carga de 10 gf durante 10 segundos (tiempo de carga) según ASTM E 384-89. Se realizó la observación de la microestructura de las secciones transversales mediante ESEM FEI Quanta 200 con el detector de electrones retrodispersados a un potencial de $20 \mathrm{kV}$ en modo alto vacío.

\subsubsection{Ensayo de adhesión}

La adhesión se evaluó mediante indentación Rockwell C según VDI 3198 [140]. Para ello, se empleó un durómetro BSG DL 171 y un penetrador cónico de diamante con una punta de $200 \mu \mathrm{m}$ de diámetro. Se efectuaron tres indentaciones en las muestras con tratamiento de APQ aplicando una carga de $150 \mathrm{~kg}$. Posteriormente, se realizó la observación de las superficies mediante ESEM. La norma VDI 3198 define la calidad de adhesión en una escala que va desde HF1 a HF6. En general, HF1-HF4 define una adherencia suficiente del recubrimiento al sustrato, mientras que HF5 y HF6 representa una adherencia insuficiente [140].

\subsection{Resultados y Discusión}

\subsubsection{Caracterización topográfica}

\subsubsection{Blastinizado}

En las tablas 5.3 y 5.4 se muestran los valores promedio obtenidos, mediante el programa EZEImage [68], para los parámetros de rugosidad de las muestras B1 a B5. Además, se analizaron los resultados obtenidos en cada región teniendo en cuenta dos tamaños de áreas $\left(145 \times 153 \mu \mathrm{m}^{2}\right.$ y $\left.68 \times 73 \mu \mathrm{m}^{2}\right)$ para evaluar su efecto en los parámetros estudiados. 
Tabla 5.3: Parámetros de rugosidad obtenidos con SEM-EZEImage para un área de $145 \times 153 \mu \mathrm{m}^{2}$. Los números entre paréntesis indican el error en la última cifra significativa.

\begin{tabular}{|c|c|c|c|c|c|}
\hline Parámetro & $\begin{array}{c}\text { B1 } \\
180 \mu \mathrm{m} ; \\
3,5 \mathrm{bar}\end{array}$ & $\begin{array}{c}\text { B2 } \\
180 \mu \mathrm{m} ; \\
4,5 \mathrm{bar}\end{array}$ & $\begin{array}{c}\text { B3 } \\
300 \mu \mathrm{m} ; \\
3,5 \mathrm{bar}\end{array}$ & $\begin{array}{c}\text { B4 } \\
300 \mu \mathrm{m} ; \\
4,5 \mathrm{bar}\end{array}$ & $\begin{array}{c}\text { B5 } \\
300 \mu \mathrm{m} ; 5 \\
\text { bar }\end{array}$ \\
\hline $\mathrm{Sq}(\mu \mathrm{m})$ & $1,4(1)$ & $1,40(8)$ & $2,0(1)$ & $2,17(4)$ & $2,3(2)$ \\
\hline $\mathrm{Sa}(\mu \mathrm{m})$ & $1,1(1)$ & $1,1(1)$ & $1,5(1)$ & $1,70(3)$ & $1,8(1)$ \\
\hline $\mathrm{Ssk}$ & $-0,2(1)$ & $-0,2(1)$ & $-0,2(1)$ & $-0,1(2)$ & $-0,2(1)$ \\
\hline $\mathrm{Sku}$ & $4,1(3)$ & $4,0(5)$ & $4,2(3)$ & $3,6(2)$ & $3,4(2)$ \\
\hline $\mathrm{Sz}(\mu \mathrm{m})$ & $18(2)$ & $18(2)$ & $24(2)$ & $21(1)$ & $21(2)$ \\
\hline $\mathrm{Sbi}$ & $0,64(1)$ & $0,64(1)$ & $0,63(1)$ & $0,64(3)$ & $0,64(1)$ \\
\hline $\mathrm{Sci}$ & $1,46(2)$ & $1,47(2)$ & $1,48(2)$ & $1,5(1)$ & $1,45(3)$ \\
\hline $\mathrm{Svi}$ & $0,13(1)$ & $0,13(1)$ & $0,13(1)$ & $0,12(1)$ & $0,125(3)$ \\
\hline $\mathrm{D}$ & $2,58(2)$ & $2,58(2)$ & $2,54(2)$ & $2,55(1)$ & $2,53(1)$ \\
\hline
\end{tabular}

Tabla 5.4: Parámetros de rugosidad obtenidos con SEM-EZEImage para el área de $68 \times 73 \mu \mathrm{m}^{2}$. Los números entre paréntesis indican el error en la última cifra significativa.

\begin{tabular}{|c|c|c|c|c|c|}
\hline Parámetro & $\begin{array}{c}\mathrm{B} 1 \\
180 \mu \mathrm{m} ; \\
3,5 \mathrm{bar}\end{array}$ & $\begin{array}{c}\mathrm{B} 2 \\
180 \mu \mathrm{m} ; \\
4,5 \mathrm{bar}\end{array}$ & $\begin{array}{c}\text { B3 } \\
300 \mu \mathrm{m} ; \\
3,5 \mathrm{bar}\end{array}$ & $\begin{array}{c}\text { B4 } \\
300 \mu \mathrm{m} ; \\
4,5 \mathrm{bar}\end{array}$ & $\begin{array}{c}\text { B5 } \\
300 \mu \mathrm{m} ; 5 \\
\text { bar }\end{array}$ \\
\hline $\mathrm{Sq}(\mu \mathrm{m})$ & $1,3(3)$ & $1,4(1)$ & $1,8(1)$ & $2,0(2)$ & $2,2(1)$ \\
\hline $\mathrm{Sa}(\mu \mathrm{m})$ & $1,0(2)$ & $1,1(1)$ & $1,4(1)$ & $1,6(2)$ & $1,7(1)$ \\
\hline $\mathrm{Ssk}$ & $0,1(3)$ & $0,2(2)$ & $-1,0(1)$ & $-0,8(2)$ & $-1,0(2)$ \\
\hline $\mathrm{Sku}$ & $3,1(4)$ & $3,0(2)$ & $3,4(3)$ & $3,3(2)$ & $3,6(4)$ \\
\hline $\mathrm{Sz}(\mu \mathrm{m})$ & $10(4)$ & $11(1)$ & $13(1)$ & $14(1)$ & $16(1)$ \\
\hline $\mathrm{Sbi}$ & $0,60(6)$ & $0,67(4)$ & $0,79(4)$ & $0,9(1)$ & $0,82(6)$ \\
\hline Sci & $1,5(2)$ & $1,45(3)$ & $1,43(6)$ & $1,38(8)$ & $1,38(7)$ \\
\hline Svi & $0,12(3)$ & $0,114(7)$ & $0,12(1)$ & $0,11(1)$ & $0,13(1)$ \\
\hline $\mathrm{D}$ & $2,59(1)$ & $2,61(1)$ & $2,571(4)$ & $2,55(2)$ & $2,55(1)$ \\
\hline
\end{tabular}

Los parámetros Sa y Sq, en concordancia con los resultados obtenidos en el capítulo 4, también presentan la misma tendencia (tablas 5.3 y 5.4). Dong y otros [118] recomiendan el uso de Sq en vez de Sa pero, en este caso, es indistinto el uso de cualquiera de los dos parámetros por lo que se hará referencia al parámetro Sa. En primer lugar, se puede observar que el parámetro Sa no presenta dependencia con el 
área analizada. Por otro lado, teniendo en cuenta las condiciones de proceso, Sa aumenta con el aumento de presión y el tamaño de partícula (figura 5.1). Sin embargo, se observa una dependencia menos significativa con las variaciones de presión y más pronunciada con la diferencia de tamaño de las partículas. Considerando la misma condición de tiempo (50 segundos) y presión (3,5 bar) pero diferente tamaño de partícula (muestras B1 y B3), Sa se incrementa para un tamaño de partícula mayor (muestra B3) [101]. En las figuras 5.2a y 5.2b se pueden observar las imágenes SEM de la topografía de las muestras B1 y B3, respectivamente.

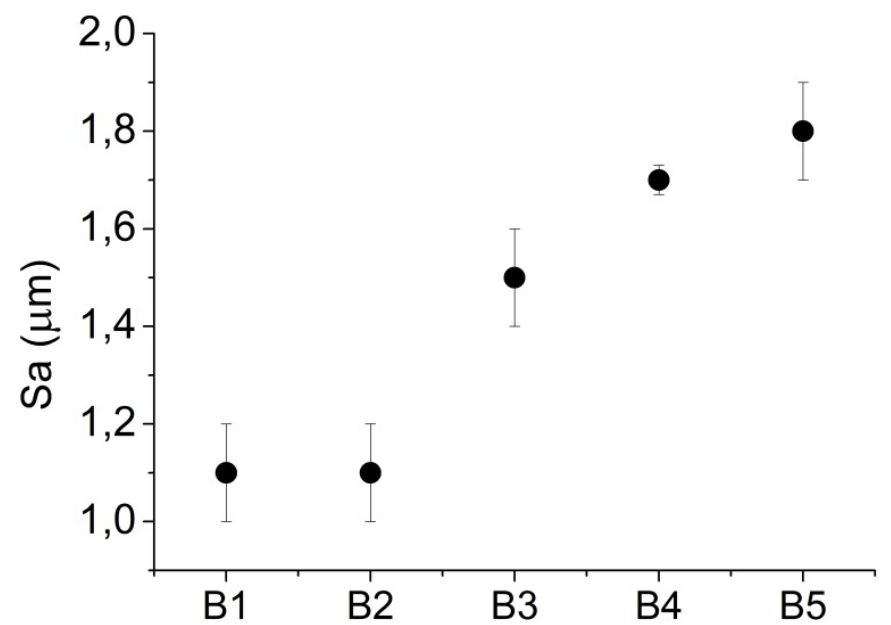

Figura 5.1: Comportamiento del parámetro Sa para los datos correspondientes al área $145 \times 153 \mu m^{2}$
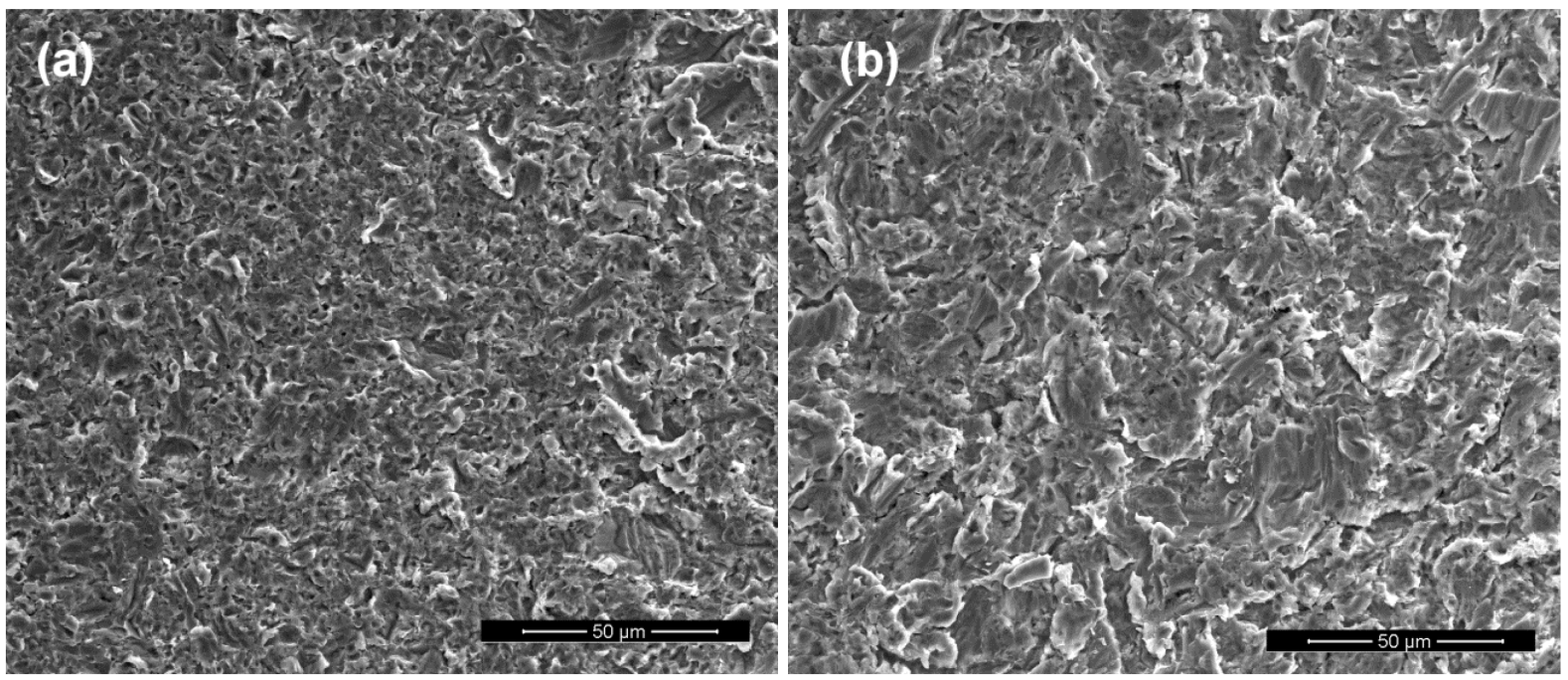

Figura 5.2: Imágenes de SEM de las muestras (a) B1 y (b) B3 
Por otro lado, los resultados de las tablas 5.3 y 5.4 indican que, dentro del error, no existe una diferencia significativa entre los parámetros Ssk, Sku y Sz, para las diferentes muestras en el área más grande, mientras que para aquellos correspondientes a un área más pequeña $\left(68 \times 73 \mu \mathrm{m}^{2}\right)$, se observa una diferencia entre los dos grupos de muestras correspondientes a los dos tamaños de partículas. Estos resultados indican una clara dependencia de los parámetros Sz, Ssk y Sku con el tamaño del área analizada en muestras sometidas a procesos de blastinizado. Sin embargo, para los dos tamaños de áreas, los valores negativos de Ssk, en las muestras B3-5, indican que las partículas de mayor tamaño generaron superficies con picos más redondeados y con una distribución cercana a la normal $(S k u \approx 3)$. En cuanto a los parámetros funcionales (Sbi, Sci y Svi), el único que presenta variación con el tamaño del área analizada es el parámetro Sbi.

Por último, los resultados del estimador de la dimensión fractal D (ver capítulo 4) indican que depende en menor medida del tamaño del área y su variación no es muy significativa teniendo en cuenta los respectivos errores. No obstante, se observa que las muestras que fueron sometidas a la acción de partículas más pequeñas presentan valores de dimensión fractal levemente mayores y viceversa. Este resultado estaría mostrando el hecho de que las partículas más grandes generan deformaciones más continuas que las partículas más pequeñas, en concordancia con los resultados obtenidos de Ssk y Sku. 


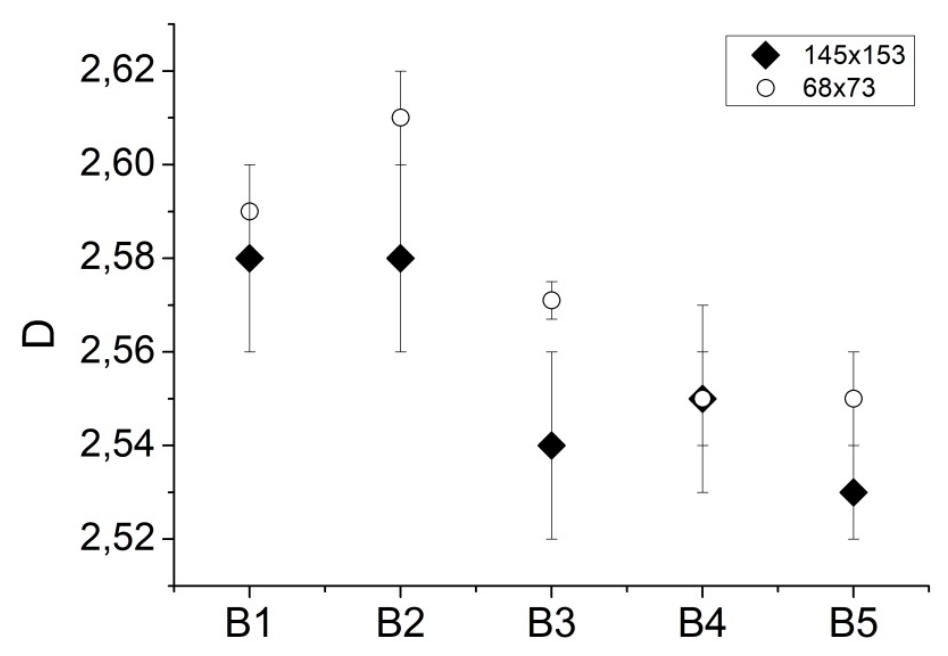

Figura 5.3: Estimador de la dimensión fractal (D).

\subsubsection{Blastinizado y anodizado por plasma químico}

En la tabla 5.5 se muestran los valores obtenidos mediante el programa EZEImage para los parámetros de rugosidad de las muestras $\mathrm{Ba}, \mathrm{Bb}$, MAPQa y BAPQa. En las figuras 5.4-5.7 se pueden observar las imágenes SEM y los gráficos de algunos de los parámetros de las muestras analizadas.

Tabla 5.5: Parámetros de rugosidad obtenidos con SEM-EZEImage. Los números entre paréntesis indican el error en la última cifra significativa.

\begin{tabular}{|c|c|c|c|c|}
\hline Parámetro & $\mathbf{B a}$ & $\mathbf{B b}$ & MAPQa & BAPQa \\
\hline Sq $(\mu \mathrm{m})$ & $1,8(1)$ & $1,4(2)$ & $1,5(2)$ & $1,37(5)$ \\
\hline Sa $(\mu \mathrm{m})$ & $1,39(7)$ & $1,1(1)$ & $1,3(1)$ & $1,09(4)$ \\
\hline Ssk & $-0,4(1)$ & $-0,17(7)$ & $0,1(1)$ & $-0,22(8)$ \\
\hline Sku & $3,8(6)$ & $3,5(2)$ & $2,8(2)$ & $3,13(6)$ \\
\hline Sz $(\mu \mathrm{m})$ & $13(1)$ & $12(1)$ & $10,5(8)$ & $11,5(5)$ \\
\hline Sbi & $0,64(2)$ & $0,63(2)$ & $0,61(2)$ & $0,63(2)$ \\
\hline Sci & $1,47(5)$ & $1,50(5)$ & $1,56(6)$ & $1,50(5)$ \\
\hline Svi & $0,132(8)$ & $0,130(7)$ & $0,10(1)$ & $0,118(6)$ \\
\hline
\end{tabular}



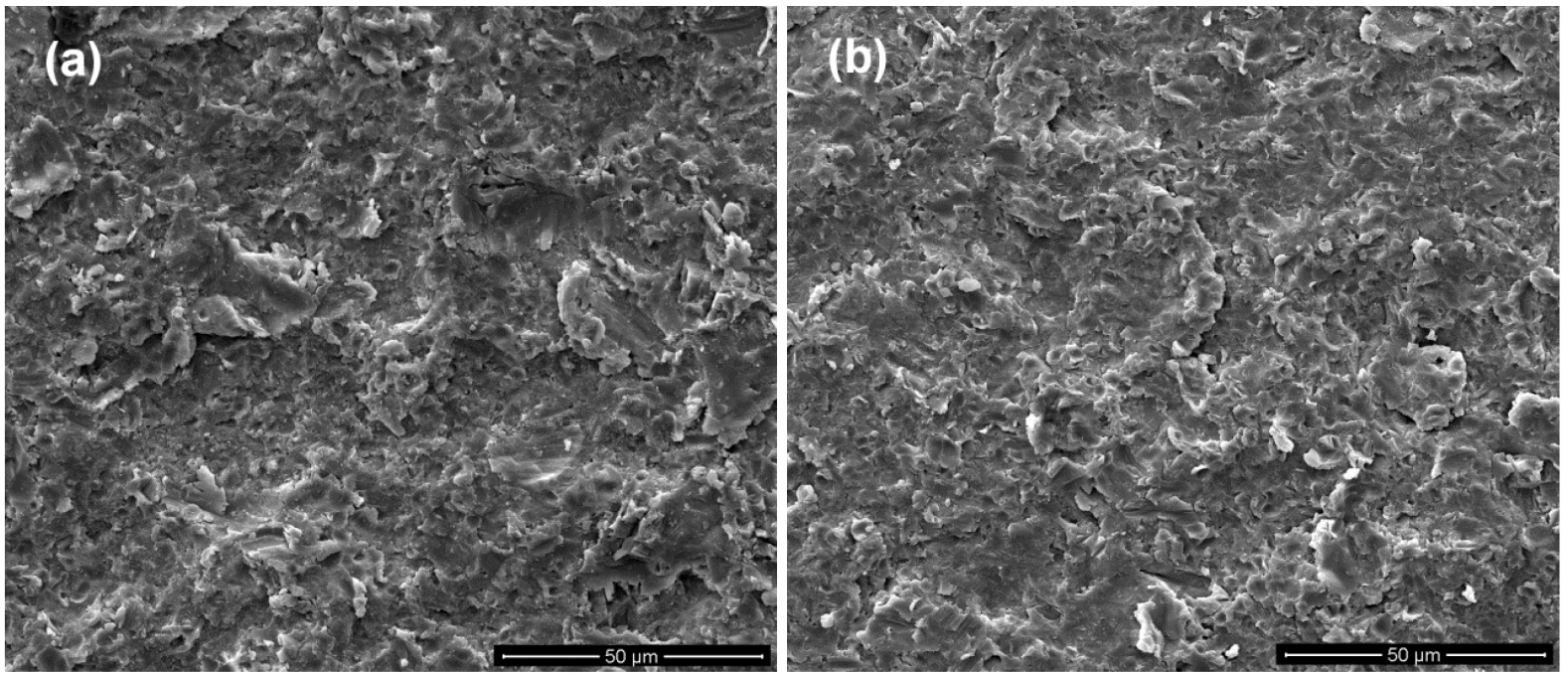

Figura 5.4: Imágenes de SEM de las muestras (a) Ba y (b) Bb.
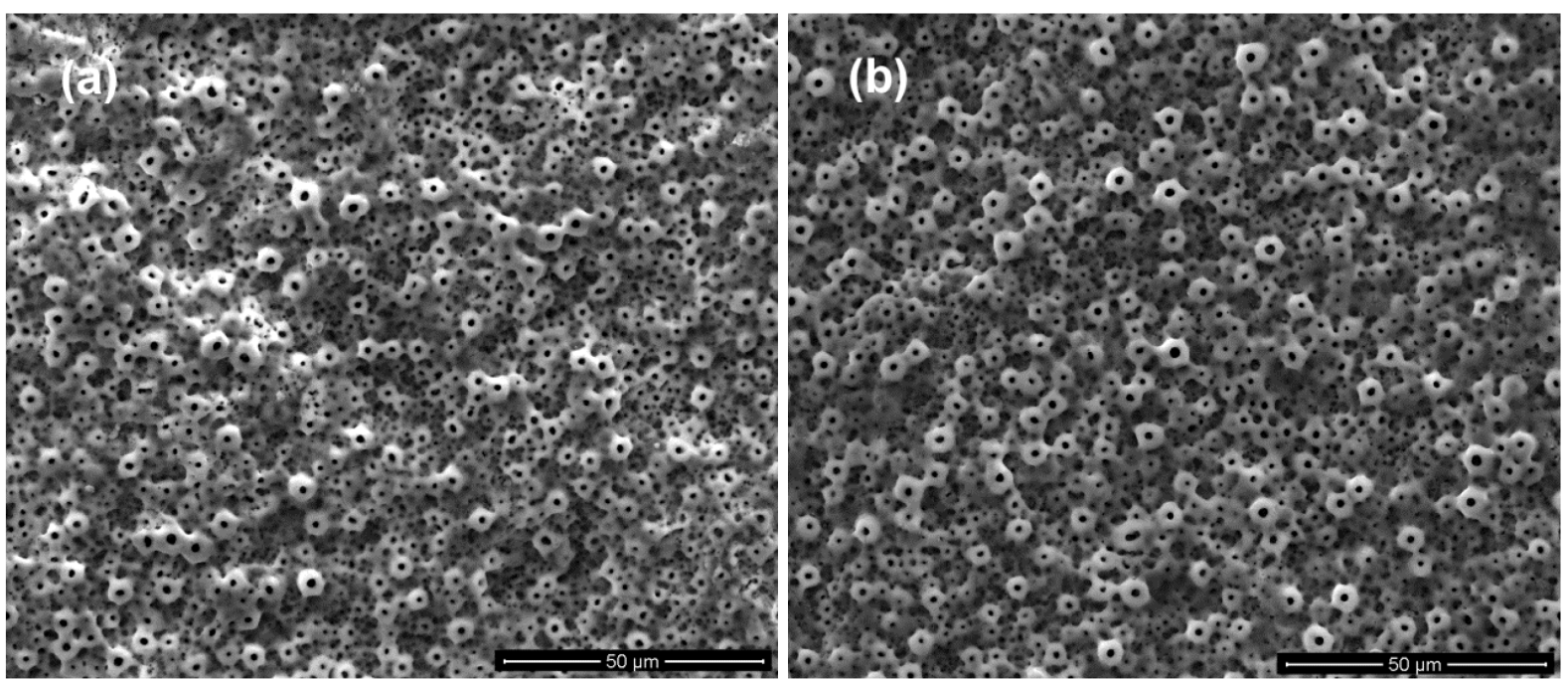

Figura 5.5: Imágenes de SEM de las muestras (a) BAPQa y (b) MAPQa.
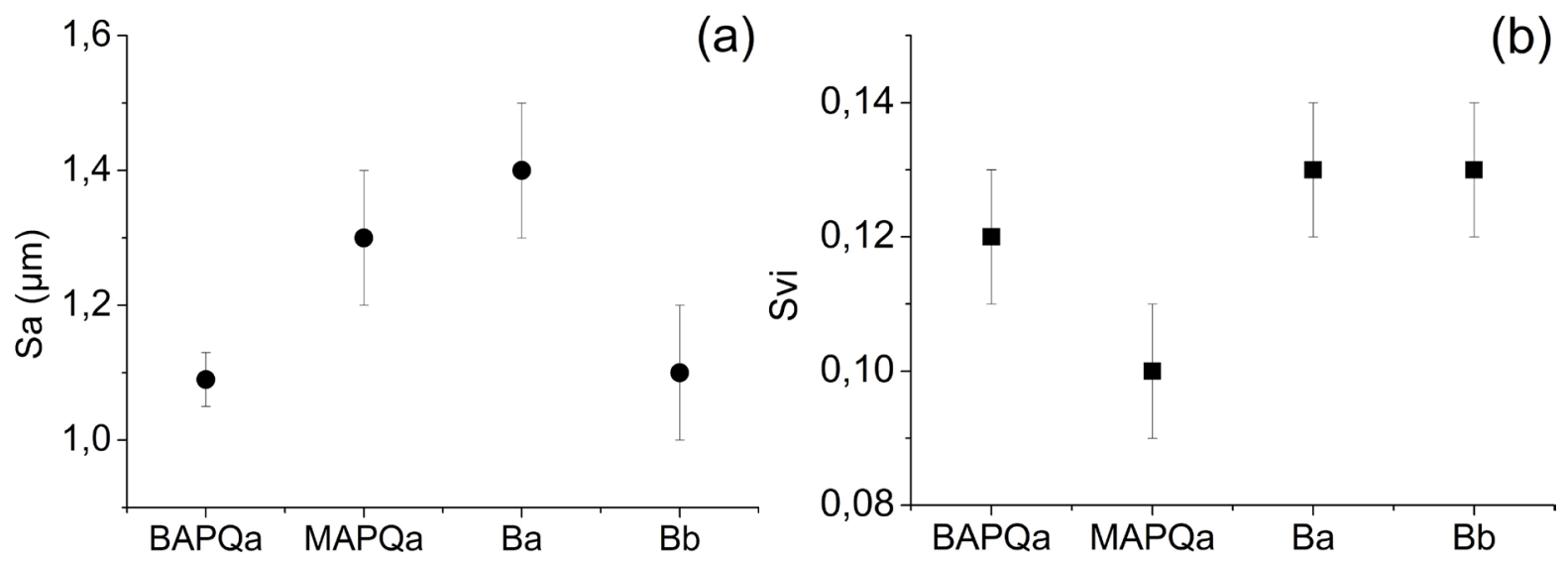

Figura 5.6: Comportamiento de los parámetros (a) Sa y (b) Svi. 

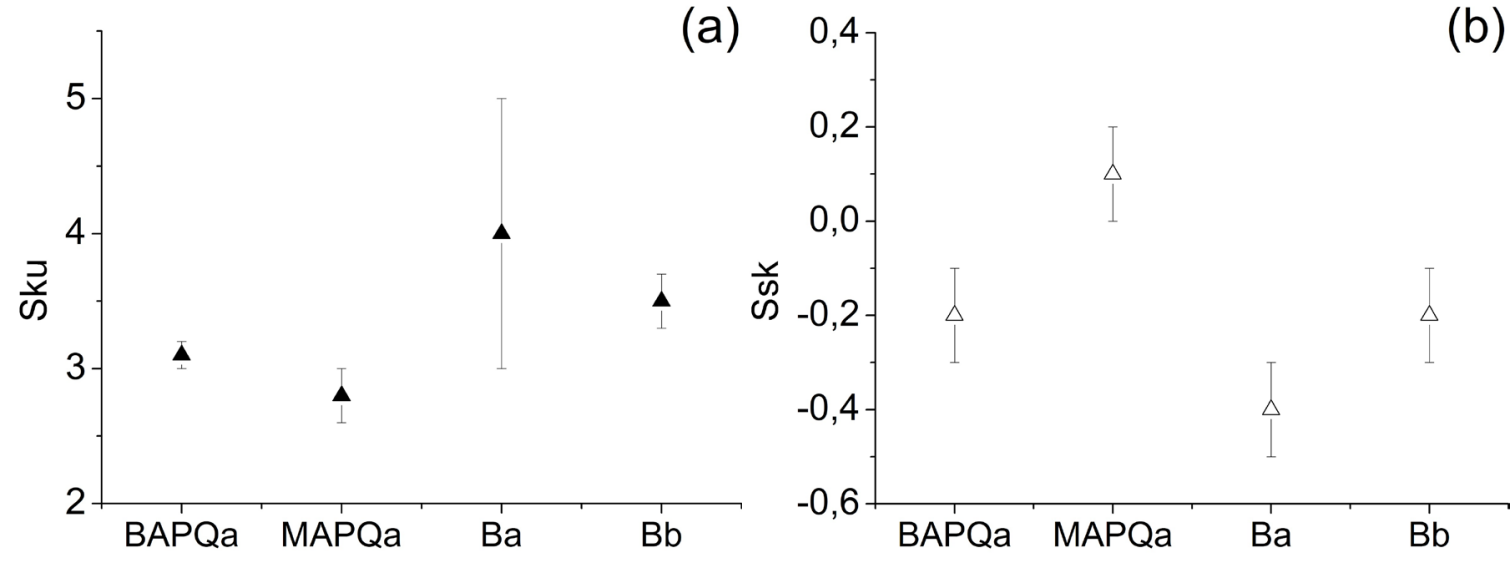

Figura 5.7: Comportamiento de los parámetros (a) Sku y (b) Ssk.

De los resultados obtenidos para las muestras $\mathrm{Ba}$ y $\mathrm{Bb}$, se puede observar que Sa es el parámetro que presenta una variación mayor (figura 5.6a), similar a los resultados obtenidos en las muestras blastinizadas de la sección 5.3.1.1, aunque en este caso se utilizaron condiciones de presión (6 bar) y tiempo (2 minutos) mayores. El resto de los parámetros no presentan, dentro del error, diferencias significativas. Como el parámetro Ssk depende del área y posición dentro la muestra y presenta errores grandes, se considera que no manifiesta una variación importante (sección 5.3.1.1). Esto indica que la distribución topográfica de ambas muestras es similar, como se puede observar en las figuras 5.4a y 5.4b. La disminución del parámetro Sa en la muestra $\mathrm{Bb}$ con respecto a $\mathrm{Ba}$, seguramente se debe a la reducción del tamaño de la partícula, utilizada en el proceso de blastinizado (ver sección 5.3.1.1).

En las figuras 5.5a y 5.5b se pueden observar las imágenes de SEM de las muestras anodizadas con y sin tratamiento previo de blastinizado, respectivamente. De los parámetros de rugosidad obtenidos, se puede observar que el único parámetro que presenta una variación considerable es el Ssk (Figura 5.7b), indicando que la muestra MAPQa presenta una pequeña tendencia a formar una superficie con mayor proporción de picos que la muestra BAPQa.

Los valores de Sa, Ssk y Sku obtenidos en la muestra BAPQa (figuras 5.6a, 5.7a y $5.7 b)$, indican que el tratamiento de anodizado generó superficies con picos más 
redondeados y con una distribución casi normal (Sku $\approx 3)$. En cuanto a los parámetros funcionales, si bien dentro del error Svi no presenta diferencias significativas, es el que manifiesta una mayor variación en comparación con Sci y Sbi. La muestra BAPQa tiene un valor de Svi más cercano al gaussiano $(\mathrm{Svi} \approx 0,11)$ que Ba (Figura 5.6b). Este resultado, en conjunto con el valor obtenido de Sa, indicaría que en la muestra BAPQa, la diferencia de alturas promedio disminuye pero como los parámetros Sbi y Sci no se modifican entre los dos tratamientos, el parámetro de retención de fluido en el valle (Svi) deberá disminuir generando una superficie más homogénea, en concordancia con los resultados de los parámetros de amplitud. Según Wennerberg y Albrektsson [32], las superficies homogéneas, con picos más suaves y con valores de Sa en el rango 1-2 $\mu \mathrm{m}$, como sucede en el caso de la muestra BAPQa, presentan una mejor osteointegración.

\subsubsection{Caracterización Mecánica}

\subsubsection{Ensayo de Microdureza Vickers}

La caracterización mecánica a partir de microdureza Vickers se llevó a cabo en las muestras MAPQb, BAPQa y BAPQb. La muestra MAPQa tiene el mismo sustrato que MAPQb (por lo tanto la misma sección transversal), por lo que es indistinto utilizar cualquiera de las dos muestras. Es necesario aclarar que se utilizaron las muestras anodizadas por plasma químico, ya que de esta manera se evitaron los efectos de borde que se producen durante la preparación metalográfica en las secciones transversales.

Jiang y otros [139] han observado tres regiones diferentes en las muestras de titanio c.p blastinizadas. Una capa severamente deformada cercana a la superficie, una región deformada con maclas y el sustrato sin deformación. Sin embargo, a partir de la observación de las secciones transversales de las muestras BAPQa y BAPQb en imágenes obtenidas por SEM (Figura 5.8) no se revela la presencia de una morfología 
irregular en la sub-superficie de estas muestras debida al endurecimiento por deformación.

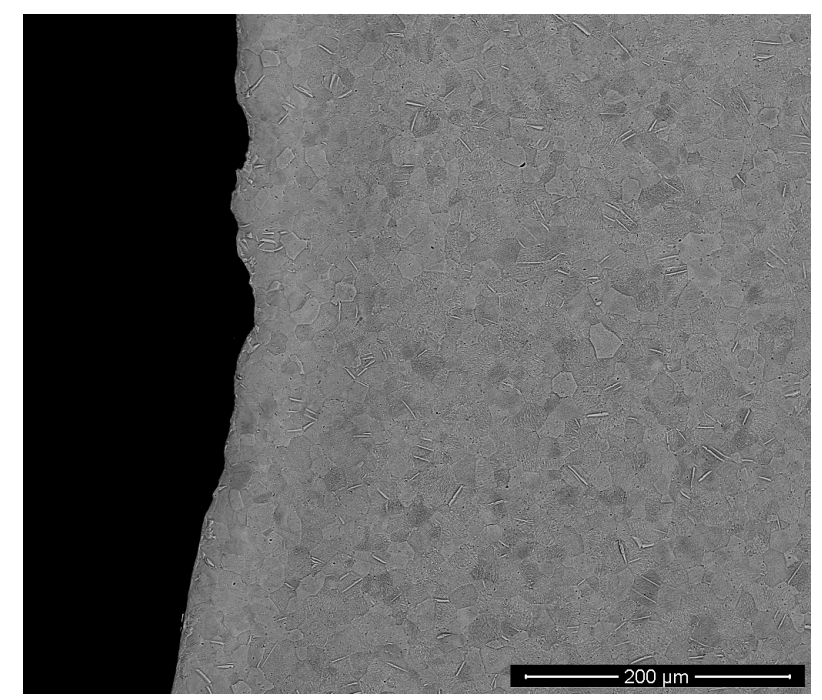

Figura 5.8: Imagen SEM de la muestra BAPQb

En la tabla 5.6 se presentan los resultados de microdureza HV de las distintas muestras. Las medidas se realizaron aproximadamente a $10 \mu \mathrm{m}$ de la superficie del metal base, donde se considera se localizaría una capa deformada producto del tratamiento superficial de blastinizado [139]. Del análisis de los datos obtenidos, se observa que la dureza de las muestras MAPQb y BAPQa es similar. Sin embargo, se observa un incremento en la dureza de $\mathrm{BAPQb}$ que podría estar causado por la disminución que se produce en el tamaño de partícula de blastinizado con el tiempo de uso. El incremento de la dureza confirmaría la presencia de una capa endurecida en la sub-superficie del metal base que no pudo revelarse mediante las técnicas metalográficas aplicadas en este estudio. Por otro lado, es necesario mencionar que se intentó medir la microdureza en la superficie del recubrimiento de las muestras BAPQa y BAPQb pero esto no se pudo llevar a cabo debido a la irregularidad en la topografía de las mismas.

Tabla 5.6: Microdurezas transversales (HV) de muestras MAPQb, BAPQa y BAPQb.

\begin{tabular}{|c|c|c|c|}
\hline & MAPQb & BAPQa & BAPQb \\
\hline $\begin{array}{c}\text { Dureza (HV) } \pm \text { DE } \\
\text { Carga 10 gf }\end{array}$ & $224 \pm 4$ & $230 \pm 10$ & $279 \pm 13$ \\
\hline
\end{tabular}




\subsubsection{Ensayo de Adhesión}

Como se mencionó anteriormente, el tratamiento de APQ genera un recubrimiento bioactivo dentro del cual se destaca su buena adherencia al metal base [135], siendo ésta una de las propiedades principales en un compuesto recubrimiento-sustrato.

La calidad y la resistencia adhesiva de las muestras con tratamiento APQ (MAPQb, BAPQa y BAPQb) se evaluaron mediante el ensayo de indentación Rockwell C [140]. El principio del método se puede observar en la Figura 5.9 [58].

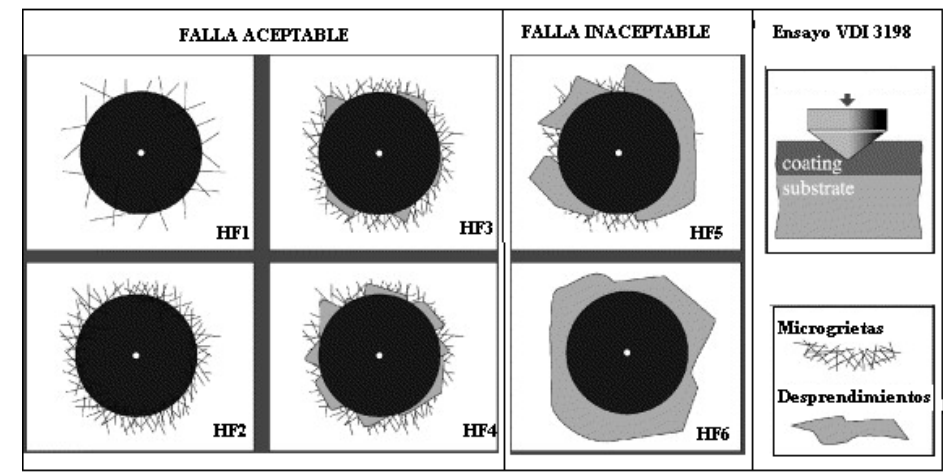

Figura 5.9: Clasificación de la calidad de adhesión según la norma VDI 3198 [58].

Se realizaron tres indentaciones en cada muestra con una carga de $150 \mathrm{~kg}$ y luego de cada indentación se verificó la integridad de la punta de diamante. Posteriormente, las indentaciones se observaron mediante SEM. La calidad de adhesión de las muestras se comparó con la clasificación suministrada por la norma VDI 3198 (figura 5.9) [58]. 


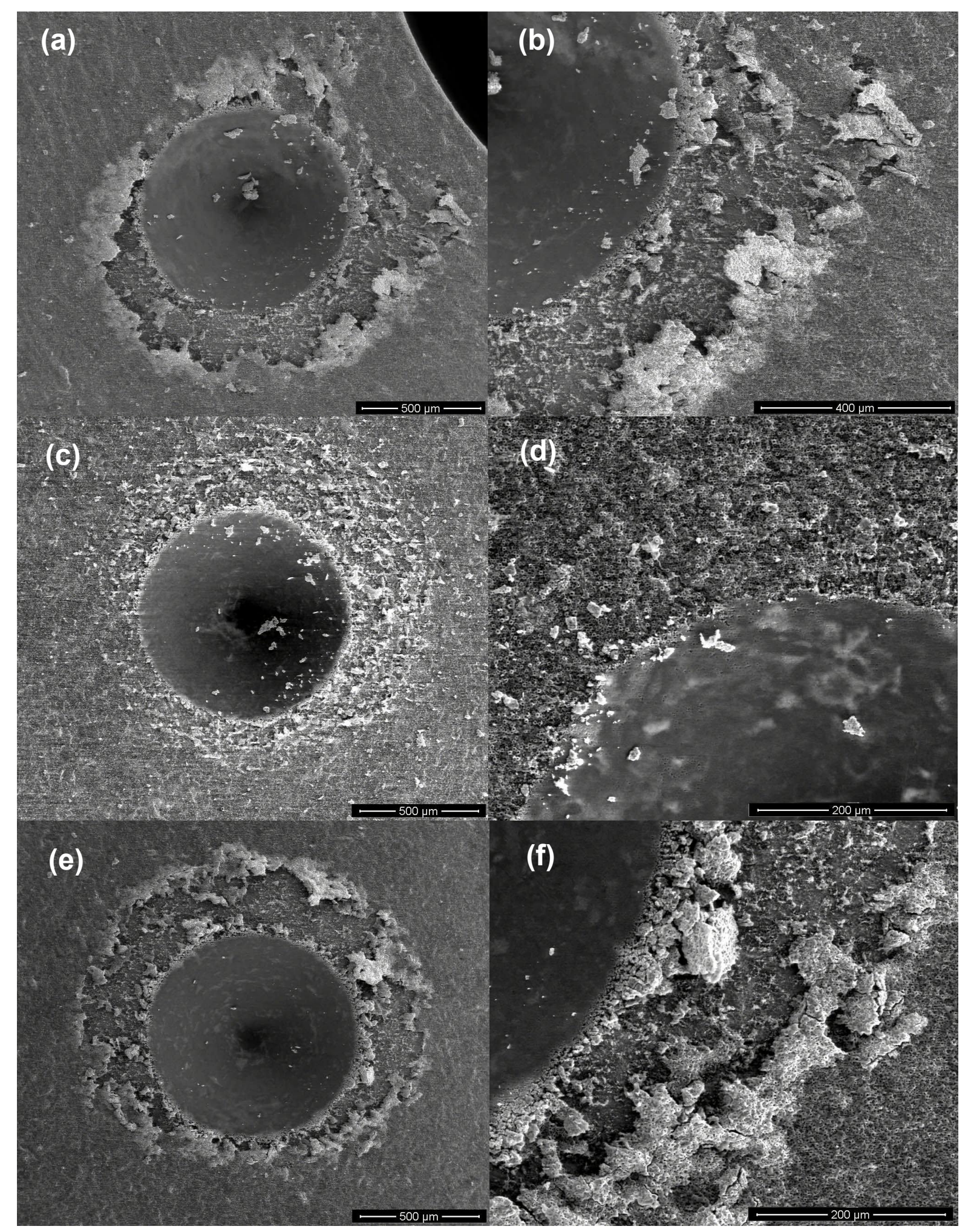

Figura 5.10: Imágenes de SEM de las indentaciones del ensayo de adhesión de las muestras (a-b) MAPQb, (c-d) BAPQa y (e-f) BAPQb.

En la figura 5.10 se observan las imágenes de SEM de las indentaciones del ensayo de adhesión de las muestras anodizadas con y sin tratamiento de blastinizado previo. 
Del análisis de la figura 5.10 y de acuerdo a la clasificación suministrada por la norma VDI 3198 (figura 5.9), la muestra BAPQa se clasificaría entre HF3-HF4 representando una adherencia aceptable. Los recubrimientos con adherencia aceptable garantizarían fuertes enlaces interfaciales entre el recubrimiento y el sustrato [58]. Sin embargo, en las muestras MAPQb y BAPQb se puede observar una delaminación extendida circunferencialmente a la indentación y se clasificarían entre HF5 y HF6 representando una adherencia insuficiente. Por otro lado, se puede observar que la muestra MAPQb presenta mayores desprendimientos del recubrimiento que la muestra $\mathrm{BAPQb}$.

A partir del estudio de los datos obtenidos se puede señalar que la adhesión metalrecubrimiento disminuye a medida que aumenta el consumo del electrolito utilizado en el tratamiento de anodizado. Se considera además, que la aplicación de un tratamiento superficial de blastinizado previo a la aplicación de un tratamiento de anodizado (APQ), podría generar una rugosidad que favorece levemente la adherencia sustrato metálico-recubrimiento.

\subsection{Conclusiones}

\subsubsection{Caracterización topográfica}

Como se mencionó en el capítulo 4, la correcta elección de los parámetros de rugosidad dependerá de las características del tratamiento superficial utilizado y del objetivo del estudio realizado. En el estudio de la rugosidad de las muestras sometidas a distintas condiciones de blastinizado, los resultados obtenidos indican que el parámetro Sa (o Sq) es el que sufre una variación más significativa dentro del tratamiento de blastinizado efectuado bajo distintas condiciones. Sin embargo, es importante combinarlo con otros parámetros como el estimador de la dimensión fractal (D) que presenta una idea de la homogeneidad de la superficie y con los parámetros Ssk y Sku que, si bien presentan una dependencia del área analizada, su análisis conjunto con Sa y D, permite caracterizar mejor la topografía de la superficie. 
En general, el blastinizado tendría una dependencia más significativa con el cambio en el tamaño de granalla que con las variaciones de presión. En lo que concierne a la rugosidad de las muestras anodizadas, los resultados indican que la aplicación de un tratamiento de blastinizado previo genera un ligero cambio en la rugosidad del APQ, que pudo observarse en la variación de los parámetros Sa, Svi, Ssk. Además, a partir de estos parámetros se pudo distinguir que la muestra de APQ con blastinizado previo presentaría una mejor condición topográfica que el resto.

\subsubsection{Dureza}

El incremento en la dureza transversal de la muestra BAPQb, respecto a las muestras MAPQb y BAPQa, podría estar causado por la disminución que se produce en el tamaño de partícula de blastinizado con el tiempo de uso. La medición de microdureza podría utilizarse, como una forma alternativa a la observación metalográfica, para comprobar la presencia de la capa deformada debido a la dificultad que implica el revelado de la microestructura en muestras de titanio.

\subsubsection{Adhesión}

A partir de la norma VDI 3198, se logró determinar que la muestra BAPQa presenta una adherencia aceptable y la muestra BAPQb tiene una adherencia insuficiente. La causa de este comportamiento puede atribuirse a que la adherencia del recubrimiento se encuentra afectada por el consumo de los componentes del electrolito utilizado en el anodizado. Las muestras BAPQb y MAPQb presentaron una adherencia insuficiente, aunque la muestra $\mathrm{BAPQb}$ tuvo desprendimientos del recubrimiento algo menores que $\mathrm{MAPQb}$. En este sentido, se considera que la rugosidad que genera el blastinizado favorecería levemente la adherencia sustrato metálico-recubrimiento. 


\subsubsection{Conclusiones generales}

En el blastinizado se observaron variaciones en la rugosidad y la microdureza transversal con los cambios en el tamaño de la granalla utilizada, que luego presenta una influencia en el tratamiento de APQ posterior. Los resultados del ensayo de adhesión indican que la adherencia del recubrimiento al sustrato se encontraría afectada por el uso y el consumo de los insumos, como el cambio del tamaño de granalla y el tiempo de uso del electrolito, utilizados en los tratamientos de blastinizado y APQ, respectivamente.

La combinación de los análisis de rugosidad con ensayos de microdureza y adhesión podrían ser utilizados para caracterizar muestras de titanio para implantes con tratamiento de blastinizado y anodizado por plasma químico. En particular, puede ser útil en la puesta a punto de estos procesos en otros materiales para implantes, como el Ti6Al4V, en el cual no se encuentra tan ampliamente desarrollado como en el caso del titanio c.p. 


\title{
CAPÍTULO 6
}

\section{DETERMINACIÓN DE ESPESORES DE ÓXIDO DE TITANIO EN IMPLANTES ANODIZADOS MEDIANTE MICROANÁLISIS POR SONDA DE ELECTRONES}

\begin{abstract}
El espesor de una película delgada se puede relacionar con las intensidades de los rayos $\mathrm{X}$ emitidos bajo el bombardeo de electrones. El objetivo del presente capítulo es el desarrollo de un método para medir espesores de óxido de titanio en biomateriales a partir de los espectros de rayos $X$ generados en un microscopio electrónico de barrido. Las capas de óxido estudiadas se generaron con diferentes voltajes de anodizado en una solución de ácido fosfórico y bórico $\left(\mathrm{H}_{3} \mathrm{PO}_{4} / \mathrm{H}_{3} \mathrm{BO}_{3}\right)$. Para cada muestra se registró la intensidad del pico $\mathrm{K} \alpha$ del oxígeno, la cual fue relacionada con el espesor correspondiente. Debido a una alteración local del material causada por el haz de electrones, es necesario efectuar una recalibración. Para este propósito se usó la técnica de espectroscopía de retrodispersión de Rutherford. El método es útil para espesores de óxido de titanio en el intervalo de interés de los implantes dentales y ortopédicos (10 a 100 $\mathrm{nm})$, y podría extenderse a mayores espesores seleccionando adecuadamente la energía del haz de electrones.
\end{abstract}

\subsection{Introducción}

El anodizado es uno de los tratamientos más ampliamente utilizados en titanio y sus aleaciones. Este tratamiento, descripto en el capítulo 5, produce diferentes tipos de películas de óxidos metálicos. Generalmente, se utilizan distintos electrolitos acuosos $-\mathrm{H}_{2} \mathrm{SO}_{4}, \mathrm{H}_{3} \mathrm{PO}_{4}, \mathrm{HNO}_{3}, \mathrm{CH}_{3} \mathrm{COOH}, \mathrm{Ca}(\mathrm{OH})_{2}, \mathrm{Na}(\mathrm{OH})$, entre otros- en el proceso. La estructura y propiedades químicas de las películas y recubrimientos dependen de parámetros del anodizado tales como voltaje, composición del electrolito, temperatura y corriente [135].

El titanio posee en su superficie una delgada capa espontánea de óxido de titanio de 1,5 a $10 \mathrm{~nm}$ de espesor [141], considerada bioinerte puesto que es suficientemente estable y no genera reacciones adversas en los fluidos y tejidos del cuerpo humano [12,135], la aplicación del anodizado en titanio le otorga una serie de ventajas, entre las cuales se encuentran: la formación de una capa con una elevada adhesión al sustrato [135] y el aumento del espesor del óxido pasivo que influencia la interacción del implante con el medio biológico [142] e incrementa la resistencia a la corrosión 
[12]. En particular, el anodizado en ácido fosfórico presenta algunas ventajas en comparación con otros electrolitos, ya que permite generar capas de óxido compactas, tubulares o porosas y mejora considerablemente la biocompatibilidad, debido a la incorporación de iones fosfato [143].

Conocer con precisión el espesor del óxido del titanio anodizado es importante, ya que este parámetro afecta el comportamiento del implante. Diversas técnicas han sido utilizadas para determinar los espesores en distintas condiciones de anodizado; por ejemplo: espectrofotometría de reflectancia de luz [144], espectroscopía de retrodispersión de Rutherford [145], espectroscopia Auger [146] y microscopía de fuerzas atómicas [142], cubriendo diferentes rangos de voltaje de anodizado (AV): 5$80 \mathrm{~V}, 20-84 \mathrm{~V}, 20-130 \mathrm{~V}$ y 50-250 V, respectivamente, para espesores $d$ mayores que 30 nm.

Recientemente, se desarrolló un método de determinación de espesores mediante microanálisis con sonda de electrones (EPMA). Dicho método se basa en la dependencia de la intensidad de emisión de la línea característica $\mathrm{K} \alpha$ de rayos $\mathrm{X}$ del oxígeno con el espesor de capa de óxido y utiliza la elipsometría como técnica de referencia para calibrar los espesores obtenidos [147]. Con este enfoque, se caracterizaron películas de óxido de titanio, crecidas potenciodinámicamente sobre sustratos de titanio, utilizando una solución de $\mathrm{HClO}_{4}$ 0,01 M y voltajes de anodizado entre 1 y $10 \mathrm{~V}$, obteniéndose resultados bastante precisos.

En ese trabajo, los autores encontraron una tasa de crecimiento del óxido con el voltaje de anodizado mucho menor de lo esperado. A partir de este resultado y al estudiar la evolución de la muestra durante la adquisición del espectro, los autores concluyeron que la muestra es modificada por el haz de electrones incidente, lo que probablemente provoca la migración de los átomos de O desde el punto del haz de incidencia. Por esta razón, no es posible obtener un método directo para la determinación de espesores por EPMA. Para resolver este problema, los autores encontraron una relación entre la intensidad del pico experimental O-K $\alpha$ y el voltaje de anodizado, que se asoció con el espesor de óxido utilizando la elipsometría como 
técnica de referencia. Esta técnica permite obtener una relación entre el espesor de óxido y el voltaje de anodizado, de manera que mediante una calibración adecuada, la intensidad del pico de $\mathrm{O}-\mathrm{K} \alpha$ se puede utilizar para determinar el espesor de capas de óxido formadas electroquímicamente con diferentes voltajes de anodizado.

En el trabajo mencionado, la calibración se realizó para las películas de $\mathrm{TiO}_{2}$ formadas por anodizado en una solución de $\mathrm{HClO}_{4}$ 0,01 M, con voltajes entre 1 y 10 V.

En este capítulo se desarrolla una alternativa al método de Filippin y otros [147] para determinar espesores de óxido de titanio, obtenidos mediante anodizado en una solución de $1 \% \mathrm{H}_{3} \mathrm{BO}_{3} / 5 \% \mathrm{H}_{3} \mathrm{PO}_{4}(\%$ p/p) en el rango de 5 a $90 \mathrm{~V}$. En esta variante se efectúa la recalibración mediante espectroscopía de retrodispersión de Rutherford (RBS), la cual permite extender el método de caracterización de espesores a un rango más amplio de voltajes, más acorde a los espesores de interés para implantes dentales y ortopédicos. Es importante mencionar que una vez realizada la recalibración con RBS, se puede prescindir de esta técnica para caracterizar otras muestras preparadas en forma similar, requiriéndose únicamente EPMA, técnica de mucho mayor disponibilidad y menor costo.

\subsection{Materiales y métodos}

\subsubsection{Preparación de muestras}

Para el presente estudio se utilizó titanio c.p. ASTM grado 4 (0,0039\% N, 0,0112\% C, 0,11\% Fe, 0,24\% O, 0,00\% H, Ti BAL). Los tratamientos de anodizado se efectuaron en dos grupos de cilindros mecanizados: uno de $6 \mathrm{~mm}$ de diámetro y 3 mm de espesor (tipo 1) y el otro de $10 \mathrm{~mm}$ de diámetro y $4 \mathrm{~mm}$ de espesor (tipo 2).

El primer paso en la preparación de la muestra consistió en un decapado durante 1 minuto en una solución de $1 \% \mathrm{HF} / 5 \% \mathrm{H}_{2} \mathrm{SO}_{4}$ (\% p/p). A continuación, las muestras se anodizaron en una solución de $1 \% \mathrm{H}_{3} \mathrm{BO}_{3} / 5 \% \mathrm{H}_{3} \mathrm{PO}_{4}(\% \mathrm{p} / \mathrm{p})$ a temperatura ambiente, ajustando el potencial a diferentes valores entre 5 y $90 \mathrm{~V}$. El procedimiento se llevó a 
cabo a partir de un anodizado galvanostático para cada voltaje, es decir, la corriente se mantuvo constante (2 A para todos los voltajes) durante el tiempo necesario para alcanzar cada potencial preestablecido. Finalmente, las muestras se lavaron con agua destilada dos veces, se secaron y se envasaron individualmente en films de polietileno.

Los voltajes aplicados en el anodizado fueron 5, 10, 15, 20, 25, 50, 70 y $90 \mathrm{~V}$ para las muestras de tipo 1 y $30 \mathrm{~V}$ para la muestra de tipo 2. Los tratamientos de anodizado se efectuaron utilizando una fuente Sorensen DLM 600-5E $3 \mathrm{~kW}, 0-600 \mathrm{~V}, 0-5 \mathrm{~A}$.

\subsubsection{Mediciones realizadas mediante RBS y EPMA}

Los espectros RBS se obtuvieron utilizando partículas $\alpha$ de 2,00; 3,04 y 3,05 $\mathrm{MeV}$. El haz incidente impactó las muestras perpendicularmente y las partículas $\alpha$ retrodispersadas fueron detectadas con un detector de barrera de superficie ubicado a $165^{\circ}$ con respecto a la dirección del haz incidente. Las mediciones se realizaron con un acelerador Tándem de 1,7 MV.

En cuanto a los espectros de rayos $\mathrm{X}$ inducidos por electrones, se obtuvieron con una microsonda JEOL JXA 8230, mediante el espectrómetro dispersivo en longitudes de onda (WDS) asociado a dicho equipo. La alta resolución del WDS permite resolver la importante superposición entre la línea $\mathrm{K} \alpha$ del oxígeno y las líneas L del titanio. Las muestras se irradiaron utilizando un haz de electrones de $4 \mathrm{keV}$ con una corriente entre 79,7 y 80,4 nA. El espectro de rayos $\mathrm{X}$ se adquirió utilizando un cristal LDE1 con una ventana de mylar frontal y las energías de los fotones cubrieron el rango de 467 a $583 \mathrm{eV}$, con un paso de 0,002 Å entre canales. Para todas las mediciones el tiempo de permanencia fue de 1,3 segundos por canal. 


\subsection{Resultados y discusión}

En un experimento de EPMA, los electrones incidentes sufren un gran número de interacciones con los átomos y pueden ser completamente detenidos dentro de la muestra si éstas son lo suficientemente gruesas (alrededor de $150 \mathrm{~nm}$ en $\mathrm{TiO}_{2}$ para electrones de $4 \mathrm{keV}$, según una estimación realizada utilizando la fórmula de Kanaya-Okayama). En el caso de una muestra compuesta por una capa nanométrica de $\mathrm{TiO}_{2}$ formada sobre un sustrato de titanio, cuanto mayor sea el espesor de la capa de óxido, más intenso será el pico de $\mathrm{O}-\mathrm{K} \alpha$ detectado. Este comportamiento, sin embargo, ya no se exhibe cuando el espesor de la capa de óxido es similar o superior al rango de los electrones. Para este caso límite, los electrones son completamente detenidos dentro del óxido y una capa de óxido más gruesa no contribuiría con fotones $\mathrm{O}-\mathrm{K} \alpha$ adicionales.

La relación entre la intensidad del pico O-K $\alpha$ y el espesor de la película se investigó mediante simulaciones de Monte Carlo llevadas a cabo a partir del paquete de software PENELOPE, con el fin de encontrar un valor conveniente para la energía incidente de electrones [147]. Se encontró que para el intervalo de espesores analizado, los electrones de $4 \mathrm{keV}$ permiten una aplicación del método propuesto con buena sensibilidad.

\subsubsection{RBS}

El estudio de películas delgadas es una de las principales aplicaciones de la espectroscopía de retrodispersión de Rutherford. En materiales estratificados, tanto la superficie como las interfases subsiguientes, pueden ser estudiadas por medio de la señal de partículas retrodispersadas. Se pueden obtener dos magnitudes independientes del espectro RBS: el ancho de energía $\Delta \mathrm{E}$ entre los bordes de señal correspondientes a las interfases adyacentes y el número total de cuentas incluidas en el intervalo espectral entre ambos bordes. A partir de estos valores, se puede obtener el número de átomos por unidad de área contenidos en la capa 
correspondiente. Cuando la película está compuesta por más de un elemento en una mezcla uniforme, la contribución de cada elemento al espectro de retrodispersión puede ser deconvolucionada permitiendo la determinación de la composición atómica de la película.

Aun cuando RBS es una técnica confiable para la determinación de espesores y composiciones de diferentes muestras, EPMA es de mayor accesibilidad que RBS y de menor costo. Por esta razón, el desarrollo de un método para la determinación de espesores basado en EPMA (calibrado inicialmente con RBS) es de gran interés.

Los espectros obtenidos mediante excitación con partículas $\alpha$ fueron procesados con el programa SIMNRA [148], para obtener el espesor de los films. En la figura 6.1 se muestran, a modo de ejemplo, los espectros obtenidos para las muestras correspondientes a $90 \mathrm{~V}$ y $5 \mathrm{~V}$ mediante excitación de partículas $\alpha$ de $2 \mathrm{MeV}$. Para el primer caso, se puede observar que en las regiones de energía correspondientes a eventos de retrodispersión dentro de la capa de óxido de titanio (alrededor de 0,7 $\mathrm{MeV}$ para el oxígeno y 1,3 MeV para el titanio) aparece una estructura compleja que no puede describirse correctamente con una estequiometría única. Por este motivo, para las muestras anodizadas a 90, 70 y $50 \mathrm{~V}$, se utilizó un modelo de dos capas: $\mathrm{TiO}_{2}$ para la capa superior y $\mathrm{Ti}_{2} \mathrm{O}_{3}$ para la inferior, es decir, la capa en contacto con titanio metálico. La menor cantidad de oxígeno que se encuentra a mayor profundidad es razonable y característica de cualquier proceso de difusión. En el caso de las muestras más delgadas, no es posible observar este nivel de detalle, por lo que se supuso una única capa de $\mathrm{TiO}_{2}$. 


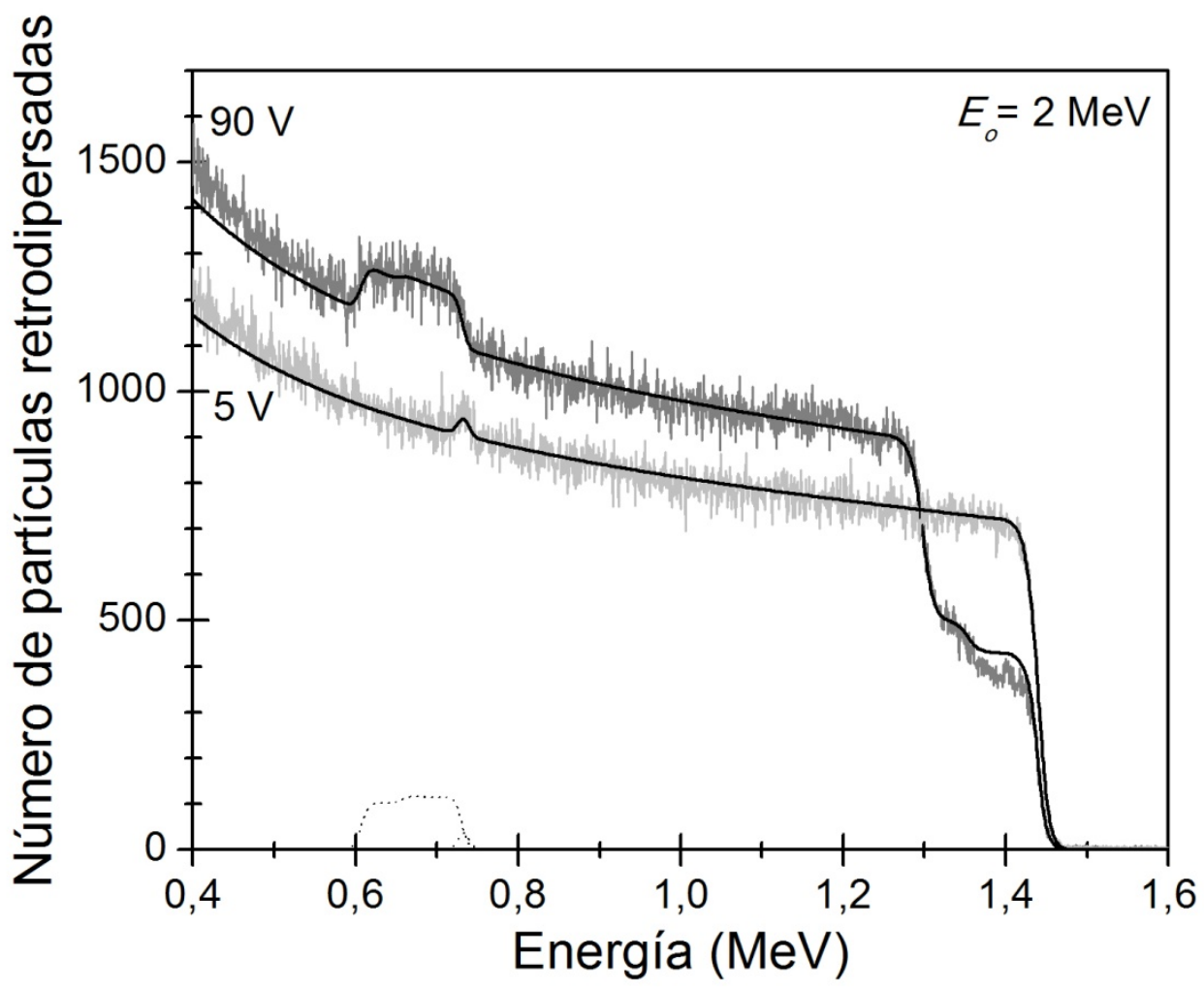

Figura 6.1: Espectros RBS obtenidos de las muestras anodizadas a $90 \mathrm{~V}$ (curva superior) y $5 \mathrm{~V}$ (curva inferior) inducidos por excitación de partículas $\alpha$ de 2,00 MeV. Línea gris sólida: datos experimentales; línea negra sólida: ajuste; línea de trazos: contribución del oxígeno.

Se puede observar que para los espectros correspondientes a muestras con menor espesor de óxido, la relación señal/ruido empeora por la disminución de los espesores de óxido. Dicha situación introduce mayores incertidumbres en la determinación del espesor. Con el fin de resolver este inconveniente, las muestras anodizadas a 5, 10 y $15 \mathrm{~V}$ fueron procesadas siguiendo una estrategia diferente: se utilizó la reacción nuclear $\mathrm{O}^{16}(\alpha, \alpha) \mathrm{O}^{16}$, la cual ocurre a 3,04 MeV [149], aprovechando la intensificación de la señal del pico de oxígeno. En la figura 6.2 se muestran los espectros RBS producidos por partículas $\alpha$ con energías nominales de 3,04 y 3,05 $\mathrm{MeV}$ para la muestra correspondiente a $5 \mathrm{~V}$. Como puede observarse en comparación con la figura 6.1, la relación señal/ruido es mucho mayor para los espectros obtenidos con las mayores energías de incidencia, las cuales posibilitan la reacción nuclear 
mencionada. También puede verse en la figura 6.2 que pequeñas variaciones en la energía de incidencia modifican sustancialmente la intensidad de la señal en energías cercanas a la energía característica de la reacción nuclear. Por lo tanto, es importante determinar con precisión la energía de la partícula incidente, que puede diferir ligeramente del valor nominal. Con este propósito, la energía del haz se ajustó con el programa SIMNRA en los espectros producidos en la muestra de $90 \mathrm{~V}$ con energías nominales de haz de 3,04 y 3,05 MeV. Los espesores de $\mathrm{TiO}_{2}$ y $\mathrm{Ti}_{2} \mathrm{O}_{3}$ se tomaron del espectro de $2 \mathrm{MeV}$ y se mantuvieron fijos. Los valores resultantes, 3,027 y 3,041 MeV, respectivamente, sustituyeron los valores nominales 3,04 y $3,05 \mathrm{MeV}$, introduciéndose como parámetros constantes en el programa SIMNRA para determinar los espesores a partir del procedimiento de ajuste.

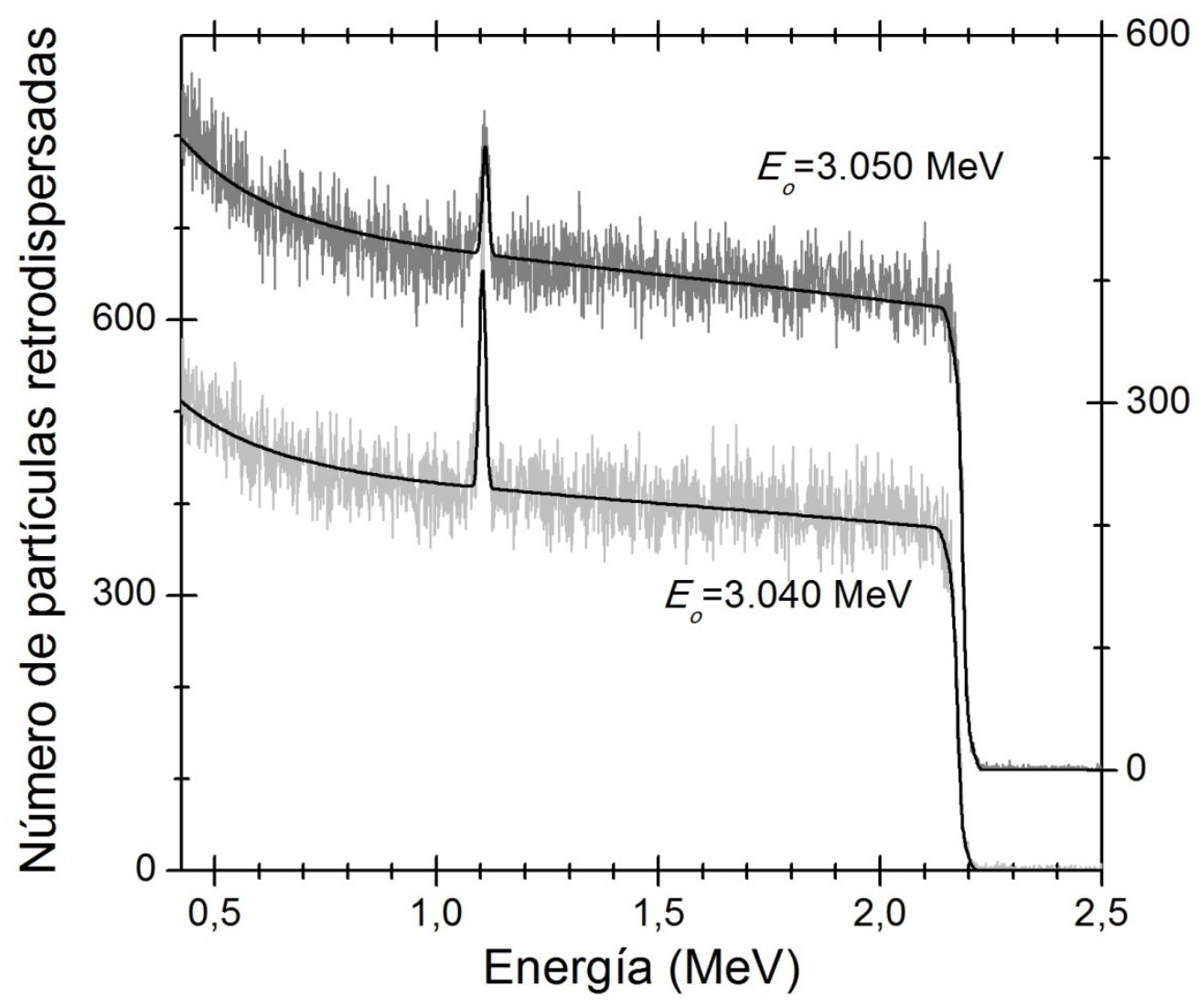

Figura 6.2: Espectros RBS obtenidos de las muestras anodizadas a $5 \mathrm{~V}$ obtenidos con excitación de partículas $\alpha$ con energías nominales de 3,05 MeV (curva superior) y 3,04 MeV (curva inferior). Línea gris sólida: datos experimentales; línea negra sólida: ajuste. 
Los espesores obtenidos se muestran en la tabla 6.1. El ajuste de los espectros experimentales de RBS da como resultado espesores atómicos, es decir, número de átomos por unidad de área; para obtener espesores lineales se utilizaron las densidades nominales de los óxidos implicados: $4,23 \mathrm{~g} / \mathrm{cm}^{3}$ para $\mathrm{TiO}_{2}$ y $4,49 \mathrm{~g} / \mathrm{cm}^{3}$ para $\mathrm{Ti}_{2} \mathrm{O}_{3}$. Para las muestras anodizadas a 5, 10 y $15 \mathrm{~V}$, los espesores informados corresponden al promedio de los valores obtenidos con ambas energías de incidencia utilizadas. En este caso, el error fue estimado como la semidiferencia de esos dos valores. Para las otras muestras, la incerteza se asoció a la diferencia entre los espesores obtenidos mediante dos estrategias de ajuste independientes.

Tabla 6.1: Valores de espesores obtenidos mediante RBS para los distintos voltajes de anodizado. Los números entre paréntesis corresponden a los errores estimados en las últimas cifras significativas.

\begin{tabular}{|c|c|c|c|c|c|}
\hline \multirow{2}{*}{$\begin{array}{c}\text { Voltaje de } \\
\text { anodizado } \\
(V)\end{array}$} & \begin{tabular}{c}
$|c|$ \\
\multirow{2}{*}{$\begin{array}{c}\text { Espesor } \\
\text { atómico } \\
10^{15} \text { at./cm }\end{array}$}
\end{tabular} & \multicolumn{4}{|c|}{ Espesor lineal (nm) } \\
\cline { 2 - 6 } & $\mathrm{TiO}_{2}$ & $\mathrm{Ti}_{2} \mathrm{O}_{3}$ & $\mathrm{TiO}_{2}$ & $\mathrm{Ti}_{2} \mathrm{O}_{3}$ & Total \\
\hline 5 & 80 & - & 8,4 & - & $8(2)$ \\
\hline 10 & 140 & - & 15 & - & $15(3)$ \\
\hline 15 & 200 & - & 21 & - & $21(3)$ \\
\hline 20 & 360 & - & 38 & - & $38(4)$ \\
\hline 25 & 470 & - & 49 & - & $49(7)$ \\
\hline 50 & 660 & 250 & 69 & 25 & $94(7)$ \\
\hline 70 & 1070 & 200 & 112 & 20 & $130(10)$ \\
\hline 90 & 990 & 610 & 104 & 60 & $164(4)$ \\
\hline
\end{tabular}




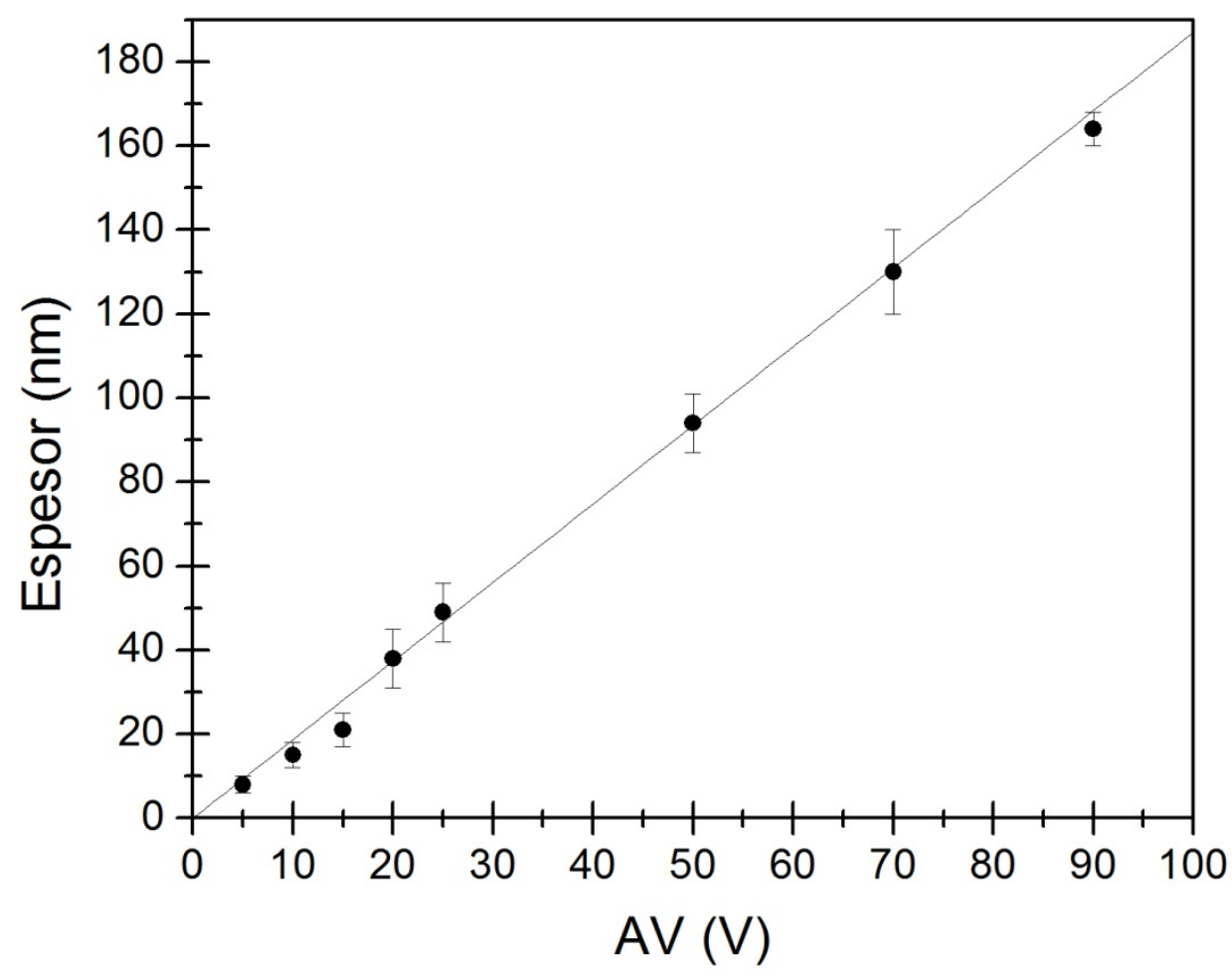

Figura 6.3: Valores de espesor obtenidos mediante RBS en función del voltaje de anodizado. Puntos: datos experimentales; línea continua: ajuste lineal sin ordenada al origen.

Los valores de espesor obtenidos mediante RBS muestran un comportamiento lineal con el voltaje de anodizado (figura 6.3). Teniendo en cuenta esta tendencia, se propuso la siguiente relación para ajustar los datos de espesor experimental (d) en función del voltaje de anodizado (AV):

$d=a+b(A V-0,89)$

Donde 0,89 es el voltaje de inicio de formación de óxido expresado en voltios, como se estima en [146]. Los valores obtenidos a partir del ajuste fueron $a=(0 \pm 2) \mathrm{nm}$ y $b=$ $(1,87 \pm 0,04) \mathrm{nm} / \mathrm{V}$. 


\subsubsection{EPMA}

Como se mencionó al comienzo de esta sección, en el método propuesto se utiliza la intensidad del pico O-K $\alpha$ como indicador del espesor de la capa de óxido anodizado. La determinación de esta intensidad debe realizarse con algunas precauciones, ya que la energía de la línea $\mathrm{O}-\mathrm{K} \alpha$ se encuentra muy próxima a la energía de las líneas L de titanio (alrededor de $70 \mathrm{eV}$ mayor). Este hecho puede conducir a problemas de deconvolución espectral, dependiendo de la resolución del espectrómetro utilizado. Con el fin de estudiar la viabilidad del método, se adquirió un espectro de la muestra anodizada a $30 \mathrm{~V}$ en el intervalo entre 375 y $583 \mathrm{eV}$, como puede observarse en la figura 6.4. El pico más intenso corresponde a la línea $\mathrm{O}-\mathrm{K} \alpha$, mientras que a energías más bajas se pueden observar dos estructuras correspondientes a las líneas L de titanio: las líneas LIIM ${ }_{\text {IV }}\left(\mathrm{L} \beta_{1}\right)$ y $\operatorname{LiII} \mathrm{M}_{\mathrm{IV}, \mathrm{V}}\left(\mathrm{L} \alpha_{1,2}\right)$ aparecen alrededor de $450 \mathrm{eV}$, y para energías cercanas a $390 \mathrm{eV}$, las líneas

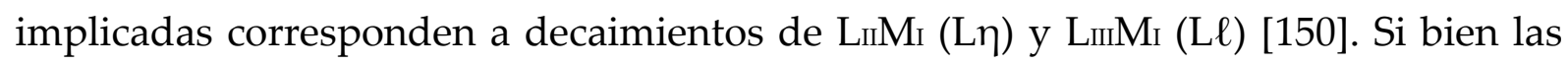
diferentes líneas involucradas en el espectro L de titanio no pueden ser separadas, los picos de Ti-L y O-K $\alpha$ se observan claramente diferenciados con la resolución del espectrómetro dispersivo de longitud de onda utilizado. Cabe mencionar que un espectrómetro dispersivo de energía (EDS) tiene una resolución de alrededor de 100 eV para la energía considerada, lo que implica que una deconvolución confiable es imposible de realizar con este tipo de espectrómetro. 


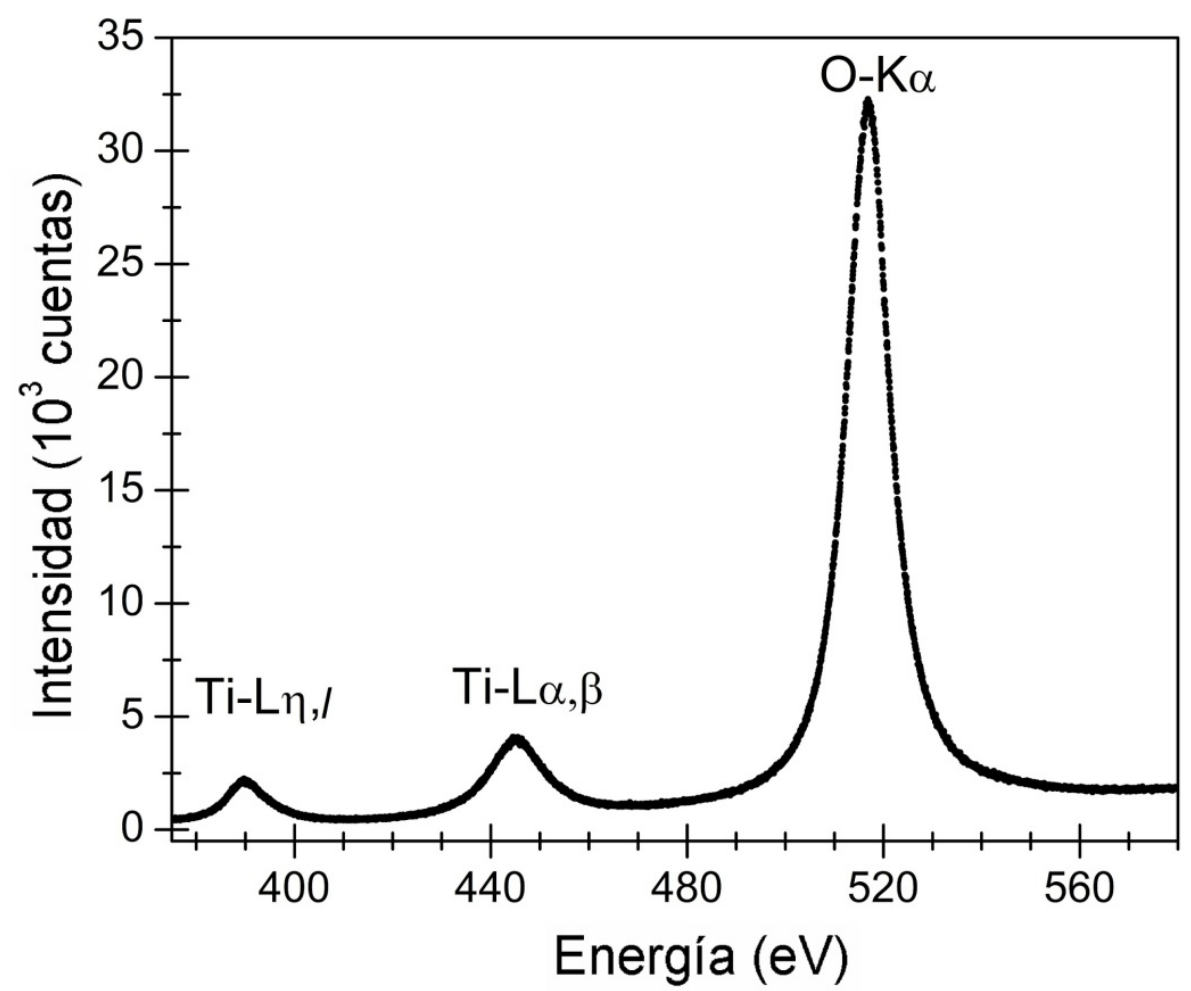

Figura 6.4: Espectro de la muestra de titanio anodizada a 30V.

Puesto que para la determinación de espesor de la capa anodizada sólo se utiliza la intensidad $\mathrm{O}-\mathrm{K} \alpha$, los espectros fueron adquiridos en un intervalo de energía que comprende específicamente a esa línea para todas las muestras estudiadas en adelante; esta estrategia permite obtener espectros con buena estadística en tiempos razonables, con la ventaja adicional de evitar el daño de la muestra que se produce por la irradiación con electrones en períodos prolongados [147]. La intensidad neta del pico de O-K $\alpha$ se determinó restando la contribución del fondo al valor del máximo del pico. El error de esta intensidad neta se estimó a partir de la dispersión de los datos experimentales en los canales alrededor del máximo. Las intensidades netas se normalizaron dividiendo por el valor de la corriente del haz, que se estimó como el promedio de los valores medidos antes y después de la adquisición del espectro. No fue necesario normalizar por el tiempo de adquisición, ya que este parámetro se mantuvo idéntico para todos los espectros. El error asociado con la 
intensidad normalizada I se estimó propagando los errores de la intensidad neta y la corriente de haz, los cuales son aproximadamente $2 \%$ y $0,2 \%$, respectivamente.

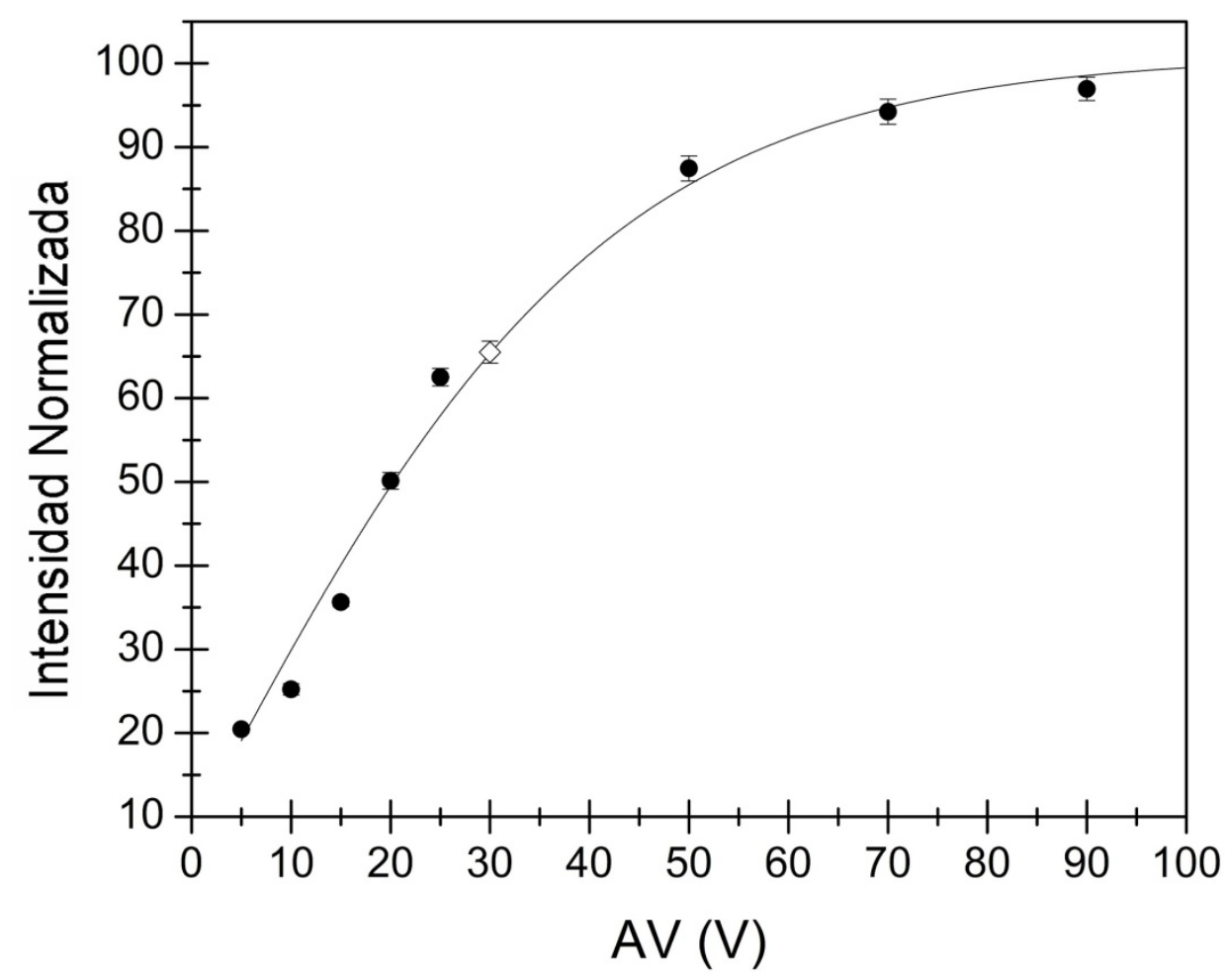

Figura 6.5: Intensidad normalizada de la línea O-K $\alpha$ en función del voltaje de anodizado. Puntos llenos: datos experimentales utilizados para realizar el ajuste; punto hueco: punto de validación; línea continua: ajuste.

En la figura 6.5 se muestran los valores obtenidos para las intensidades normalizadas I en función del voltaje de anodizado (AV). Estos datos experimentales fueron ajustados utilizando la función propuesta por Filippin y otros [147]:

$I=\alpha+\beta \tanh (\gamma A V)$

Los parámetros obtenidos mediante el ajuste fueron: $\alpha=8 \pm 3, \beta=93 \pm 7$ y $\gamma=(0,024 \pm$ $0,003) \mathrm{V}^{-1}$. La ecuación final que relaciona el espesor con la intensidad neta normalizada se obtiene a partir de las ecuaciones (6.1) y (6.2): 
$d=b\left[\frac{1}{2 \gamma} \ln \left(\frac{1+\frac{I-\alpha}{\beta}}{1-\frac{I-\alpha}{\beta}}\right)-0,89\right]+a$

En la tabla 6.2, se puede observar una comparación entre los valores de espesor medidos por RBS y los obtenidos a partir de la ecuación (6.3) (EPMA-RBS). La incerteza en el espesor calculado mediante esta ecuación se estimó por propagación de errores, teniendo en cuenta los errores de ajuste para los parámetros $a$ y $b$, es decir, la incerteza en el ajuste del espesor obtenido mediante RBS (ecuación (6.1)), y para los parámetros $\alpha, \beta$ y $\gamma$ de EPMA (ecuación (6.2)). Se puede observar que los espesores calculados con ambos métodos son indistinguibles entre sí considerando los errores asociados. Además, la diferencia relativa entre los valores calculados por ambos métodos es inferior al 10\%, excepto en dos casos. Cabe destacar que, de acuerdo con la ecuación (6.2), una pequeña variación en I se refleja en una gran variación en AV para voltajes de anodizado mayores que $70 \mathrm{~V}$ (figura 6.5). Este hecho es responsable de las grandes incertidumbres asociadas con espesores superiores a $100 \mathrm{~nm}$, como se muestra en la tabla 6.2. Es claro que el método propuesto es sensible a las variaciones de espesor, siempre y cuando dicho espesor permanezca marcadamente por debajo del rango de electrones en el material analizado. Para la energía del haz utilizada en este estudio, el rango de Kanaya-Okayama es inferior a $200 \mathrm{~nm}$, y el ajuste obtenido puede aplicarse en forma confiable para espesores de hasta aproximadamente la mitad de este intervalo, lo cual está dentro del alcance del presente estudio. Si se deben determinar espesores más grandes, es necesario usar energías de haz mayores, las cuales se deben establecer estimando el rango de electrones correspondiente en el material. 
Tabla 6.2: Espesores obtenidos para los distintos voltajes de anodizado con EPMA y RBS. Los números entre paréntesis corresponden a los errores en las últimas cifras significativas.

\begin{tabular}{|c|c|c|c|}
\hline \multirow{2}{*}{$\begin{array}{c}\text { AV } \\
\text { (Volt) }\end{array}$} & \multicolumn{2}{|c|}{ Espesor (nm) } & \multirow[b]{2}{*}{$\begin{array}{c}\text { Diferencia } \\
\text { relativa }\end{array}$} \\
\hline & RBS & EPMA-RBS & \\
\hline 5 & $8(2)$ & $9(3)$ & $13 \%$ \\
\hline 10 & 15(3) & 13(3) & $13 \%$ \\
\hline 15 & $21(3)$ & $22(4)$ & $5 \%$ \\
\hline 20 & $38(4)$ & $36(5)$ & $5 \%$ \\
\hline 25 & $49(7)$ & $51(6)$ & $4 \%$ \\
\hline 50 & $94(7)$ & $97(13)$ & $3 \%$ \\
\hline 70 & $130(10)$ & $130(20)$ & $0 \%$ \\
\hline 90 & $164(4)$ & $150(30)$ & $9 \%$ \\
\hline
\end{tabular}

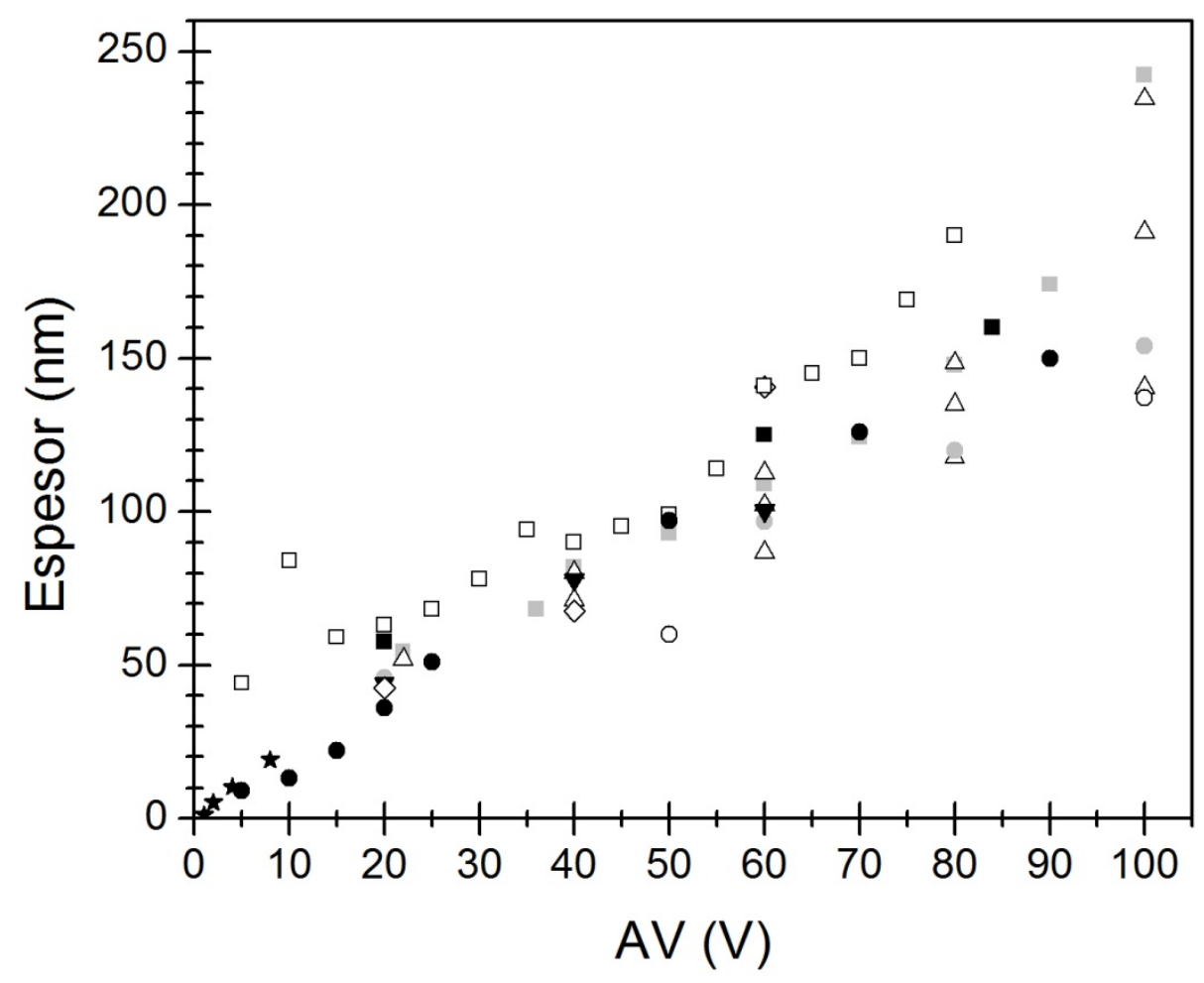

Figura 6.6: Espesor en función del voltaje de anodizado. La forma de los símbolos se asocia con las diferentes soluciones utilizadas para el anodizado. Círculos negros: este trabajo; círculos huecos: [142] con ácido fosfórico; círculos grises: [146] con ácido fosfórico; cuadrados negros: [145] con ácido sulfúrico; cuadrados huecos: [144] con ácido sulfúrico; cuadrados grises: [146] con ácido sulfúrico; triángulos ascendentes:

[146] con ácido acético; triángulos descendentes: [146] con hidróxido de calcio; rombos: [146] con hidróxido de sodio; estrellas: [147] con ácido perclórico. 
La validez de la relación obtenida entre la intensidad de la línea O-K $\alpha$ y el voltaje de anodizado se corroboró comparando la intensidad medida con el valor calculado mediante la ecuación (6.2) para el espectro correspondiente a una muestra anodizada a $30 \mathrm{~V}$, no utilizada para obtener la relación dada en dicha ecuación. Como puede verse en la figura 6.5, el acuerdo es muy bueno. El valor de espesor obtenido utilizando la ecuación (6.3) fue $57 \mathrm{~nm}$, lo cual es consistente con la tendencia encontrada entre 5 y $90 \mathrm{~V}$ (tabla 6.2).

Los espesores obtenidos por medio de la ecuación (6.3) se muestran en la figura 6.6 en función de $A V$, junto con los resultados obtenidos por varios autores empleando diferentes métodos, rangos de voltaje y soluciones de anodizado. Se puede observar que, a pesar de las diferentes condiciones de los experimentos, las tasas de crecimiento son comparables. Un análisis más detallado de los resultados disponibles en la literatura se presenta en la tabla 6.3. Para cada conjunto de datos se ajustó una función lineal, cuya pendiente representa la tasa de crecimiento de óxido. La calidad de cada ajuste se indica mediante el coeficiente de regresión lineal $R^{2}$. En todos los casos la función de ajuste utilizada es $\mathrm{d}=\mathrm{b} \cdot \mathrm{AV}$, excepto para los casos correspondientes a este trabajo y el de Filippin y otros [147], para los cuales se utilizó la ecuación (6.1). Esta expresión toma en cuenta el voltaje de comienzo de formación de óxido por anodizado, el cual sólo puede influir en el ajuste cuando los voltajes estudiados son pequeños.

Al comparar las tasas de crecimiento tabuladas, se puede observar que los métodos en los que se utilizó $\mathrm{H}_{2} \mathrm{SO}_{4}, \mathrm{NaOH}$ y $\mathrm{HCl}$ presentan los mayores valores, entre 2,0 y 2,5 nm/V. Por otra parte, cuando se utiliza $\mathrm{H}_{3} \mathrm{PO}_{4}$, como en el presente trabajo, se producen las tasas más bajas (entre 1,52 y 1,74), aunque hay que tener en cuenta que en este trabajo se utiliza $\mathrm{H}_{3} \mathrm{PO}_{4}$ en una mezcla con $\mathrm{H}_{3} \mathrm{BO}_{3}$. 
Tabla 6.3: Análisis detallado del crecimiento anódico de óxido de titanio sobre titanio metálico en diferentes condiciones experimentales. Los números entre paréntesis corresponden a los errores en las últimas cifras significativas.

\begin{tabular}{|c|c|c|c|c|}
\hline Ref. & $\begin{array}{c}\text { Solución de } \\
\text { anodizado }\end{array}$ & $\begin{array}{c}\text { Rango AV } \\
(\mathrm{V})\end{array}$ & $\begin{array}{c}\text { Tasa de } \\
\text { crecimiento } \\
(\mathrm{nm} / \mathrm{V})\end{array}$ & $\mathrm{R}^{2}$ \\
\hline$[146]$ & $\mathrm{H}_{2} \mathrm{SO}_{4}$ & $22-130$ & $2,2(1)$ & 0,88 \\
\hline$[145]$ & $\mathrm{H}_{2} \mathrm{SO}_{4}$ & $20-84$ & $2,0(2)$ & 0,92 \\
\hline$[144]$ & $\mathrm{H}_{2} \mathrm{SO}_{4}$ & $5-80$ & $2,3(1)$ & 0,75 \\
\hline$[146]$ & $\mathrm{H}_{3} \mathrm{PO}_{4}$ & $20-100$ & $1,53(6)$ & 0,96 \\
\hline$[142]$ & $\mathrm{H}_{3} \mathrm{PO}_{4}$ & $50-200$ & $1,52(8)$ & 0,96 \\
\hline $\begin{array}{c}\text { Este } \\
\text { trabajo }\end{array}$ & $5 \% \mathrm{H}_{3} \mathrm{PO}_{4} / 1 \% \mathrm{H}_{3} \mathrm{BO}_{3}$ & $5-90$ & $1,74(8)$ & 0,988 \\
\hline$[146]$ & $\mathrm{CH}_{3} \mathrm{COOH}$ & $20-100$ & $1,79(9)$ & 0,79 \\
\hline$[146]$ & $\mathrm{Ca}(\mathrm{OH})_{2}$ & $20-60$ & $1,8(1)$ & 0,90 \\
\hline$[146]$ & $\mathrm{Na}(\mathrm{OH})$ & $20-60$ & $2,1(2)$ & 0,91 \\
\hline$[147]$ & $\mathrm{HClO} 4$ & $1-8$ & $2,5(2)$ & 0,989 \\
\hline
\end{tabular}

\subsection{Conclusiones}

En este capítulo se ha desarrollado un método para determinar el espesor de capas de óxido de titanio sobre titanio metálico (c.p. ASTM grado 4) para el intervalo entre 5 y $100 \mathrm{~nm}$, rango de interés en la fabricación de implantes dentales y ortopédicos. Si bien el método se desarrolló sobre la base de mediciones de EPMA y RBS, su aplicación a través del uso de la ecuación (6.3) a otras muestras del mismo tipo (capa de $\mathrm{TiO}_{2}$ sobre sustrato de $\mathrm{Ti}$ ) sólo requiere nuevas mediciones de EPMA, técnica que es mucho más accesible que la realización de experimentos RBS. Este método permitiría a los fabricantes de implantes llevar a cabo el control de calidad en el análisis cuantitativo de los tratamientos de anodizado. Este enfoque también puede extenderse a espesores mayores aumentando la energía incidente del haz de electrones a un valor óptimo, de acuerdo con el intervalo de espesores a estudiar. El método desarrollado ha sido validado en una muestra anodizada a $30 \mathrm{~V}$, para la cual el valor de espesor obtenido apoya la factibilidad del presente enfoque. Además, 
la tasa de crecimiento de óxido obtenida con el método desarrollado en este trabajo está de acuerdo con los valores reportados en la literatura.

El método propuesto se puede extender fácilmente a la determinación de espesores de películas de óxidos formados electroquímicamente bajo diferentes condiciones experimentales; por ejemplo, sobre la aleación de titanio Ti6Al4V, que es ampliamente utilizada como material de implante. Dicha aleación forma una capa compuesta principalmente por $\mathrm{TiO}_{2}$ y $\mathrm{Al}_{2} \mathrm{O}_{3}$, cuyo espesor aumenta con el voltaje de anodizado. El método desarrollado en este trabajo podría extenderse para obtener ambos espesores de los óxidos por separado, midiendo las intensidades de pico de $\mathrm{O}-\mathrm{K} \alpha$ y Al-K $\alpha$. 


\section{CONCLUSIONES GENERALES}

En el presente trabajo de tesis se planteó como objetivo el desarrollo de métodos y estrategias de caracterización superficial de biomateriales metálicos con diferentes tipos de terminaciones superficiales (mecanizados, blastinizados, pasivados químicos, anodizados, anodizados por plasma químico y combinaciones) para aplicaciones traumatológicas, ortopédicas y odontológicas. Para lograr este propósito, se utilizaron técnicas espectroscópicas y microscopía electrónica de barrido en combinación con ensayos de microdureza, adhesión y polarización potenciodinámica cíclica. Dependiendo de los requerimientos del biomaterial con diferentes tratamientos superficiales para distintas aplicaciones, se desarrollaron diferentes estrategias en la cuales se combinaron, compararon y evaluaron los resultados obtenidos con las distintas técnicas mencionadas.

Si bien las discusiones y conclusiones particulares se han incorporado en cada uno de los capítulos donde fueron presentados los resultados obtenidos, a continuación se presentan las conclusiones generales.

En primer lugar, los resultados obtenidos en el estudio sobre las incertezas de mediciones en pits de corrosión a partir de imágenes de microscopía electrónica de barrido 3D a bajas magnificaciones, indican que se puede alcanzar valores precisos de sus profundidades en el intervalo de 30-150 $\mu \mathrm{m}$. Las diferencias relativas entre los valores de altura obtenidos mediante estereometría y los obtenidos a partir de una sección transversal son menores al 7\% en dicho intervalo. No obstante, los errores relativos pueden ser incluso menores si se utilizan mayores magnificaciones y ángulos de inclinación, sobre todo cuando las profundidades son pequeñas (menores a $30 \mu \mathrm{m})$ y es necesario reconstruir el perfil completo del pit de corrosión. Además, se logró poner a punto la técnica de los pares estéreo en pits de corrosión generados en biomateriales y contrastar los resultados obtenidos con un método electroquímico.

Por otro lado, a partir de la selección de un conjunto adecuado de parámetros de rugosidad para caracterizar los tratamientos superficiales efectuados en 
biomateriales se consiguió vincular los parámetros de diseño de los tratamientos con las superficies finales y verificar su reproducibilidad. En lo que respecta a los biomateriales de aceros inoxidables, la correlación de resultados de rugosidad con ensayos de microdureza y polarización potenciodinámica cíclica, evidenció que el tratamiento de blastinizado debe llevarse a cabo bajo condiciones controladas para obtener propiedades superficiales y subsuperficiales similares y que un pasivado químico (en determinadas condiciones) posterior al blastinizado permite incrementar la resistencia al picado de las muestras blastinizadas. En cuanto a los biomateriales de titanio mecanizados con tratamientos de blastinizado y/o anodizado por plasma químico, los resultados de rugosidad en combinación con ensayos de microdureza y adhesión revelaron que la rugosidad que genera el blastinizado favorecería la adherencia sustrato-recubrimiento y que la superficie es alterada por el uso y la degradación de los insumos utilizados para la realización de los tratamientos superficiales.

Finalmente, se desarrolló un método para medir espesores de óxido de titanio en biomateriales a partir de espectros de rayos $\mathrm{X}$ obtenidos mediante microanálisis con sonda de electrones y efectuando una recalibración inicial con espectroscopía de retrodispersión de Rutherford. En este método se registró la intensidad K $\alpha$ del oxígeno, la cual fue relacionada con el espesor correspondiente. El método es útil para espesores de óxido de titanio en el intervalo de interés de los implantes dentales y ortopédicos (10 a $100 \mathrm{~nm}$ ), y podría extenderse a mayores espesores seleccionando adecuadamente la energía del haz de electrones. También podría extenderse a la determinación de espesores de películas de óxidos formados electroquímicamente bajo diferentes condiciones experimentales; por ejemplo, sobre la aleación de titanio Ti6Al4V, que es ampliamente utilizada como material de implante. 
A partir de los resultados presentados en esta tesis, las perspectivas de investigación que se derivan se orientan a la aplicación y ampliación de las estrategias de caracterización desarrolladas incorporando otras técnicas, entre las cuales se pueden mencionar la difracción de rayos X, la espectroscopía infrarroja y Raman, entre otras. En particular, es de interés correlacionar los parámetros de rugosidad con los ensayos de mojabilidad y de resistencia a la corrosión en superficies de titanio con diferentes tratamientos. Por otro lado, sería de interés estudiar la influencia de los parámetros del proceso de anodizado por plasma químico (con la aplicación de un blastinizado previo en diferentes condiciones) en las características de las superficies obtenidas para varios tipos de electrolitos. Finalmente, para llegar a estudiar en aplicaciones más específicas los distintos acabados y recubrimientos superficiales caracterizados, sería muy útil evaluarlos mediante ensayos de fluido corporal simulado (SBF). 


\section{BIBLIOGRAFÍA}

[1] A. Bobbio. The first endosseous alloplastic implant in the history of man. Bull. Hist. Dent. 20 (1972) 1-6.

[2] E. Crubezy, P. Murail, L. Girard, J.P. Bernadou. False teeth of the Roman world. Nature 391 (1998) 29-30.

[3] G. Duffo. Biomateriales: Una mejor calidad de vida. Eudeba. 2010.

[4] B.D. Ratner. A history of biomaterials. En: B.D. Ratner, A.S. Hoffman, F.J. Schoen, J.E. Lemons (eds.), Biomaterials Science: An introduction to materials in medicine. Academic Press. 2013.

[5] P.I. Branemark, U. Breine, B. Johansson, P.J. Roylance, H. Röckert, J.M. Yoffey. Regeneration of bone marrow. Acta. Anat. 59 (1964) 1-46.

[6] R. Rodas-Rivera. Historia de la implantologia y la oseointegración, antes y después de Branemark. Rev. Estomatol Herediana 23(1) (2013) 39-43.

[7] B.D. Ratner, A.S. Hoffman, F.J. Schoen, J.E. Lemons. Biomaterials Science: An Evolving, Multidisciplinary Endeavor. En: B.D. Ratner, A.S. Hoffman, F.J. Schoen, J.E. Lemons (eds.), Biomaterials Science: An introduction to materials in medicine. Academic Press. 2013.

[8] B.D. Ratner, S.J. Bryant. Biomaterials: Where We Have Been and Where We Are Going. Annu. Rev. Biomed. Eng. 6 (2004) 41-75.

[9] J.W. Boretos, M. Eden. Contemporary Biomaterials, Material and Host Response, Clinical Applications, New Technology and Legal Aspects. Noyes Publications. 1984.

[10] Q. Chen, G.A. Thouas. Metallic implant biomaterials. Materials Science and Engineering R 87 (2015) 1-57. 
[11] B.M. Holzapfel, J.C. Reichert, J.-T. Schantz, U. Gbureck, L. Rackwitz, U. Nöth, F. Jakob, M. Rudert, J. Groll, D.W. Hutmacher. How smart do biomaterials need to be? A translational science and clinical poin $\mathrm{t}$ of view. Advanced Drug Delivery Reviews 65 (2013) 581-603.

[12] M. Navarro, A. Michiardi, O. Castaño, J.A. Planell. Biomaterials in orthopaedics. J. R. Soc. Interface 5 (2008) 1137-1158.

[13] V. Goriainov, R. Cook, J.M. Latham, D.G. Dunlop, R.O.C. Oreffo. Bone and metal: An orthopaedic perspective on osseointegration of metals. Acta Biomaterialia 10 (2014) 4043-4057.

[14] S. Bauer, P. Schmuki, K. von der Mark, J. Park. Engineering biocompatible implant surfaces Part I: Materials and surfaces. Progress in Materials Science 58 (2013) 261-326.

[15] M. Kulkarni, A. Mazare, P. Schmuki, A. Iglič. Biomaterial surface modification of titanium and titanium alloys for medical applications. En: A. Seifalian, A. de Mel, D.M. Kalaskar (eds.), Nano-medicine. One Central Press. 2014.

[16] D.F.Williams. On the mechanisms of biocompatibility. Biomaterials 29 (2008) 2941-2953.

[17] M. Geetha, A.K. Singh, R. Asokamani, A.K. Gogia. Ti based biomaterials, the ultimate choice for orthopaedic implants - A review. Progress in Materials Science 54 (2009) 397-425.

[18] E.P. Ivanova, K. Bazaka, R.J. Crawford. Cytotoxicity and biocompatibility of metallic biomaterials. En: E.P. Ivanova, K. Bazaka, R.J. Crawford (eds.), New functional biomaterials for medicine and healthcare. Elsevier. 2014.

[19] P. Bilmes. Modos de falla y avances en diseños de biomateriales para ortopedia y traumatología, V Congreso Cubano de Ingeniería Mecánica y Metalurgia, 1-5 de 
diciembre de 2008, Palacio de las Convenciones de La Habana-Cuba, ISBN 978-959261-405-5.

[20] M. Niinomi. Fatigue characteristics of metallic biomaterials. International Journal of Fatigue 29 (2007) 992-1000.

[21] Y. Oguchi, T. Akahori, T. Hattori, H. Fukui, M. Niinomi. Change in Mechanical Strength and Bone Contactability of Biomedical Titanium Alloy with Low Young's Modulus Subjected to Fine Particle Bombarding Process. Materials Transactions 56(2) (2015) 218-223.

[22] T. Kokubo, K. Hata, T. Nakamura, T. Yamamura. Apatite formation on ceramics, metals, and polymers induced by a $\mathrm{CaO}-\mathrm{SiO}_{2}$-based glass in simulated body fluid. En: W. Bonfield, G.W. Hastings, K.E. Tanner (eds.), Bioceramics. ButterworthHeinemainn. 1991.

[23] T. Albrektsson, C. Johansson. Osteoinduction, osteoconduction and osseointegration. Eur Spine J 10 (2001) 96-101.

[24] J.E. Davies. Mechanisms of endosseous integration. Int J Prosthodont 11(5) (1998) 391-401.

[25] S. Fujibayashi, M. Neo, H.-M. Kim, T. Kokubo, T. Nakamura. Osteoinduction of porous bioactive titanium metal. Biomaterials 25 (2004) 443-450.

[26] S.E. Rodil. Modificación Superficial de Implantes Metálicos. Revista Latinoamericana de Metalurgia y Materiales 29(2) (2009) 67-83.

[27] A. Nouri, C. Wen. Introduction to surface coating and modification for metallic biomaterials. En: C. Wen (ed.), Surface Coating and Modification of Metallic Biomaterials. Elsevier. 2015.

[28] G. Mani. Surface properties and characterization of metallic biomaterials. En: C. Wen (ed.), Surface Coating and Modification of Metallic Biomaterials. Elsevier. 2015. 
[29] G. Mani, C.E. Macias, M.D. Feldman, D. Marton, S. Oh, C.M. Agrawal. Delivery of paclitaxel from cobalt-chromium alloy surfaces without polymeric carriers. Biomaterials 31 (2010) 5372-5384.

[30] G. Mani, D. Johnson, D. Marton, V.L. Dougherty, M.D. Feldman, D. Patel, A.A. Ayon, C.M. Agrawal. Stability of self-assembled monolayers on titanium and gold. Langmuir 24 (2008) 6774-6784.

[31] D.M. Dohan Ehrenfest, P.G. Coelho, B.-S. Kang, Y.-T. Sul, T. Albrektsson. Classification of osseointegrated implant surfaces: materials, chemistry and topography. Trends in Biotechnology 28(4) (2009) 198-206.

[32] A. Wennerberg, T. Albrektsson. Effects of titanium surface topography on bone integration: a systematic review. Clin Oral Implant Res 20(4) (2009) 172-84.

[33] H.I. Chang, Y. Wang. Cell responses to surface and architecture of tissue engineering scaffolds. En: D. Eberli (ed.), Regenerative medicine and tissue engineering-cells and biomaterials. InTech. 2011.

[34] A. Wennerberg, C. Hallgren, C. Johansson, S. Danelli,. A histomorphometric evaluation of screw-shaped implants each prepared with two surface roughnesses. Clinical Oral Implants Research 9 (1998) 11-19.

[35] P.M. Brett, J. Harle, V. Salih, R. Mihoc, I. Olsen, F.H. Jones, M. Tonetti. Roughness response genes in osteoblasts. Bone 35 (2004) 124-133.

[36] A. Wennerberg, T. Albrektsson. Suggested guidelines for the topographic evaluation of implant surfaces. Int J Oral Maxillofac Implants 15 (2000) 331-344.

[37] A. Wennerberg, A. Ide-Ektessabi, S. Hatkamata, T. Sawase, C. Johansson, T. Albrektsson, A. Martinelli, U. Södervall, H. Odelius. Titanium release from implants prepared with different surface roughness - an in vitro and in vivo study. Clin Oral Implant Res 15 (2004) 505-512. 
[38] H.J. Ronold, S.P. Lyngstadaas, J.E. Ellingsen. Analysing the optimal value for titanium implant roughness in bone attachment using a tensile test. Biomaterials 24 (2003) 4559-4564.

[39] A. Trommler, D. Gingell, H. Wolf. Red blood cells experience electrostatic repulsion but make molecular adhesions with glass. Biophysical Journal 48 (1985) 835-841.

[40] M. Kulkarni, A. Mazare, J. Park, E. Gongadze, M.S. Killian, S. Kralj, K. von der Mark, A. Iglic, P. Schmuki. Protein interactions with layers of $\mathrm{TiO}_{2}$ nanotube and nanopore arrays: Morphology and surface charge influence. Acta Biomaterialia 45 (2016) 357-366.

[41] S. Bodhak, S. Bose, A. Bandyopadhyay. Role of surface charge and wettability on early stage mineralization and bone cell-materials interactions of polarized hydroxyapatite. Acta Biomaterialia 5 (2009) 2178-2188.

[42] J.A. Planell, M. Navarro, G. Altankov, C. Aparicio, E. Engel, J. Gil, M.P. Ginebra, D. Lacroix. Materials surface effects on biological interactions. En: V.P. Shastri, G. Altankov, A. Lendlein (eds.), Advances in regenerative medicine: role of nanotechnology, and engineering principles. Springer. 2010.

[43] T.S. Meiron, A. Marmur, I.S. Saguy. Contact angle measurement on rough surfaces. Journal of Colloid and Interface Science 274 (2004) 637-644.

[44] P. Tengvall. How surfaces interact with the biological environment. En: J.E. Ellingsen, S.P. Lyngstadaas (eds.), Bio-implant interface, improving biomaterials and tissue reactions. CRC Press. 2003.

[45] L. Bacakova, E. Filova, M. Parizek, T. Ruml, V. Svorcik. Modulation of cell adhesion, proliferation and differentiation on materials designed for body implants. Biotechnol Adv 29 (2011) 739-767. 
[46] K. Anselme, A. Ponche, M. Bigerelle. Relative influence of surface topography and surface chemistry on cell response to bone implant materials. Part 2: biological aspects. Proceedings of the Institution of Mechanical Engineers H 224 (2010) 14871507.

[47] M. Vallet Regi, L. Munuera. Biomateriales: aquí y ahora. Dykinson. 2000.

[48] J.I. Goldstein, D.E. Newbury, P. Echlin, D.C. Joy, C.E. Lyman, E. Lifshin, L. Sawyer, J.R. Michael. Scanning Electron Microscopy and X-Ray Microanalysis, Tercera Edición. Springer. 2003.

[49] D. Brandon, W.D. Kaplan. Microstructural Characterization of Materials, Segunda edición. John Wiley and Sons, Ltd. 2008.

[50] K. Kanaya, S. Okayama. J. Phys. D. Appl. Phys. 5 (1972) 43.

[51] P. Echlin. Handbook of sample preparation for scanning electron microscopy and x-ray microanalysis, Primera edición. Springer. 2010.

[52] D.J. Stokes. Recent advances in electron imaging, image interpretation and applications: environmental scanning electron microscopy. Phil. Trans. R. Soc. Lond. $361(2003)$ 2771-2787.

[53] P.E.J. Flewitt, R.K. Wild. Physical methods for materials characterization, Segunda edición. Institute of physics publishing. 2003.

[54] R.E. Whan. ASM Handbook Volumen 10 Materials Characterization, Quinta impresión. ASM International. 1998.

[55] J. Heath, N. Taylor. EDAX Energy Dispersive Spectroscopy. John Wiley and Sons, Ltd. 2014.

[56] L.J. Korb, D.L. Olson. ASM Handbook Volumen 13 Corrosion, Cuarta impresión. ASM International. 1994. 
[57] G.F. Vander Voort. ASM Handbook Volumen 8 Mechanical testing and evaluation, Primera impresión. ASM International. 2000.

[58] N. Vidakis, A. Antoniadis, N. Bilalis. The VDI 3198 indentation test evaluation of a reliable qualitative control for layered compounds. Journal of Materials Processing Technology 143-144 (2003) 481-485.

[59] E. Gemelli, A. Scariot, N.H. Almeida Camargo. Thermal Characterization of Commercially Pure Titanium for Dental Applications. Materials Research 10 (2007) 241-246.

[60] J. Xiong, X. Wang, Y. Li, P.D. Hodgson. Interfacial Chemistry and Adhesion between Titanium Dioxide Nanotube Layers and Titanium Substrates. J. Phys. Chem. C 115 (2011) 4768-4772.

[61] M.S. Yilmaz, E. Atar, O. Sahin, E.S. Kayali. Improving the Surface Properties of Cp-Ti by Pulsed Electro-Spark Deposition. Acta physica polonica A 125 (2014).

[62] G.S. Lane. The application of stereographic techniques to the scanning electron microscope. J. Phys. E: Sci. Instrum. 2(7) (1969) 565-569.

[63] G.S. Lane. Dimensional measurements. En: J.W.S. Hearle, J.T. Sparrow, P.M. Cross (Eds.), The Use of the Scanning Electron Microscope. Pergamon Press. 1972.

[64] J. Stampfl, S. Scherer, M. Gruber, O. Kolednik. Reconstruction of surface topographies by scanning electron microscopy for application in fracture research. Appl. Phys. A 63 (1996) 341-346.

[65] P.A. Davies, V. Randle. Combined application of electron backscatter diffraction and stereo-photogrammetry in fractography studies. J. Microsc. 204 (2001) 29-38.

[66] Z. Huang, D.A. Dikin, W. Ding, Y. Qiao, X. Chen, Y. Fridman, R.S. Ruoff. Threedimensional representation of curved nanowires. J. Microsc. 216 (2004) 206-214. 
[67] R.D. Bonetto, J.L. Ladaga, E. Ponz. Measuring Surface Topography with Scanning Electron Microscopy. II. Analysis of Three Estimators of Surface Roughness in Second-dimension and Third-dimension. Microsc. Microanal. 12(2) (2006) 178-186.

[68] E. Ponz, J.L. Ladaga, R.D. Bonetto. Measuring Surface Topography with Scanning Electron Microscopy. I. EZEImage: A program to Obtain 3D Surface Data. Microsc. Microanal. 12(2) (2006) 170-177.

[69] M. Jahnisch, S. Fatikow. 3-D vision feedback for nanohandling monitoring in a scanning electron microscope. International Journal of Optomechatronics 1 (2007) 426.

[70] F. Marinello, P. Bariani, E. Savio, A. Horsewell, L. De Chiffre. Critical factors in SEM 3D stereo microscopy. Meas. Sci. Technol. 19, 065705. 2008.

[71] H. Ostadi, K. Jiang, P.D. Prewett. Characterisation of FIB milling yield of metals by SEM stereo imaging technique. Microelec. Eng. 86 (2009) 1021-1024.

[72] M. Malboubi, H. Ostadi, S. Wang, Y. Gu, K. Jiang. Effects of the Surface Morphology of Pipette Tip on Giga-seal Formation. Engineering Letters 17:4. 2009.

[73] S. Fatikow, C. Dahmen, T. Wortmann, R. Tunnell. Vision Feedback for Automated Nanohandling. Proceedings of the 2009 IEEE International Conference on Information and Automation. Zhuhai/Macau, China, 806-811. 2009.

[74] C.R.F. Azevedo, E.R. Marques. Three-dimensional analysis of fracture, corrosion and wear surfaces. Eng. Failure Anal. 17 (2010) 286-300.

[75] X. Chen, H. Ostadi, K. Jiang. Three-dimensional surface reconstruction of diatomaceous frustules. Anal. Biochem. 403 (2010) 63-66.

[76] H. Ostadi, K. Jiang, D.W.L. Hukins. A comparison of surface roughness analysis methods applied to urinary catheters. Prec. Eng. 34 (2010) 798-801. 
[77] P. Hortolà. Using digital anaglyphy to improve the relief effect of SEM micrographs of bloodstains. Micron 40 (2009) 409-412.

[78] K. Ikeuchi, B.K.P. Horn. Numerical Shape from Shading and Occluding Boundaries. Artif. Intell. 17 (1981) 141-184.

[79] C.G.H. Walker, M.M. El Gomati, V. Romanovsky. Reconstruction of images of surface height in scanning electron microscopy. Microscopy of Semiconducting materials: Proceedings of the 14th conference 107, 495-498. 2005.

[80] R. Pintus, S. Podda, M. Vanzi. Image alignment for 3D reconstruction in a SEM. Microelectronics Reliability 45 (2005) 1581-1584.

[81] W. Drzazga, J. Paluszynski, W. Slowko. Three-dimensional characterization of microstructures in a SEM. Meas. Sci. Tech. 17 (2006) 28-31.

[82] R. Pintus, S. Podda, M. Vanzi. An Automatic Alignment Procedure for a FourSource Photometric Stereo Technique Applied to Scanning Electron Microscopy. IEEE Trans. Instr. Meas. 57(5) (2008) 989-996.

[83] J. Paluszynski, W. Slówko. Measurements of the surface microroughness with the scanning electron microscope. J. Microsc. 233 (2008) 10-17.

[84] M. Wzorek, A. Czerwinski, J. Ratajczak, R. Dylewicz, J. Katcki. Selective etching of dislocations in GaN and quantitative SEM analysis with shape-reconstruction method. Micron 40 (2009) 37-40.

[85] M. Wzorek, A. Czerwinski, J. Ratajczak, A. Lui, E. Iacob, J. Katcki. Depth measurements of etch-pits in GaN with shape reconstruction from SEM images. J. Microsc. 237 (2010) 242-245.

[86] T. Vynnyk, T. Schultheis, T. Fahlbusch, E. Reithmeier. 3D-measurement with the stereo scanning electron microscope on sub-micrometer structures. J. Europ. Opt. Soc. Rapid Publications 5, 10038s-1-8. 2010. 
[87] API 570. Piping Inspection Code- Inspection, Repair, Alteration, and Rerating of In-Service Piping Systems, American Petroleum Institute Publication, Segunda edición. 1998.

[88] API 579. Fitness-for-Service, American Petroleum Institute Publication, Primera edición. 2000.

[89] API 581. Risk Based Inspection, American Petroleum Institute Publication, Primera edición. 2000.

[90] O.E.M. Pohler. Failures of Metallic Orthopedic Implants. En Failure Analysis and Prevention, Vol. 11, ASM Handbook, Novena edición, ASM International. 1986.

[91] B. Choules, J. Metcalf, J. Merk. Can a Critical Breakdown Potential be Established for Electrochemical Corrosion Testing of Medical Devices According to ASTM F2129?. Medical Device Materials V: Proceedings from the Materials \& Processes for Medical Devices Conference, Minneapolis, Estados Unidos, pp. 19-22. 2009.

[92] T. Wang, J. Yu, B. Dong. Surface nanocrystallization induced by shot peening and its effect on corrosion resistance of $1 \mathrm{Cr} 18 \mathrm{Ni}$ Ti stainless steel. Surface \& Coatings Technology 200 (2006) 4777-4781.

[93] C. Sun. Fast stereo matching using rectangular subregioning and 3D maximumsurface techniques. Inter. J. Comput. Vision 47 (2002) 99-117.

[94] P. Bariani, L. De Chiffre, H.N. Hansen, A. Horsewell. Investigation on the traceability of three dimensional scanning electron microscope measurements based on the stereo-pair technique. Prec. Eng. 29 (2005) 219-228.

[95] E. Heitz. Analytical Methods in Corrosion Science and Engineering, P. Marcus, F. Mansfeld (Eds.), pp. 444. 2006. 
[96] B.E. Wilde, E. Williams. The use of current/voltage curves for the study of localized corrosion and passivity breakdown on stainless steel in chloride media. Electrochimica Acta 16 (1971) 1971-1985.

[97] C. Aparicio, F.J. Gil, C. Fonseca, M. Barbosa, J.A. Planell. Corrosion behaviour of commercially pure titanium shot blasted with different materials and sizes of shot particles for dental implant applications. Biomaterials 24 (2003) 263-273.

[98] V. Barranco, E. Onofre, M.L. Escudero, M.C. García-Alonso. Characterization of roughness and pitting corrosion of surfaces modified by blasting and thermal oxidation. Surf. Coat. Tech. 204 (2010) 3783-3793.

[99] V. Azar, B. Hashemi, M. Rezaee Yazdi. The effect of shot peening on fatigue and corrosion behavior of 316L stainless steel in Ringer's solution. Surf. Coat. Tech. 204 (2010) 3546-3551.

[100] B.D. Ratner, A.S. Hoffman. Thin films, grafts, and coatings. En: Biomaterials Science: An introduction to materials in medicine, B.D. Ratner, A.S. Hoffman, F.J. Schoen, J.E. Lemons (Eds.), Academic Press. 1996.

[101] A. Arvidsson, B.A. Sater, A. Wennerberg, The role of functional parameters for topographical characterization of bone-anchored implants. Clin. Implant Dent. Relat Res. 8 (2006) 70-76.

[102] V. Barranco, M.L. Escudero, M.C. García-Alonso. 3D, chemical and electrochemical characterization of blasted Ti6Al4V surfaces: Its influence on the corrosion behavior. Electrochim. Acta 52 (2007) 4374-4384.

[103] M. Multigner, E. Frutos, J.L. González-Carrasco, J.A. Jiménez, P. Marín, J. Ibáñez. Influence of the sandblasting on the subsurface microstructure of 316LVM stainless steel: Implications on the magnetic and mechanical properties. Mater. Sci. Eng. C 29 (2009) 1357-1360. 
[104] M. Multigner, S. Ferreira-Barragáns, E. Frutos, M. Jaafar, J. Ibáñez, P. Marín, M.T. Pérez-Prado, G. González-Doncel, A. Asenjo, J.L. González-Carrasco. Superficial severe plastic deformation of 316 LVM stainless steel through grit blasting: Effects on its microstructure and subsurface mechanical properties. Surf. Coat. Technol. 205 (2010) 1830-1837.

[105] J.C. Galván, L. Saldaña, M. Multigner, A. Calzado-Martín, M. Larrea, C. Serra, N. Vilaboa, J.L. González-Carrasco. Grit blasting of medical stainless steel: implications on its corrosion behavior, ion release and biocompatibility. J. Mater. Sci. Mater. Med. 23 (2012) 657-666.

[106] B. Arifvianto, Suyitno, K.A. Wibisono, M. Mahardika. Influence of grit blasting treatment using steel slag balls on the subsurface microhardness, surface characteristics and chemical composition of medical grade 316L stainless steel. Surf. Coat. Technol. 210 (2012) 176-182.

[107] F. Reidenbach. ASM Metals Handbook Volume 5: Surface Engineering, Décima edición, ASM International. 1994.

[108] K. Poorna Chander, M. Vashista, K. Sabiruddin, S. Paul, P.P. Bandyopadhyay. Effects of grit blasting on surface properties of steel substrates. Mater. Des., 30 (2009) 2895-2902.

[109] F. Otsubo, K. Kishitake, T. Akiyama, T. Terasaki. Characterization of blasted austenitic stainless steel and its corrosion resistance. J. Therm. Spray Technol. 12 (2003) 555-559.

[110] A. Ben Rhouma, H. Sidhom, C. Braham, J. Lédion, M.E. Fitzpatrick. Effects of surface preparation on pitting resistance, residual stress, and stress corrosion cracking in austenitic stainless steels. J. Mater. Eng. Perform. 10 (2001) 507-514.

[111] A.W. Momber, Y.C. Wong. Overblasting effects on surface properties of lowcarbon steel. J. Coat. Tech. Res. 2 (2005) 453-461. 
[112] R. Singh, N.B. Dahotre. Corrosion degradation and prevention by surface modification of biometallic materials. J. Mater. Sci. Mater. Med. 18 (2007) 725-751.

[113] M. Faller, S. Buzzi, O. Trzebiatowski. Corrosion behaviour of glass-bead blasted stainless steel sheets and other sheets with dull surface finish in a chloride solution. Mater. Corros. 56 (2005) 373-378.

[114] "Standard Test Method for Microindentation Hardness of Materials", E384-99, ASTM Standards.

[115] H.C. Man, D.R. Gabe. The determination of pitting potentials. Corros. Sci. 21 (1981) 323-326.

[116] M.D. Pereda, C.A. Gervasi, C.L. Llorente, P.D. Bilmes. Microelectrochemical corrosion study of supermartensitic welds in chloride-containing media. Corros. Sci. 53 (2011) 3934-3941.

[117] K.J. Stout, P.J. Sullivan, W.P. Dong, E. Mainsah, N. Luo, T. Mathia, H. Zahouani. "The Development of Methods for the Characterization of Roughness in Three Dimensions", Commission of the European Communities, Universidad de Birmingham. 1993.

[118] W.P. Dong, P.J. Sullivan, K.J. Stout. Comprehensive study of parameters for characterising three- dimensional surface topography: III: Parameters for characterising amplitude and some functional properties. Wear 178(1-2) (1994) 29_ 43.

[119] M. Bigerelle, D. Najjar, T. Mathia, A. Iost, T. Coorevits, K. Anselme. An expert system to characterise the surfaces morphological properties according to their tribological functionalities: The relevance of a pair of roughness parameters. Tribology Int. 59 (2013) 190-202. 
[120] L.T. Brown. “The use of 3D surface analysis techniques to investigate the wear of matt surface finish femoral stems in total hip replacement", Tesis de doctorado, University of Huddersfield. 2006.

[121] C. Cionea. "Microstructural Evolution of Surface Layers during Electrolytic Plasma Processing", Tesis de doctorado, University of Texas at Arlington. 2010.

[122] M. Niemczewska-Wojcik. The influence of the surface geometric structure on the functionality of implants. Wear 271(3-4) (2011) 596-603.

[123] J. Löberg. "Integrated Biomechanical, Electronic and Topographic Characterization of Titanium Dental Implants", Tesis de doctorado, University of Gothenburg. 2011.

[124] P. O’Hare, B.J. Meenan, G.A. Burke, G. Byrne, D. Dowling, J.A. Hunt. Biological responses to hydroxyapatite surfaces deposited via a co-incident microblasting technique. Biomaterials 31 (2010) 515-522.

[125] R.A. Gittens, T. McLachlan, R. Olivares-Navarrete, Y. Cai, S. Berner, R. Tannenbaum, Z. Schwartz, K.H. Sandhage, B.D. Boyan. The effects of combined micron-/submicron-scale surface roughness and nanoscale features on cell proliferation and differentiation. Biomaterials 32 (2011) 3395-3403.

[126] T. Provder, B. Kunz. Application of profilometry and fractal analysis to the characterization of coatings surface roughness. Prog. Org. Coat. 27(1-4) (1996) 219226.

[127] S. Amada, T. Hirose. Influence of grit blasting pre-treatment on the adhesion strength of plasma sprayed coatings: fractal analysis of roughness. Surf. Coat. Technol. 102(1-2) (1998) 132-137. 
[128] D. Risović, S. Mahović Poljaček, M. Gojo. On correlation between fractal dimension and profilometric parameters in characterization of surface topographies. Appl. Surf. Sci. 255 (2009) 4283-4288.

[129] X. Liang, B. Lin, X. Han, S. Chen. Fractal analysis of engineering ceramics ground surface. Appl. Surf. Sci. 258 (2012) 6406-6415.

[130] C. José, R.D. Bonetto, L.A. Gambaro, M.P. Guauque Torres, M.L. Foresti, M.L. Ferreira, L.E. Briand. Investigation of the causes of deactivation-degradation of the comercial biocatalyst Novozym ${ }^{\circledR} 435$ in ethanol and ethanol-aqueous media. Journal of Molecular Catalysis B: Enzymatic 71 (2011) 95-107.

[131] W.S. Rasband, ImageJ, U.S. National Institutes of Health, Bethesda, Estados Unidos. 2012. http://rsb.info.nih.gov/ij/index.html.

[132] A. Mendez-Vilas, M.G. Donoso, J.L. Gonzalez Carrasco, M.L. Gonzalez-Martín. Looking at the micro-topography of polished and blasted Ti-based biomaterials using atomic forcé microscopy and contact angle goniometry. Colloids and Surfaces B: Biointerfaces 52 (2006) 157-166.

[133] F.J. Gil, J.A. Planell, A. Padrós, C. Aparicio. The effect of shot blasting and heat treatment on the fatigue behavior of titanium for dental implant applications. Dental Mater. 23 (2007) 486-491.

[134] ISO 23317:2012 Implants for surgery - In vitro evaluation for apatite forming ability of implant materials. 2012.

[135] X. Liu, P.K. Chu, C. Ding. Surface modification of titanium, titanium alloys, and related materials for biomedical applications. Materials Science and Engineering R 47 (2004) 49-121.

[136] Z.Q. Yao, Y. Ivanisenko, T. Diemant, A. Caron, A. Chuvilin, J.Z. Jiang, R.Z. Valiev, M. Qi, H.J. Fecht. Synthesis and properties of hydroxyapatite-containing 
porous titania coating on ultrafine-grained titanium by micro-arc oxidation. Acta Biomaterialia 6 (2010) 2816-2825.

[137] L. Le Guéhennec, A. Soueidan, P. Layrolle, Y. Amouriq. Surface treatments of titanium dental implants for rapid osseointegration. Dental Materials 23 (2007) 844854.

[138] C.R. Choi, H.S. Yu, C.H. Kim, J.H. Lee, C.H. Oh, H.W. Kim, H.H. Lee. Bone Cell Responses of Titanium Blasted with bioactive glass particles. Journal of Biomaterials Applications 25 (2010) 99-117.

[139] X.P. Jiang, X.Y. Wang, J.X. Li, D.Y. Li, C.-S. Man, M.J. Shepard, T. Zhai. Enhancement of fatigue and corrosion properties of pure $\mathrm{Ti}$ by sandblasting. Materials Science and Engineering: A 429 (2006) 30-35, 2006.

[140] Verein Deutscher Ingenieure Normen, VDI 3198, VDI-Verlag, Dusseldorf. 1991.

[141] Y.J. Lee, D.Z. Cui, H.R. Jeon, H.J. Chung, Y.J. Park, Y.J. Kim, Y.J. Kim. Surface characteristics of thermally treated titanium surfaces. J Periodontal Implant Sci 42 (2012) 81-87.

[142] N.K. Kuromoto, R.A. Simão, G.A. Soares. Titanium oxide films produced on commercially pure titanium by anodic oxidation with different voltages. Mater Charact 58 (2007) 114-121.

[143] E. Krasicka-Cydzik. Anodic layer formation on titanium and its alloys for biomedical applications. En: Nurul Amin AKM, editor. Titanium alloys - Towards achieving enhanced properties for diversified applications, InTech. 2012.

[144] A. Karambakhsh, A. Afshar, S. Ghahramani, P. Malekinejad. Pure commercial titanium color anodizing and corrosion resistance. J Mater Eng Perform 20 (2011) $1690-1696$. 
[145] Y. Serruys, T. Sakout, D. Gorse. Anodic oxidation of titanium in $1 \mathrm{M} \mathrm{H}_{2} \mathrm{SO}_{4}$, studied by Rutherford backscattering. Surf Sci 282 (1993) 279-287.

[146] Y.T. Sul, C.B. Johansson, Y. Jeong, T. Albrektsson. The electrochemical oxide growth behavior on titanium in acid and alkaline electrolytes. Med Eng Phys 23 (2001) 329-346.

[147] F.A. Filippin, O.E. Linarez Pérez, M. López Teijelo, R.D. Bonetto, J. Trincavelli, L.B. Avalle. Thickness determination of electrochemical titanium oxide $\left(\mathrm{Ti} / \mathrm{TiO}_{2}\right)$ formed in $\mathrm{HClO}_{4}$ solutions. Electrochim Acta 129 (2014) 266-275.

[148] Mayer M, SIMNRA User's Guide, Report IPP 9/113, Max-Planck-Institut für Plasmaphysik, Garching, Alemania. 1997. http://home.mpcdf.mpg.de/ mam/

[149] Mayer JW, Rimini E. Ion Beam Handbook for Material Analysis, Primera edición. Academic Press. 1977.

[150] J.A. Bearden. X-ray wavelengths. Rev Mod Phys 39 (1967) 78-124. 